\title{
Pilot Implementation of a Field Study Design to Evaluate the Impact of Source Control Measures on Indoor Air Quality in High- Performance Homes
}

SH Widder, M Chamness, J Peterson, Pacific Northwest National Laboratory BC Singer, RL Maddalena, H Destaillats, ML Russell, Lawrence Berkeley National Laboratory

October 2014

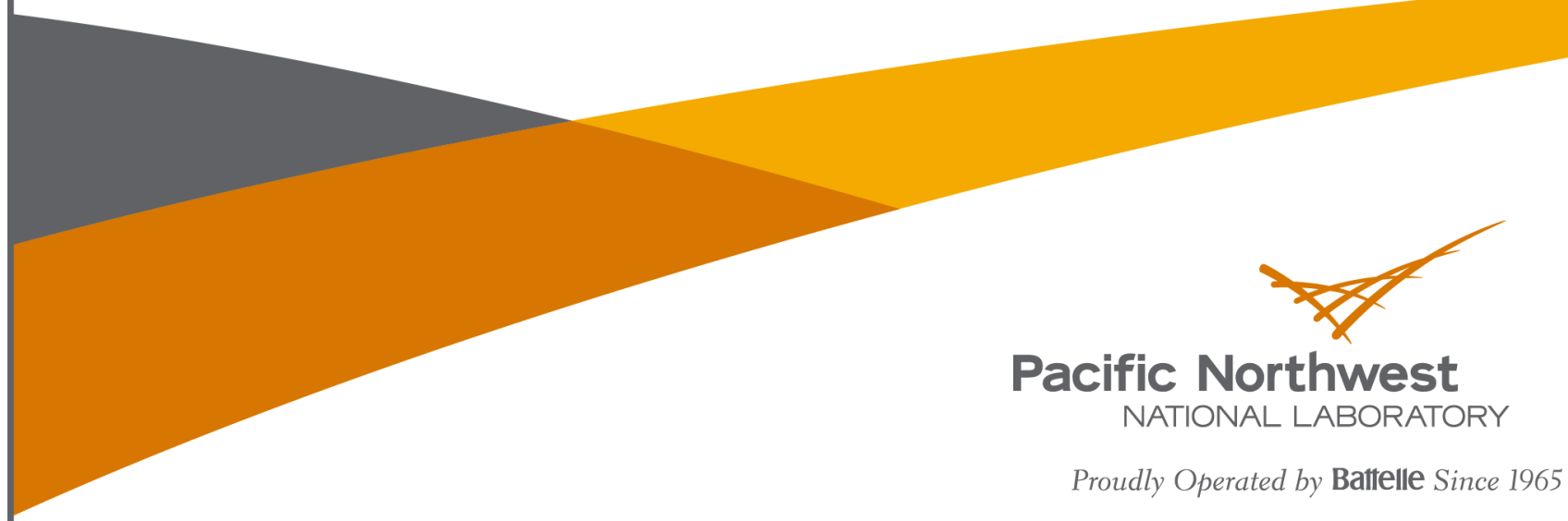




\title{
DISCLAIMER
}

This report was prepared as an account of work sponsored by an agency of the United States Government. Neither the United States Government nor any agency thereof, nor Battelle Memorial Institute, nor any of their employees, makes any warranty, express or implied, or assumes any legal liability or responsibility for the accuracy, completeness, or usefulness of any information, apparatus, product, or process disclosed, or represents that its use would not infringe privately owned rights. Reference herein to any specific commercial product, process, or service by trade name, trademark, manufacturer, or otherwise does not necessarily constitute or imply its endorsement, recommendation, or favoring by the United States Government or any agency thereof, or Battelle Memorial Institute. The views and opinions of authors expressed herein do not necessarily state or reflect those of the United States Government or any agency thereof.

\author{
PACIFIC NORTHWEST NATIONAL LABORATORY \\ operated by \\ BATTELLE \\ for the \\ UNITED STATES DEPARTMENT OF ENERGY \\ under Contract DE-AC05-76RL01830
}

Printed in the United States of America
Available to DOE and DOE contractors from the Office of Scientific and Technical Information,
P.O. Box 62, Oak Ridge, TN 37831-0062;
ph: (865) 576-8401
fax: $(865) 576-5728$
email: reports@adonis.osti.gov

Available to the public from the National Technical Information Service

5301 Shawnee Rd., Alexandria, VA 22312

ph: (800) 553-NTIS (6847)

email: orders@ntis.gov <http://www.ntis.gov/about/form.aspx>

Online ordering: http://www.ntis.gov

This document was printed on recycled paper. 


\section{Pilot Implementation of a Field Study Design to Evaluate the Impact of Source Control Measures on Indoor Air Quality in High- Performance Homes}

SH Widder, M Chamness, J Peterson, Pacific Northwest National Laboratory

BC Singer, RL Maddalena, H Destaillats, ML Russell, Lawrence Berkeley National Laboratory

October 2014

Prepared for the U.S. Department of Energy under Contract DE-AC05-76RL01830

Pacific Northwest National Laboratory

Richland, Washington 99352 



\section{Summary}

Controlling indoor air pollutant sources is a foundational approach to ensuring good indoor air quality (IAQ) in residences. As a voluntary standard for home builders and buyers interested in IAQ, the Indoor airPLUS (IaP) program of the U.S. Environmental Protection Agency (EPA) includes provisions intended to reduce emissions of potentially harmful volatile organic compounds (VOCs) from building materials and finishes used in IaP homes. The U.S. Department of Energy (DOE) Zero Energy Ready Home ${ }^{1}$ standard incorporates IaP provisions with the objective of advancing comprehensive home performance. The IaP provisions for low-emitting materials and finishes rely on a variety of existing labeling programs and standards. IaP requires the use of Voluntary Product Standard 1 (PS1) or PS2 certified plywood and oriented strand board; low-formaldehyde emitting wood products; low- or no-VOC paints and coatings as certified by Green Seal Standard GS-11, GreenGuard, Scientific Certification Systems Indoor Advantage Gold Standard, Master Painters Institute Green Performance Standard, or another third-party rating program; and Green Label-certified carpet and carpet cushions. While requirements for materials and finishes that emit lower quantities and less toxic VOCs are expected to be beneficial on a theoretical basis, there is only limited empirical evidence about their efficacy in measurably reducing contaminant exposures in new homes.

The goal of this project was to develop a field study design and to conduct a pilot implementation to evaluate the IAQ impacts of IaP provisions related to low-emitting materials and finishes in new residential homes. Researchers from Pacific Northwest National Laboratory (PNNL) and Lawrence Berkeley National Laboratory (LBNL) developed a detailed experimental plan to measure VOCs and other relevant parameters, over time, in two groups of otherwise similar new homes that differ primarily in their specification of low-emitting materials and finishes. The test group was targeted as homes that comply with IaP's low-emitting material requirements (i.e., Sections 6.1, 6.2, 6.3, and 7.2). Control homes were to be constructed to the Washington State building code with conventional materials. The intent was that test and control homes would be in the same geographic location with generally similar or matched construction style, size and amenities. The homes would be evaluated at similar age and under similar internal and external (seasonal) environmental conditions. The impact of IaP provisions was to be evaluated based on measured concentrations and calculated whole-house emission rates of speciated VOC and volatile carbonyl concentrations, normalized to floor area. The study design included the following sampling events: 1) collection of active samples designed to measure building-related VOCs with homes operating under specified, controlled conditions, and 2) a weeklong passive sample designed to capture the impact of occupant behavior and related activities on measured VOCs indoors. The combination of detailed short-term measurements with the home under controlled/consistent conditions during pre- and post-occupancy and the weeklong passive sampling data was intended to separate building and occupantrelated emission sources and to help isolate and quantify variability in the monitored homes. The study design was incorporated into a Human Subjects research protocol that was reviewed and approved by the institutional review boards (IRBs) of PNNL and LBNL.

Since the study required that measurements occur in homes prior to occupancy, the identification of potential participants was through builders constructing homes in the Tri-Cities area. Outreach to

\footnotetext{
${ }^{1}$ http://energy.gov/eere/buildings/zero-energy-ready-home
} 
builders started in early 2014 with the goal of identifying homes that would be completed in the spring of 2014.

Owners of three homes that met essential project criteria agreed to participate in the study and measurements were conducted in these homes between April and August 2014. The study homes included a conventional construction home (C1) and two homes meeting the relevant IaP specifications (IaP1 and IaP2). Samples were collected using active sampling under controlled conditions during preoccupancy and post-occupancy events in all three homes and through passive monitoring under normal operating conditions after the post-occupancy controlled sampling event in $\mathrm{C} 1$ and IaP2. Collected samples were analyzed to determine concentrations of volatile carbonyls including formaldehyde, acetaldehyde, and acetone and over 40 other VOCs; speciated VOCs were summed to provide an estimate of overall VOC levels. Perfluorocarbon tracers (PFT) were released into the homes at measured emission rates and air concentrations of these compounds were measured to enable calculation of outdoor air dilution rates for indoor sources. These dilution rates were combined with measured VOC concentrations and home size to calculate floor-area-specific VOC emission rates. These emission rates were used to compare VOC emissions characteristics of the homes, which varied in size. For a variety of reasons, a second post-occupancy sampling event (which was planned to occur roughly 2-3 months later) could not be implemented at any of the homes. Limited funding necessitated suspension of the planned three-year project by the end of September 2014. To accommodate this end date, in-home measurements and recruitment of additional homes was suspended in August 2014.

This report presents data and results from pilot implementation of the study protocol in the three homes noted above. It also presents lessons learned that should be considered if the study protocol is implemented in the future. Owing to the limited sample of homes and the limited duration of measurements at each home, the study's core research questions could not be robustly answered with the data that were collected. The collected data nevertheless provide information that is relevant to these questions.

Specifically, overall concentrations of VOCs measured during pre-occupancy varied widely across the three homes. The highest levels, measured in IaP2, were more than $2 \mathrm{x}$ and $6 \mathrm{x}$ as high as preoccupancy VOCs in C1 and IaP1, respectively. There was a very steep drop in overall VOC levels between pre- and post-occupancy in IaP2 (from 13,800 to $2400 \mu \mathrm{g} \mathrm{m}^{-3}$ ) despite relatively similar outdoor air dilution rates during the two sampling events and only about a 3-week interval. The steepness of this decline suggests one or more emissions sources occurring just before or even during the pre-occupancy sampling event. The builder noted that some finish work and an extensive cleaning occurred in the days just before the measurements were made and several of the specific VOCs that were present at high concentrations are indicative of paint stripping, paint, and wood floor finishes. The VOC mixture observed during IaP2 pre-occupancy sampling contained very high concentrations of chemicals that are used as solvents but also present in gasoline. A gasoline-powered washer could have been the source of source of many of the elevated VOCs observed during this sampling period.

Overall VOC levels decreased between pre- and post-occupancy in $\mathrm{C} 1$ but increased between preand post-occupancy in IaP1. The post-occupancy concentrations of the summed VOCs were more similar across homes, covering the range of $2400 \mu \mathrm{g} \mathrm{m}^{-3}$ (IaP2) to $3700 \mu \mathrm{g} \mathrm{m}^{-3}$ (C1).

There were substantial increases $(>50 \%)$ in volatile carbonyl concentrations between pre- and postoccupancy in $\mathrm{C} 1$ and $\mathrm{IaP} 1$. IaP2 had the highest concentrations of formaldehyde and acetaldehyde pre- 
occupancy, but post-occupancy concentrations of these compounds were lower in IaP2 than in the other two homes. Floor area-normalized emission rates of formaldehyde and acetaldehyde - which are two air pollutants that most commonly exceed health-based standards in homes - were very similar across the three homes.

There were numerous valuable lessons learned from this pilot implementation. Most important is the recognition that it is extremely difficult to execute a standardized pre-occupancy sampling event without substantially controlling the highly variable course of events that occur around new home completion and occupancy. Since many homes are not fully completed until just before and sometimes after the initial occupancy, the impact of solvents, paints, floor finishes, cleaners, etc. on VOC concentrations preoccupancy is extremely variable. If the study is ever continued with its current design, this should be a major focus. Substantial effort also needs to be allocated to documenting the timing and details of builder activities prior to pre-occupancy. Another important finding is that it is difficult to find control homes that utilize no low-emitting materials. Despite the builder's assertion that $\mathrm{C} 1$ had very limited use of lowemitting materials and finishes, we were able to determine that a substantial fraction of the materials and finishes were actually rated and/or certified as having low VOC emissions.

If this research is pursued again in the future, we note two alternative approaches that should be considered. The first is to conduct a highly controlled study in which the specific collections of materials and finishes that would go into IaP and non-IaP homes are selected in consultation with builders and material suppliers, and these materials and finishes are combined in appropriate ratios into simulated new homes that are evaluated over time in laboratory chamber testing. This would provide clear information about differences between the materials and finishes used in the homes, though the relative importance of occupant materials and activities would remain unknown. Another approach would be to measure VOCs in a large enough number of IaP and non-IaP homes roughly 6 months post-occupancy to assess whether there is any discernible difference in VOC concentrations between the two cohorts of IaP and non-IaP homes. The homes could be paired by season and location and conditions could be constrained, although not tightly controlled. The sampling events would be much less costly than those of our proposed study design; so larger sample sizes would be achievable with similar budgets. The rationale for such an approach is that, although the difference in IAQ contaminants would not be measured pre- and postoccupancy and the measurements would also capture the variability of occupant activities and sources, any important benefit of the source control provisions should be both durable and observable through such variations in VOCs from variable occupant possessions and activities. 



\section{Acknowledgments}

The research team is grateful to the builders and homeowners who opened their homes to the researchers and cooperated with the requirements of the research protocol. Thank you also to Kathy Ertell, who guided the research team on the Human Subjects Review submission process and other PNNL staff who contributed to the success of the project, including Michael Baechler, Rose Bartlett, and Jamie Spangle who assisted with the administration and management of the project and Susan Ennor for her editorial expertise.

This research would also not be possible without the support of the project sponsors, Eric Werling and Sam Rashkin, the U.S. Department of Energy Project Managers for the Building America Program. 



\title{
Acronyms and Abbreviations
}

\author{
${ }^{\circ} \mathrm{C}$ \\ ${ }^{\circ} \mathrm{F}$ \\ AER \\ ANSI \\ APA \\ ASHRAE \\ BFB \\ CARB \\ $\mathrm{cc}$ \\ $\mathrm{CDPH}$ \\ $\mathrm{cfm}$ \\ cfm25 \\ cfm50 \\ $\mathrm{CO}_{2}$ \\ CRI \\ CT \\ d \\ DOE \\ EPA \\ $\mathrm{ft}$ \\ $\mathrm{ft}^{2}$ \\ GC \\ HBATC \\ HPLC \\ HPVA \\ HSPF \\ HUD \\ HVAC \\ $\mathrm{hr}$ \\ $\mathrm{IaP}$ \\ IAQ \\ ISTD \\ KCMA \\ LEED \\ $\mathrm{m}^{3}$ \\ MDF \\ degrees Celsius \\ degrees Fahrenheit \\ air exchange rate \\ American National Standards Institute \\ American Plywood Association \\ Association of Heating, Refrigeration, and Air-Conditioning Engineers \\ 1-bromo-4-fluorobenzene \\ California Air Resources Board \\ cubic centimeter(s) \\ California Department of Public Health \\ cubic feet per minute \\ cubic feet per minute at 25 pascals of depressurization with respect to the outside \\ cubic feet per minute at 50 pascals of depressurization with respect to the outside \\ carbon dioxide \\ Carpet and Rug Institute \\ current transducer \\ day(s) \\ U.S. Department of Energy \\ U.S. Environmental Protection Agency \\ foot(feet) \\ square foot(feet) \\ gas chromatography \\ Home Builders Association of the Tri-Cities \\ high-performance liquid chromatography \\ Hardwood Plywood and Veneer Association \\ Heating Season Performance Factor \\ U.S. Department of Housing and Urban Development \\ heating, ventilation, and air-conditioning \\ hour \\ Indoor airPLUS \\ Indoor air quality \\ internal standard \\ Kitchen Cabinet Manufacturers Association \\ Leadership in Energy and Environmental Design \\ cubic meter(s) \\ medium-density fibreboard
}




$\begin{array}{ll}\text { mg } & \text { milligram(s) } \\ \text { min } & \text { minute(s) } \\ \text { mL } & \text { milliliter(s) } \\ \text { MPI } & \text { Master Painters Institute } \\ \text { MS } & \text { mass spectromtery } \\ \text { MSDS } & \text { Material Safety \& Data Sheets } \\ \text { NA } & \text { not applicable } \\ \text { NGBS } & \text { National Green Building Standard } \\ \text { OD } & \text { outer diameter } \\ \text { OSB } & \text { oriented strand board } \\ \text { PFT } & \text { perfluorocarbon tracer } \\ \text { ppb } & \text { parts per billion } \\ \text { PS } & \text { Voluntary Product Standard } \\ \text { RH } & \text { relative humidity } \\ \text { s } & \text { second(s) } \\ \text { SCS } & \text { Scientific Certification Systems } \\ \text { SEER } & \text { Seasonal Energy Efficiency Rating } \\ \text { T } & \text { temperature } \\ \text { TD } & \text { thermal desorption } \\ \text { TD-GC/MS } & \text { thermal-desorption gas chromatography/mass spectrometry } \\ \text { VOC } & \text { volatile organic compounds } \\ & \end{array}$




\section{Table of Contents}

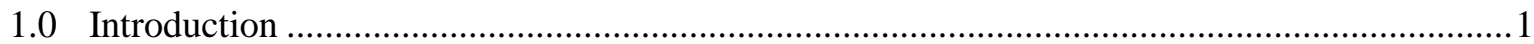

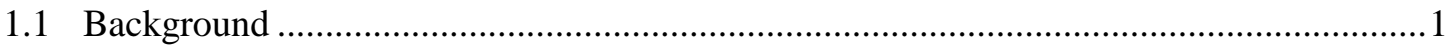

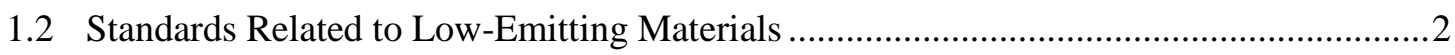

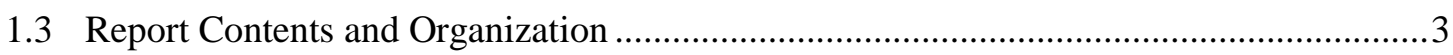

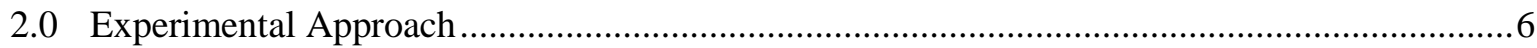

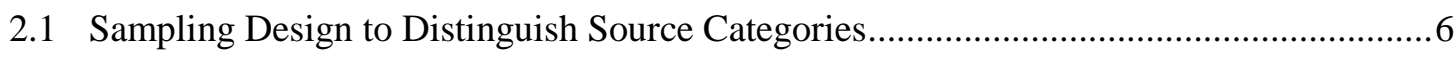

2.1.1 Controlled Active Sampling Periods ...............................................................

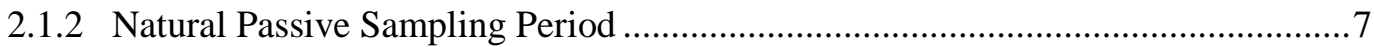

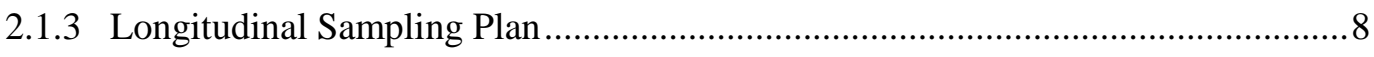

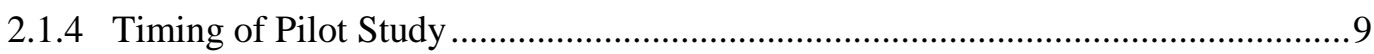

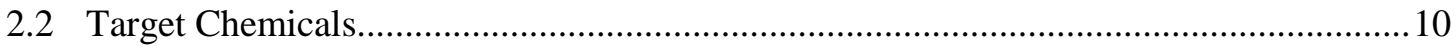

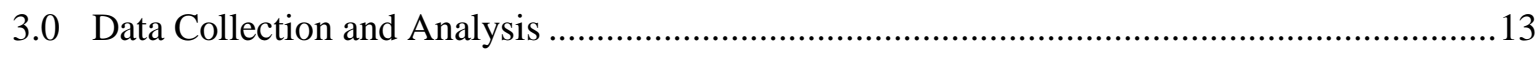

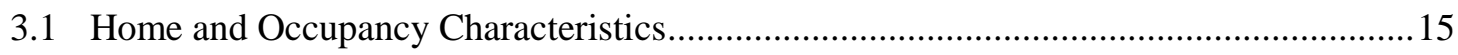

3.1.1 Building Materials and Furnishings Inventory …...............................................16

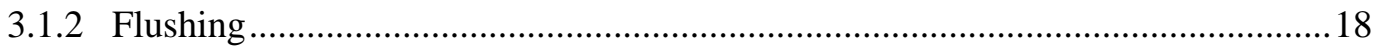

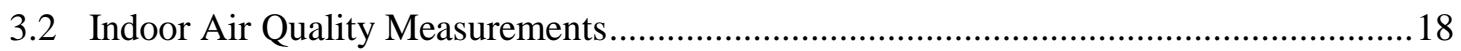

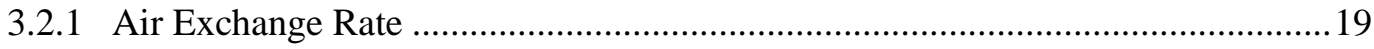

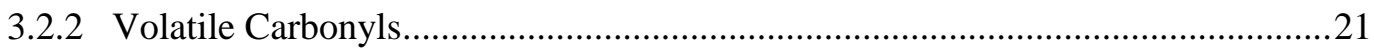

3.2.3 Speciated Volatile Organic Compounds and PFT Samplers ...............................21

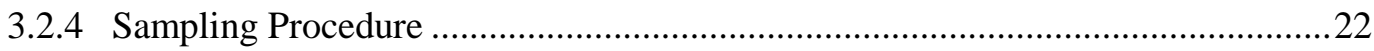

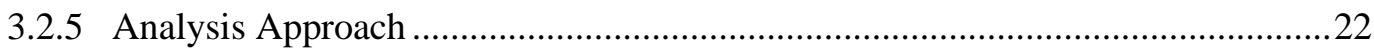

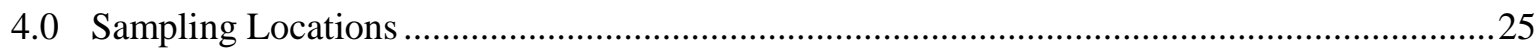

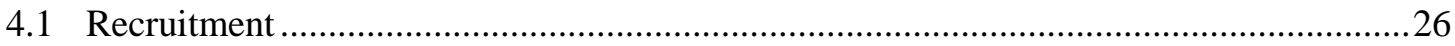

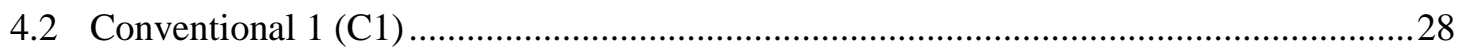

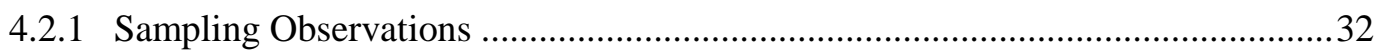

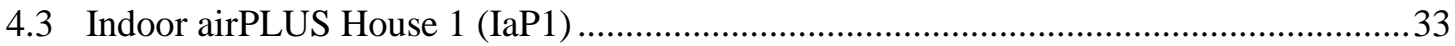

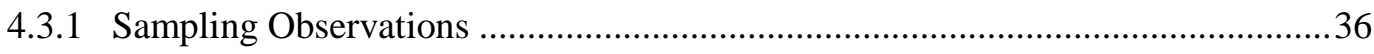

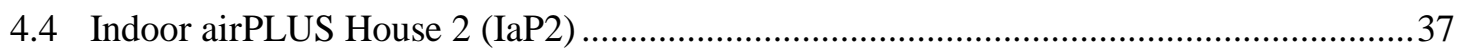

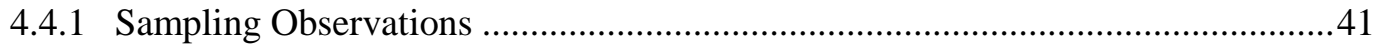

5.0 Measurements at Pilot Homes: Results and Discussion ....................................................43

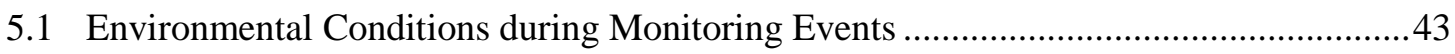

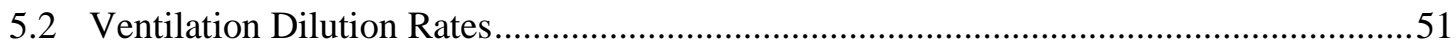

5.2.1 PFT Emitters and Emission Rates ...............................................................52

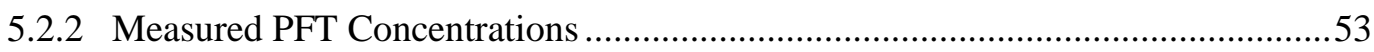

5.2.3 Calculated Outdoor Air Dilution Rates ............................................................5

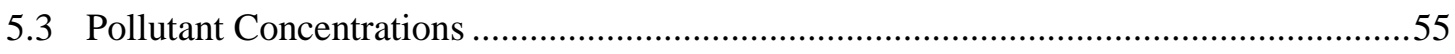

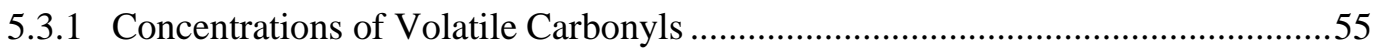


5.3.2 Concentrations of Other Volatile Organic Compounds …..................................58

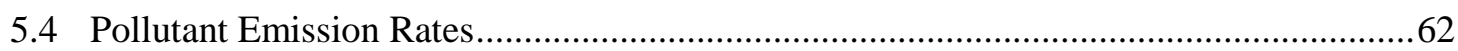

5.4.1 Emission Rates of Very Volatile Carbonyls.......................................................62

5.4.2 Emission Rates of Other Volatile Organic Compounds .........................................64

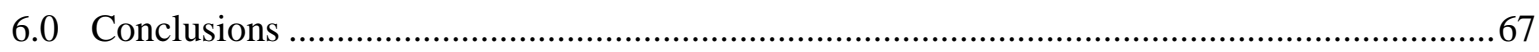

6.1 Lessons Learned on Recruitment and Experimental Plan ...........................................67

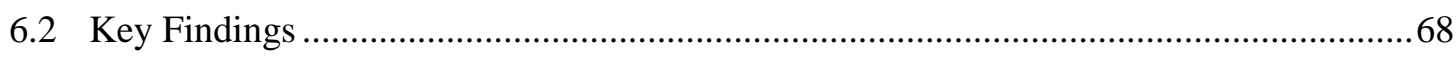

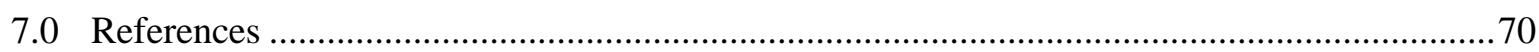

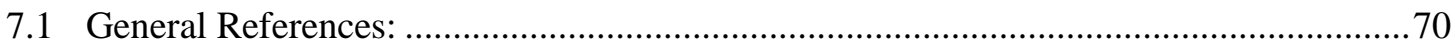

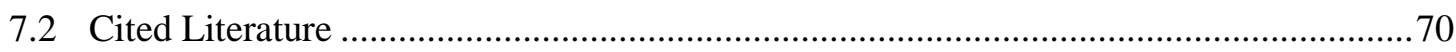

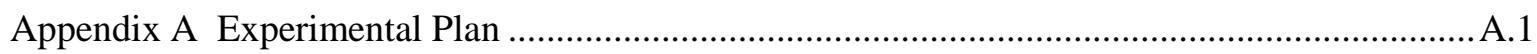

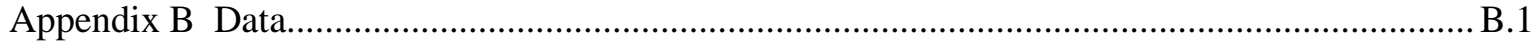




\section{Figures}

3.1. Three Emitter Vials Positioned Upside Down in an Emitter Cage for Deployment ............21

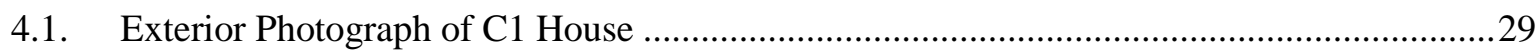

4.2. Downstairs Great Room Furniture (Zone 1) .................................................................. 31

4.3. Home Entertainment Center Furniture ........................................................................... 31

4.4. Location of Emitters and Active Samplers in the Lower Level of C1 (Zone 1; left) and Upper Level of C1 (Zone 2; right) During Pre-Occupancy Sampling Period ........................ 32

4.5. Location of Emitters, Active Samplers, and Passive Samplers in the Lower Level of C1 (Zone 1; left) and Upper Level of C1 (Zone 2; right) During Post-Occupancy Sampling

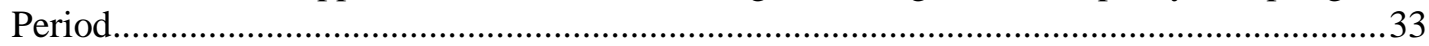

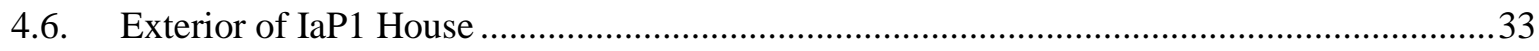

4.7. New Furnishings in IaP1 Living Room at Start of Post-Occupancy Sampling....................35

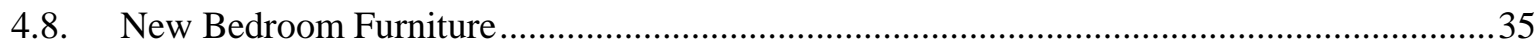

4.9. Location of Emitters and Active Samplers in IaP1 During Pre-Occupancy Sampling

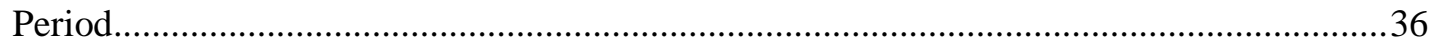

4.10. Location of Emitters, Active Samples, and Passive Samplers in IaP1 During

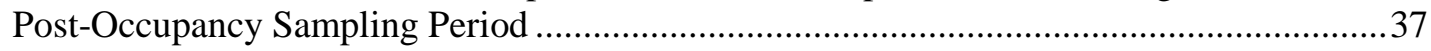

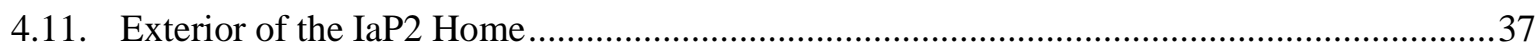

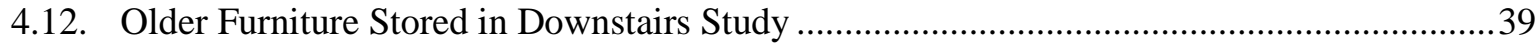

4.13. Older Personal Belongings Stored in Upstairs Laundry Room ..........................................39

4.14. Boxes of Clothing and Linens Stored in Upstairs Bedroom.............................................40

4.15. New Leather Couches, Ottoman and Area Rug in Living Room of IaP2 .........................40

4.16. New Guest Room Furniture and Bedding ....................................................................41

4.17. Location of Emitters and Active Samplers in the $1^{\text {st }}$ Floor of IaP2 (Zone 1; left) and $2^{\text {nd }}$ Floor of IaP2 (Zone 2; right) During Pre-Occupancy Sampling Period ....................41

4.18. Location of Emitters and Active Samplers on the $1^{\text {st }}$ Floor of IaP2 (Zone 1; left) and $2^{\text {nd }}$ Floor of IaP2 (Zone 2; right) During Post-Occupancy Sampling Period..................42

5.1. Interior Ambient Temperatures Measured During the Pre-Occupancy Active Sampling

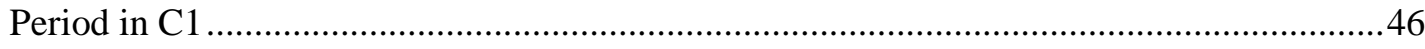

5.2. Interior Relative Humidity Measured During the Pre-Occupancy Active Sampling Period

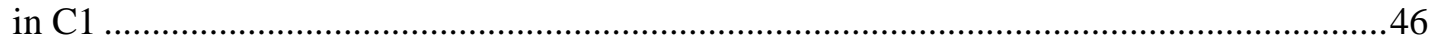

5.3. Interior Temperature Measured During the Post-Occupancy Active Sampling Period in C147

5.4. Interior Relative Humidity Measured During the Post-Occupancy Active Sampling Period

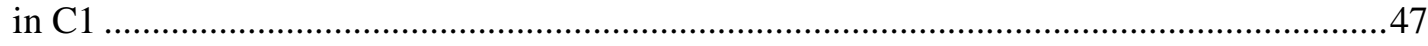

5.5. Interior Temperature Measured During the Pre-Occupancy Active Sampling Period in

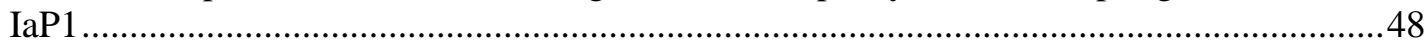

5.6. Interior Relative Humidity Measured During the Pre-Occupancy Active Sampling Period

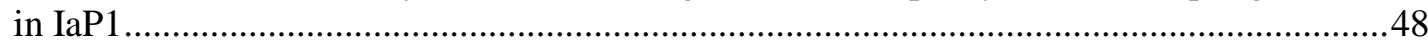

5.7. Interior Temperature Measured During the Post-Occupancy Active Sampling Period in $\mathrm{IaP} 1$ 
5.8. Interior Relative Humidity Measured During the Post-Occupancy Active Sampling Period in IaP1

5.9. Interior Temperature Measured During the Pre-Occupancy Active Sampling Period in $\mathrm{IaP} 2$.

5.10. Interior Relative Humidity Measured During the Pre-Occupancy Active Sampling Period in IaP2.

5.11. Interior Temperature Measured During the Post-Occupancy Active Sampling Period in $\mathrm{IaP} 2$.

5.12. Interior Relative Humidity Measured During the Post-Occupancy Active Sampling Period in $\mathrm{IaP} 2$.

5.13. Formaldehyde Concentrations in the Three Study Homes, Determined with Active Sampling. Error bars represent range of $n=2$ or standard deviation of $n \geq 3$ samples........56

5.14. Acetaldehyde Concentrations in the Three Study Homes, Determined with Active Sampling. .56

5.15. Acetone Concentrations in the Three Studied Homes, Determined with Active Sampling ..57

5.16. Sum of VOC Concentrations Measured Indoors on the Three Homes..................................58

5.17. Normalized Emission Rates of Formaldehyde in the Three Study Homes .........................63

5.18. Normalized Emission Rates of Acetaldehyde in the Three Study Homes ...........................63

5.19. Normalized Emission Rates of Acetone in the Three Study Homes ..................................63

5.20. Normalized Emission Rates of the Sum of All Identified VOCs (TVOCs) in Each

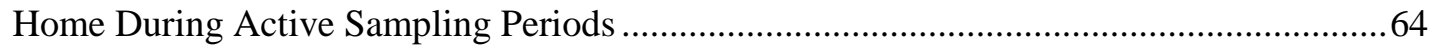

5.21. Normalized Emission Rates of Two Individual VOCs in Each Home During Active Sampling Periods .66 


\section{Tables}

1.1. Indoor airPLUS and HBATC BuiltGreen Specifications ................................................

2.1. Dates of Pre-Occupancy Active Sampling Period, Post-Occupancy Active Sampling Period, and Post-Occupancy Passive Sampling Period in Each Sampled Home

2.2. Summary List of Compounds that are Typically Found Indoors along with Possible Sources or Classifications.

3.1. Summary of Measurements Occurring During Each Sampling Period................................ 13

3.2. Measurement Parameters, Measurement Equipment, and Sampling Rates.......................... 16

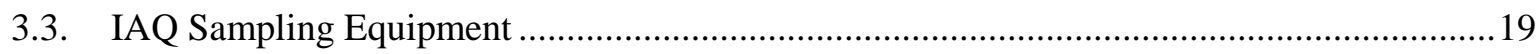

3.4. PFT Gases Used in Emitters to Determine Air Exchange Rate...........................................20

4.1. Criteria to Determine Candidate Homes for Study Participation ........................................25

4.2. Characteristics of Homeowners Used to Determine Inclusion or Exclusion..........................26

4.3. Schedule of Homeowner Stipends and Amounts ..............................................................2

4.4. Key House Characteristics for Conventional $1(\mathrm{C} 1)$...........................................................29

4.5. Major Composite Wood, Paints and Finishes, and Carpet Products Used in C1 Home

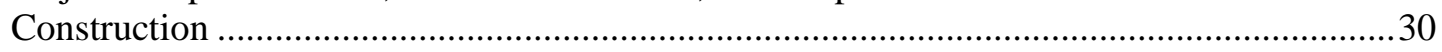

4.6. Key House Characteristics for the IaP1 Home ................................................................... 34

4.7. Major Composite Wood, Paints and Finishes, and Carpet Products Used in IaP1 Home

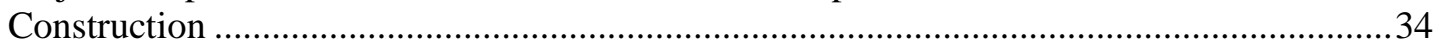

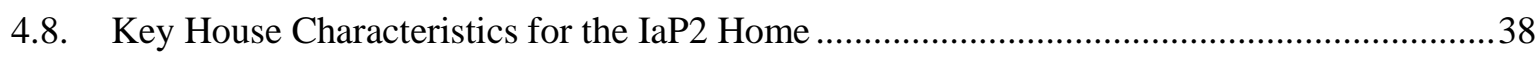

4.9. Major Composite Wood, Paints and Finishes, and Carpet Products Used in IaP2 Home

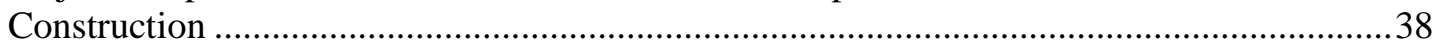

5.1. Location of T/RH Loggers in Each House and Associated Emitter Cage (in parentheses) ...43

5.2. Summary of 4-Hour and 12-Hour Integrated Average Temperature and Relative Humidity Observed Prior to and During Each Active Sample in Each Home and Associated Variability. .45

5.3. Emission Rates of Emitters Deployed in Each Zone of the Three Sampled Homes ..............52

5.4. Valid PFT Concentrations (in $\mu \mathrm{g} \mathrm{m}^{-3}$ ) Determined in the Three Sampled Homes.................54

5.5. Whole-House Dilution Rates (expressed in $\mathrm{m}^{3} \mathrm{~h}^{-1}$ ) ...........................................................55

5.6. Comparison of Aldehyde Concentrations Determined with Active and Passive Sampling ...58

5.7. Speciated VOC Concentrations $\left(\mu \mathrm{g} \mathrm{m}^{-3}\right)$ Determined from Active and Passive Sampling....59

B.1. Summary of Calculated Emission Rates for Each Emitter in $\mathrm{C} 1$..................................... B.2

B.2. Summary of Calculated Emission Rates for Each Emitter in IaP1 ....................................... B.4

B.3. Summary of Calculated Emission Rates for Each Emitter in IaP2 .................................. B.5

B.4. Summary of Calculated Emission Rates for Each Emitter ............................................. B.8 



\subsection{Introduction}

The U.S. Department of Energy's (DOE's) Zero Energy Ready Home and other voluntary programs currently include the requirements of the U.S. Environmental Protection Agency's (EPA's) Indoor airPLUS (IaP) program for achieving measureable reductions in indoor air concentrations of volatile organic compounds (VOCs) and aldehydes and related contaminant exposures in homes. However, the effectiveness of the IaP requirements has not been validated in the field. The objective of the pilot field study reported herein was to develop a robust experimental approach and to present pilot data to verify the approach and quantify preliminary indoor air quality (IAQ) benefits of applying the IaP requirements for low-emitting materials and finishes in new home construction. To this end, the Pacific Northwest National Laboratory (PNNL) and Lawrence Berkeley National Laboratory (LBNL) research team developed a detailed experimental plan to measure IAQ constituents and other parameters, over time, in new homes constructed with materials compliant with IaP's low-emitting material and ventilation requirements (i.e., Sections 6.1, 6.2, 6.3, and 7.2 of EPA's IaP Construction Specifications ${ }^{1}$ ) and similar homes constructed to the state building code using conventional materials. As part of the pilot study, IAQ sampling occurred in two newly constructed IaP homes and one newly constructed conventional home during the summer of 2014.

\subsection{Background}

As tighter homes are constructed and an increasing number of synthetic compounds are introduced into the built environment there is potential to change the types and concentrations of chemicals to which occupants are exposed. There is some evidence that new U.S. homes can have levels of potentially hazardous VOCs that exceed health-based standards (Offermann 2009). VOCs can be mitigated by increasing ventilation or by controlling sources (Hult et al. 2014). Since increasing ventilation involves an increase in energy use, the source control option is generally preferable.

A variety of standards and rating programs have been introduced to identify building materials that are designed to have lower emission rates of key contaminants of concern and a number of building materials are being introduced that are certified to these standards. For example, the DOE's Zero Energy Ready Home ${ }^{2}$ program requires certification under the EPA Indoor airPLUS (IaP) label. The IaP program requires, among other things, the use of Voluntary Product Standard 1 (PS1) or PS2 certified plywood and oriented strand board (OSB); low-formaldehyde-emitting wood products; low- or no-VOC paints and coatings as certified by Green Seal Standard GS-11, GreenGuard Environmental Institute (GreenGuard) ${ }^{3}$, Scientific Certification Systems (SCS) ${ }^{4}$ Indoor Advantage Gold Standard, MPI Green Performance Standard, or another third-party rating program; and Green Label-certified carpet and carpet cushions.

DOE's Zero Energy Ready (high-performance) home program includes IaP provisions for lowemitting materials and finishes. While requirements for materials and finishes that emit lower quantities

\footnotetext{
${ }^{1}$ References to the IaP Construction Specifications refer to Version 1 (Rev. 02) of that document and are available at http://www.epa.gov/indoorairplus/construction_specifications.html

${ }^{2} \mathrm{http}: / /$ energy.gov/eere/buildings/zero-energy-ready-home

${ }^{3} \mathrm{http}: / / \mathrm{www}$.greenguard.org/en/index.aspx

${ }^{4}$ http://www.scsglobalservices.com/
} 
and less toxic VOCs are expected to be beneficial on a theoretical basis, there is only limited empirical evidence about their efficacy in measurably reducing contaminant exposures in new homes. Collection of such data will allow IAQ source control programs, such as IaP, to potentially focus on the most important materials and sources in homes, which could increase the benefits and decrease the burden of complying with such a program. In addition, data relating use of low-emitting materials and whole-house emission rates of IAQ contaminants could help to determine how using low-emitting materials might affect the necessary ventilation rate for high-performance homes. If source emission rates are reduced by use of IaP-certified materials and finishes, then it may be possible to reduce the necessary "building-related" ventilation rate in those homes, further reducing energy use and possibly reducing capital costs of providing mechanical ventilation.

\subsection{Standards Related to Low-Emitting Materials}

Several major home labeling programs are currently available. The EPA launched the IaP home labeling program in 2009, a significant milestone in the effort to assist homebuyers in identifying residences with good IAQ. The program recognizes new homes equipped with a comprehensive set of IAQ features, including the use of low-emission materials and coatings. Other major programs include the Leadership in Energy and Environmental Design (LEED) rating for homes from the U.S. Green Building Council and the National Green Building Standard (NGBS) from the National Association of Home Builders (NAHB). The DOE's Zero Energy Ready Home program offers two paths to home labeling both of which include addressing IAQ based on the IaP Construction Specifications, including use of low-VOC-emitting building materials.

This study is specifically focused on evaluating the source control requirements associated with the EPA's IaP program that are prominent in the DOE Zero Energy Ready program. IaP requires the use of low-emitting paints, coatings, carpet, and carpet pads, and formaldehyde-free OSB, and other wood products. Specifically, sections 6.1, 6.2, and 6.3 of the IaP Construction Specifications specify certain certifications materials must meet. In addition, section 7.2 of the IaP Construction Specifications requires the home to be ventilated after material installation and prior to occupancy, to help minimize exposure to any remaining contaminants. The Home Builders Association of the Tri-Cities (HBATC) also offers a BuiltGreen program ${ }^{1}$ with many similar requirements for material selection and installation. These certifications and requirements are summarized and compared in Table 1.1.

With regard to certification agencies and procedures, various organizations and testing laboratories certify low-emission materials. In California, testing methods and performance criteria are based on California Department of Public Health Standard Method (Section 01350), "Standard Method for the Testing and Evaluation of Volatile Organic Chemical Emissions from Indoor Sources Using Environmental Chambers." The standard is gaining nationwide acceptance as the benchmark for evaluating the emission rates of VOCs from various materials in the laboratory. The current version of the standard includes commercial buildings such as offices and schools and new single-family residences. SCS and GreenGuard are two major certification organizations in the United States with substantial databases on low-emission materials and household products, although lists of certified low-emission materials or products are also compiled by other organizations as well. These include the High

\footnotetext{
${ }^{1}$ http://www.hbatc.com/for-members/built-green.html\#bf_miniCal_107
} 
Performance Products Database from the Collaborative for High Performance School (CHPS) developed in partnership with the EPA ${ }^{1}$, and the Pharos Project materials rating system from the Healthy Building Network $(\mathrm{HBN})^{2}$.

Emissions characteristics of building materials have been extensively reported but use of these materials is voluntary and health-based standards or guidelines to ensure good IAQ and regulations to limit the use of potentially hazardous materials are still lacking. Current rating systems and low-emitting material certifications are aimed at addressing issues of sustainability, energy efficiency, and IAQ. However, there is a lack of field validation of the efficacy of such rating and certification systems on achieving measurable improvements in IAQ.

\subsection{Report Contents and Organization}

This report presents the fundamental research questions along with a detailed experimental plan developed to address these questions. This experimental plan is presented as Appendix A of this report. The plan was implemented for three homes and the report includes details on the data collection and analysis approach, a thorough description of the sampling locations and field observations, a summary of IAQ data and results from the pilot field study, and a discussion of results. Finally, the report provides lessons learned from the pilot study, and presents the key conclusions resulting from the work to date along with recommendations for future work.

\footnotetext{
${ }^{1}$ http://www.chps.net/dev/Drupal/node/445

2 https://www.pharosproject.net/
} 
Table 1.1. Indoor airPLUS and HBATC BuiltGreen Specifications

\begin{tabular}{|c|c|c|}
\hline $\begin{array}{c}\text { Indoor airPLUS } \\
\text { Section and } \\
\text { Specification } \\
\end{array}$ & Certification Details & $\begin{array}{c}\text { Tri-Cities Home Builders Association } \\
\text { BuiltGreen Equivalent }\end{array}$ \\
\hline $\begin{array}{l}\text { Materials 6.1: } \\
\text { Certified low- } \\
\text { formaldehyde } \\
\text { composite wood } \\
\text { materials AND } \\
\text { structural plywood } \\
\text { AND OSB PS1 or } \\
\text { PS2 compliant. }\end{array}$ & 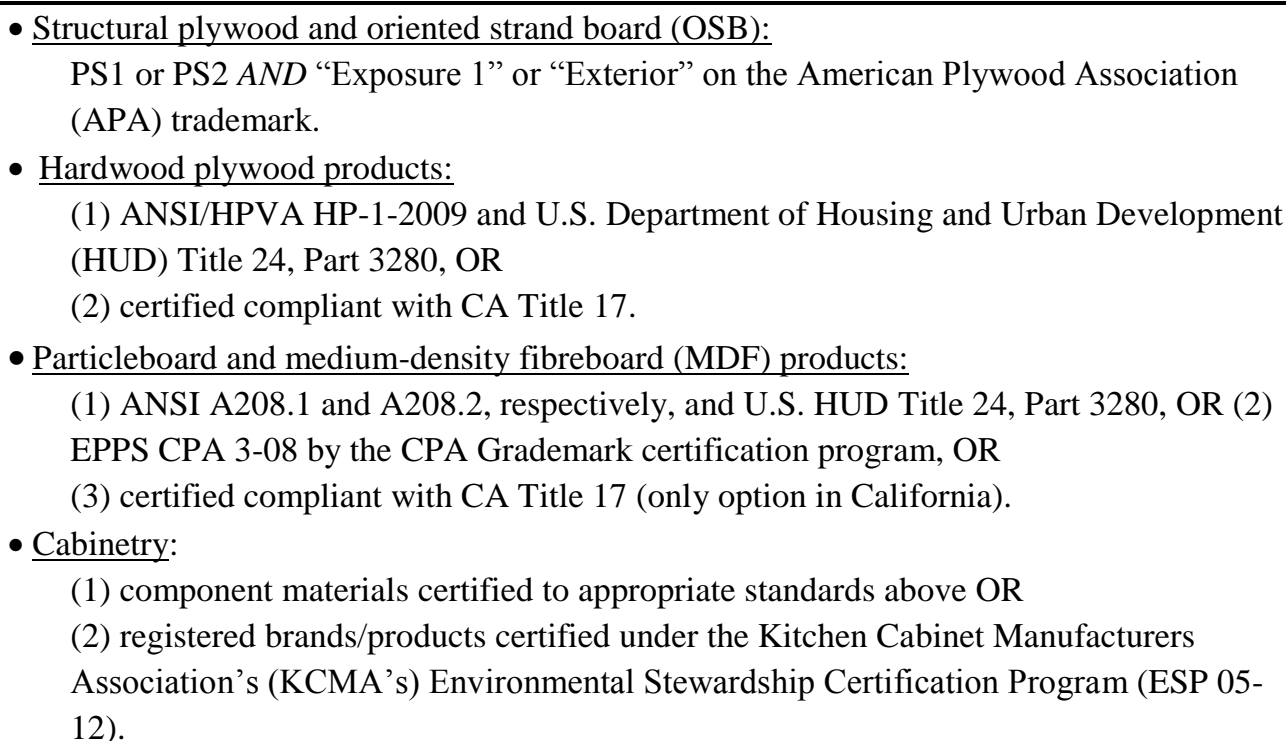 & $\begin{array}{l}\text { - Credit 4-27: Use plywood and } \\
\text { composites of exterior grade or urea- } \\
\text { formaldehyde-free (for interior use) } \\
\text { - Credit 4-28: Use cabinets and } \\
\text { countertops made without added urea- } \\
\text { formaldehyde board or exterior grade } \\
\text { plywood, and low- or non-toxic finish } \\
\text { - Credit 4-30: Use materials without } \\
\text { added urea-formaldehyde for finish } \\
\text { work, including shelving, window and } \\
\text { door trim, and base molding. }\end{array}$ \\
\hline
\end{tabular}

- Interior paints and finished composing $\geq 90 \%$ of interior covered surface area:

Certified low-VOC $\quad$ (2) Greenguard Certification Systems (CSC) Standard EC-10.2-2007, Indoor Advantage

paints and finishes used.
(3) Master Painters Institute (MPI) Green Performance Standards X-Green, GPS-1 or GPS-2, OR

(4) A third-party low-emitting product list based on CA Section 01350 (CDPH Standard Method V1.1-2010).

\section{Materials 6.3:}

Carpet, carpet adhesives CRI

Green Label Plus

AND carpet

cushion CRI Green

Label.

\section{- Carpets and carpet adhesives:}

At least $90 \%$ of the surface area covered by carpet and carpet adhesives use labeled Carpet and Rug Institute (CRI) Green Label Plus program AND carpet cushion certified to CRI Green Label program.
- Credit 4-32: Use low- or non-VOC and non-toxic interior paints and finishes on all interior surfaces.
-Credit 4-13: If using carpet, specify low VOC carpets with the CRI IAQ Program 
Table 1.1. (contd)

\begin{tabular}{|c|c|c|}
\hline $\begin{array}{c}\text { Indoor airPLUS } \\
\text { Section and } \\
\text { Specification } \\
\end{array}$ & Certification Details & $\begin{array}{c}\text { Tri-Cities Home Builders Association } \\
\text { BuiltGreen Equivalent }\end{array}$ \\
\hline $\begin{array}{l}\text { Final 7.2: Home } \\
\text { ventilated before } \\
\text { occupancy. }\end{array}$ & $\begin{array}{l}\text { - Ventilate the home with outside air at the highest rate practical, meeting ventilation } \\
\text { requirements for outdoor air flow and humidity control: During and shortly after installing } \\
\text { products that are known sources of contaminants (e.g., cabinets, carpet padding and } \\
\text { painting), AND during the period between finishing and occupancy. } \\
\text { - If whole-house ventilation cannot be scheduled prior to occupancy, advise the buyer to } \\
\text { operate the ventilation system at the highest rate it can provide during the first few months } \\
\text { of occupancy, meeting the above requirements. }\end{array}$ & \\
\hline Complete & - Comply with all requirements of IaP. & $\begin{array}{l}\text { - Credit 4-2: Certify house under Energy } \\
\text { Star Indoor Air Package (or other } \\
\text { program as approved by the Director) }\end{array}$ \\
\hline $\begin{array}{l}\text { HBATC Built } \\
\text { Green Program } \\
\text { provisions not } \\
\text { addressed by } \\
\text { EPA's Indoor } \\
\text { airPLUS program }\end{array}$ & NA & $\begin{array}{l}\text { - Insulation } \\
\text { o Credit 4-24: use urea- } \\
\text { formaldehyde-free insulation or } \\
\text { Greenguard certified product and } \\
\text { ○ Credit 4-25: do not use fiberglass } \\
\text { insulation (excluding ductwork). } \\
\text { - Sealers, grouts, mortars, caulks, stains, } \\
\text { pigments, additives, and adhesives } \\
\text { o Credit 4-26: use only non- or low- } \\
\text { VOC/toxic, water-based, solvent- } \\
\text { free sealers, grouts, mortars, caulks, } \\
\text { stains, pigments, additives, and } \\
\text { adhesives inside the house. }\end{array}$ \\
\hline
\end{tabular}




\subsection{Experimental Approach}

The PNNL and LBNL research team developed a detailed experimental plan (see Appendix A) to collect data necessary to answer the following primary research questions:

- What are the relative contributions of VOCs from 1) materials and finishes that are embedded in the finished constructed home, 2) materials (e.g., furnishings) and consumer products brought into the home by occupants, and 3) activities of occupants including the use of consumer products?

- Are the concentrations and composition of building-related VOCs measured in new IaP homes significantly different than new homes built with conventional materials?

- How do concentrations of building-related VOCs change over time in IaP and conventional homes?

The study plan was not designed to separately evaluate the impact of the "first flush" required by IaP section 7.2; but the plan could be expanded to accomplish this objective. The complete experimental plan is provided as Appendix A.

The impact on IAQ in the sampled homes is quantified based on differences in volatile carbonyl (formaldehyde, acetaldehyde, acetone) and other speciated VOC concentrations and calculated floor-areanormalized emission rates determined under consistent environmental and home operation conditions in IaP and conventional homes of similar age, location, and construction style. Specific VOCs of interest are discussed in Section 2.2. Descriptions of the methods employed to measure environmental parameters, outdoor air dilution rates (using perfluorocarbon tracers, PFTs), carbonyl and VOC concentrations and other parameters are presented in Section 3.0. Other parameters include general home characteristics; characterization of large furnishings and associated materials; temperature $(\mathrm{T})$ and relative humidity (RH); energy use; operation of intermittent ventilation equipment; and occupancy characteristics.

\subsection{Sampling Design to Distinguish Source Categories}

The experimental plan was designed to evaluate the impact of low-emitting materials and finishes in new homes recognizing that there are several major source categories that affect VOC concentrations. The three primary pollutant source categories considered in this project were intrinsic building-related materials, the contents of the finished building, and the occupant activities. To distinguish between these major source categories, two types of samples were used: 1) highly controlled, short-term active samples to precisely characterize the building-related chemical emissions (pre-occupancy) and the addition of building contents (post-occupancy), and 2) a weeklong integrated passive sample designed to measure pollutants related to occupant behavior and related activities (post-occupancy). The combination of detailed short-term measurements collected when the home was maintained under controlled, consistent conditions and the weeklong passive sampling data provide the opportunity to begin to separate the different major emission source categories and help isolate and quantify variability in the monitored homes. 


\subsubsection{Controlled Active Sampling Periods}

The highly controlled active sampling events were conducted both pre- and post-occupancy to separate the intrinsic building-related pollutants from the building contents. During each active sampling event, two short-term (1-hour) integrated samples were collected during times when the homes were unoccupied or activities were minimized using time-programmable sampling units. In addition, replicate samples were collected at different times of the day to quantify the possible diurnal effects on the emission profiles. Samples were collected from two different locations in the homes and one outdoor location to quantify spatial variation in emission profiles and correct for possible outdoor sources in the indoor measurements.

Distinguishing between the building contents and the occupant activities during the post-occupancy sampling periods required that the homes be maintained under controlled and consistent conditions and ideally be either unoccupied or the occupant activities be minimized. For homeowners that are typically home all day, the researchers requested that the homeowners schedule activities such that the home is unoccupied for a period of several hours prior to and including the 1-hour daytime sampling on the active sampling day. Note, this sometimes meant the daytime sample was scheduled at a time that was convenient for the homeowner and was not always consistent home to home. If occupants remained in the homes during testing, steps were taken to ensure that occupants minimized activity-based emissions during the active sampling periods. Specifically, the experimental plan describes requesting that homeowners 1) maintain their thermostat set point between $74-78^{\circ} \mathrm{F}$ in summer and $68-72^{\circ} \mathrm{F}$ in winter with no setbacks, 2) operate the air handler fan continuously, 3) refrain from opening windows and exterior doors, and 4) refrain from activities that are known to emit large quantities of VOCs into the home (e.g., cleaning, cooking without a range hood, etc.). Homeowners were also provided with a list of activities to avoid and verbally reminded about the discouraged activities prior to each sampling event. An example list is provided in the experimental plan as part of Appendix A.

During the pilot field study, the sampled homes exhibited significantly lower thermostat set points than initially expected. To minimize disturbance to the homeowners and maintain consistent temperatures between active and passive sample periods, homeowners were asked to maintain their thermostats between $68-72^{\circ} \mathrm{F}$ during that active sample periods and $65-75^{\circ} \mathrm{F}$ during the passive sample period. The specific thermostat setting observed in each house and the measured interior $\mathrm{T}$ and $\mathrm{RH}$ conditions are reported in Sections 4.0 and 5.1Error! Reference source not found., respectively. Although the homeowners were directed to refrain from large cooking and cleaning events, or other VOC-generating activities, as listed on the "list of discouraged activities" reference sheet as part of the pilot study, these instructions were not always followed precisely. For example, in one home the heating, ventilation, and air-conditioning (HVAC) system malfunctioned during the post-occupancy sampling event and the homeowners opened the windows and turned on fans to maintain comfort during the early morning (i.e., 4:00 AM) active sample. In another home, the homeowner opened windows briefly in the kitchen after cooking a fragrant meal. The sampling observations relevant to each home are described in Section 4.0.

\subsubsection{Natural Passive Sampling Period}

Immediately following the 24-hour active sampling period during the post-occupancy sampling events, the experimental plan prescribes collecting weeklong passive samples under natural conditions. 
These weeklong, integrated samples collected under "typical" occupancy conditions-in combination with the short-term, controlled samples - provide a measure of the contribution of occupants' activities to IAQ (including emission of personal care products, cleaning products, combustion, fragrances) and the effect that occupants' activities have on emissions from building materials and building contents during a "typical" week. ${ }^{1}$ To characterize the likely concentrations observed during routine activities, homeowners were instructed to operate their homes as they normally would. The sampling periods were scheduled at times when homeowners were not planning to, and agreed not to, conduct unusual activities or events that only occur on an infrequent basis (e.g., oven cleaning, carpet cleaning, large parties, vacations, etc.). In general, the passive sampling procedures were implemented as described in the experimental plan and the homeowners cooperated with instructions provided by the research team during these sampling periods, including reporting on home operation and activities during the passive sampling periods (as described in further detail in Section 3.0 and the experimental plan in Appendix A).

\subsubsection{Longitudinal Sampling Plan}

A longitudinal sampling plan was developed for each home to explore how the composition and relative concentration of VOCs changed after the home was occupied and as the home aged. The plan includes testing each home at least one time pre-occupancy and one time post-occupancy and then returning to re-test the home over a defined schedule post-occupancy. Post-occupancy samples are specified to occur at 2-4 weeks post-occupancy, 6-13 weeks post-occupancy, and 12 months postoccupancy, according to the experimental plan. The specific timing of each sampling event is important because the building-related VOC emission rates are expected to decay over time and it is important that homes are in the same time frame or stage in their "life cycle" in order to ensure comparable results. For example, the experimental plan intends the pre-occupancy sampling period to occur prior to the "final cleaning" that builders typically perform before the homeowners take possession but after the flush period specified in IaP homes. This ensures that the pre-occupancy sample provides a representative characterization of the emission profile of the building materials used in home construction and is not only influenced by the contaminants related to any cleaning products used during the final cleaning event. More importantly, if a sample in one home were to occur after the final cleaning event, it would be more difficult to compare the results from that sampled house to the other sampled homes where sampling occurred prior to the "final cleaning."

Additional sampling periods pre-occupancy or more than 12 months post-occupancy are also discussed briefly to further expand the data set. Additional pre-occupancy sampling may include additional controlled sampling as different building materials are introduced, controlled sampling pre- and post-flush, and/or a long-term passive sample to serve as a baseline/comparison between subsequent controlled and natural samples.

\footnotetext{
${ }^{1}$ The experimental plan specifies passive, long-term sampling only during the first two post-occupancy sampling events ( 1 month and 3 months post-occupancy although only the first post-occupancy cycle was completed).
} 


\subsubsection{Timing of Pilot Study}

In this pilot study, pre- and post-occupancy sampling periods were conducted in one conventional (C1) and two IaP homes (IaP1 and IaP2) ${ }^{1}$ between April 26 ${ }^{\text {th }}, 2014$ and August 22 $2^{\text {nd }}, 2014$ according to the schedule shown in Table 2.1. As shown in Table 2.1, the post-occupancy passive sampling period was not conducted in IaP2. This was a result of the late induction of IaP2 into the study and resources constraints associated with truncating the project to a 1-year pilot study, rather than the multi-year longitudinal effort originally envisioned in the experimental plan. Other minor deviations in the timing, specifically for the pre-occupancy sampling period, occurred in IaP2 as well because the homeowners had already moved some of their existing (i.e., old) furniture and clothing into a few of the rooms prior to taking full ownership and occupancy of the home. These items were present during the pre-occupancy sampling. In addition, there was not time in the construction schedule to accommodate the pre-occupancy sampling prior to the home's "final cleaning" and the closing date. As such, the IaP2 home had already undergone the "final cleaning" prior to pre-occupancy sampling. The cleaning personnel used by the builder reported using only typical residential cleaning products. ${ }^{2}$

It is also worth noting that the post-occupancy sampling period, approximately 1 month after the homeowner moved in, was intended to capture a time period after the initial move-in activity had subsided and "typical" life had resumed for the homeowners. This timing was intended to reduce inconvenience for the homeowners and to ensure that the post-occupancy sample would capture conditions representative of those the homeowners would be exposed to on a daily basis. However, in scheduling the post-occupancy sampling period, it became clear to the research team that the moving process for two out of three of the sampled homes was a process that was spread out over several weeks and up to 2 months. For example, new furnishings for IaP1 arrived over the course of the first month of occupancy, but the homeowners' existing, older furnishings and boxed clothing, etc., were not arriving until 2 months after the initial occupation date. These furnishings were arriving with a second occupant who was driving with their remaining belongings from Alaska. In IaP2, all of the homeowners' belongings had been moved into the home, but had not been completely unpacked at the time of postoccupancy sampling. Despite efforts to understand sampling conditions and communicate consistently and clearly with the homeowners, many times it often seemed difficult for even the homeowners to predict the moving schedule or what they predicted was inconsistent with what actually occurred. Such scheduling issues make exact implementation of the experimental plan, as designed, difficult. In addition, because the age of installed materials is also important in characterizing emission rates, the postoccupancy sampling period was scheduled approximately 1 month (2-4 weeks) post-occupancy in all homes.

Detailed sampling notes for each home and sampling period are provided in Section 4.0.

\footnotetext{
${ }^{1}$ Due to a delay in the construction of several planned IaP-certified homes, the two sampled IaP homes were not IaP-certified, but did comply with HBATC's BuiltGreen requirements and section 6.1, 6.2, 6.3, and 7.2 of EPA's IaP Construction Specifications. See section 3.1 for more information.

${ }^{2}$ Palm Olive ${ }^{\circledR}$ dish soap, Soft Scrub ${ }^{\circledR}$ for tubs, Bona ${ }^{\circledR}$ hardwood floor cleaner, Weiman ${ }^{\circledR}$ stainless steel cleaner and polish, and Melaleuca Tough and Tender ${ }^{\circledR}$ for vinyl and acrylic flooring. Goo Gone ${ }^{\circledR}$ is used in limited applications if sticky stuff is found anywhere and occasionally Goof Off ${ }^{\circledR}$ is applied if any paint is found on finished surfaces.
} 
Table 2.1. Dates of Pre-Occupancy Active Sampling Period, Post-Occupancy Active Sampling Period, and Post-Occupancy Passive Sampling Period in Each Sampled Home

\begin{tabular}{llll}
\hline Home & $\begin{array}{l}\text { Pre-Occupancy Active Sample } \\
\text { Period }\end{array}$ & $\begin{array}{l}\text { Post-Occupancy Active } \\
\text { Sample Period }\end{array}$ & $\begin{array}{l}\text { Post-Occupancy Passive } \\
\text { Sample Period }\end{array}$ \\
\hline C1 & April 26-27, 2014 & May 22-23, 2014 & May 23-30, 2014 \\
IaP1 & May 30-21, 2014 & July 15-16, 2014 & July 16-23, 2014 \\
IaP2 & August 2-3, 2014 & August 21-22, 2014 & $\begin{array}{l}\text { No post-occupancy passive } \\
\text { sampling occurred. }\end{array}$ \\
\hline
\end{tabular}

Subsequent, long-term post-occupancy sampling periods at approximately 3 months (6-13 weeks) and 1 year (12 months) post-occupancy were not pursued in the sampled homes due to the limited duration of the pilot field study. Therefore, the results presented in Section 5.0 of the report describe only the pre-occupancy and 1-month post-occupancy sampling periods.

\subsection{Target Chemicals}

There are hundreds of chemicals present in indoor air in residential homes that can be introduced by building materials, building contents (e.g., furniture, window coverings, toys, etc.), occupants and their activities (e.g., cleaning products, personal care products, emissions from cooking, candles, incenses, etc.), outdoor air, or a combination of these four sources. Table 2.2 provides a summary list of a subset of indoor chemicals along with a classification and/or source. A number of compounds can be found in a variety of products or materials making it difficult to characterize sources in fully furnished occupied homes.

Table 2.2. Summary List of Compounds that are Typically Found Indoors along with Possible Sources or Classifications

\begin{tabular}{|c|c|c|}
\hline Chemical & Classification or Source & Ref. \\
\hline Hexane & $\begin{array}{l}\text { Gasoline evaporative emissions; cleaning agent in printing, textile, } \\
\text { automotive and furniture industries; quick-drying glues for crafts and in } \\
\text { consumer products (shoes, leather) }\end{array}$ & 1 \\
\hline Methylene chloride & $\begin{array}{l}\text { Paint stripper; may be found in some aerosol and pesticide products; found } \\
\text { in some holiday decorations }\end{array}$ & 1 \\
\hline Carbon tetrachloride & Dry-cleaning solvent; previously used as a refrigerant & 1 \\
\hline Chloroform & Water contaminant released during water use & 1 \\
\hline Benzene & Cigarette smoke; gasoline evaporative emissions & 1 \\
\hline Butanal & $\begin{array}{l}\text { Used in production of resins, rubber, solvents, plasticizers and high } \\
\text { molecular weight polymers; naturally occurring in some foods and plants }\end{array}$ & 2 \\
\hline $\begin{array}{l}\text { Heptane, Octane, } \\
\text { Butylbenzene }\end{array}$ & Gasoline evaporative emissions & 1,8 \\
\hline Toluene & $\begin{array}{l}\text { Consumer products including paint, paint thinners, lacquers, adhesives and } \\
\text { rubber; cigarette smoke; gasoline evaporative emissions }\end{array}$ & 1 \\
\hline $\mathrm{D} 3, \mathrm{D} 4, \mathrm{D} 5^{(\mathrm{a})}$ & $\begin{array}{l}\text { Manufacturer of silicones; personal care products; carriers, lubricants and } \\
\text { solvents in commercial applications }\end{array}$ & 3 \\
\hline Tetrachloroethylene & Dry-cleaning solvent; some consumer products & 1 \\
\hline
\end{tabular}


Table 2.1. (contd)

\begin{tabular}{|c|c|c|}
\hline Chemical & Classification or Source & Ref. \\
\hline $\begin{array}{l}\text { Hexanal, Heptanal, Octanal, } \\
\text { Nonanal, Decanal, } \\
\text { Benzaldehyde }\end{array}$ & $\begin{array}{l}\text { Flavors and perfumes; product of secondary reactions between ozone and } \\
\text { unsaturated compounds }\end{array}$ & 1 \\
\hline Ethylbenzene & Inks and paints; gasoline evaporative emissions & 1 \\
\hline $\mathrm{m} / \mathrm{p}$-Xylene, o-Xylene & $\begin{array}{l}\text { Consumer products including cleaning agents, paint thinners and varnishes; } \\
\text { cigarette smoke; gasoline evaporative emissions }\end{array}$ & 1 \\
\hline a-Pinene & Fragrance in cleaning products, air fresheners, and personal care products & 1 \\
\hline $\begin{array}{l}\text { Decane, Undecane, } \\
\text { Dodecane, Tetradecane, } \\
\text { Hexadecane }\end{array}$ & $\begin{array}{l}\text { Kerosene, diesel and home heating oil evaporative emissions; solvent; } \\
\text { component of paints and varnishes; used in the rubber and paper industry }\end{array}$ & $\begin{array}{c}4,5 \\
7\end{array}$ \\
\hline 2-Butoxyethanol & $\begin{array}{l}\text { Paint thinners and strippers, varnish removers, and herbicide; liquid soaps, } \\
\text { cosmetics, commercial and household cleaners, and dry-cleaning } \\
\text { compounds; some ink and spot removers }\end{array}$ & 1 \\
\hline 3-Carene, g-Terpinene & Cologne, perfume, soap, shaving cream, deodorant, air freshener & 11 \\
\hline $\begin{array}{l}\text { 1,2,4-Trimethylbenzene, } \\
\text { 1,2,3-Trimethylbenzene }\end{array}$ & Fuel evaporative emissions; paints; cleaners & 6 \\
\hline d-Limonene & $\begin{array}{l}\text { Fragrance in air fresheners, insecticides, and personal care products (hand } \\
\text { sanitizers); solvent for cleaning products }\end{array}$ & 1 \\
\hline 2-Ethyl-1-hexanol & $\begin{array}{l}\text { Cleaning products; insecticides; paint related products; rugs and bathmats; } \\
\text { sheet vinyl flooring }\end{array}$ & 9 \\
\hline a-Terpineol & Insecticides; solvents; plasticizers; perfumes; synthetic pine oil & 1 \\
\hline TMPD-MIB $^{(b)}$ & additive to latex paint & 10 \\
\hline $\begin{array}{l}\text { Dimethyl phthalate, Diethyl } \\
\text { phthalate, Dibutyl phthalate }\end{array}$ & Plasticizer in consumer products & 1,12 \\
\hline TMPD-DIB $^{(\mathrm{c})}$ & Plasticizer in resilient vinyl flooring & 1 \\
\hline $\begin{array}{l}\text { (a) D3 - Hexamethylcyclotri } \\
\text { (b) 2,2,4-Trimethyl-1,3-pent } \\
\text { (c) 2,2,4- Trimethyl-1,3-pen } \\
\text { 1. Bennett, Deborah, Michae } \\
\text { Doug Sullivan (University of } \\
\text { and Medium Size Commercic } \\
\text { California. } \\
\text { 2. EPA Fact Sheet } \\
\text { 3. http://oehha.ca.gov/multin } \\
\text { 4. http://scorecard.goodguid } \\
\text { 5. http://ntp.niehs.nih.gov/nt } \\
\text { 6. http://www.epa.gov/chem } \\
\text { 7. http://www.tera.org/peer/ } \\
\text { \%20revised.pdf } \\
\text { 8. http://pubs.usgs.gov/circ/c } \\
\text { 9. http://scorecard.goodguid } \\
\text { 10. Chemical also identified } \\
\text { http://www.tceq.state.tx.us/as } \\
\text { 11. http://www.herc.org/new } \\
\text { 12. http://www.epa.gov/ttnat }\end{array}$ & 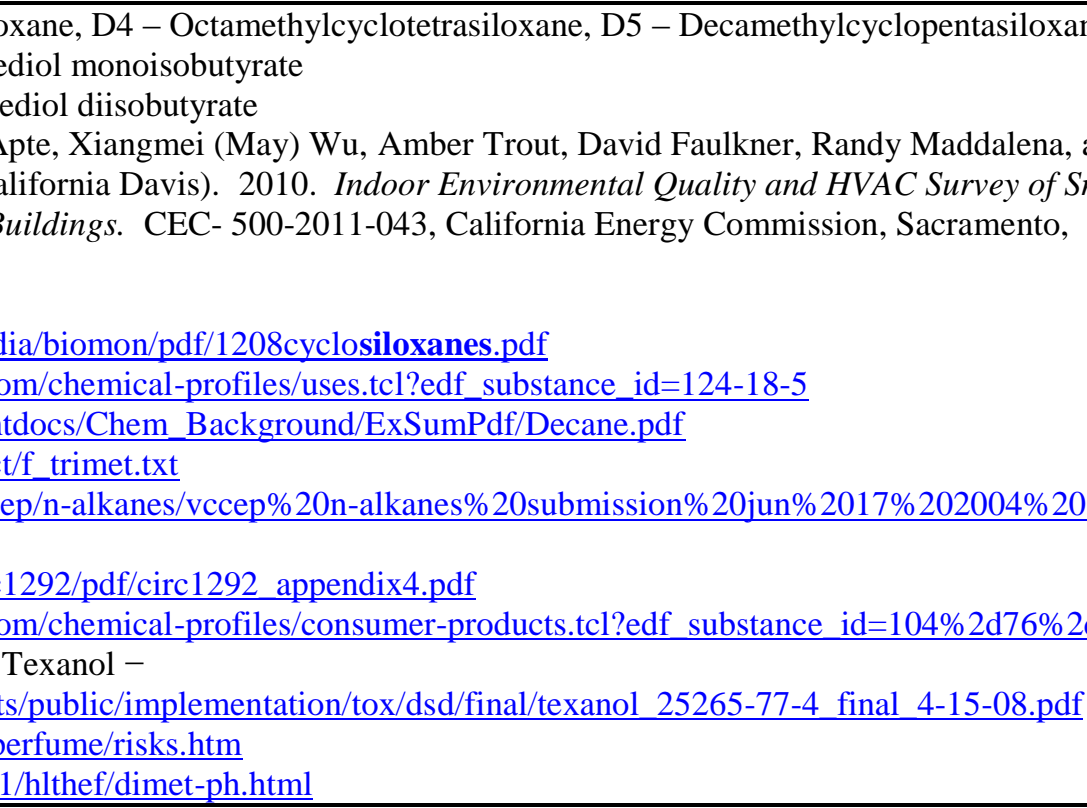 & $\begin{array}{l}\mathrm{e} \\
\text { nd } \\
\text { nall }\end{array}$ \\
\hline
\end{tabular}

Due to the small sample size and limited data collection time frame possible in this pilot study, specific identification of compounds related to building materials, building contents, and occupant 
activities was not possible. Instead, general increases in select target speciated VOCs and aldehydes were noted for pre-occupancy, post-occupancy controlled, and post-occupancy passive sampling under typical activity conditions to identify the relative contribution of each of these sources to the overall VOC

exposure of occupants. In addition, the lack of the longitudinal sampling component of the study limited the data for evaluating the long-term changes in pollutant profiles in the homes. 


\subsection{Data Collection and Analysis}

The sampling procedure, as outlined above and described in detail in the full experimental plan (included as Appendix A) consists of several data collection phases: a baseline audit, a pre-occupancy sampling event, and several sampling events that are to occur at specific time frames post-occupancy. The specific measurements outlined in the experimental plan for each sampling event are outlined in Table 3.1. Items that are italicized are identified in the experimental plan, but are not primary data requirements and were not collected during this this pilot study.

Table 3.1. Summary of Measurements Occurring During Each Sampling Period

\begin{tabular}{|c|c|}
\hline Sampling Period & Quantitative Measurements \\
\hline $\begin{array}{l}\text { Baseline Audit } \\
\text { (if necessary) }\end{array}$ & $\begin{array}{l}\text { - Envelope air tightness } \\
\text { - Duct tightness on supply and return sides } \\
\text { - Airflows of all ventilation fans (as-installed) } \\
\text { - Airflow of central air handler unit, if applicable } \\
\text { - House-to-garage air leakage }\end{array}$ \\
\hline Pre-Occupancy & $\begin{array}{l}\text { - VOCs and aldehydes using } 1 \text {-hour integrated active samplers } \\
\text { - } 2 \text { indoor locations } \\
\text { - } 1 \text { outdoor location } \\
\text { - Two different times } \\
\text { - Air exchange rate using carbon dioxide }\left(\mathrm{CO}_{2}\right) \text { decay analysis }{ }^{(\mathrm{c})} \text { and passive emitters } \\
\text { - T \& } \mathrm{RH} \text { in several locations during entire } 24 \text {-hour sampling period } \\
\text { - Characterization of types of materials and finishes } \\
\text { - Door and window opening } \\
\text { - } \mathrm{CO}_{2} \text { concentration during sampling }\end{array}$ \\
\hline $\begin{array}{l}2-4 \text { Weeks Post- } \\
\text { Occupancy, } \\
6-13 \text { Weeks Post- } \\
\text { Occupancy, and } \\
12 \text { Months Post- } \\
\text { Occupancy }\end{array}$ & $\begin{array}{l}\text { - VOCs and aldehydes using 1-hour integrated active samplers }{ }^{(\mathrm{b})} \\
-\quad 2 \text { indoor locations } \\
-\quad 1 \text { outdoor location } \\
-\quad 2 \text { different times } \\
\text { - VOCs and aldehydes (indoors + outdoors) using passive sampling (multiple locations) } \\
\text { under natural conditions }{ }^{(\mathrm{b})} \\
\text { - Air exchange rate using passive emitters and samplers during both controlled and } \\
\text { natural (multiple PFT tracers) } \\
\text { - T \& RH in several locations throughout the house } \\
\text { - Characterization of types of major furnishings and wall/window coverings } \\
\text { - Homeowner survey } \\
\text { - Bath and kitchen exhaust fan operation via survey or energy measurement } \\
\text { - Operation of other exhaust systems within the pressure boundary, e.g., dryers, water } \\
\text { - } \text { Opeater either via survey or energy measurement } \\
\text { - Deasurement } \\
\text { - } \text { Coor and window opening in least three locations }+ \text { outdoors: HVAC return, kitchen, master bedroom }\end{array}$ \\
\hline \multicolumn{2}{|c|}{$\begin{array}{l}\text { (a) Air flow of central air handler is applicable if air handler is integrated as part of the ventilation system (i.e., } \\
\text { central-fan integrated supply ventilation systems). } \\
\text { (b) See Section } 3.1 .1 \text { for more information. } \\
\text { (c) In the experimental plan, additional measurements of } \mathrm{CO}_{2} \text { in addition to T\&RH were included to monitor } \\
\text { environmental conditions and occupancy characteristics. These were not pursued as part of this limited field } \\
\text { campaign due to resource constraints and the fact that they were not necessary to answer the primary research } \\
\text { questions posed in Section 2.0. }\end{array}$} \\
\hline
\end{tabular}


During the initial baseline audit, data are taken to characterize the home and system performance, characterize materials used in home construction, and document the construction timeline. An inventory of materials used to construct each home and the building characteristics are used to help understand differences in observed indoor contaminant concentrations. In this pilot study, baseline audit and construction information was obtained from the builder for all sampled homes. However, in-field ventilation flow rates were verified with an exhaust fan blow box ${ }^{1}$ to verify operation as installed.

Under the experimental plan, after construction has been completed and immediately prior to the new homeowners moving into the home, pre-occupancy samples are collected. The pre-occupancy samples consist of a 24-hour active sampling event during which time two 1-hour active samples are collected, typically one in the early morning hours and one in the middle of the day. The periodically sampled parameters during the pre-occupancy period include speciated VOCs and aldehydes and PFT tracer gases (for determining the air exchange rate). The experimental plan also describes measuring real-time environmental conditions (i.e., $\mathrm{T}$ and $\mathrm{RH}$ ) at multiple locations indoors and one location outdoors, carbon dioxide $\left(\mathrm{CO}_{2}\right)$ concentrations indoors, and window and door openings over this time period as well, but only $\mathrm{T}$ and RH measurements were included in the pilot study. During the 24-hour active sampling period, the home is to be kept in an "undisturbed" condition as much as possible. During pre-occupancy, this includes limiting any remaining construction activities in and around the house as much as possible.

In this pilot study, the pre-occupancy samplers were scheduled prior to the move-in and "first cleaning" in all but one of the homes, as discussed previously. During all pre-occupancy sampling periods the homes were undisturbed, as intended. This was not verified with quantitative measurement of window and door openings, but was confirmed with the homeowner and the builder in all cases. Sampling during the pre-occupancy period includes active VOC and aldehyde samplers to characterize IAQ contaminants, active PFT samplers and PFT emitters necessary for determining dilution rate, and short-term passive VOC and PFT samples to measure background for the active samples. Real-time T and RH measurements were collected throughout the sampling period.

In the experimental plan, each of the post-occupancy sampling periods consists of both short-term active and long-term passive IAQ sampling events. The post-occupancy short-term, active sample is meant to replicate the pre-occupancy sampling event. Similar to the pre-occupancy sampling event, this active sample is intended to capture the "undisturbed" emission characteristics of the home and, as such, occupant activities are restricted during this time. As discussed previously in Section 2.1 the homeowners are asked to keep their thermostats between $74-78^{\circ} \mathrm{F}$ in summer (actual setbacks were $68-72^{\circ} \mathrm{F}$ ), keep windows and exterior doors closed, and refrain from activities that emit a significant quantity of VOCs and would affect IAQ measurements. Such activities include extensive cooking at high temperature, major cleaning using cleaning products, use of candles or air fresheners, or extensive use of solvents (e.g., painting with oil paints, painting your nails, scale models, etc.). ${ }^{2}$ In the experimental plan, the postoccupancy sampling event also includes the additional weeklong passive sampling event

\footnotetext{
${ }^{1}$ http://www.energyconservatory.com/sites/default/files/documents/flow_box_manual_dg-700.pdf

${ }^{2}$ Homeowners were provided with a list of discouraged activities during active sampling periods. The list is included in the experimental plan in Appendix A.
} 
that begins immediately following the 24-hour active sampling period. ${ }^{1}$ The primary measurements targeted during the weeklong passive sampling period include integrated samples for aldehydes, speciated VOCs, and air exchange rates via PFT tracer gases, as well as time-resolved measurements of $\mathrm{T}$ and $\mathrm{RH}$ at up to seven locations indoors and one location outdoors. In addition to the IAQ monitoring, field measurements collected during the weeklong passive sampling event, as described in the experimental plan, consist of characterization of large furnishings and associated materials, as well as operation of intermittent ventilation equipment and specific appliances, and occupancy characteristics.

The post-occupancy sampling implemented in this pilot study was conducted 2-4 weeks after homeowners had moved into their homes in all three sampled homes using the same active VOC, aldehyde, and PFT sampler arrangements (with PFT emitters) as were deployed in the pre-occupancy sampling period. The sampling and emitter locations were chosen to be similar to those used in the preoccupancy period, so that the samplers would be subject to similar air flow patterns and conditions, in case inconsistent mixing patterns were present in the house. This allows for better comparison of the results derived from the pre-occupancy and post-occupancy active samplers. In C1 and IaP1, postoccupancy passive samplers were deployed immediately following the post-occupancy sampling period. As previously noted, post-occupancy passive sampling was not implemented in IaP2 due to the late entrance of the home into the study and the limited duration of this pilot field campaign. In all homes, window and door opening and closure, operation of ventilation fans, and use of other depressurizing appliances were tracked via the homeowner survey, included in the experimental plan in Appendix A. Ambient $\mathrm{CO}_{2}$ measurements were not pursued in any of the homes, as they are not a primary measurement required for quantification of differences in indoor air contaminants between homes built with conventional or low-emitting materials.

The specific equipment and methods used to collect house characteristic data and IAQ measurements are described in Sections 3.1 and 3.2, respectively.

\subsection{Home and Occupancy Characteristics}

Table 3.2 lists the various measurement parameters, measurement equipment, and sampling rates for all but the IAQ measurements, which are discussed in Section 3.1.1. Details on data collection and analysis regarding house characteristics are discussed further in the experimental plan, included as Appendix A.

\footnotetext{
${ }^{1}$ While each post-occupancy period was intended to include a long-term passive sample to capture the IAQ impacts of homeowner activities, the experimental plan provided significant flexibility to include either the 24-hour active sample, the week-long passive sample, or both in any of the scheduled post-occupancy sampling periods for any given house, based on the needs of the research program.
} 
Table 3.2. Measurement Parameters, Measurement Equipment, and Sampling Rates

\begin{tabular}{|c|c|c|}
\hline Parameters & $\begin{array}{c}\text { Measurement or } \\
\text { Characterization Approach }\end{array}$ & Sampling Interval \\
\hline House conditioned floor area and layout & $\begin{array}{l}\text { House plans obtained from } \\
\text { builder }\end{array}$ & Initial baseline $^{(\mathrm{a})}$ \\
\hline Infiltration (cfm50) & $\begin{array}{l}\text { Blower Door or obtained from } \\
\text { builder }\end{array}$ & Initial baseline ${ }^{(a)}$ \\
\hline Duct leakage (cfm25) & $\begin{array}{l}\text { Duct Blaster or obtained from } \\
\text { builder }\end{array}$ & Initial baseline $^{(a)}$ \\
\hline Exhaust fan flow (cfm) & Powered flow hood & Initial ba \\
\hline Space T \& RH (4 interior locations) & $\mathrm{HOBO} \mathrm{T} / \mathrm{R}$ & $15 \mathrm{~min}$ \\
\hline Bath fan power $(\mathrm{Wh}) /$ runtime $(\mathrm{min} / \mathrm{hr})$ & Homeowner survey $^{(b)}$ & Continuous, per e \\
\hline $\begin{array}{l}\text { Kitchen exhaust fan power (Wh)/runtime } \\
(\mathrm{min} / \mathrm{hr})\end{array}$ & Homeowner survey $^{(b)}$ & Continuous, per event \\
\hline $\begin{array}{l}\text { Operation of kitchen, dryer, and other } \\
\text { exhausting appliances (Wh)/runtime (min/hr) }\end{array}$ & Homeowner s & Continuous, pe \\
\hline Door and window openings & Homeowner s & Continuo \\
\hline Building materials used in home construction & Materials inventory $^{(\mathrm{c})}$ & Initial baseline $^{(a)}$ \\
\hline $\begin{array}{l}\text { Major furniture and home furnishings } \\
\text { introduced into home after occupancy }\end{array}$ & $\begin{array}{l}\text { Homeowner survey and visual } \\
\text { inspection }\end{array}$ & $\begin{array}{l}\text { At each post-occupancy } \\
\text { sampling event }\end{array}$ \\
\hline \multicolumn{3}{|c|}{$\begin{array}{l}\text { (a) Initial baseline measurements of infiltration, duct leakage, and exhaust fan flow will be taken at a time } \\
\text { close to, but not coincident with the pre-occupancy IAQ measurements. If existing data are available based on } \\
\text { a home rating, they will be used. } \\
\text { (b) In the experimental plan, more quantitative data collection methods using wired current transducer or state } \\
\text { sensors to specifically characterize the frequency and duration of use were also discussed. However, such } \\
\text { methods were not employed in this limited field campaign because the significant incremental cost associated } \\
\text { with acquiring and installing such sensors was determined to not be justified given the abbreviated data } \\
\text { collection possible in the allotted time frame. } \\
\text { (c) The builder was provided with a materials inventory tracking spreadsheet, included as part of the } \\
\text { experimental plan in Appendix A. However, varied methods were used to collected relevant information } \\
\text { about the specific materials used in home construction, their applicable certifications, and/or emissions } \\
\text { profiles. }\end{array}$} \\
\hline
\end{tabular}

\subsubsection{Building Materials and Furnishings Inventory}

For each home sampled as part of the experimental procedure, detailed information regarding the materials used in construction and major furnishings introduced into the house were collected to inform the analysis and interpretation of measured VOC and aldehyde concentrations. In addition, information regarding the use of certified low-emitting materials was used to verify that the homes in the IaP cohort used materials complying with the IaP section 6 specifications while the conventional homes were built with materials that are not certified as low-emitting. Ideally, homes in the IaP cohort would have been certified to EPA's IaP standard (independently or via certification with DOE's Zero Energy Ready Home). However, unfortunately, homes built to these specifications were not completed within the sampling time frame of the project. As such, the research team recruited homes that were built to the local HBATC's BuiltGreen specifications, which are similar to the IaP low-emitting materials specifications, as shown in Table 1.1. However, because of the potential discrepancy between the two programs, information about the materials used to construct each home was gathered to verify that relevant materials meet the specific certifications and requirements of the IaP program and, if not, note what materials were not compliant, why not, and any expected impact on IAQ contaminant concentrations measured in the home. Information regarding the certification of low-emitting materials and specific emission rates of relevant materials was also gathered for the conventional house to quantify the extent of 
certified low-emitting materials used in its construction. Because it is becoming more common to find low-emitting versions of some materials (e.g., paint), it is possible that some low-emitting materials were used in the construction of the conventional home based purely on price and availability.

To verify the use of low-emitting materials in both the IaP and conventional homes, information regarding the materials used in home construction was initially obtained from the participating builders. Builders were asked to provide as much information as possible about the specific materials used to construct the house using a predefined materials inventory template (included in the experimental plan in Appendix A), including information on the manufacturer and brand, how much of the materials was used in the home and where, the age of the material, from whom the material was purchased and when, any relevant certifications, and the Material Safety \& Data Sheet (MSDS) for the material, if available. Often, it was more convenient for the builder to provide the material supplier and date of purchase and other relevant data were gathered by the researchers. For example, if the information provided by the builder did not indicate certification under the relevant standard (e.g., PS1 or PS2 for structural plywood and OSB, Greenguard or Green Seal for paints and finishes, or Green Label Plus for carpets and carpet padding), an online search was made and/or the manufacturer was contacted to confirm or deny certification with the relevant standards.

Where certified materials were not used, information regarding the chemicals used in manufacturing specific materials and their relevant emission rates was collected based on the MSDSs for these products. The listed emission rates contained in the product literature or MSDS were compared to the required standards to determine if the given product was "equivalent to" a certified low-emitting material for the purposes of the study. For example, the cabinets used in the IaP1 home were not reported by the builder as being constructed using component materials certified to appropriate standards ${ }^{1}$ or a registered brand certified under KCMA's Environmental Stewardship Certification Program ${ }^{2}$ (ESP 05-12). Therefore, information on the components used to construct the cabinets was obtained from the builder/cabinet maker, Northwood Cabinets. In this case low-formaldehyde-emitting flakeboard and particleboard were used and the material was deemed compliant with the IaP section 6.1 requirements.

The materials inventory data were divided and tracked according to the material categorization used in the IaP section 6 subsections (i.e., composite woods, interior paints and finishes, and carpets and carpet adhesives). If all the materials used in the construction of the home in each of these categories met the relevant certification requirements or were otherwise deemed compliant, the home was determined to be equivalent to an IaP-certified home for the purpose of this study. It should be noted that the builder who constructed both IaP homes sampled in the study allows the homeowners to select some finishes in the home, including the flooring. In the case of IaP1, an engineered hardwood was selected that was not certified to any low-emitting material standards and very limited information was available about the product. Additional materials, such as grout, cleaners, and varnishes, were also cataloged. The addition of these materials allows for a complete description of the IAQ of each home in the study.

\footnotetext{
${ }^{1}$ Specifically, structural plywood and oriented strand board (OSB) that is complaint with PS1 or PS2 AND "Exposure 1" or "Exterior" on the American Plywood Association (APA) trademark; plywood that is compliant with ANSI/HPVA HP-1-2009 and U.S. Department of Housing and Urban Development (HUD) Title 24, Part 3280, OR certified compliant with CA Title 17; and particleboard and medium-density fibreboard products that are certified to ANSI A208.1 and A208.2, respectively, and U.S. HUD Title 24, Part 3280, OR EPPS CPA 3-08 by the CPA Grademark certification program, OR CA Title 17 (only option in California).

${ }^{2}$ http://www.kcma.org/Professionals/Environmental_Stewardship_Program
} 
After the home was occupied, a survey was also conducted of major furnishings and home products that the homeowner introduced into the home that were expected to affect the IAQ measurements. These included new furnishings, drapes, air fresheners and cleaning products, wall hangings, area rugs, etc. Any furnishings older than 1-2 years were also noted, but are expected to affect the IAQ in the home much less significantly than new materials because the initial off-gassing has, for the most part, already occurred. The aggregated materials list from the builder and the homeowner was used to evaluate analytical results of the active and/or passive sampling against materials known to have been used in a particular home. The IaP-relevant materials used in the construction of each home are tabulated in Section 4.0. A general description of the major furnishings is also provided.

\subsubsection{Flushing}

Under section 7.2, "Ventilation after Material Installation," of EPA's IaP program, each home is required to be ventilated with outside air "at the highest rate practical, meeting ventilation requirements for outdoor air flow and humidity control (see Specifications 4.5 and 4.8 of the IaP Construction Specifications ${ }^{1}$ ) during and shortly after installing products that are known sources of contaminants (e.g., cabinets, carpet padding and painting), and during the period between finishing and occupancy." The IaP requirements also accommodate the variable moving schedules of homeowners and allow builders to "advise the buyer to operate the ventilation system at the highest rate it can provide during the first few months of occupancy" if whole-house ventilation cannot be scheduled prior to occupancy, instead of meeting the above requirements. In the $\mathrm{C} 1$ home, no flushing or alternate ventilation was performed preoccupancy. In the IaP1 and IaP2 homes, the ventilation system was reported by the builder to be operated at the highest rate available 24 hours per day beginning as soon as the ventilation system was operational and extending until the home was occupied. Pre-occupancy sampling typically occurred at the tail end or after this time. However, the ventilation fans were set to operate normally (on their set schedule) during pre-occupancy sampling. The builder was not able to provide verification that the required period of increased ventilation actually happened, only confirm that the HVAC contractor was instructed to do so.

\subsection{Indoor Air Quality Measurements}

As discussed previously, the sampling procedure for each home presented in the experimental plan includes 1) highly controlled short-term samples conducted pre-occupancy and post-occupancy, as well as 2) long-term passive samples conducted under "natural conditions" during occupied periods to characterize the impact of normal occupant activities on sampled concentrations. ${ }^{2}$ According to the experimental plan, active samples are collected using calibrated sample pumps programmed to collect 60minute samples at a programmed time. Passive samples are sampled passively (no pump), providing an integrated sample that captures the time-integrated concentration over the full duration of sampling. In both cases, the samplers are calibrated, commercially available sampling tubes and cartridges. The IAQ sampling equipment is described in more detail in Sections 3.2.2 and 3.2.3.

\footnotetext{
${ }^{1}$ http://www.epa.gov/indoorairplus/pdfs/construction_specifications.pdf

2 Note, occupants were still asked to refrain from "atypical" activities during the sampling week, such as oven cleaning, major house cleaning events, and other activities that do not occur on a routine basis.
} 
Measurements of fresh-air dilution rate in the homes were made in conjunction with each sampling event using a PFT tracer gas mass balance approach. This approach accounts for dilution of indoor contaminants from both natural infiltration through the building envelope and any mechanical, or intentional, ventilation. Measurement of dilution rate is an important parameter for conversion of measured concentrations of VOCs and aldehydes in the air to whole-house emission rates, which can be compared across different homes. In addition, these dilution rates can be important for analyzing and interpreting the ventilation-normalized aging for building (and contents) related emissions. The tracer gas measurements are described further in Section 3.2.1.

In this pilot study, the $\mathrm{CO}_{2}$ decay method of determining dilution rate was only used in $\mathrm{C} 1$ and not in subsequent homes due to timing and resource constraints. All other sampling equipment was in accordance with the experimental plan. However, in some cases, the active sample volumes were more or less than the intended 60 minutes. This resulted from pump programming or low-battery errors. The equipment used to collect IAQ samples is listed in Table 3.3.

Table 3.3. IAQ Sampling Equipment

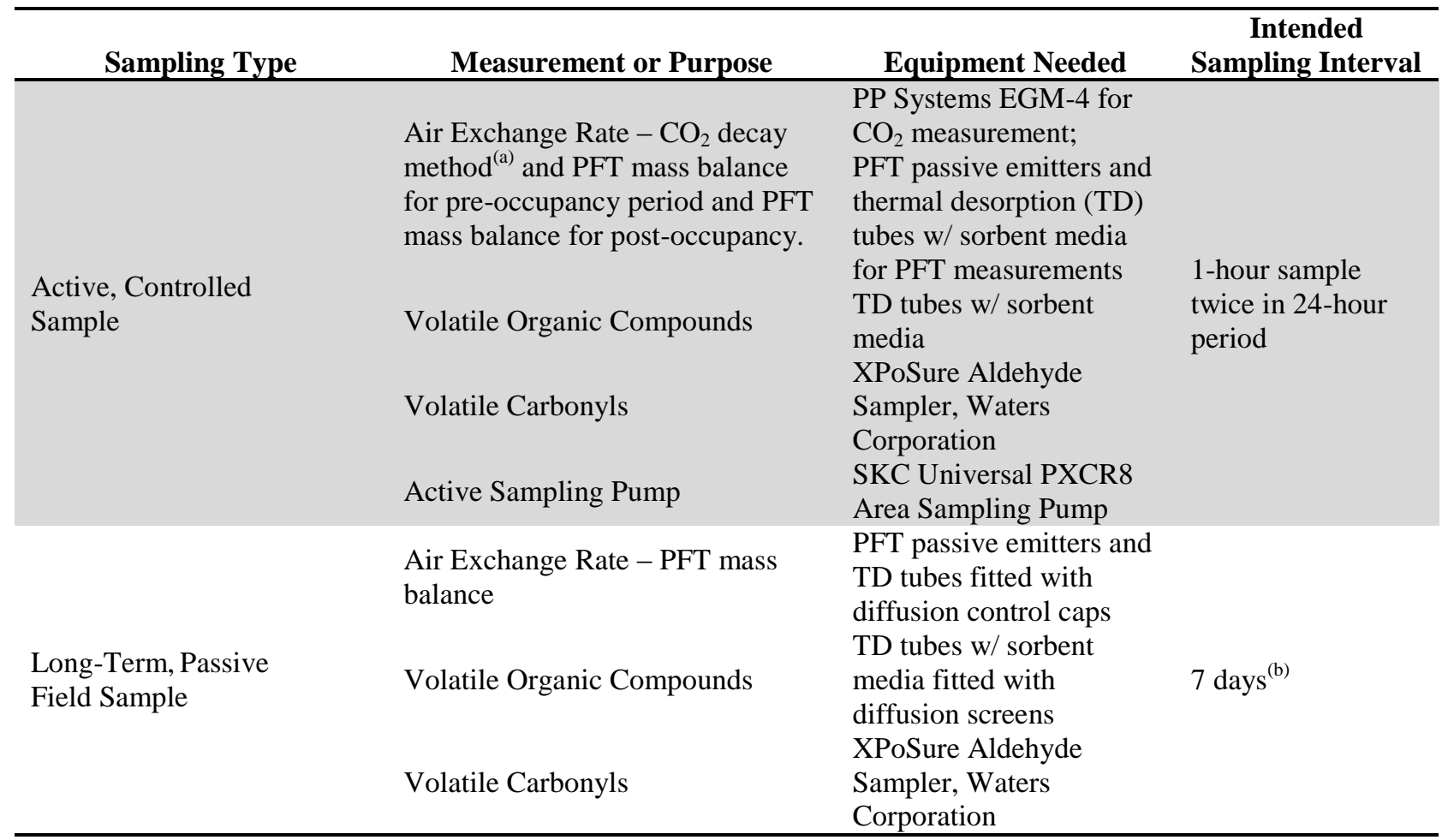

(a) The $\mathrm{CO}_{2}$ decay method may not be conducted in all pre-occupancy samples due to time and/or resource constraints.

(b) Note, the time frame of passive sampling may vary from the estimated 7-day period based on coordination of sampler deployment and retrieval and subject to homeowner convenience.

\subsubsection{Air Exchange Rate}

The air exchange rate is primarily determined using PFTs emitted into the space at a known and constant rate and PFT samplers to measure the observed concentration (the PFT samplers are described in Section 3.2.3). Assuming a well-mixed zone, the air exchange, or dilution, rate can be determined based 
on a mass balance. The PFT emitters consist of a $1.5-\mathrm{mL}$ glass vial filled with one of three different PFTs, placed approximately every 200 to $300 \mathrm{ft}^{2}$ throughout the home. During the pilot study, the emitters were placed 2-5 ft off the floor in areas that are not directly affected by heating or cooling sources or exposed to direct sunlight. The three PFTs used in this study are listed in in Table 3.4 along with their chemical formula and chemical abstract number.

Table 3.4. PFT Gases Used in Emitters to Determine Air Exchange Rate ${ }^{1}$

\begin{tabular}{llll}
\hline Compound & Name & Formula & CAS \# \\
\hline Perfluoro-1,2-dimethylcyclobutane $^{(a)}$ & PDCB & C6F12 & 2994-71-0 \\
Perfluoromethylcyclohexane $^{(\mathrm{b})}$ & PMCH & C7F14 & $355-02-2$ \\
Perfluoro-1,3-dimethylcyclohexane $^{(\mathrm{c})}$ & m-PDMCH & C8F16 & $335-27-3$ \\
\hline
\end{tabular}

(a) MSDS available at:

http://www.chemicalbook.com/ProductChemicalPropertiesCB8403290_EN.htm

(b) MSDS available at:

http://www.chemicalbook.com/ProductChemicalPropertiesCB9301481_EN.htm

(c) MSDS available at:

http://www.chemicalbook.com/ProductChemicalPropertiesCB0490412 EN.htm

The PFT emitters (vials) were deployed in "cages" containing three emitters each, with approximately one emitter cage in each major room and up to 24 emitters per home ( 8 of each type). The emitters were placed upside down to maintain contact between the liquid PFT and a silicon liner in the vial cap. Diffusion of the PFT through the silicon liner provides constant emission rates for extended periods of time. An example of an emitter "cage" is shown in Figure 3.1. For homes with one floor and one main zone, one of each PFT was placed in each emitter cage. For homes with two or more floors and/or zones, the PFT emitters were deployed in the emitter cages such that one PFT was equally distributed through the house and the other two PFTs were isolated to each zone (i.e., cages were loaded as $(A, B, B)$ for zone one and $(\mathrm{A}, \mathrm{C}, \mathrm{C})$ for zone two. Deploying the emitters in the zoned configuration provides data for estimation of overall air exchange rate along with the determination of any directional air flow patterns, large differences in air exchange rates, or inter-zonal mixing.

\footnotetext{
${ }^{1}$ Note, all of these PFTs have been reviewed by toxicologists at PNNL and SafeBridge, for DOE, and determined to be non-toxic in the concentration of $<1 \mathrm{ppm}$ (SafeBridge, 2013a,b). Perfluoro-1,2-dimethylcyclobutane (PDCB), perfluoromethylcyclohexane (PMCH), and perfluoro-1,3-dimethylcyclohexane (m-PDMCH or m-PDCH) were analyzed together as cohort of similar perfluorinated tracers based on their chemical structure (Safebridge 2013a). Perfluoro-2,4-dimethyl-3-ethylpentane (PDEMP) was analyzed with perfluoro-methylethylpetane as a group of aliphatic perfluorinated tracers and was found to have similar toxicological effects and higher acceptable air concentration limit for 1-week exposures of 20 ppm (Safebridge 2013b).
} 


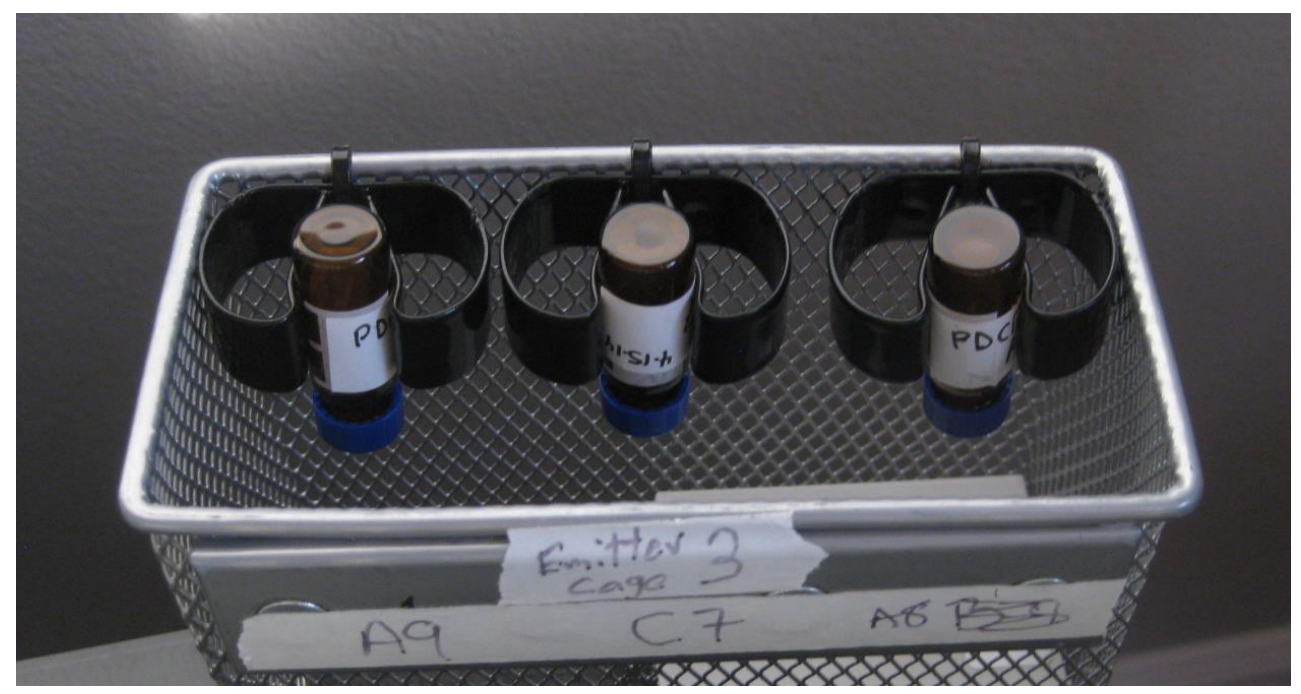

Figure 3.1. Three Emitter Vials Positioned Upside Down in an Emitter Cage for Deployment

The PFT emitters were constructed and initially calibrated at LBNL. The emission rate of the PFT emitters was preliminarily determined in the lab as approximately $0.1 \mathrm{mg} / \mathrm{hr}$ and was confirmed in the field by weighing the emitters before and after each IAQ sampling event, and periodically in between sampling periods.

\subsubsection{Volatile Carbonyls}

The target compounds in the volatile carbonyl analysis were formaldehyde, acetaldehyde, and acetone. Additional carbonyls are collected and can be quantified with along with the VOCs. Volatile carbonyl samples were collected on commercially available silica gel cartridges coated with 2,4dinitrophenyl-hydrazine (XPoSure Aldehyde Sampler, Waters Corporation). Ozone scrubbers were used routinely during active sampling; one outdoor sample in $\mathrm{C} 1$ pre-occupancy was not outfitted with an ozone scrubber due to operator error. The same XPoSure cartridges were also used for passive sampling, but without ozone scrubbers. Formaldehyde and acetaldehyde sampling rates for using of these cartridges in residential passive sampling applications are reported by Mullen et al. (2013).

\subsubsection{Speciated Volatile Organic Compounds and PFT Samplers}

Both passive and active sampling for VOCs were conducted using commercially available thermal desorption (TD) tubes. The VOC TD tubes were made of glass $(0.6 \mathrm{~cm} \mathrm{OD} \times 17.5 \mathrm{~cm} \mathrm{~L})$ containing a sorbent bed consisting of two parts (v/v) Tenax and one part Carboseive (Supelco). The passive sampling rate for the commercially packed tubes was determined experimentally for a wide range of VOCs at LBNL (Maddalena et al. 2013). The passive and active sampling for PFTs was conducted using custompacked stainless steel TD tubes containing a graphitized carbon material similar to small bits of charcoal that strongly adsorb chemicals from air. The steel TD tubes were fitted with a reducing fitting (Swage Straight Reducer Fitting-400-R-2) on the inlet side to control diffusive sample rate. The sampling rate was calibrated with co-located active and passive sampling in a simulated room environment at LBNL.

The active sampling events were conducted with programmed sampling pumps. Since the sampling tubes were loaded on the pumps and remained uncapped for periods of 18 hours or more, it was expected 
that the TD tubes would collect sample passively in addition to the programmed 1-hour active sampling period. To determine the background level of contaminant in the active sampling tubes related to diffusive uptake during the uncapped period, additional uncapped tubes were deployed and co-located with each active sampling location. The amount of individual VOCs or PFTs on the tubes was confirmed to be less than $\sim 2 \%$ for all compounds using these co-located diffusion correction tubes.

\subsubsection{Sampling Procedure}

The active samples collected during the pre-occupancy period and the 24-hour controlled postoccupancy period were collected using time-programmable pumps that were pre-calibrated and loaded with sample tubes/cartridges and deployed in the homes in at least two indoor locations (a minimum of one location on each floor) that were expected to be reasonably well mixed (i.e., close to a return air or exhaust duct) and one outdoor location. The PFT emitter cages, timer-controlled pumps loaded with samplers, and data loggers for $\mathrm{T}$ and $\mathrm{RH}$ were deployed the afternoon/evening prior to the early morning sampling event. As less than 12 hours elapsed between emitter deployment and the first active sample, it is likely that the concentration in the home had not yet reached steady state. The experimental plan and associated sampling protocol (see Appendix A) describes how, ideally, the homes would be visited 24hours prior to active sampling to verify controlled, active sampling conditions and deploy the emitters. However, such timing was not possible in this limited field study due to the complexities of coordinating with the builder and homeowner as the home was being finished.

The time-controlled pumps collected active samples (VOC/PFT/aldehyde) in the early morning and then again during the following day. The passive blank VOC and PFT sample tubes used for diffusion correction were also deployed during the active sampling event to correct for any passive uptake when the active samplers were deployed (i.e., exposed to the air), but not actively sampling via the pumped sample. The collected samples were retrieved the following afternoon/evening.

During post-occupancy sampling events, passive samplers were deployed at locations similar to those used for active sampling. The specific active and passive sampling locations are noted, for each house, in Section 4.0, below. Duplicate samples (at least one per passive sample) were collected at a subset of locations and field blanks (at least one per sample period) were collected for quality assurance.

To help eliminate external error the builder was consulted to identify painting, cleaning, or other activities the week before the pre-occupancy testing that might impact sampling results. Similarly, before and after post-occupancy testing the homeowner was consulted to determine what materials/chemicals had been used recently that might alter the testing space. These included additions of new furniture, chemical usage, burning candles, or deep-frying food.

\subsubsection{Analysis Approach}

All samples collected at sampled homes were packaged and shipped in coolers containing ice packs to LBNL for analysis and quantification. 


\subsubsection{Chemical Analysis of VOCs and PFTs}

The TD tubes are conditioned prior to each use by helium purge $(\sim 30 \mathrm{cc} / \mathrm{min})$ for 1 hour at $300^{\circ} \mathrm{C}$ in batches of 10 tubes. Conditioned tubes (analytical blanks) are routinely analyzed to confirm target VOCs are below method quantification limits.

VOCs are quantitatively analyzed by thermal-desorption gas chromatography/mass spectrometry (TD-GC/MS) generally following EPA Method TO-17, "Determination of Volatile Organic Compounds in Ambient Air Using Active Sampling onto Sorbent Tubes" (EPA 1999b). Prior to analysis, a gaseous internal standard (ISTD) is added to each sampler by syringe, then an additional helium flow is passed through the tube for 3 minutes. The ISTD consists of 180 nanograms (ng) of 1-bromo-4-fluorobenzene (BFB) prepared continuously in a diffusion oven. The ISTD is used to check on the operation of the system, to provide a retention-time marker, and to enable quantitative analysis. Tubes are thermally desorbed and focused using a thermodesorption auto-sampler (Model TDSA2; Gerstel), a thermodesorption oven (Model TDS3, Gerstel), and a cooled injection system (Model CIS4; Gerstel). The cooled injection system is fitted with a sorbent-filled glass liner. Tubes are desorbed at a starting temperature of $25^{\circ} \mathrm{C}$ with a 1 -minute delay followed by a $60^{\circ} \mathrm{C} / \mathrm{min}$ ramp to $285^{\circ} \mathrm{C}$ and a 10 -minute hold time with the transfer line temperature at $275^{\circ} \mathrm{C}$. The cryogenic inlet is cooled throughout desorption then heated within 0.5 minutes to $300^{\circ} \mathrm{C}$ at a rate of $12^{\circ} \mathrm{C} / \mathrm{s}$ and held for 3 minutes. A 5:1 split injection is used to improve peak shape in the analysis. Compounds are resolved by GS and detected/quantified using either electron impact MS (5973; Agilent Technologies) operated in scan mode with mass range from 30.0 to 450 atomic mass unit for VOCs or a micro electron capture detector for PFTs. Target compounds are quantified by multi-point calibrations prepared with pure standards using BFB as an internal standard for the MS or using a multi-point external standard for the PFTs.

\subsubsection{Chemical Analysis of Volatile Carbonyls}

The target compounds in the volatile carbonyl analysis included formaldehyde, acetaldehyde, and acetone. Additional carbonyls are analyzed using the VOC method described above. Volatile carbonyl samples were collected and analyzed following EPA Method TO-11, "Method for the Determination of Formaldehyde in Ambient Air Using Adsorbent Cartridge Followed by High Performance Liquid Chromatography" (EPA 1999a). Prior to analysis, cartridges were eluted with high-purity acetonitrile and the eluent was brought to a final volume of $2 \mathrm{~mL}$ before analysis. Extracts were analyzed by highperformance liquid chromatography (HPLC) (1200 Series, Agilent Technologies) using a C18 reversephase column with $65: 35 \mathrm{H}_{2} \mathrm{O}$ :acetonitrile mobile phase at $0.35 \mathrm{~mL} / \mathrm{min}$ and ultraviolet detection at 360 nanometers. Commercially available hydrazone derivatives of formaldehyde, acetaldehyde, and acetone were used to prepare multi-point calibrations for quantification of the target aldehydes. 



\subsection{Sampling Locations}

As part of the pilot field campaign, sampling was performed in three homes in the Tri-Cities, Washington area. The IaP homes were selected based on the use of materials meeting IaP section 6 and 7.2 requirements and the construction time frame. The criteria established in the experimental plan are presented in Table 4.1. The objective was to identify and select conventional homes of similar construction and constructed and occupied at a similar time in the Tri-Cities, Washington. Conventional homes were built to the Washington State code, which requires ventilation equipment and flow rates compliant with ASHRAE 62.2-2010 (ASHRAE 2010). Thus, the primary difference affecting IAQ in the IaP homes is the use of low-emitting materials and potentially a "first flush" prior to occupancy. The fact that Washington State code requires similar ventilation requirements allows for the isolation of the use of low-emitting materials as the single IaP-required variable affecting IAQ in these homes, as constructed, making Washington an ideal location for such an experiment. Obviously, a number of other occupancyrelated factors also influence the measured indoor air contaminant concentrations in these homes once they are occupied.

Table 4.1. Criteria to Determine Candidate Homes for Study Participation

\begin{tabular}{|c|c|c|}
\hline Issue & Criteria & Notes \\
\hline Timing & $\begin{array}{l}\text { Constructing homes that will be completed between } \\
\text { April } 15^{\text {th }} \text { and July } 30^{\text {th }} \text {, and occupied between May } 1^{\text {st }} \\
\text { and August } 15^{\text {th }} \text { for the summer cohort of homes. } \\
\text { Constructing homes that will be occupied between } \\
\text { November } 1^{\text {st }} \text {, 2014, and January } 15^{\text {th }}, 2015 \text {, for the } \\
\text { winter cohort of homes. }\end{array}$ & $\begin{array}{l}\text { Preference will be given to homes completed } \\
\text { by June } 30^{\text {th }} \text {. } \\
\text { Preference will be given to homes completed } \\
\text { by December } 15^{\text {th }}, 2014 \text {. }\end{array}$ \\
\hline $\begin{array}{l}\text { Construction } \\
\text { Materials }\end{array}$ & $\begin{array}{l}\text { Building homes that will completely comply with IaP } \\
\text { section } 6.1 \text { through } 6.3 \text { and } 7.2 \text { or constructing homes } \\
\text { with no materials certified as complying with the } \\
\text { standards referenced in IaP section } 6.1 \text { and } 6.2 \text {. }\end{array}$ & $\begin{array}{l}\text { Preference will be given to home fully } \\
\text { complying with DOE Challenge Home } \\
\text { criteria }^{(a)} \text { for IaP homes and homes with no } \\
\text { low-emitting materials for conventional } \\
\text { homes. }\end{array}$ \\
\hline
\end{tabular}

(a) At the time of study development, the DOE high-performance home certification program was called DOE Challenge Home. The program is now called DOE Zero Energy Ready Home program.

The study design envisioned recruiting and sampling in 24 homes divided equally between conventional and IaP and also divided into summer- and winter-focused sampling cohorts. Criteria that were established in the experimental plan for the second cohort of sample homes (expected to be recruited in fall 2014) are included in italic font. However, these criteria are not relevant for the abbreviated pilot study reported on here.

It was also thought that the IaP homes would be part of the Badger Mountain South development in Richland, Washington, as the developer had committed to encourage builders and homeowners to consider DOE Zero Energy Ready Home ${ }^{1}$ criteria and established the HBATC BuiltGreen criteria as a minimum standard for building in the community. Construction delays in the Badger Mountain South community necessitated a broader recruitment effort. Three homes were successfully recruited and

\footnotetext{
${ }^{1}$ U.S. Department of Energy. 2013. DOE Challenge Home National Program Requirements (Rev. 03). Available at: http://www.energy.gov/sites/prod/files/2013/11/f5/doe_challenge_home_requirementsv3.pdf
} 
sampled in this limited pilot study due to delays in construction in the Badger Mountain South community and other logistical challenges related to time frames of home completion and occupancy. These are discussed in more detail in Section 4.1.

\subsection{Recruitment}

This research project required phases of builder and homeowner engagement, data collection, analysis, and reporting. Builder and homeowner engagement was conducted by personal contact via phone and electronic means. First, an initial group of builders were identified that are likely to be constructing homes during the time frame of interest either fully complying with IaP low-emitting material requirements (i.e., IaP sections 6.1 through 6.3 and 7.2) or including no materials certified as low-emitting based on the standards listed in IaP sections 6.1 through 6.3. This initial group of builders was identified through coordination with the HBATC and the developer of Badger Mountain South, a local development intending to build significant numbers of DOE Challenge Homes and/or homes built to the HBATC's BuiltGreen Program. Candidate builders were selected based on the timing of new home construction, whether the homes are intended to be "spec" homes or built to order, the materials used, and other construction specifications. A list of questions that builders were asked during recruitment is included in the experimental plan (Error! Reference source not found.).

Once candidate builders were identified, outreach to homeowners purchasing the builders' homes was then conducted through realtors, through the builders themselves, or by PNNL researchers (if the builder or realtor provided the homeowner contact information directly). For all candidate homeowners, the builder was asked to share a study information sheet (included in the experimental plan in Error! Reference source not found.) with the new homebuyers. The Homeowner Information Sheet explains the background for the study, what participation entails, and provides contact information for the PNNL researchers conducting the study whom the homeowner may contact for more information. Interested homeowners were provided with more detailed information and, if they chose to participate, they were asked to sign the homeowner agreement (included in the experimental plan in Error! Reference source not found.).

In general, homeowner participation in the study was based on occupying a new home that meets the criteria listed in Table 4.2and agreement to cooperate with researchers during the sampling events (as demonstrated by signing the homeowner agreement). However, this study is designed to characterize the difference between VOCs (including aldehydes) in IaP versus conventional homes under typical occupancy scenarios. As such, occupants were also asked to provide information on several characteristics that may affect the quality or representative nature of the IAQ measurements and, as such, may also present a reason for exclusion. The requested information and the justifications for exclusion are provided in Table 4.2.

Table 4.2. Characteristics of Homeowners Used to Determine Inclusion or Exclusion

\begin{tabular}{lll}
\hline Issue & Criteria & Notes \\
\hline Home & $\begin{array}{l}\text { Ownership of a home meeting the } \\
\text { criteria established in Table 2.2 }\end{array}$ & This is a primary criterion for inclusion \\
Consent & $\begin{array}{l}\text { Demonstration of willingness to } \\
\text { participate in the study through } \\
\text { signing of the Homeowner }\end{array}$ & This is a primary criterion for inclusion \\
\hline
\end{tabular}


Agreement

Table 4.2. (contd)

\begin{tabular}{|c|c|c|}
\hline Issue & Criteria & Notes \\
\hline Ventilation & $\begin{array}{l}\text { Operation of home ventilation } \\
\text { systems using typical schedules, } \\
\text { including window operation. }\end{array}$ & $\begin{array}{l}\text { Preference will be given to homeowners who do not } \\
\text { frequently open windows because it will be more likely } \\
\text { that they will comply with the request to keep windows } \\
\text { closed during the 24-hour controlled sampling event. }\end{array}$ \\
\hline Temperature & $\begin{array}{l}\text { Maintenance of home interior } \\
\text { temperature set points within } 4^{\circ} \mathrm{F} \text { of } \\
\text { the ASHRAE } 55-2010 \text { specified } \\
\text { region }\left(60-74^{\circ} \mathrm{F} \text { in winter and } 69-\right. \\
83^{\circ} \mathrm{F} \text { in summer) }\end{array}$ & $\begin{array}{l}\text { Interior temperature will affect the emission rate of } \\
\text { chemicals from various building materials and, thus, will } \\
\text { affect the concentrations of contaminants measured in the } \\
\text { homes. Especially warm or cold homes could reduce or } \\
\text { exaggerate emission rates and make comparison among } \\
\text { homes difficult. }\end{array}$ \\
\hline Occupancy & $\begin{array}{l}\text { No more than } \mathrm{N}+2 \text { occupants where } \\
\mathrm{N} \text { is the number of bedrooms and no } \\
\text { more than five pets. }\end{array}$ & $\begin{array}{l}\text { Extremely high occupancy or pet ownership could result } \\
\text { in excessive introduction of people-related pollutants that } \\
\text { will interfere with measurement of building-related } \\
\text { pollutants and may not be representative of typical } \\
\text { households. }\end{array}$ \\
\hline $\begin{array}{l}\text { Smoking and } \\
\text { other } \\
\text { particulate- } \\
\text { generating } \\
\text { activities }\end{array}$ & $\begin{array}{l}\text { No daily smoking, candle burning, or } \\
\text { use of incense in the home. }\end{array}$ & $\begin{array}{l}\text { Smoking, candle burning, and use of incense are known } \\
\text { to generate significant amounts of particulates, VOCs, } \\
\text { and aldehydes that would likely overwhelm other } \\
\text { pollutant sources in the homes and make it difficult to } \\
\text { determine the impact of IaP criteria. }\end{array}$ \\
\hline $\begin{array}{l}\text { Other } \\
\text { activities }\end{array}$ & No specific criteria established & $\begin{array}{l}\text { Homeowners that frequently engage in other activities } \\
\text { that would have a significant impact on IAQ in the home } \\
\text { or otherwise interfere with the measurements or study } \\
\text { results will be evaluated individually. }\end{array}$ \\
\hline
\end{tabular}

Subsequent to entering the study, homeowners were contacted via phone or email to schedule IAQ sampling visits. During this initial phone call, homeowners were asked general questions regarding their anticipated activities for the upcoming sample week and these responses were tracked. During IAQ sampling, homeowners were also asked to log their activities daily using a survey tool (see experimental plan in Error! Reference source not found.). Homeowners were paid a stipend in compensation for any inconvenience and disruption caused by participation in the study according to the schedule in Table 4.3. In the multi-year sampling time frame initially envisioned in experimental plan, additional stipend amounts were included, with increasing amounts as time went on, reflecting the increasing value of the data and encouraging homeowners to complete the full suite of IAQ sampling periods. The stipend amounts were selected to be large enough to be significant, given the anticipated socioeconomic situation of the new homeowners likely to participate in the study (homebuyers in the Tri-Cities), but low enough so as not to unduly influence their decision to participate or not participate. Contingent upon an executed homeowner agreement in one of their homes, builders were also provided a $\$ 500$ stipend to compensate them for their time and cooperation coordinating with PNNL researchers to collect materials samples, collect home construction characteristics, access homes prior to homeowner occupancy, and conduct related activities. 
Table 4.3. Schedule of Homeowner Stipends and Amounts

\begin{tabular}{lcc}
\hline \multicolumn{1}{c}{ IAQ Sampling Period } & $\begin{array}{c}\text { Sampling Stipend } \\
\text { Amount }\end{array}$ & $\begin{array}{c}\text { Maximum Available Logging } \\
\text { Stipend Amount }^{(\mathbf{a})}\end{array}$ \\
\hline Pre-Occupancy & $\$ 50$ & $\$ 0$ \\
Post-Occupancy & $\$ 50$ & $\$ 50$ \\
\hline (a) $\quad$ Logging to be completed daily, $\$ 5 /$ day $+\$ 15$ for completing the activity log all 7 days. \\
\hline
\end{tabular}

Unfortunately, delays in construction at Badger Mountain South and the ambiguity of construction time frames for local builders made identifying candidate homes more difficult that the research team had anticipated. Initially, 83 builders working in the Tri-Cities were identified and, of these, 23 were contacted to determine their interest in participating in the study. Twenty-four potential homes being constructed in the time frame of interest for summer 2014 sampling were initially identified. However, many builders worked through realtors and did not have direct relationships with the homeowners. This made reaching out to homeowners to gauge interest in study participation logistically challenging and often included multiple follow-up phone calls to builders and different realtors to obtain contact information or assistance in reaching out to interested homeowners. In addition, construction time frames are often flexible and change as materials and contracting crews are available, making them difficult to reliably predict and schedule around.

Further, homeowners were often not aware of the closing date or when they would be moving into the home until a week or less prior to the move-in date. This often left little to no time to schedule preoccupancy sampling. Also, some homeowners declined to participate due to the chaotic nature of the transition, including potentially selling a previous house.

As such, despite considerable effort to contact and maintain consistent communication with the builders, realtors, and homeowners, the available homes for sampling, time frames of completion, only three homes were successfully recruited and sampled in the this pilot field campaign.

A general description of each sampled house, the sampling locations, and the specific sampling observations that are anticipated to affect the IAQ measurements are noted in the following sections.

\subsection{Conventional 1 (C1)}

The sampled conventional house (Conventional 1 [C1]), shown in Figure 4.1, is a single-family, twostory home with an attached garage completed on April $24^{\text {th }}, 2014$. It has five bedrooms and four baths, for a total conditioned space of $4,300 \mathrm{ft}^{2}$. The home was occupied by a family of five, three adults and two small children, and a small dog. One adult (the grandmother) and the children were typically home all day on the weekdays during the study period. Most of the family was home during the weekend. 


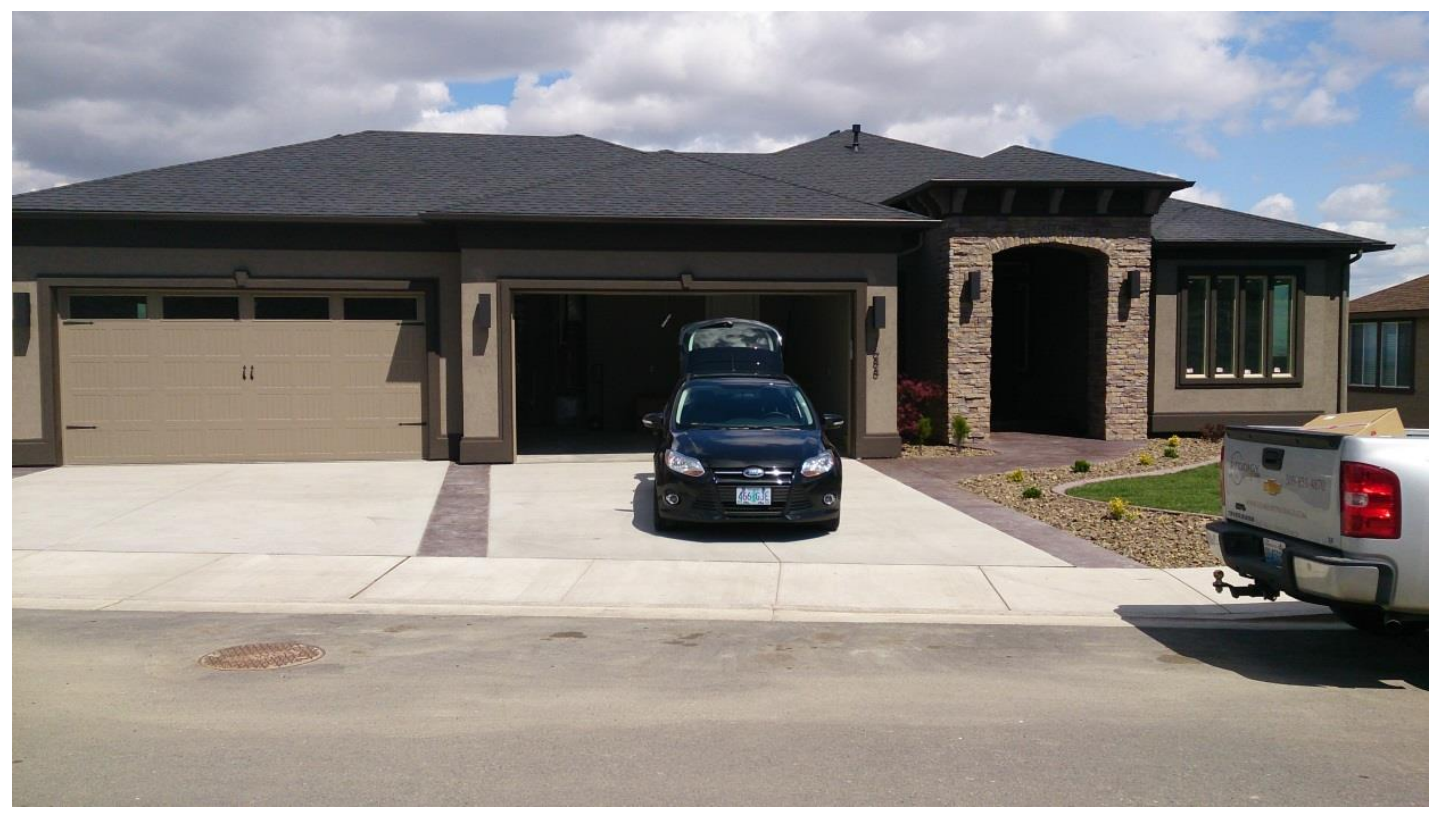

Figure 4.1. Exterior Photograph of $\mathrm{C} 1$ House

Given the large size of the home, it was conditioned with two separate 2-ton heat pump systems, with independent duct work for the upper and lower floors. Key characteristics of the home are summarized in Table 4.4

Table 4.4. Key House Characteristics for Conventional 1 (C1)

\begin{tabular}{ll}
\hline Characteristic & Value \\
\hline Home Conditioned Area & $4,300 \mathrm{ft}^{2}$ \\
Building Envelope Leakage & $2.60 \mathrm{ACH} 50$ \\
HVAC System & $1^{\text {st }}$ floor: 2-ton SEER 13/HSPF 9 Heat Pump \\
& $2^{\text {nd }}$ floor: 2-ton SEER 13/HSPF 9 Heat Pump \\
& Both thermostats set to $70^{\circ} \mathrm{F}$ with no setback. \\
& One utility room exhaust fan in upstairs laundry room $(66 \mathrm{cfm})$ with timer-based \\
& control (set to operate approximately $7 \mathrm{hr} / \mathrm{d})$ \\
& One utility room exhaust fan in downstairs laundry room (47 cfm) \\
& 5 bathroom exhaust fans $(34,50$, and $44 \mathrm{cfm}$ in upstairs bathrooms and 49 and 47 \\
& cfm in downstairs bathrooms) \\
& There are two air returns, one in the master bathroom upstairs and one downstairs \\
& beneath the staircase. \\
\hline
\end{tabular}

The home was finished with primarily hard surfaces, including engineered wood floors on the upper and lower levels. Carpeting was, however, present in the bedrooms. While this home was a conventional home, in that no low-VOC products were intentionally used, some of the paint applied in the home was found to be low-VOC certified. This is likely due to the ubiquity of low-VOC paint. The builder confirmed that this paint was purchased based on price at a local hardware store. A summary of the finishes, paint, flooring, and wood products addressed by section 6 of the IaP Construction Specifications used in this $\mathrm{C} 1$ home and any relevant certifications are listed in Table 4.5. 
Table 4.5. Major Composite Wood, Paints and Finishes, and Carpet Products Used in C1 Home Construction

\begin{tabular}{|c|c|c|c|}
\hline Material & $\begin{array}{c}\text { Manufacturer and } \\
\text { Brand }\end{array}$ & Certification(s), if any & Other Notes \\
\hline \multicolumn{4}{|l|}{ Composite Wood } \\
\hline Engineered Hardwood & National & $\begin{array}{l}\text { California Air Resources } \\
\text { Board - Phase } 1 \text { Criteria } \\
(\text { CARB } 1)^{(a)}\end{array}$ & \\
\hline Cabinets & Huntwood Cabinets & $\begin{array}{l}\text { Meets Kitchen Cabinet } \\
\text { Manufacturers } \\
\text { Association (KCMA) } \\
\text { standards }^{(b)}\end{array}$ & $\begin{array}{l}\text { Non-urea added formaldehyde } \\
\text { plywood and particle board }\end{array}$ \\
\hline $\begin{array}{l}\text { Closet and interior } \\
\text { doors }\end{array}$ & $\begin{array}{l}\text { Jeld-Wen hollow core } \\
\text { and solid core doors }\end{array}$ & CARB2 & Primer applied at factory \\
\hline $\begin{array}{l}\text { Millwork, wood stairs } \\
\text { and railings }\end{array}$ & Unknown & Unknown & $\begin{array}{l}\text { The builder did not provide } \\
\text { information on the stairs and } \\
\text { railings, thus composition or } \\
\text { certification information is not } \\
\text { available }\end{array}$ \\
\hline \multicolumn{4}{|c|}{ Interior Paints and Finishes } \\
\hline Walls and/or ceiling & Promar Zero VOC Latex & Green Guard & \\
\hline Trim and millwork & $\begin{array}{l}\text { Southwest Builders } \\
\text { Interior Latex Semi- } \\
\text { gloss }\end{array}$ & None & $\begin{array}{l}\text { Ethylene glycol } 1 \text { percent by } \\
\text { weight (wt } \% \text { ) } \\
\text { Glycol ethers } 2 \mathrm{wt} \%\end{array}$ \\
\hline Cabinet paint/finishes & Huntwood Cabinets & Meets KCMA standards & $\begin{array}{l}\text { Also recognized by Spokane } \\
\text { County Air Pollution Control } \\
\text { Authority for ultra-low VOC } \\
\text { emission finishes on cabinets }\end{array}$ \\
\hline Wood floor finish & National & CARB & \\
\hline \multicolumn{4}{|c|}{ Carpets and Carpet Adhesives } \\
\hline Carpet & Shaw & Green Label Plus & \\
\hline Carpet Padding & $\begin{array}{l}\text { Leggett \& Platt Ultra } \\
\text { Magic }\end{array}$ & Green Label & \\
\hline Carpet Adhesive & $\begin{array}{l}\text { W.F. Taylor Touchdown } \\
700 \text { Contact Cement }\end{array}$ & None & $\begin{array}{l}\text { Used in basement only; } \\
\text { N-hexane } 41-44 \mathrm{wt} \% \text {, methyl } \\
\text { ethyl ketone } 15-20 \mathrm{wt} \% \text {, and } \\
\text { toluene } 14-18 \mathrm{wt} \%\end{array}$ \\
\hline \multicolumn{4}{|c|}{$\begin{array}{l}\text { (a) CARB. "Airborne Toxic Control Measure to Reduce Formaldehyde Emissions from Composite Wood } \\
\text { Products." Title } 17 \text { of the California Code of Regulations, Section 93120.2. } \\
\text { (b) The KCMA Certification Program requires testing in accordance with ANSI/KCMA A161.1-2012, } \\
\text { "Performance \& Construction Standard for Kitchen and Vanity Cabinets." The KCMA Certification Program is } \\
\text { related to product durability and construction. There are no material composition or emissions requirements. }\end{array}$} \\
\hline
\end{tabular}

When the homeowners occupied the home, mostly new furniture was purchased for the home. Major new furnishings included leather couches and recliners in the upstairs living room, downstairs living room (Figure 4.2), and home entertainment center (Figure 4.3), where there was a noticeable "new" smell. The home also included new decorative art work and drapes. Other furnishings, including beds, dressers, a desk in the office, and the dining room table were reported to have been moved from the previous 
residence. It is also worth noting that an air freshener was installed in the HVAC system duct work immediately following occupation of the home. It is not clear if it was intended to be frequently replaced.

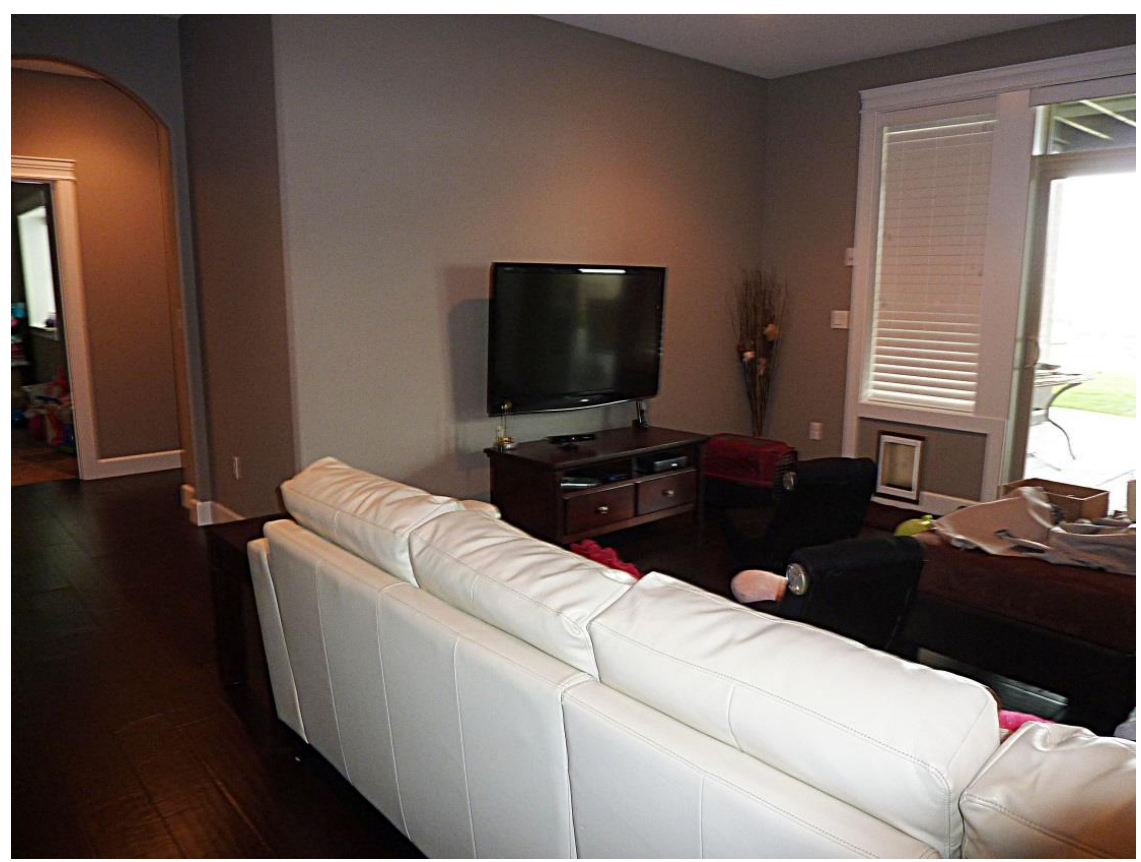

Figure 4.2. Downstairs Great Room Furniture (Zone 1)

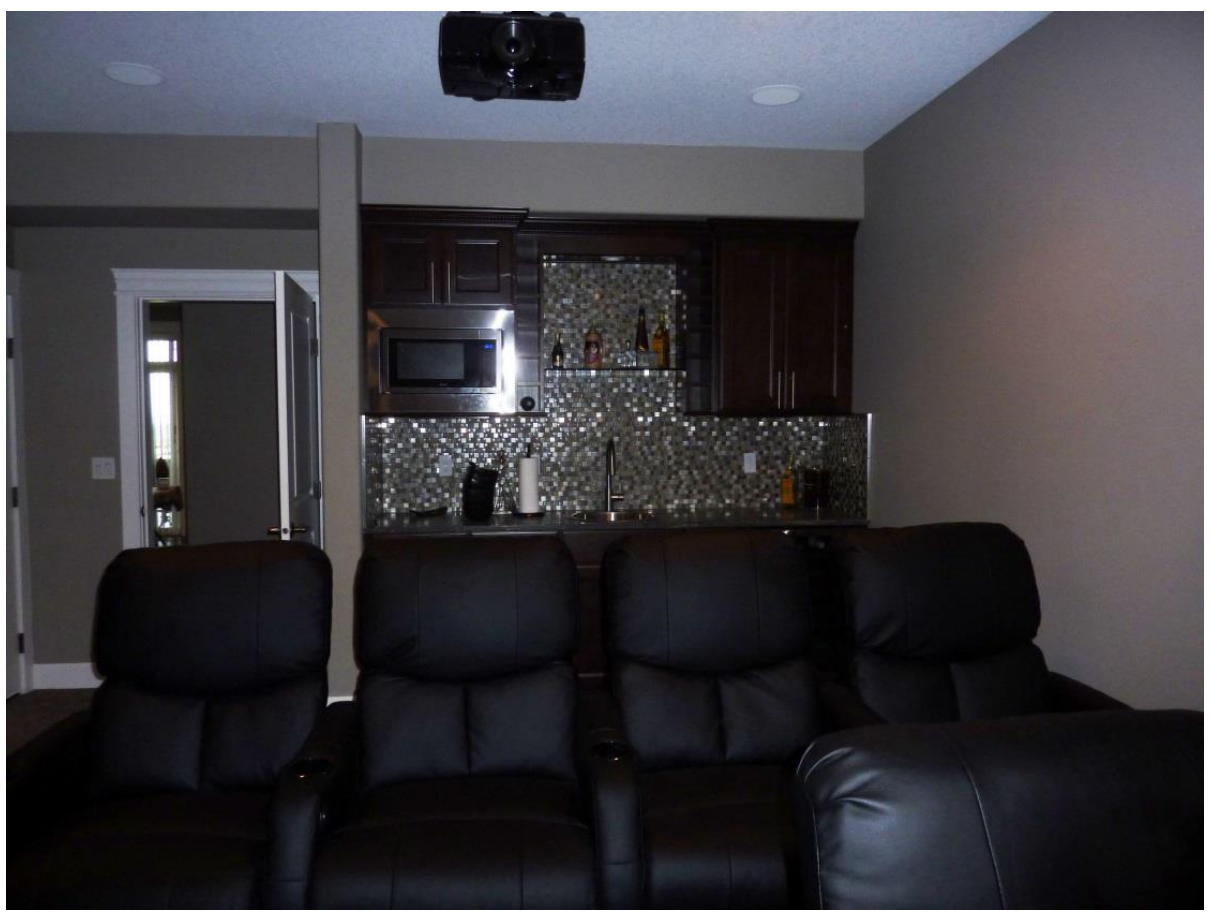

Figure 4.3. Home Entertainment Center Furniture 


\subsubsection{Sampling Observations}

Pre-occupancy sampling of the $\mathrm{C} 1$ home occurred on April $26^{\text {th }}$ and $27^{\text {th }}, 2014$. The house had not yet undergone the final cleaning. Upon entering the $\mathrm{C} 1$ home for the first time, there was an abnormal "fake wood" smell present in the air, most likely lingering from the engineered hardwood or composite wood shelving installed in the pantry and several bedroom closets. A worker was on the premises finishing punch-list items outside the home, including pressure washing the deck while the pre-occupancy sampling equipment was being set up on April $26^{\text {th }}$. Figure 4.4 shows the locations of the emitters and active sampling stands within the house.
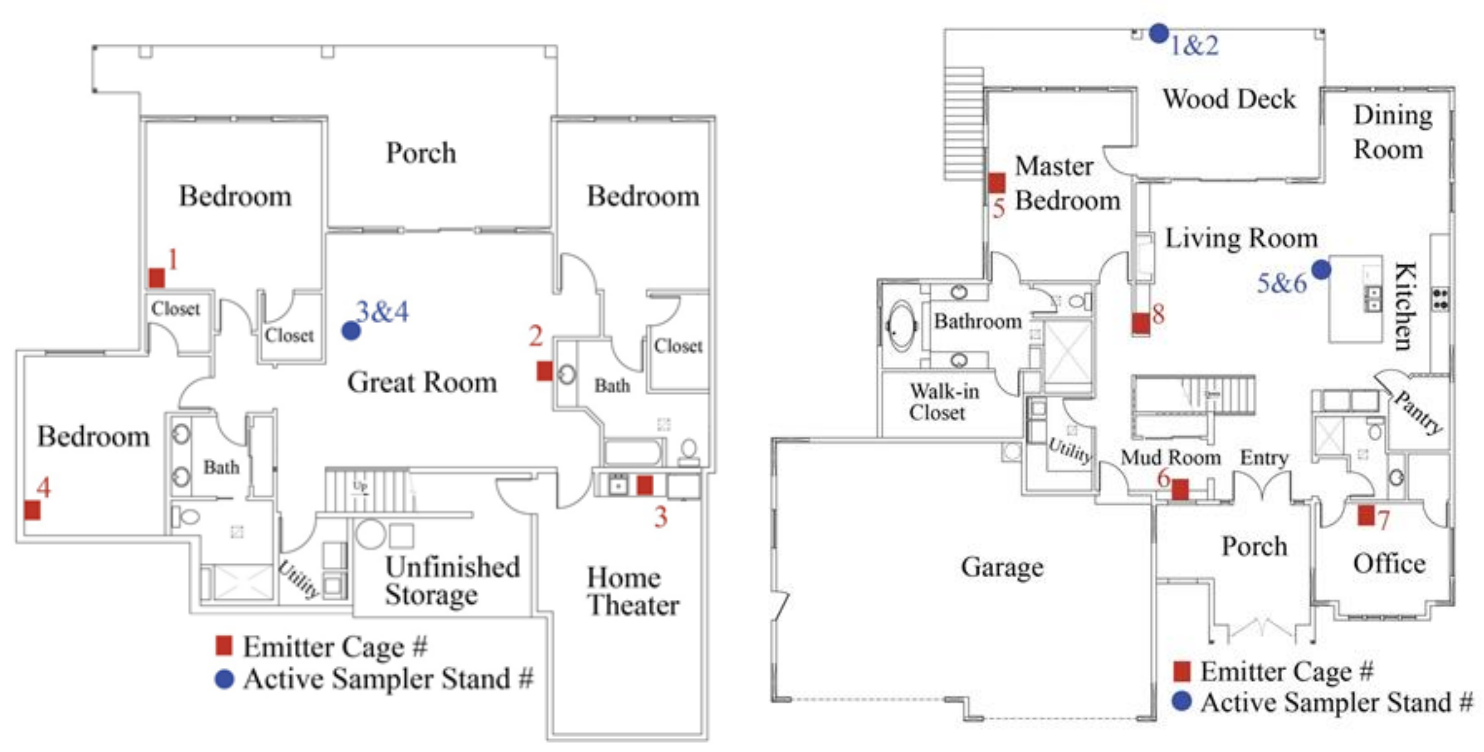

Figure 4.4. Location of Emitters and Active Samplers in the Lower Level of C1 (Zone 1; left) and Upper Level of C1 (Zone 2; right) During Pre-Occupancy Sampling Period

The active, short-term post-occupancy sampling period occurred on the evening of May $22^{\text {nd }}, 2014$, and the following morning on May $23^{\text {rd }}, 2014$. When research technicians arrived on May $22^{\text {nd }}$, a lawn care company had just finished a liquid fertilizer treatment of the yard next door. A strong odor of chemicals lingered for a period of time as a result of the treatment. During deployment of the samplers, the $\mathrm{C} 1$ home seemed unusually warm. During the 24-hour active sampling period the homeowner determined that the HVAC system was not working properly. As a result, the homeowner opened the windows and turned on the fan in the night to keep the house a comfortable temperature. In the morning, the HVAC technician was called out to the house to fix the HVAC system, which presumably suffered from a refrigerant charge issue or failure of some sort (although the homeowner was not able to confirm the source of the failure). The HVAC system was working by the time the researchers returned to the home the following afternoon to collect the active sampling equipment and deploy the passive samplers.

The passive samplers were deployed for 1 week (from May $23^{\text {rd }}$ to $30^{\text {th }}$ ), during which time, the homeowner's mother kept track of household activities in the homeowner questionnaire. During the week, approximately one to two loads of laundry were done per day, which involved running the clothes dryer at least once per day. The bath fan and kitchen range hood were operated daily with bathroom use and cooking events. Windows were also used to provide supplemental ventilation/cooling on a limited basis (one to two windows were open for 1 hour or less on four of the seven sampling days), aside from 
the day the HVAC malfunctioned as noted above. Regarding use of cleaning products and other VOCcontaining products, the homeowner reported fairly frequent use of Lysol ${ }^{\circledR}$ and cleaning products. The post-occupancy emitter, active sampling, and passive sampling locations are depicted in Figure 4.5.
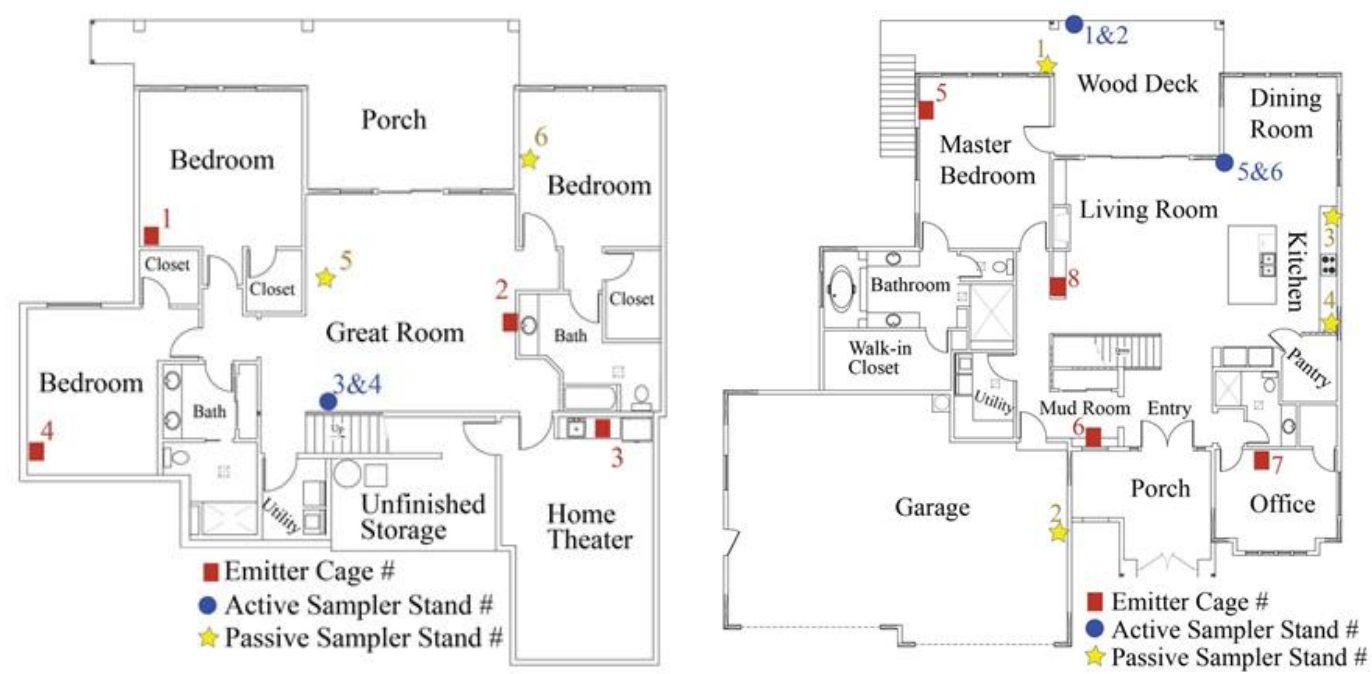

Figure 4.5. Location of Emitters, Active Samplers, and Passive Samplers in the Lower Level of C1 (Zone 1; left) and Upper Level of C1 (Zone 2; right) During Post-Occupancy Sampling Period

\subsection{Indoor airPLUS House 1 (laP1)}

The first house sampled as an IaP home was a single-family, single-story home with an attached garage, depicted in Figure 4.6. Completed around May $20^{\text {th }}$, 2014, it has three bedrooms and two baths, for a total conditioned space of $1,805 \mathrm{ft}^{2}$. During sampling, the home was occupied by a single retired person who was typically home all day every day.

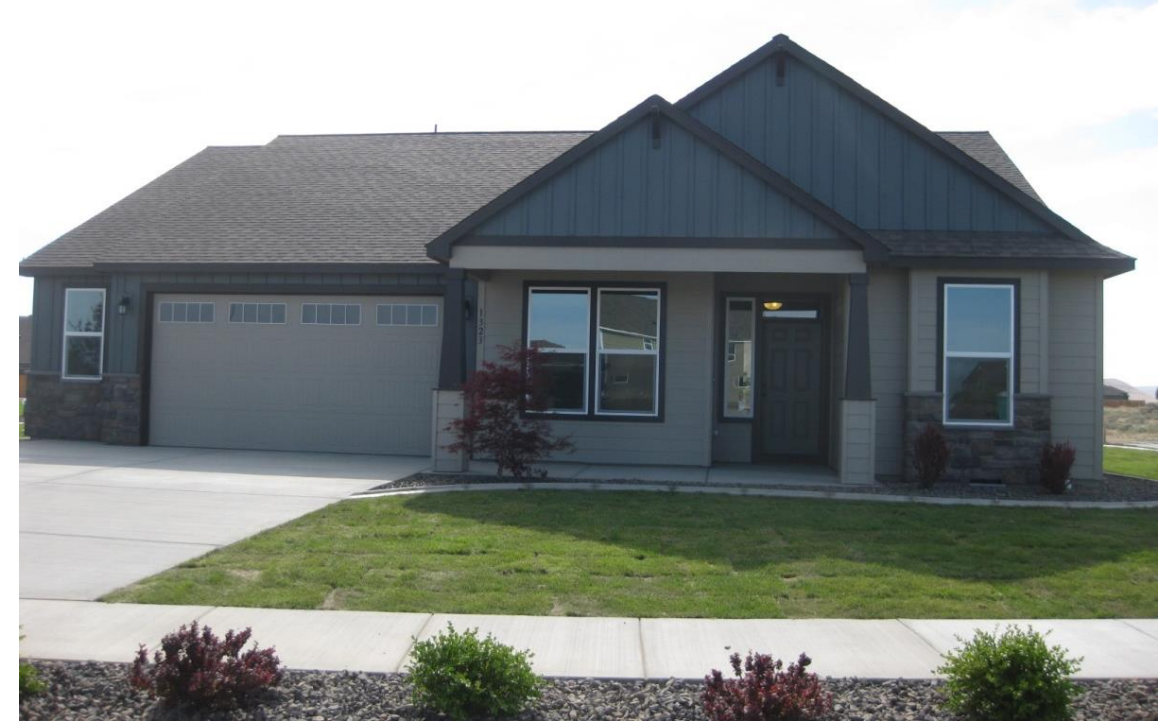

Figure 4.6. Exterior of IaP1 House 
The home had one 3-ton heat pump. Natural gas fuels the tankless water heater and fireplace (artificial logs). Both the front and back yards had been recently landscaped. Key characteristics of the home are summarized in Table 4.6.

Table 4.6. Key House Characteristics for the IaP1 Home

\begin{tabular}{ll}
\hline Characteristic & Value \\
\hline Home Conditioned Area & $1,805 \mathrm{ft}^{2}$ \\
Building Envelope Leakage & $2.58 \mathrm{ACH} 50$ \\
HVAC System & 3-ton SEER $15 / \mathrm{HSPF} 9$, heat pump \\
& Thermostat set to $70^{\circ} \mathrm{F}$ on permanent hold. Homeowner reports manually \\
& adjusting thermostat to maintain comfort between $65^{\circ} \mathrm{F}$ and $75^{\circ} \mathrm{F}$. \\
& Bathroom exhaust fans in the master bath, master toilet, and guest bath (35, \\
& 56, and $60 \mathrm{cfm}$, respectively). \\
Ventilation Systems & The guest bath has the timer-based control set to operate $17 \mathrm{hr} / \mathrm{d})$ \\
& One exhaust fan in the master closet $(62 \mathrm{cfm})$ \\
& The air return is located in hall outside the master bedroom \\
\hline
\end{tabular}

The home was finished with engineered wood floors in the kitchen and dining room and tile floors in the bathrooms, laundry room, and entry. Carpeting was present in the bedrooms and in the living room. Finished wood cabinets are present in the kitchen and bathrooms. A summary of the finishes, paint, flooring, and wood products addressed by section 6 of the EPA's IaP guidelines used in this IaP1 home and any relevant certifications is provided in Table 4.7 .

Table 4.7. Major Composite Wood, Paints and Finishes, and Carpet Products Used in IaP1 Home Construction

\begin{tabular}{|c|c|c|c|}
\hline Material & Manufacturer and Brand & Certification(s), if any & Other Notes \\
\hline \multicolumn{4}{|l|}{ Composite Wood } \\
\hline Engineered Hardwood & $\begin{array}{l}\text { Rhino Engineered Birch Santa } \\
\text { Barbra }\end{array}$ & None & $\begin{array}{l}\text { Builder allows } \\
\text { homeowners to select } \\
\text { some finishes }\end{array}$ \\
\hline Cabinets & Northwood Cabinets & None & $\begin{array}{l}\text { Particleboard and } \\
\text { flakeboard are low- } \\
\text { formaldehyde- } \\
\text { emitting }\end{array}$ \\
\hline Closet and interior doors & $\begin{array}{l}\text { Jeld-Wen hollow and solid } \\
\text { core doors }\end{array}$ & CARB2 & $\begin{array}{l}\text { Primer applied at } \\
\text { factory }\end{array}$ \\
\hline \multicolumn{4}{|c|}{ Interior Paints and Finishes } \\
\hline Ceiling & $\begin{array}{l}\text { Sherwin-Williams Promar } 700 \\
\text { Primer Finish }\end{array}$ & Green Guard & \\
\hline Walls & $\begin{array}{l}\text { Sherwin-Williams Contractors } \\
\text { Interior Latex Satin, extra } \\
\text { white }\end{array}$ & Contains no VOCs & \\
\hline Trim and Millwork & $\begin{array}{l}\text { Sherwin-Williams Southwest } \\
\text { Builders Interior Latex Semi- } \\
\text { gloss }\end{array}$ & None & $\begin{array}{l}\text { Ethylene glycol } 1 \% \\
\text { wt\%; Glycol ethers } 2 \\
\text { wt } \%\end{array}$ \\
\hline Cabinet finishes & $\begin{array}{l}\text { Northwood Cabinets mixes } \\
\text { colors in a water base for }\end{array}$ & None & $\begin{array}{l}\text { Water-based with } \\
\text { intention to be low }\end{array}$ \\
\hline
\end{tabular}




\begin{tabular}{|c|c|c|c|}
\hline & cabinet finishes & & VOC emitting \\
\hline \multicolumn{4}{|c|}{ Carpets and Carpet Adhesives } \\
\hline Carpet & Shaw Bella Tweed & Green Label Plus & \\
\hline Carpet Padding & Leggett \& Platt Ultra Magic & Green Label & \\
\hline Carpet Adhesive & None used & NA & \\
\hline
\end{tabular}

Most of the furniture in the home was new during post-occupancy sampling. It included wood bedroom dressers, night stands, head board, and mattress in the master bedroom (Figure 4.7), along with a dining room table and chairs, metal and leather bar stools, a leather couch and two matching chairs, and wood shelving in the living room (Figure 4.8), and a fabric-covered couch in the study. A leather loveseat and wood end tables were delivered on July $19^{\text {th }}$ during passive sampling.

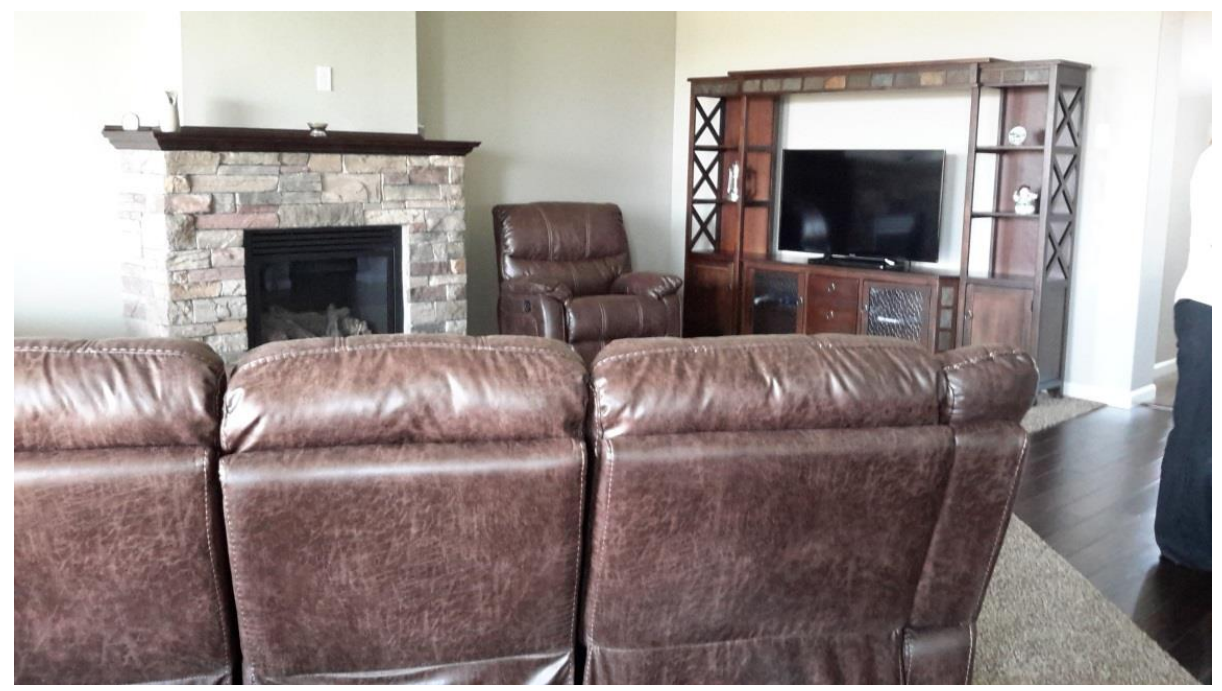

Figure 4.7. New Furnishings in IaP1 Living Room at Start of Post-Occupancy Sampling

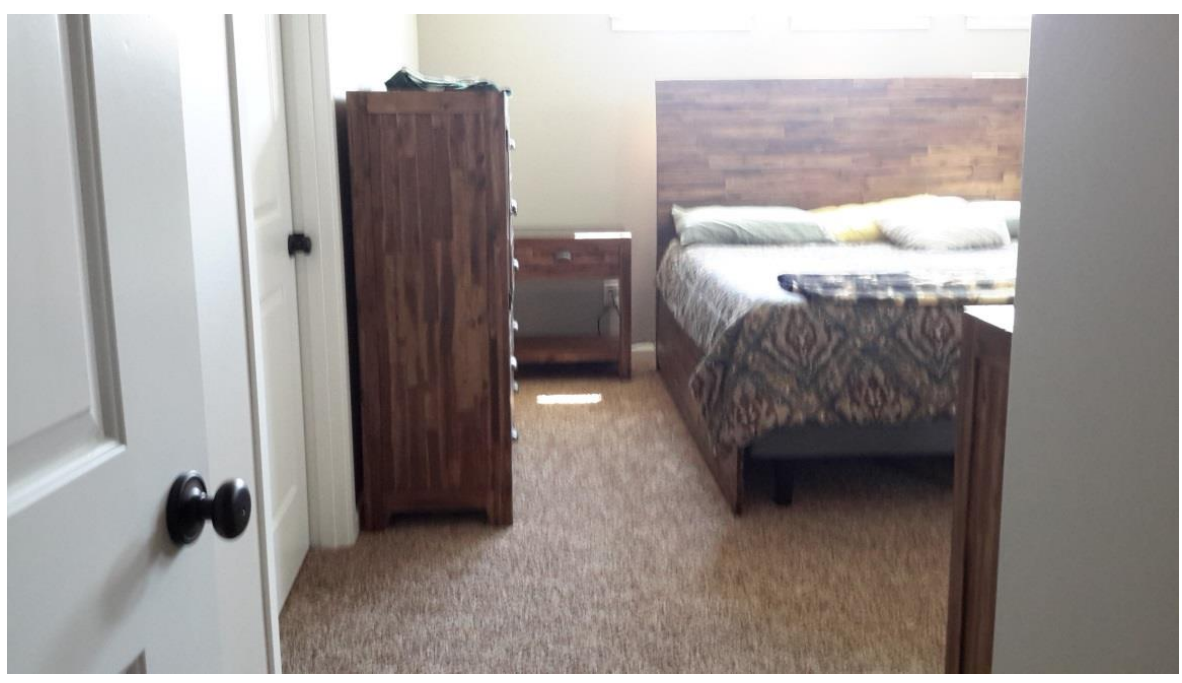

Figure 4.8. New Bedroom Furniture

Due to the homes' location in a new subdivision, significant construction activity is ongoing and ground-moving equipment continues to work on almost all sides of the home, especially behind the house. The back of the house faces the southwest, a dominant wind direction for much of the year. 


\subsubsection{Sampling Observations}

Pre-occupancy sampling equipment was set up in the IaP1 home on May $30^{\text {th }}, 2014$ and sampling occurred on May $31^{\text {st }}$, 2014. Six emitter cages were deployed as a single zone, with one of each of the three PFT gases in each of the cages. The active sampler and emitter locations are indicated in Figure 4.9. The very well-constructed home had not yet undergone final cleaning. There was a smell of stone paint when research technicians first arrived to erect sampling equipment. Sample pumps were programmed to run according to the experimental plan for 60 minutes at one of two different times. However, only the sample pumps set to run at the earlier sample period at 4:00 AM on May $31^{\text {st }}$ ran for the full 60 minutes. The other sample pumps, set to run for 60 minutes at 11:00 AM on May $31^{\text {st }}$, were only able to run for part of the second hour due to low battery power.

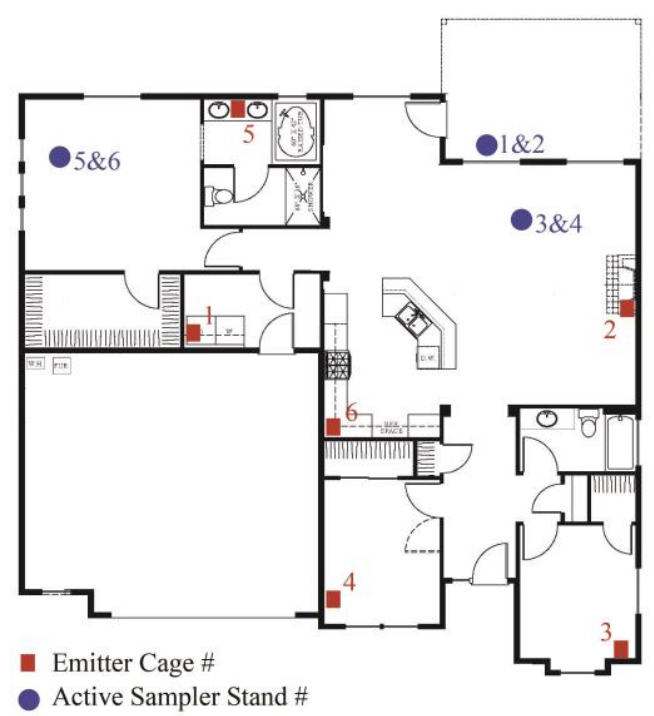

Figure 4.9. Location of Emitters and Active Samplers in IaP1 During Pre-Occupancy Sampling Period

Post-occupancy active sampling occurred on July $16^{\text {th }}, 2014$, and passive sampling took place from July $17^{\text {th }}$ to July $23^{\text {rd }}, 2014$. The emitter and sampler locations during the active and passive postoccupancy sampling periods are shown in Figure 4.10. Early in the day on July $23^{\text {rd }}$ a worker used spackle to patch a hole in the hall closet and cover two dings in the walls in the living room/kitchen area, one in the master bath and another in the master closet. The passive samplers were picked up shortly after noon on July $23^{\text {rd }}, 2014$.

During the passive sampling, the homeowner adjusted the thermostat manually, but the temperature was kept between 68 and $72^{\circ} \mathrm{F}$. A decorative air freshener was on the mantle in the living room but was not recognized as such until passive samplers were deployed on July $16^{\text {th }}, 2014$. It was left in place for the passive sampling. 


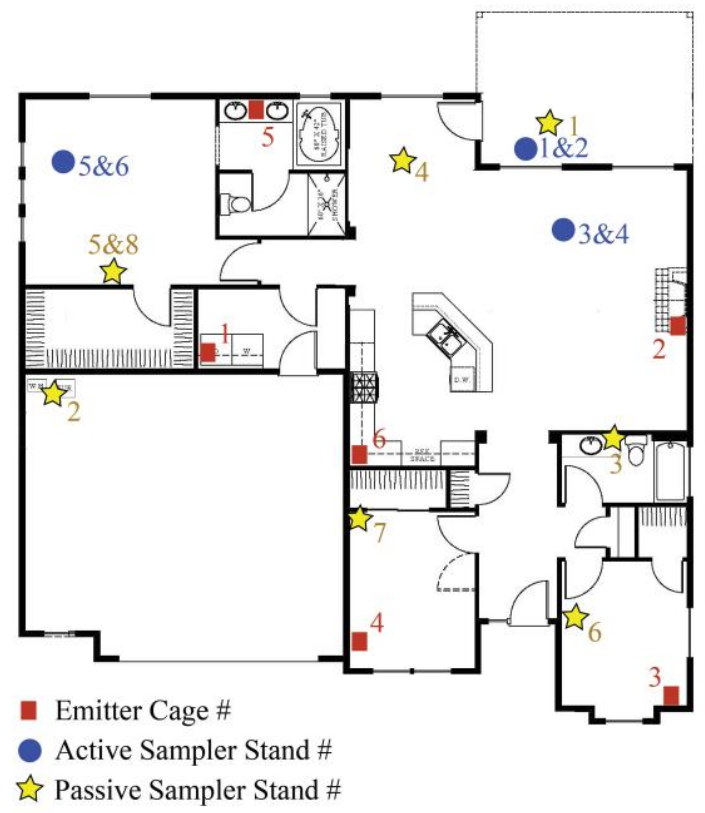

Figure 4.10. Location of Emitters, Active Samples, and Passive Samplers in IaP1 During PostOccupancy Sampling Period

\subsection{Indoor airPLUS House 2 (laP2)}

The second IaP house sampled (IaP2) is a single-family, two-story home with an attached garage completed on in July 2014, as shown in Figure 4.11. It has five bedrooms and three bathrooms, with a total conditioned space of $3,451 \mathrm{ft}^{2}$. An unusual feature of the house is an additional kitchen area with a stove and sink that can be closed off from the main kitchen.

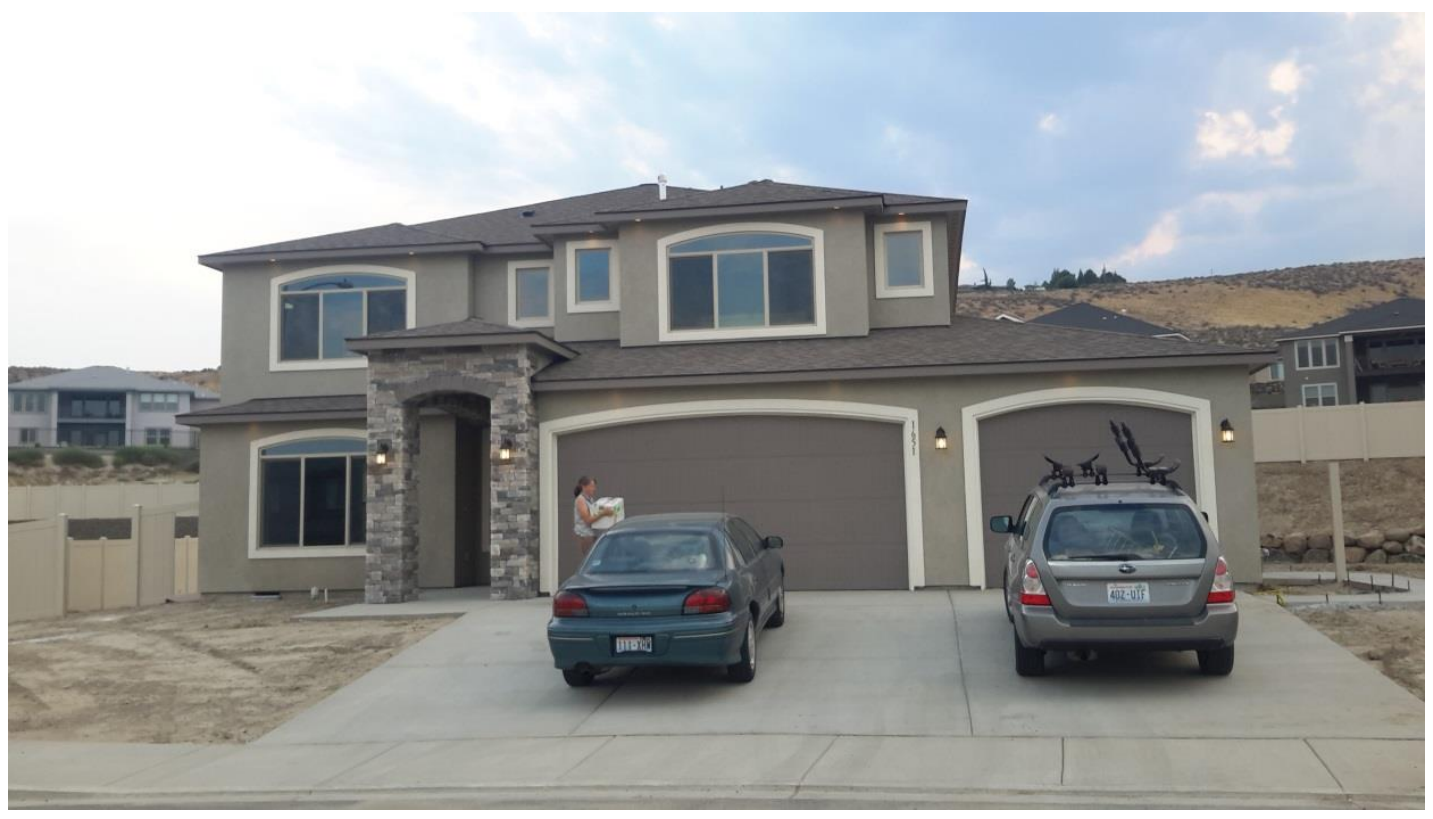

Figure 4.11. Exterior of the IaP2 Home 
The home had one 3.5-ton heat pump. Natural gas fuels the tankless water heater, fireplace (artificial logs), and stoves. The yard was not landscaped until after pre-occupancy sampling occurred. Key characteristics of the home are summarized in Table 4.8.

Table 4.8. Key House Characteristics for the IaP2 Home

\begin{tabular}{ll}
\hline Characteristic & Value \\
\hline Home Conditioned Area & $3,451 \mathrm{ft}^{2}$ \\
Building Envelope Leakage & 2.8 ACH50 \\
HVAC System & 3.5 -ton SEER $14.5 / \mathrm{HSPF} 8.2$ heat pump \\
& Thermostat set to $76^{\circ} \mathrm{F}$ on permanent hold. \\
& Bathroom exhaust fans in the master bath, master toilet, upstairs and \\
Ventilation Systems & downstairs bathrooms $(71,106,114$, and $107 \mathrm{cfm}$ respectively). The upstairs \\
& bath has the timer-based control set to operate $24 \mathrm{hr} / \mathrm{d}$. \\
& The air returns are located upstairs in the hallway near the stairs and in the \\
& bonus room
\end{tabular}

Engineered wood floors were used in the main kitchen, living room, and entry on the main floor. The stairs, bedrooms, and upstairs hall were carpeted while the bathrooms and second kitchen were tiled. There are finished wood cabinets in the kitchen, laundry room, and bathrooms. A summary of the finishes, paint, flooring, and wood products addressed by section 6 of the EPA's IaP guidelines used in this home and any relevant certifications is provided in Table 4.9.

Table 4.9. Major Composite Wood, Paints and Finishes, and Carpet Products Used in IaP2 Home Construction

\begin{tabular}{|c|c|c|c|}
\hline Material & Manufacturer and Brand & Certification(s), if any & Other Notes \\
\hline \multicolumn{4}{|l|}{ Composite Wood } \\
\hline Engineered Hardwood & $\begin{array}{l}\text { Johnson Hardwood English } \\
\text { Pub Handscraped Maple }\end{array}$ & CARB & \\
\hline Cabinets & Northwood Cabinets & None & $\begin{array}{l}\text { Particleboard and } \\
\text { flakeboard are low- } \\
\text { formaldehyde-emitting }\end{array}$ \\
\hline Closet and interior doors & $\begin{array}{l}\text { Jeld-Wen hollow and solid } \\
\text { core doors }\end{array}$ & CARB2 & $\begin{array}{l}\text { Primer applied at } \\
\text { factory }\end{array}$ \\
\hline \multicolumn{4}{|c|}{ Interior Paints and Finishes } \\
\hline Ceiling & $\begin{array}{l}\text { Sherwin-Williams Promar } 700 \\
\text { Primer Finish }\end{array}$ & Green Guard & \\
\hline Walls & $\begin{array}{l}\text { Sherwin-Williams Contractors } \\
\text { Interior Latex Satin, extra } \\
\text { white }\end{array}$ & Contains no VOCs & \\
\hline Trim and Millwork & $\begin{array}{l}\text { Sherwin-Williams Southwest } \\
\text { Builders Interior Latex Semi- } \\
\text { gloss }\end{array}$ & None & $\begin{array}{l}\text { Ethylene glycol } 1 \\
\text { wt } \% \text {; Glycol ethers } 2 \\
\text { wt } \%\end{array}$ \\
\hline Cabinet paint/finishes & $\begin{array}{l}\text { Northwood Cabinets mixes } \\
\text { colors in a water base for } \\
\text { cabinet finishes }\end{array}$ & None & $\begin{array}{l}\text { Water-based with } \\
\text { intention to be low } \\
\text { VOC emitting }\end{array}$ \\
\hline Wood floor finishes & Johnson Hardwood & CARB & \\
\hline
\end{tabular}


Table 4.9. (contd)

\begin{tabular}{llll} 
Material & Manufacturer and Brand & Certification(s), if any & Other Notes \\
\hline Carpets and Carpet Adhesives & & \\
Carpet & Shaw Philadelphia San Benito & Green Label Plus \\
Carpet Padding & Leggett \& Platt Ultra Magic & Green Label \\
Carpet Adhesive & None used & NA & \\
\hline
\end{tabular}

Prior to pre-occupancy sampling, the homeowners were allowed to store some of their existing furniture and boxes of linens and clothing in the house before they actually took possession of the home (see Figure 4.12, Figure 4.13, and Figure 4.14). All of the items were at least a year old, except for new car floor mats in the laundry room upstairs with other items. They also stored house cleaning products such as laundry soap, non-toxic oven cleaner, Windex, Lysol wipes, and dishwasher detergent in the new house. These were only stored before they moved in and were not used. Research technicians moved all of these products to the far side of the garage prior to pre-occupancy sampling. As previously discussed, prior to pre-occupancy measurements the house underwent a "final cleaning" using typical cleaning materials (see Section 2.1).

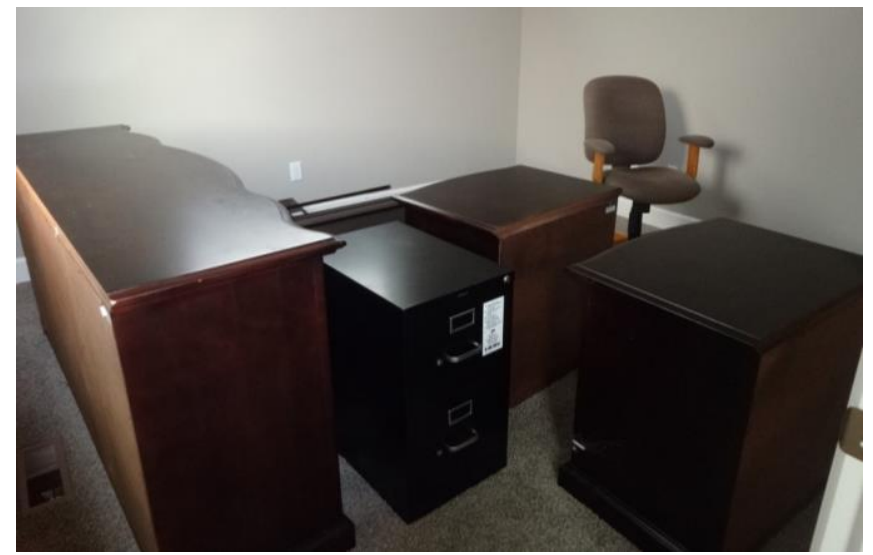

Figure 4.12. Older Furniture Stored in Downstairs Study

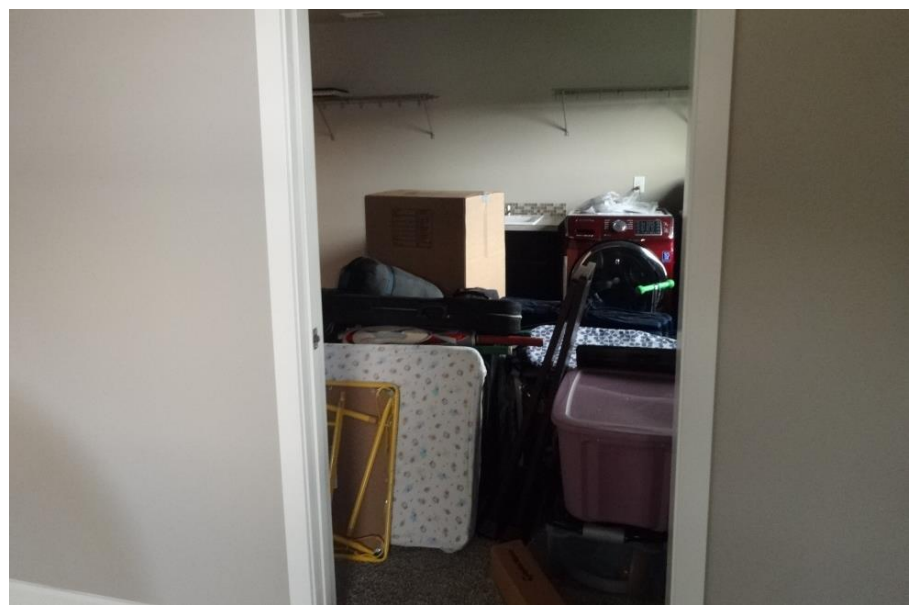

Figure 4.13. Older Personal Belongings Stored in Upstairs Laundry Room 


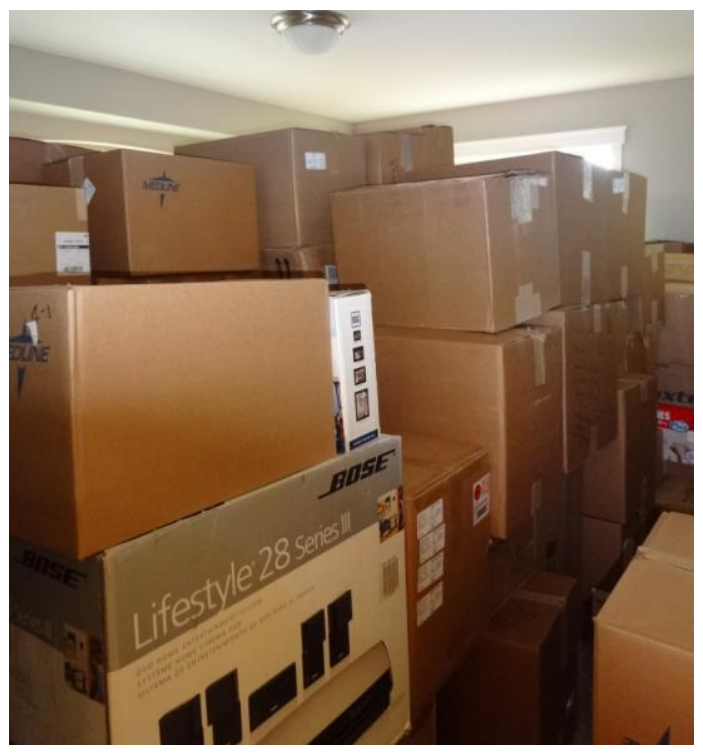

Figure 4.14. Boxes of Clothing and Linens Stored in Upstairs Bedroom

Although the homeowners were still unpacking the boxes stored in the upstairs bedroom, the house was very livable with their older and new furniture. On the main floor, new furniture (Figure 4.15) included two couches, a loveseat, and an ottoman all covered in leather; an area rug; fabric-covered dining room chairs; two couches and an ottoman; and a fabric-covered headboard and matching settee for the new bed in the guest bedroom (Figure 4.16). There were new composite wood cabinets in the garage, and the garage floor was coated with an epoxy in early August. Upstairs there was one new mattress and a new laminate-covered particleboard TV stand. All of the new furnishings were delivered on August $10^{\text {th }}$, more than 1 week prior to post-occupancy sampling.

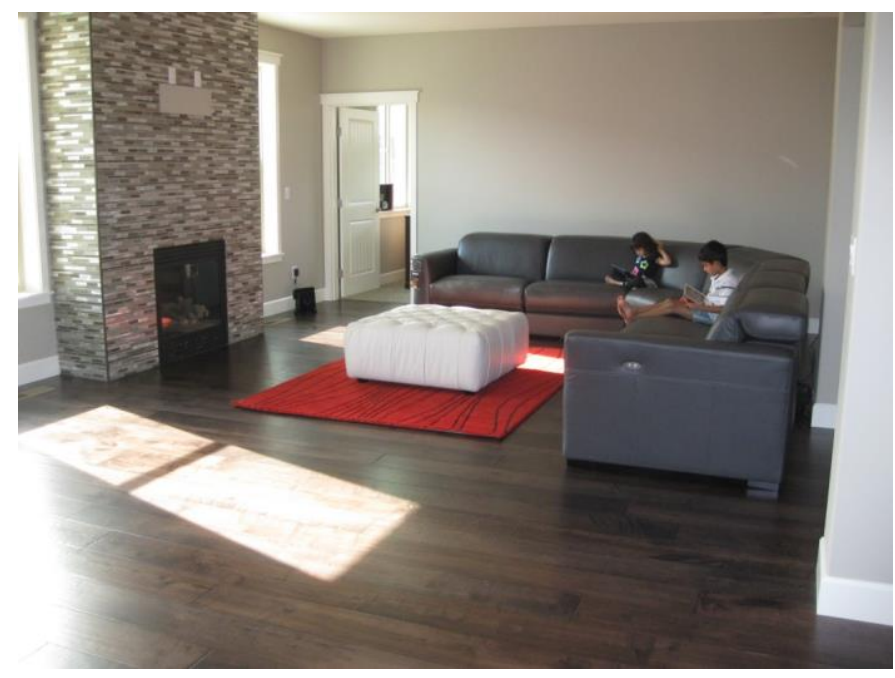

Figure 4.15. New Leather Couches, Ottoman and Area Rug in Living Room of IaP2 


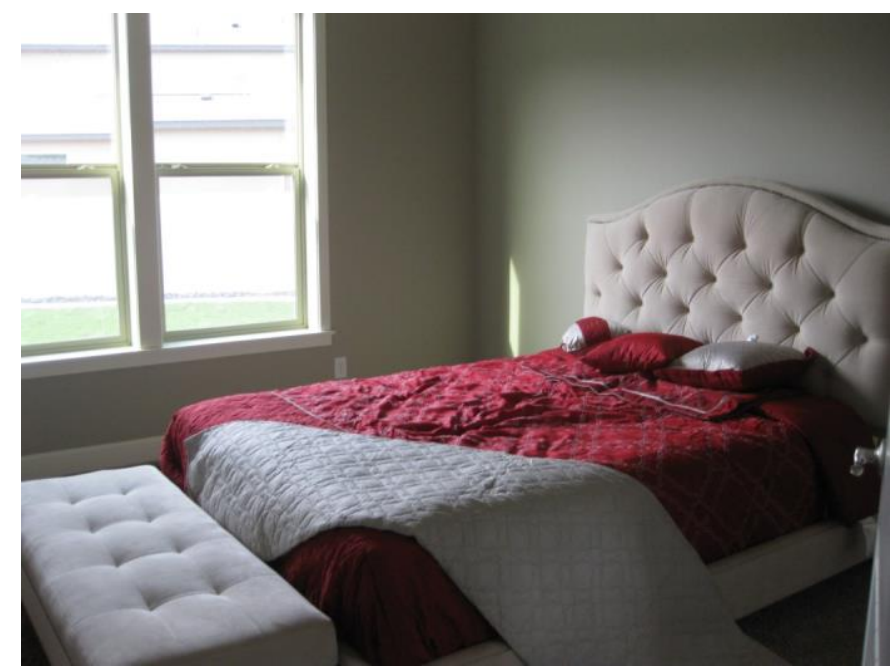

Figure 4.16. New Guest Room Furniture and Bedding

\subsubsection{Sampling Observations}

Pre-occupancy active sampling equipment was set up in the IaP2 home on August $2^{\text {nd }}, 2014$, and sampling occurred on August $3^{\text {rd }}, 2014$. Figure 4.17 depicts the locations of the emitters and samplers for both the pre-occupancy sampling.
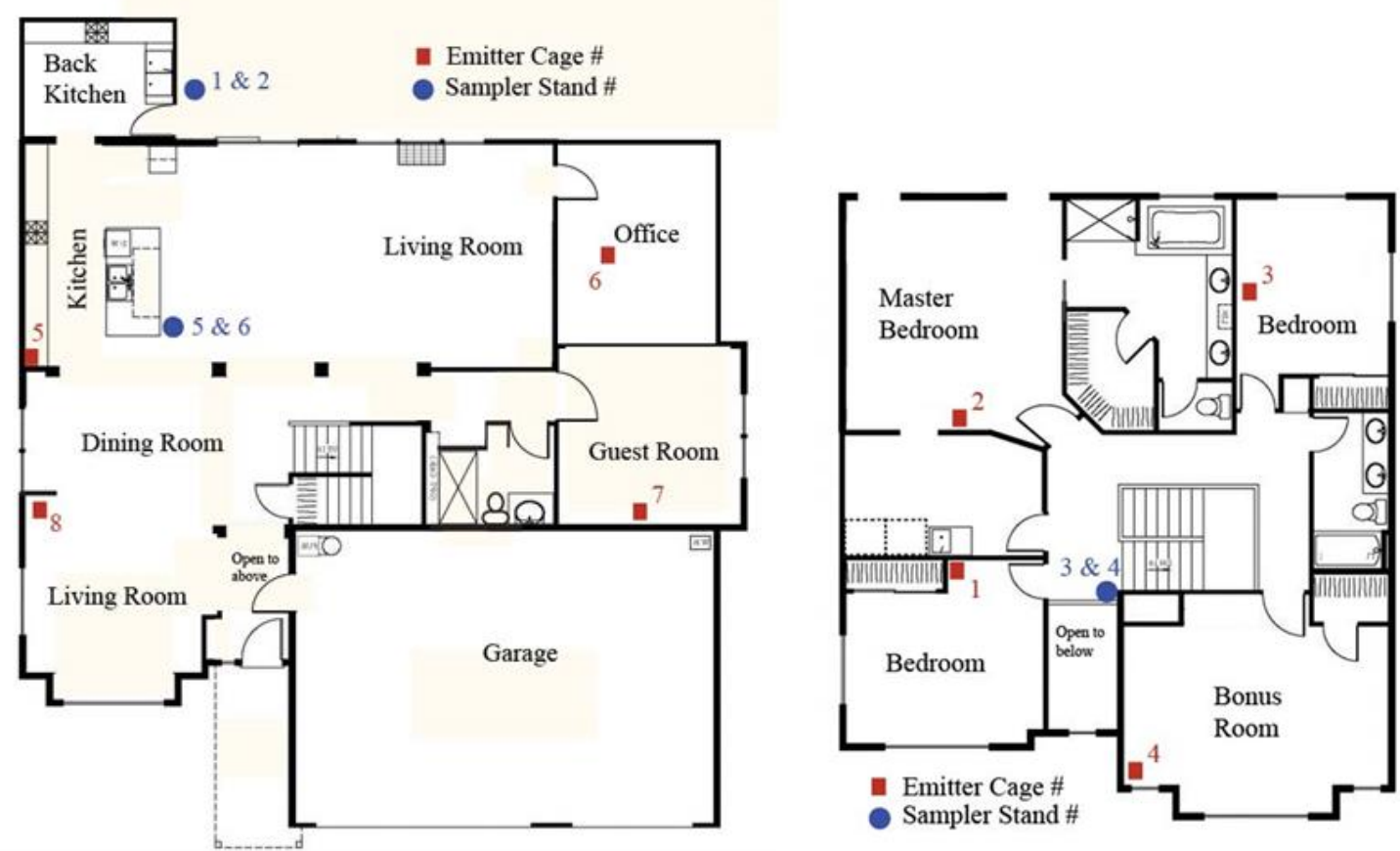

Figure 4.17. Location of Emitters and Active Samplers in the $1^{\text {st }}$ Floor of IaP2 (Zone 1 ; left) and $2^{\text {nd }}$ Floor of IaP2 (Zone 2; right) During Pre-Occupancy Sampling Period

During the week before the pre-occupancy sampling, the builder did some cabinetry repair, drywall and paint touch-ups, and the final cleaning. Active post-occupancy samplers and emitters were set up on August $21^{\text {st }}$ and retrieved on August $22^{\text {nd }}$, according to the locations noted in Figure 4.18. The 
homeowner was sealing the grout in the floor and wall tiles in the bathrooms on August $21^{\text {st }}$ and several days prior to that. The product used contains Teflon among other things.
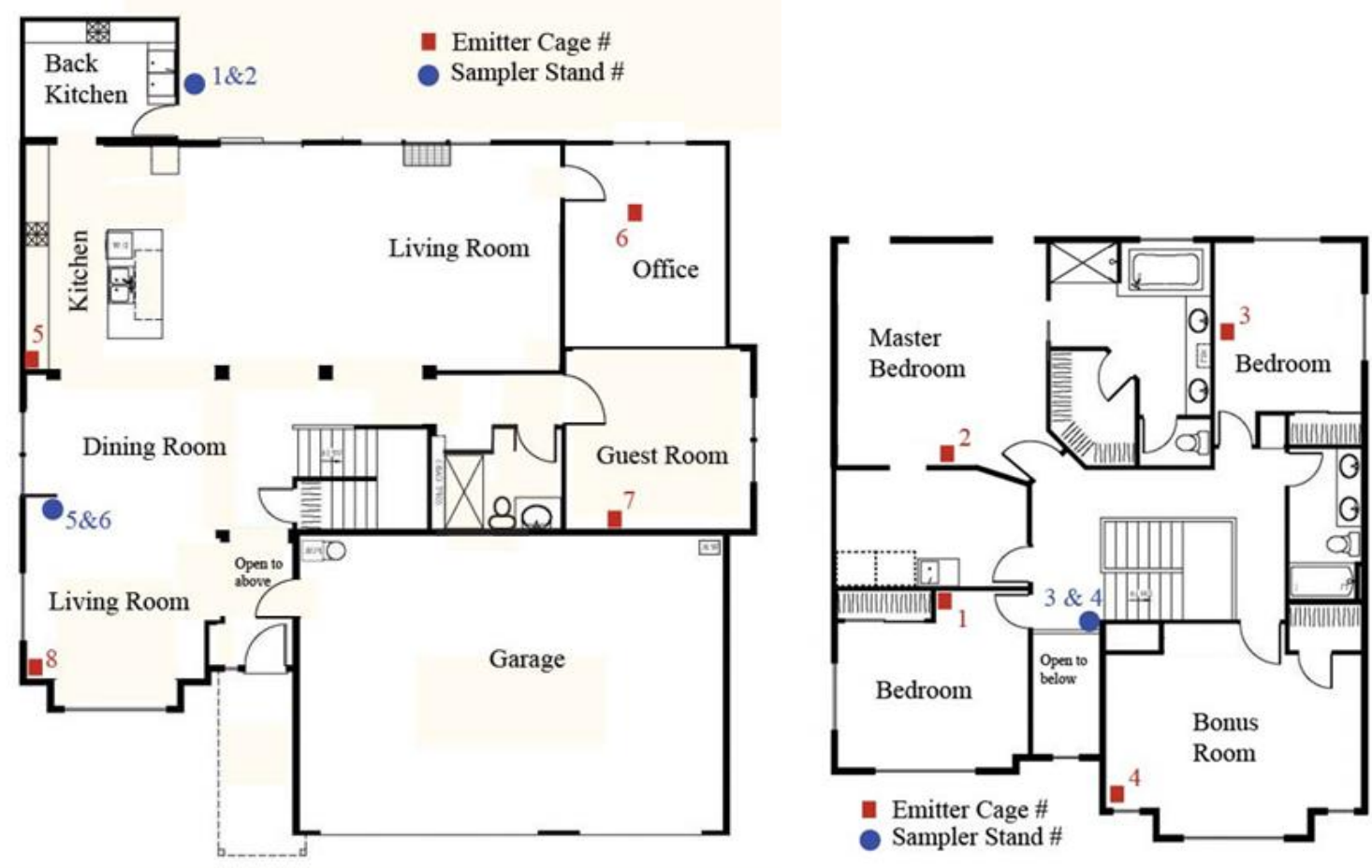

Figure 4.18. Location of Emitters and Active Samplers on the $1^{\text {st }}$ Floor of IaP2 (Zone 1 ; left) and $2^{\text {nd }}$ Floor of IaP2 (Zone 2; right) During Post-Occupancy Sampling Period.

Much of the home cooking is done in the back kitchen, which has a pocket door between it and the main kitchen. The natural gas stove in the back kitchen has a hood. The homeowner has a plug-in air freshener in place in the back kitchen. A large meal using lots of herbs and spices was prepared the evening of August $21^{\text {st }}$. The homeowner said she closed the door between the kitchens and had the window and door to the porch open for the 2-3 hours while she prepared this dish to keep the odors out of the rest of the house. When staff returned on August $22^{\text {nd }}$ to retrieve the emitters and samplers, the windows were open because the homeowner thought the house smelled of the herbs and spices. No odor was detectable to PNNL staff, although the windows had only been open for 15-20 minutes. The windows were not opened during either of the 60-minute sampling periods. 


\subsection{Measurements at Pilot Homes: Results and Discussion}

This section presents data and analysis from pre- and post-occupancy sampling events at the three homes described in the previous section. In the first two homes- $\mathrm{C} 1$ and $\mathrm{IaP} 1$ - the post-occupancy data include both active samples collected under participant-agreed-upon conditions and at times that should have limited contributions from activity-based sources, and passive sampling over a weeklong period of typical activities.

Unfortunately, the limited data set produced from the measurements reported here is not extensive enough to robustly answer the questions that the study was designed to answer. The sample of only one conventional and two IaP homes is obviously too small to enable assessment of the variation within each category of home. The lack of an extended temporal series at each home also limits the interpretation of pre- versus post-occupancy data. And the comparison across homes of pre-occupancy data appears to have been strongly impacted in at least one home by too short of an interval between active construction work and the pre-occupancy sampling. Other challenges included a malfunctioning air conditioner just prior to the pre-occupancy sampling at IaP1 and some loss of samples due to pump timer failures during several monitoring events.

Nevertheless, results from these three homes provide some possible insights into answer to the study questions. And the many challenges encountered offer important lessons that should be considered when attempting to advance any future study focused on these questions.

The following sections provide details on environmental conditions in the homes followed by a description of the measured dilution rates. Next, the concentrations of the target pollutants are presented and compared and finally the area normalized emission rates are presented and compared.

\subsection{Environmental Conditions during Monitoring Events}

The environmental conditions during monitoring events were recorded with T/RH loggers deployed along with each PFT emitter cage (six to eight per home); the results provide information on both spatial and temporal $\mathrm{T}$ and RH distributions in each home. The location of each T/RH logger in each home is indicated in Table 5.1. The logger locations were extremely similar pre- and post-occupancy. These locations can also be observed in the corresponding floor plan figures for each home depicting the location of the emitter cages, among other sampling apparatuses, presented in Section 4.0.

Table 5.1. Location of T/RH Loggers in Each House and Associated Emitter Cage (in parentheses)

\begin{tabular}{|c|c|c|c|}
\hline Hobo & Location in $\mathrm{C1}$ & Location in IaP1 & Location IaP2 \\
\hline H1 & Downstairs bedroom 1 (EC1) & Laundry room (EC1) & Upstairs bedroom 1 (EC1) \\
\hline $\mathrm{H} 2$ & Downstairs bedroom 2 (EC2) & Living room (EC2) & $\begin{array}{l}\text { Upstairs master bedroom } \\
\text { (EC2) }\end{array}$ \\
\hline $\mathrm{H} 3$ & $\begin{array}{l}\text { Downstairs entertainment room } \\
\text { (EC3) }\end{array}$ & SE bedroom (EC3) & Upstairs bedroom 2 (EC3) \\
\hline $\mathrm{H} 4$ & Downstairs great room (EC4) & SW bedroom (EC4) & Upstairs bonus room (EC4) \\
\hline H5 & Upstairs master bedroom (EC5) & Master bathroom (EC5) & Downstairs kitchen (EC5) \\
\hline
\end{tabular}


Table 5.1. (contd)

\begin{tabular}{llll}
\hline Hobo & Location in C1 & Location in IaP1 & Location IaP2 \\
\hline H6 & Upstairs mudroom (EC6) & Kitchen (EC6) & Downstairs office (EC6) \\
H7 & Upstairs office (EC7) & Not deployed & $\begin{array}{l}\text { Downstairs guest room } \\
\text { (EC7) }\end{array}$ \\
H8 & Upstairs living room (EC8) & Not deployed & $\begin{array}{l}\text { Downstairs living room } \\
\text { (EC8) }\end{array}$ \\
\hline
\end{tabular}

Because the emission rates of VOCs, including PFTs, are temperature dependent, it is important to observe environmental conditions during sampling periods and ensure they are as consistent as possible to allow for better comparability of sampled VOC concentrations. If significant deviations occur, it is sometimes possible to account for these when processing the data.

The relevant time period over which changes in environmental conditions will influence observed concentrations in a space is not precisely known. The preceding 4-12 hours are expected to be particularly relevant based on the expectation that these homes were operating on mechanical ventilation set to ensure at least a minimum air exchange rate and such a time period would capture the impact of ventilation air prior to the sampling period. The average $\mathrm{T}$ and $\mathrm{RH}$, and their variability during that period, were determined for the period of 4 and 12 hours prior to and including each sampling event, as presented in Table 5.2.

Since all the observed $\mathrm{T}$ and $\mathrm{RH}$ conditions in each of the homes were fairly consistent during each sampling period and among sampling periods, no further temperature corrections in the results were needed. The overall coefficient of variation across all homes and sampling periods for temperature was $5.6 \%$ and $14.6 \%$ for the 4 and 12 hour averaging periods, respectively. The overall coefficient of variation across all homes and sampling periods for RH was $23 \%$ and 33\%, for the 4 and 12 hour average periods, respectively. The average $\mathrm{T}$ and $\mathrm{RH}$ observed over the 4 and 12-hour sampling periods in each house are presented in Table 5.2, along with the standard deviation among the T/RH loggers over those time frames.

Although the average $\mathrm{T}$ and $\mathrm{RH}$ were fairly consistent among homes and sampling periods, some temporal and spatial variation was observed for some emitters. Figure 5.1 through Figure 5.12 depict the temperature and relative humidity of each T/RH logger for the same periods used to create the average temperatures (i.e., beginning 12 hours prior to the first sampling event and extending until the end of the second active sampling event).

In $\mathrm{C}$, temperatures were relatively constant for the pre-occupancy sampling period. However, slightly elevated RH was observed on the lower level, compared to the upper level, for the duration of the pre-occupancy sampling period, as shown in Figure 5.1 and Figure 5.2, respectively. 
Table 5.2. Summary of 4-Hour and 12-Hour Integrated Average Temperature and Relative Humidity Observed Prior to and During Each Active Sample in Each Home and Associated Variability

\begin{tabular}{|c|c|c|c|c|c|c|c|c|c|c|c|c|c|}
\hline \multirow{3}{*}{$\begin{array}{l}\text { Sample } \\
\text { Period }\end{array}$} & & \multicolumn{4}{|c|}{ C1 } & \multicolumn{4}{|c|}{ IaP1 } & \multicolumn{4}{|c|}{ IaP2 } \\
\hline & & \multicolumn{2}{|c|}{ 4hr Prior } & \multicolumn{2}{|c|}{ 12hr Prior } & \multicolumn{2}{|c|}{ 4hr Prior } & \multicolumn{2}{|c|}{ 12hr Prior } & \multicolumn{2}{|c|}{ 4hr Prior } & \multicolumn{2}{|c|}{ 12hr Prior } \\
\hline & & $\begin{array}{c}\text { Temp } \\
\left({ }^{\circ} \mathbf{F}\right)\end{array}$ & $\begin{array}{l}\text { RH } \\
(\%)\end{array}$ & $\begin{array}{c}\text { Temp } \\
\left({ }^{\circ} \mathbf{F}\right)\end{array}$ & $\begin{array}{l}\text { RH } \\
(\%)\end{array}$ & $\begin{array}{c}\text { Temp } \\
\left({ }^{\circ} \mathbf{F}\right)\end{array}$ & $\begin{array}{l}\text { RH } \\
(\%)\end{array}$ & $\begin{array}{c}\text { Temp } \\
\left({ }^{\circ} \mathbf{F}\right)\end{array}$ & $\begin{array}{l}\text { RH } \\
(\%)\end{array}$ & $\begin{array}{c}\text { Temp } \\
\left({ }^{\circ} \mathbf{F}\right)\end{array}$ & $\begin{array}{l}\text { RH } \\
(\%)\end{array}$ & $\begin{array}{c}\text { Temp } \\
\left({ }^{\circ} \mathbf{F}\right)\end{array}$ & $\begin{array}{c}\text { RH } \\
(\%)\end{array}$ \\
\hline \multirow[t]{2}{*}{ Pre-Occupancy 4 AM } & Avg & 68.17 & 35.57 & 68.37 & 33.32 & 69.81 & 35.28 & 70.74 & 35.50 & 70.95 & 47.41 & 70.53 & 43.85 \\
\hline & StDev & 2.63 & 6.21 & 2.21 & 6.62 & 0.79 & 2.14 & 0.95 & 3.49 & 1.30 & 2.58 & 1.45 & 2.50 \\
\hline \multirow[t]{2}{*}{ Pre-Occupancy 11 AM } & Avg & 68.14 & 36.82 & 68.15 & 36.10 & 69.73 & 34.71 & 69.68 & 34.97 & 71.58 & 46.17 & 71.26 & 46.77 \\
\hline & StDev & 2.77 & 5.87 & 2.70 & 6.05 & 0.86 & 2.03 & 0.54 & 1.87 & 1.14 & 2.52 & 1.18 & 2.52 \\
\hline \multirow[t]{2}{*}{ Post-Occupancy 4 AM } & Avg & 72.96 & 42.76 & 76.09 & 39.03 & 76.49 & 41.94 & 78.33 & 32.87 & 66.24 & 49.85 & 68.85 & 49.31 \\
\hline & StDev & 3.00 & 8.92 & 3.06 & 6.96 & 0.87 & 2.59 & 1.23 & 14.76 & 3.15 & 8.24 & 2.05 & 5.73 \\
\hline \multirow[t]{2}{*}{ Post-Occupancy 11 AM } & Avg & 71.76 & 44.51 & 72.37 & 43.43 & 75.32 & 44.57 & 76.07 & 43.59 & 69.55 & 50.50 & 67.98 & 50.73 \\
\hline & StDev & 1.90 & 6.85 & 2.44 & 8.02 & 0.96 & 2.49 & 0.80 & 2.55 & 1.09 & 7.66 & 1.78 & 7.48 \\
\hline
\end{tabular}




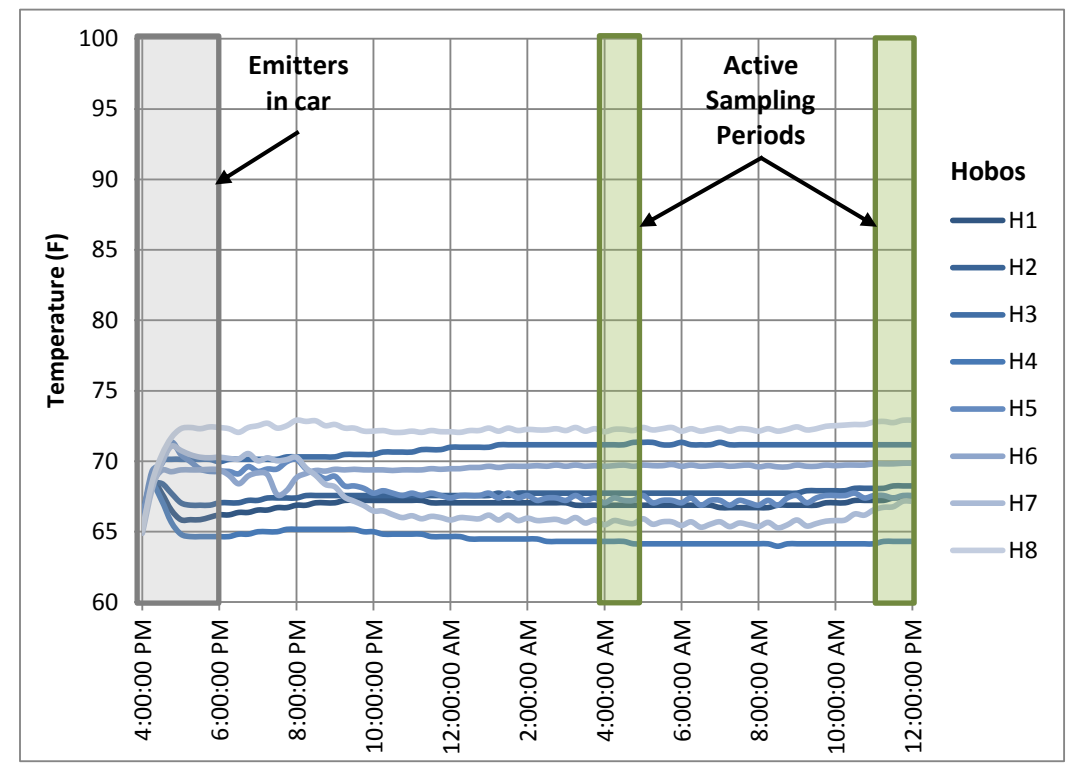

Figure 5.1. Interior Ambient Temperatures Measured During the Pre-Occupancy Active Sampling Period in $\mathrm{C} 1$

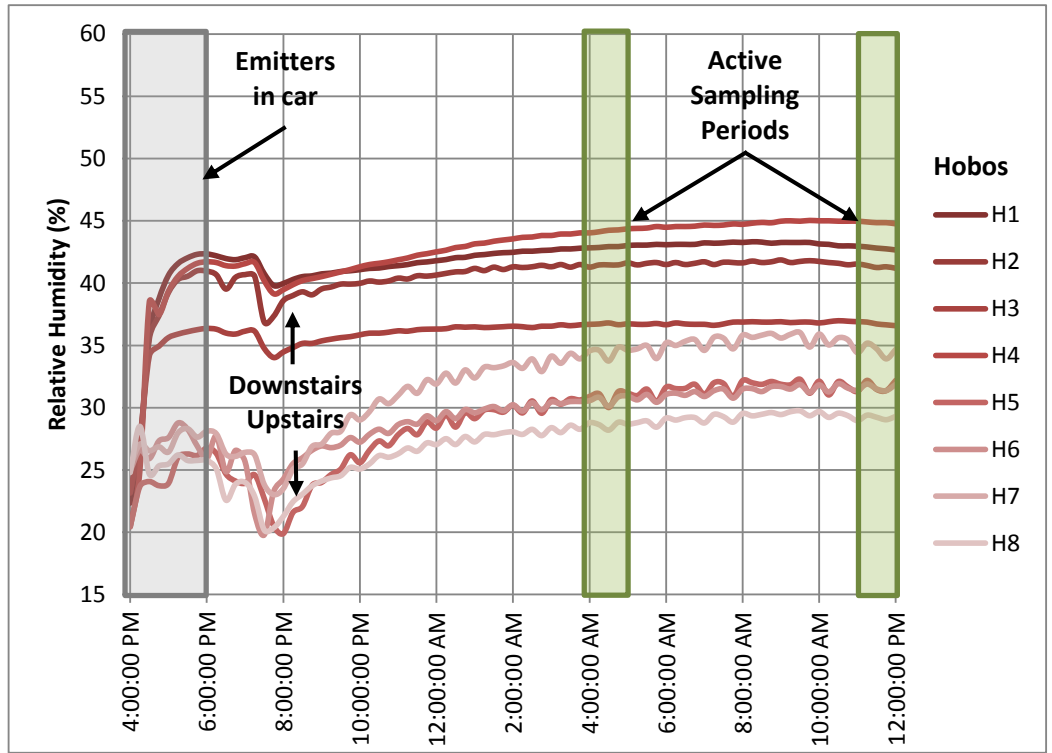

Figure 5.2. Interior Relative Humidity Measured During the Pre-Occupancy Active Sampling Period in C1

Post-occupancy, however, the emitters in $\mathrm{C} 1$ were transported and stored for a brief period in a car prior to deployment. The emitters got very hot due to the hot outdoor air temperatures in the summer afternoon, which can be seen in Figure 5.3. Temperatures measured by the T/RH loggers stabilized within an hour for the downstairs loggers. However, upstairs loggers were further impacted by the warm interior temperatures resulting from a malfunctioning HVAC system on the upper level. As a result, the $\mathrm{T} / \mathrm{RH}$ loggers show temperatures gradually decreasing back to the set point temperature of $70^{\circ} \mathrm{F}$ over the course of the 20-hour sampling event. The RH in C1 post-occupancy demonstrated the same bifrication 
by floor observed during the pre-occupancy sampling period and also did not appear to be significantly impacted by the HVAC system malfunctioning, as shown in Figure 5.4.

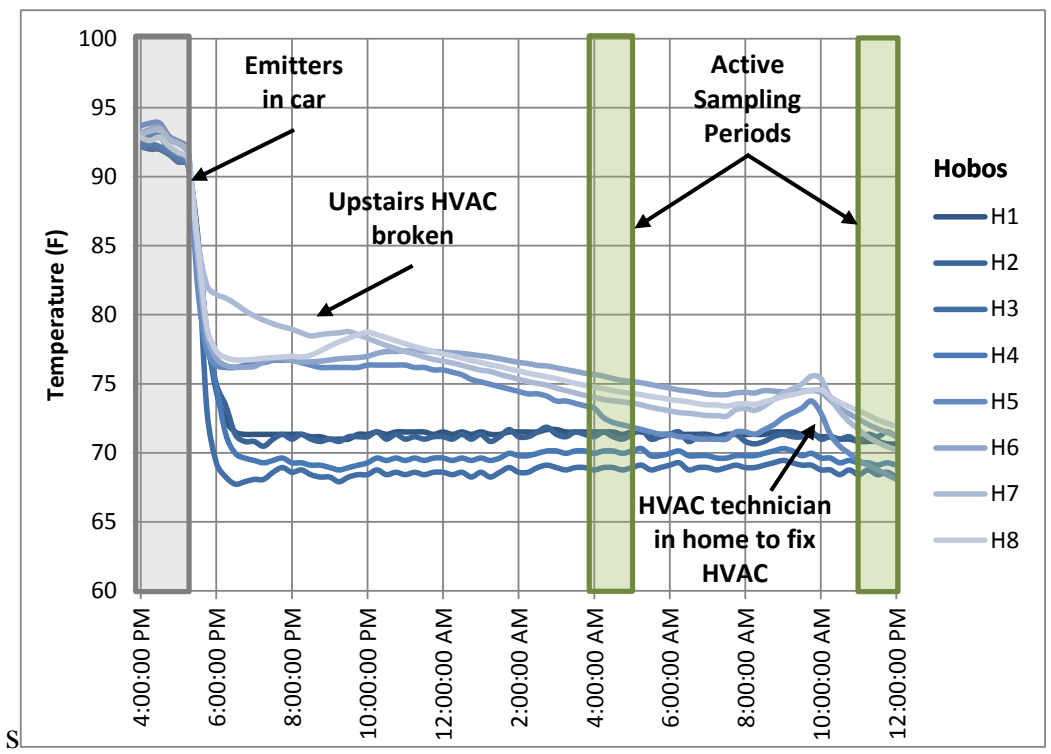

Figure 5.3. Interior Temperature Measured During the Post-Occupancy Active Sampling Period in C1

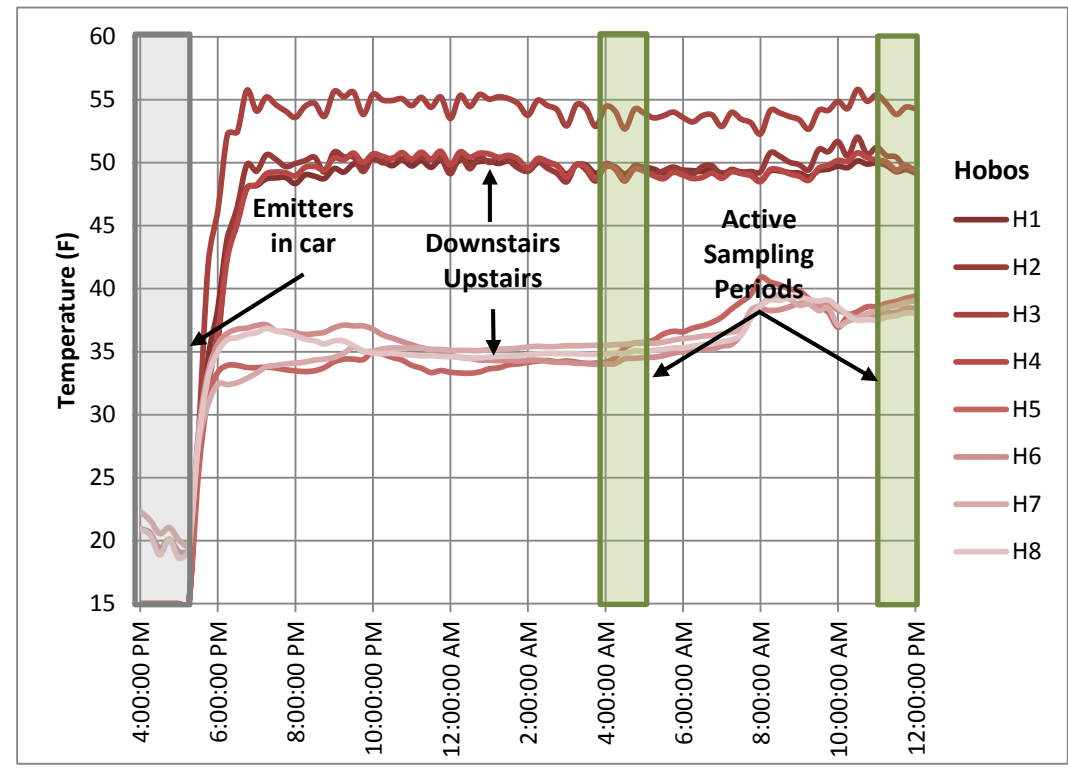

Figure 5.4. Interior Relative Humidity Measured During the Post-Occupancy Active Sampling Period in C1

In IaP1, while the T/RH loggers were deployed in the homes, the temperature was maintained within $3-4^{\circ} \mathrm{F}$ of the thermostat set point $\left(70^{\circ} \mathrm{F}\right)$ and relative humidity was similarly consistent throughout the sample period, as shown in Figure 5.5 and Figure 5.6. The emitters were also transported and stored in the car prior to deployment, however the emitters were moved into the home earlier that for $\mathrm{C} 1$ and the temperature deviation was not as extreme, except for H3. It is not clear why H3 experienced such a significant temperature spike, where the other T/RH loggers were maintained between 70 and $75^{\circ} \mathrm{F}$ during the same period. 


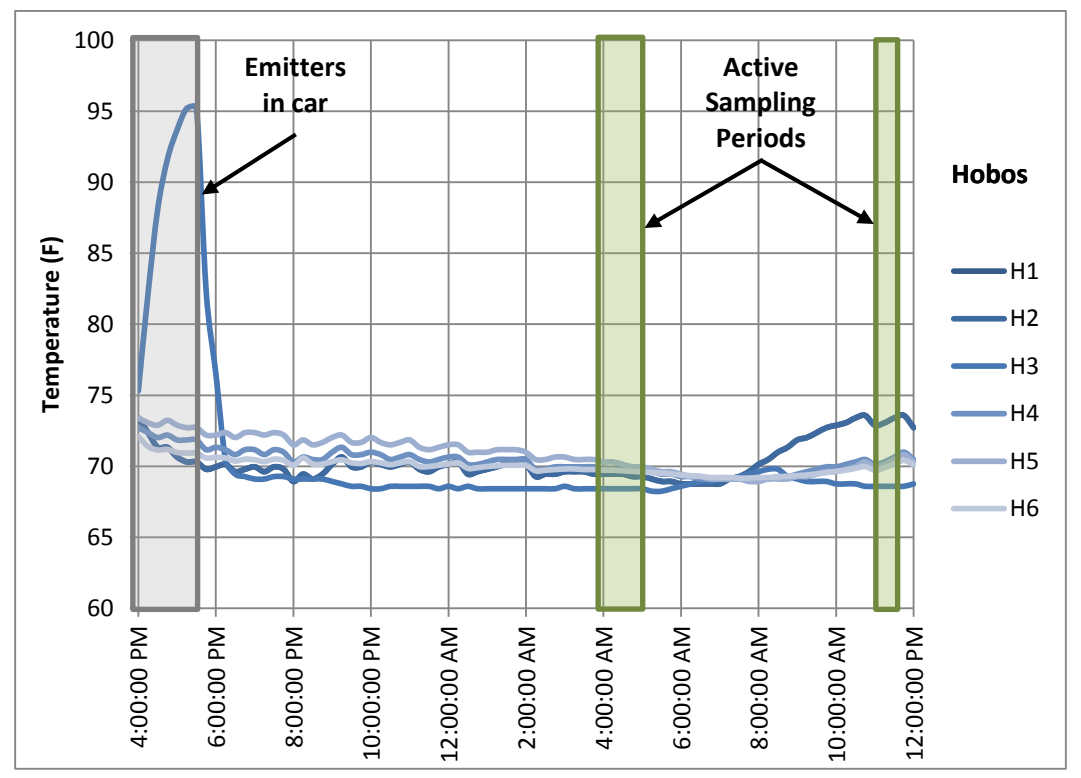

Figure 5.5. Interior Temperature Measured During the Pre-Occupancy Active Sampling Period in IaP1

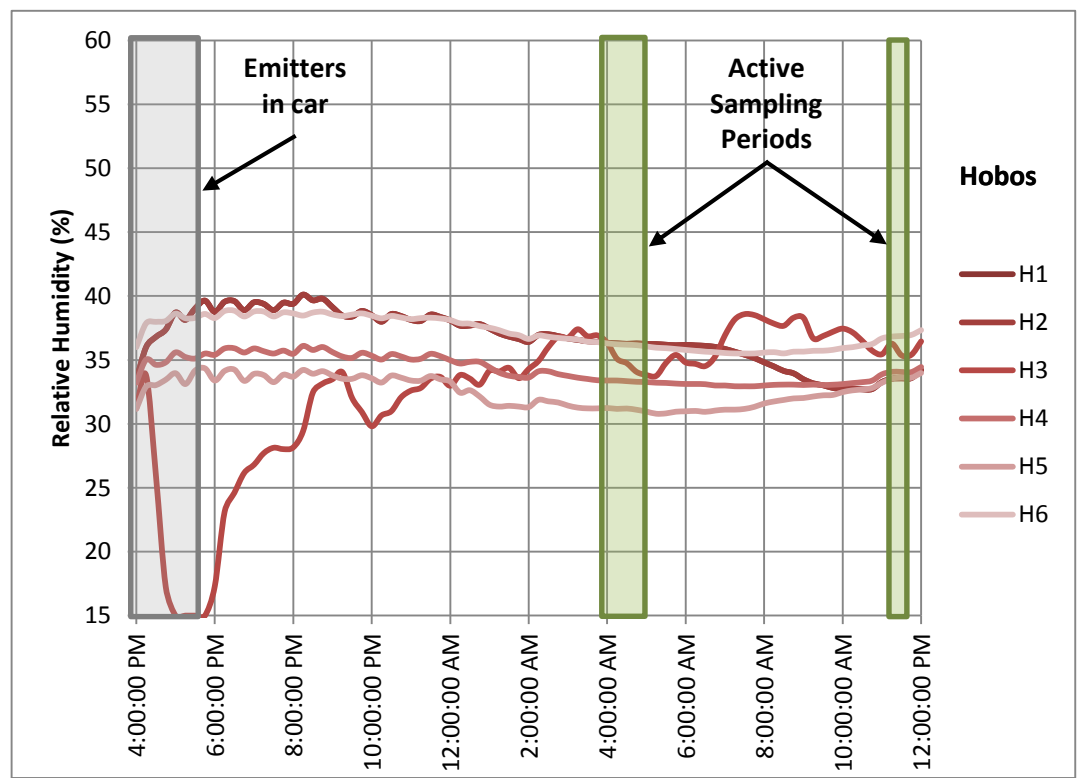

Figure 5.6. Interior Relative Humidity Measured During the Pre-Occupancy Active Sampling Period in IaP1

During the post-occupancy active sampling period in IaP1, the emitters and samplers were all fully deployed by 4:00 pm the afternoon prior to the active sampling periods (i.e., 12 hours prior to the first active sampling event). As such, transportation and storage time frames are not shown in Figure 5.7 and Figure 5.8 and the interior $\mathrm{T}$ and $\mathrm{RH}$ were maintained relatively consistently throughout the 18-hour sample period, with the exception of the laundry room, which was observed to be approximately $5^{\circ} \mathrm{F}$ cooler than the other rooms throughout the active sample period. This is probably due to the fact that the laundry room in the closest to the air handler and, thus, has the shortest supply duct and most cool air delivered to it. In addition, it does not have any windows and is located near the center of the house (it 
opened to the garage), which would limit heat load from solar insolation and infiltration. It is also possible that the homeowner closed the door to the laundry room, further isolating and cooling the room.

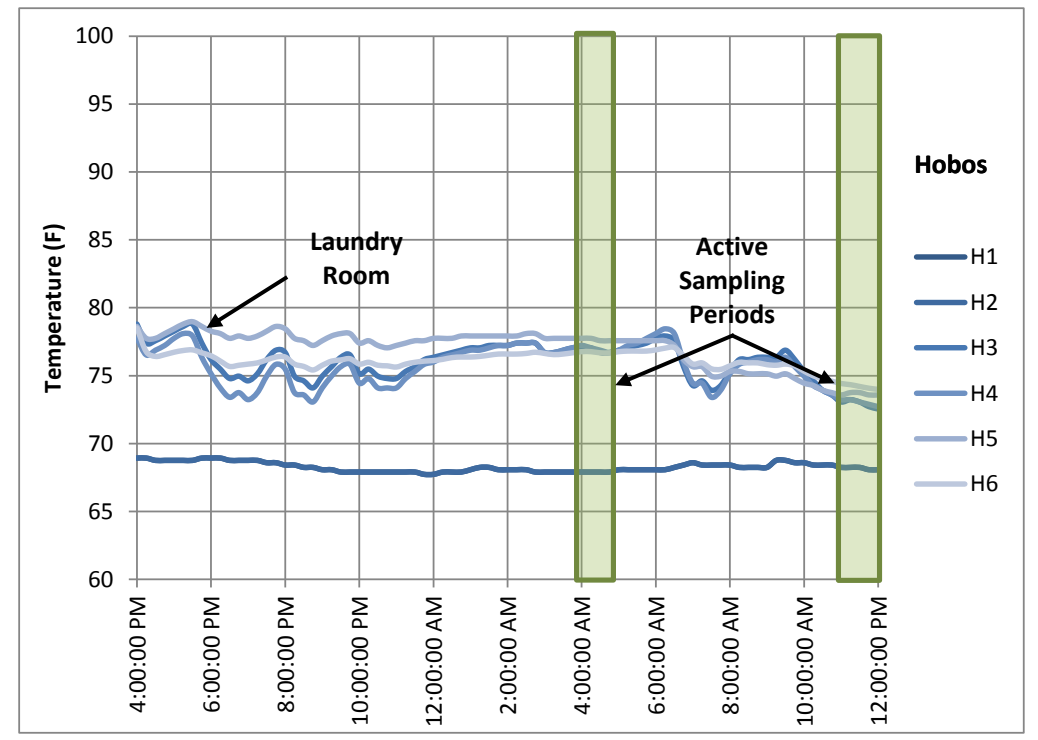

Figure 5.7. Interior Temperature Measured During the Post-Occupancy Active Sampling Period in IaP1

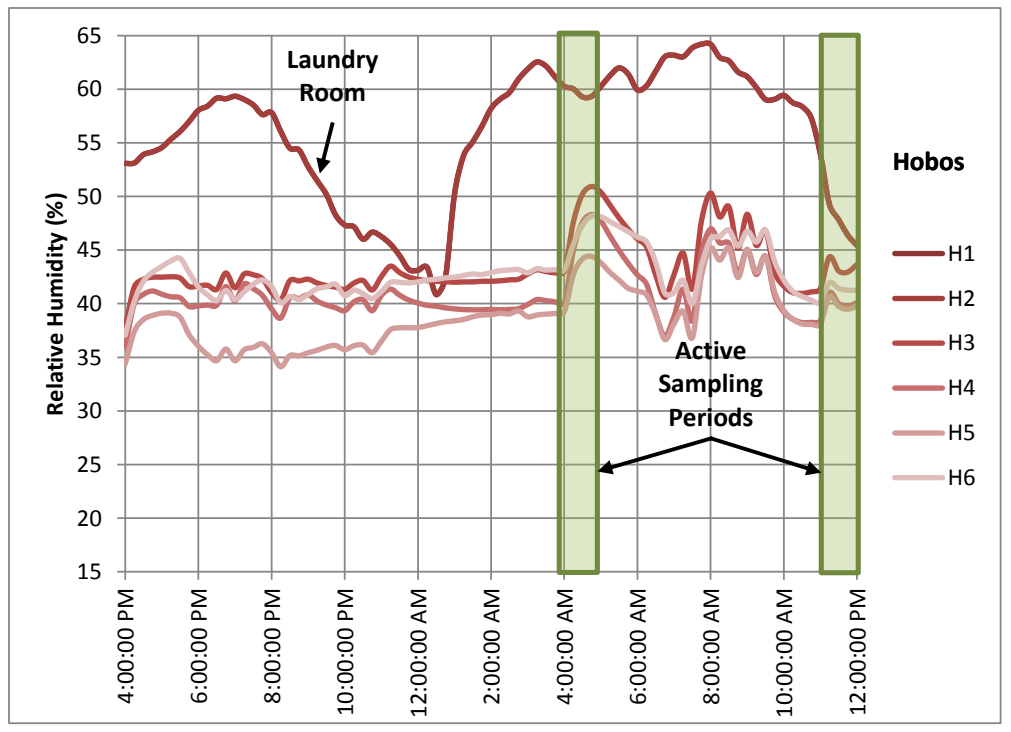

Figure 5.8. Interior Relative Humidity Measured During the Post-Occupancy Active Sampling Period in $\mathrm{IaP} 1$

During pre-occupancy in IaP2, temperature and relative humidity were very consistent throughout the active sampling period, with the exception of the portion of time when the emitters were stored in a hot car during transportation to the field site and prior to deployment, as shown in Figure 5.9 and Figure 5.10. 


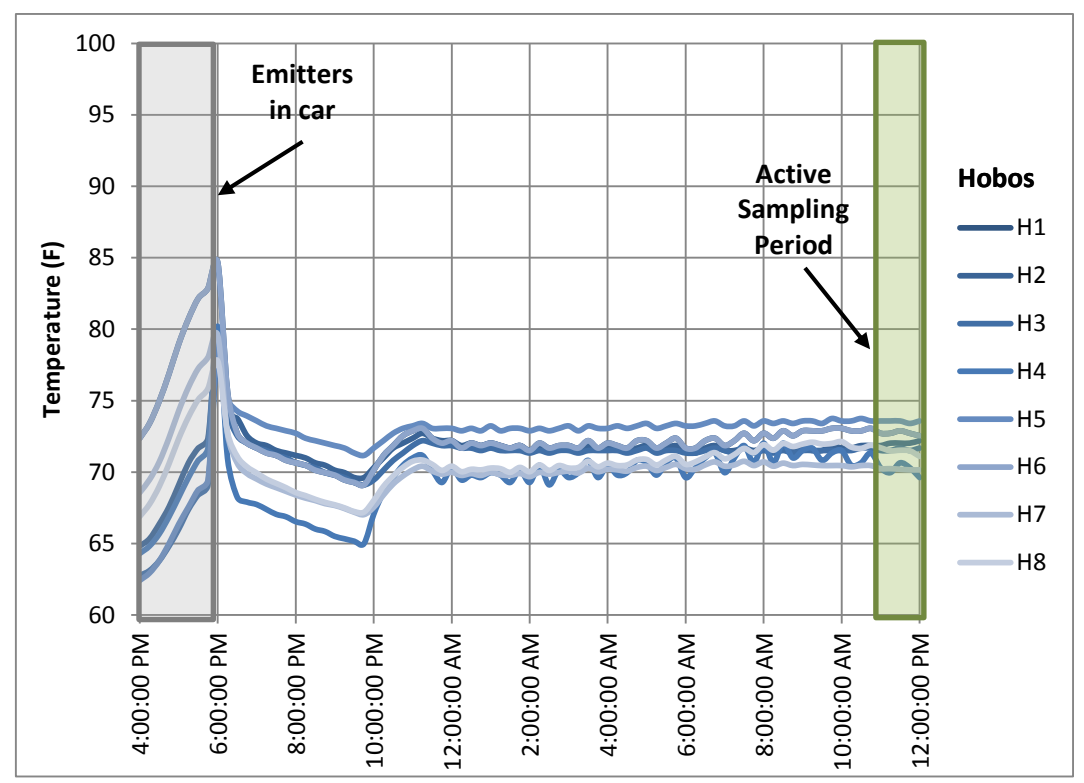

Figure 5.9. Interior Temperature Measured During the Pre-Occupancy Active Sampling Period in IaP2

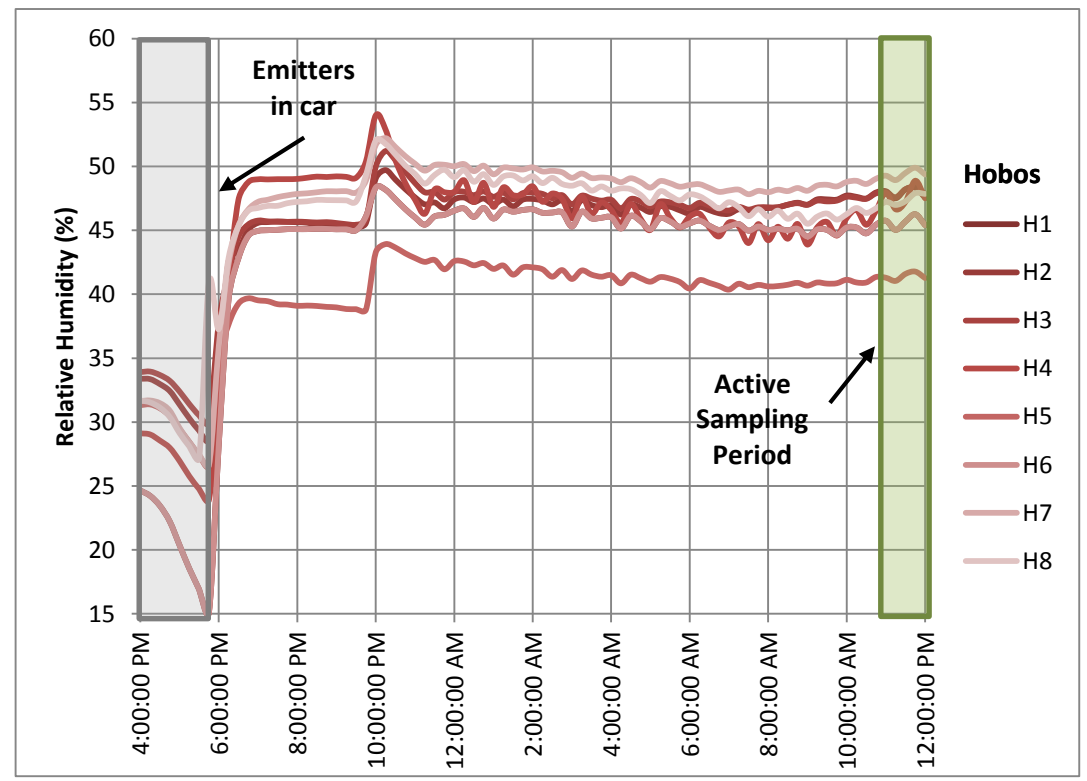

Figure 5.10. Interior Relative Humidity Measured During the Pre-Occupancy Active Sampling Period in $\mathrm{IaP} 2$

After observing the sometimes dramatic impact of the hot temperatures experienced during transportation and storage of the emitter cages and related T/RH loggers prior to sampling events, the research team began storing the emitter cages in a cooler with blue ice in the car prior to deployment. The effect of this improvement to the sampling protocol is observed in Figure 5.11 and Figure 5.12, where the $\mathrm{T}$ and $\mathrm{RH}$ are kept closer to the anticipated sampling temperature during transportation and storage. During post-occupancy sampling, the master bedroom exhibited slightly elevated RH, which could be due to occupancy or occupant-related activities in the master bedroom, such as showering. The home also appeared to exhibit a setback during the evening, which could increase RH related to the decreasing interior temperature and decreased moisture capacity of cooler air. 


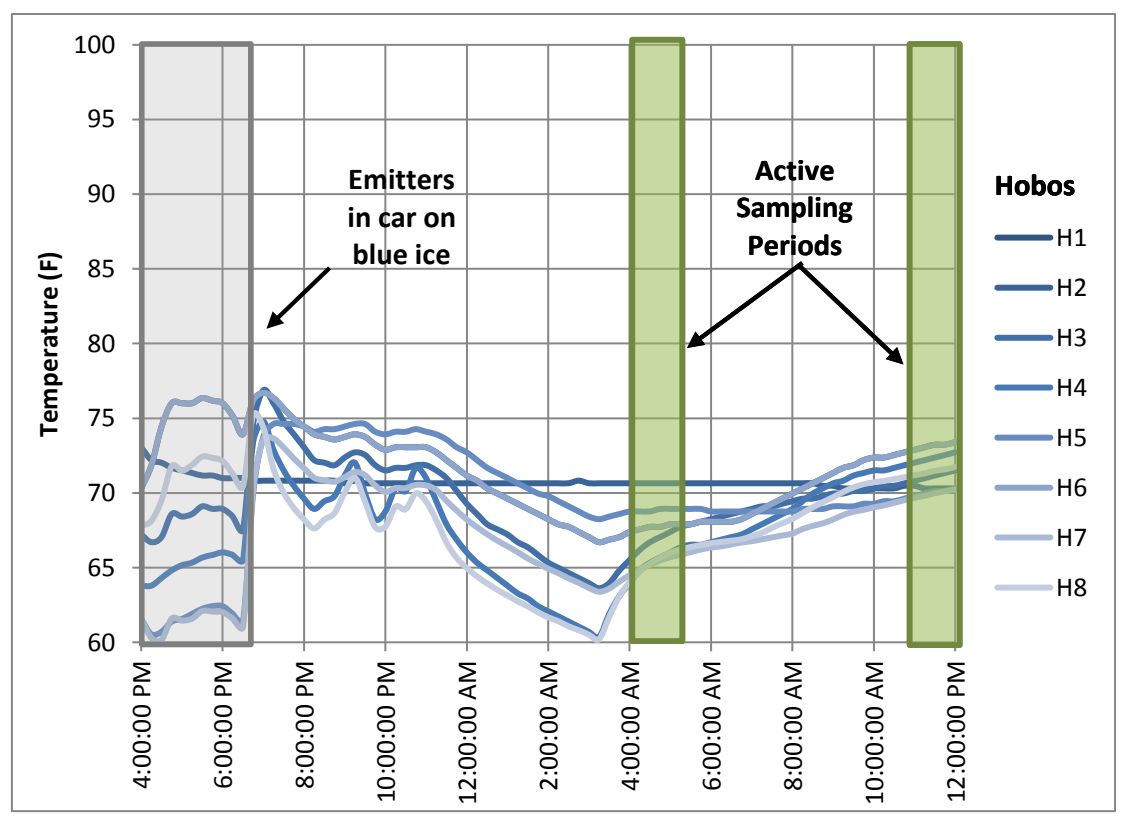

Figure 5.11. Interior Temperature Measured During the Post-Occupancy Active Sampling Period in IaP2

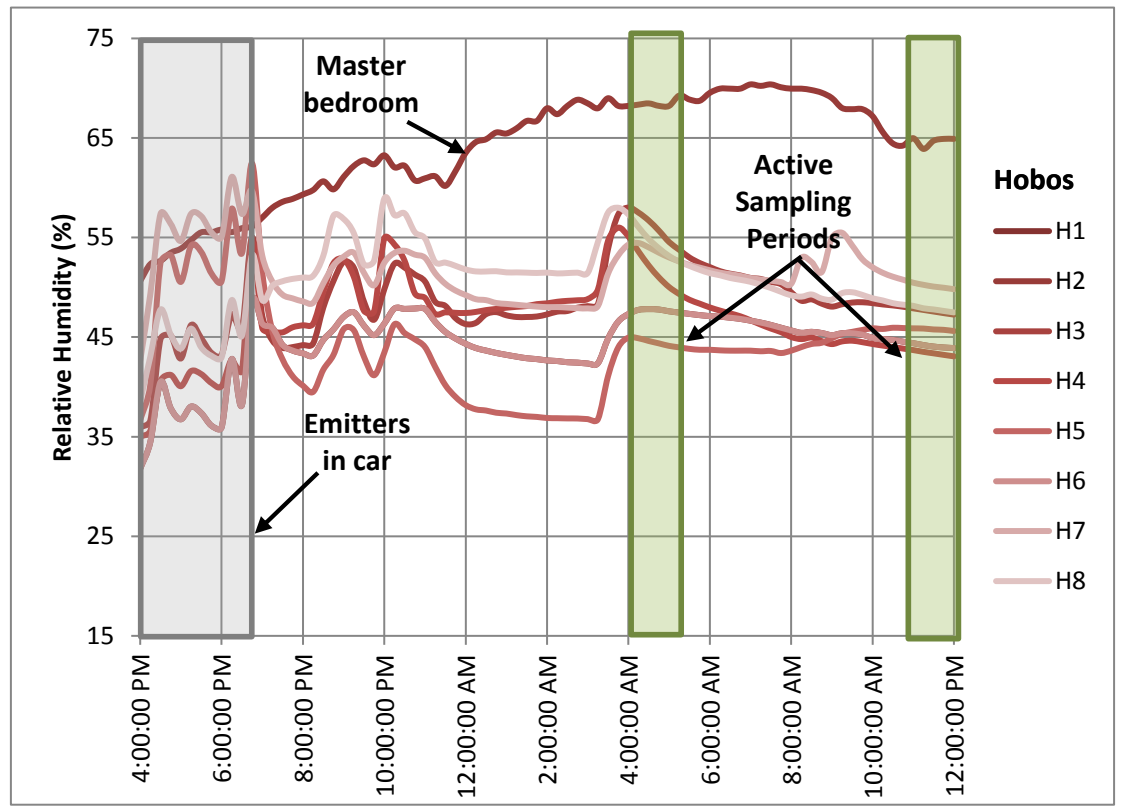

Figure 5.12. Interior Relative Humidity Measured During the Post-Occupancy Active Sampling Period in IaP2

\subsection{Ventilation Dilution Rates}

Ventilation (outdoor air) dilution rates were determined for a PFT sources dispersed throughout each story in each home (assuming each story can be approximated as a well-mixed zone) and dispersed throughout the entirety of each home. Dilution was determined for central sampling locations in each zone. The determined values represent the rate at which a dispersed source, such as a specific VOC emitted from building materials, would be diluted with outdoor air (due to a combination of mechanical 
ventilation and natural air infiltration) prior to reaching a sampler. The dilution rate has units of $\mathrm{m}^{3} / \mathrm{hr}$ and is calculated as the source emission rate of a given constituent, in $\mu \mathrm{g} / \mathrm{hr}$, divided by the observed concentration of that constituent, in $\mu \mathrm{g} / \mathrm{m}^{3}$.

In the pilot study, a dilution rate was calculated for each sampled home based on the calculated emission rate of PFT gas in each zone (see Section 5.2.1) and measured PFT concentrations in that zone and adjacent zones (see Section 5.2.2). The zonal analysis, in homes with multiple floors, provides information on any significant directionality to the airflow pattern (e.g., first floor to second floor) that would affect interpretation of the measured VOC results.

Based on this calculated emission rate for each house and the concentration of IAQ contaminants measured in this study (i.e., volatile carbonyls and other VOCs), an emission rate for each contaminant or for groups of contaminants can be calculated using a similar relationship. That is, the calculated wholehouse dilution rate for each house can be multiplied by the measured contaminant concentration to determine an emission rate for that contaminant (See Section 5.4).

\subsubsection{PFT Emitters and Emission Rates}

The PFT mass release from each emitter vial was determined for each deployment and used to estimate the average emission rate of tracer gas over the sampling event. The resulting emission rates for each deployment period in each home are summarized in Table 5.3. During the post-occupancy sampling event, the emitters were left in place for both the active and passive deployments so there is only one set of emission rates post-occupancy. The emission rates were similar during the pre- and post-occupancy sampling events, as shown by the absolute percent difference in Table 5.3. The average difference was less than $12 \%$ overall, while the whole-house values all differed by less than $10 \%$.

Table 5.3. Emission Rates of Emitters Deployed in Each Zone of the Three Sampled Homes

\begin{tabular}{|c|c|c|c|c|c|}
\hline House & PFT & Location & $\begin{array}{c}\text { Pre-Occupancy } \\
\text { Rate (mg/hr) }\end{array}$ & $\begin{array}{c}\text { Post-Occupancy } \\
\text { Rate (mg/hr) }\end{array}$ & $\begin{array}{c}\text { Absolute Percent } \\
\text { Difference }\end{array}$ \\
\hline \multirow{5}{*}{$\mathrm{C} 1$} & PDCB & Zone 1 & 3.5 & 4.0 & $13 \%$ \\
\hline & $\mathrm{PMCH}$ & Zone 2 & 2.8 & 3.2 & $12 \%$ \\
\hline & m-PDMCH & Zone 1 & 1.2 & 0.9 & $26 \%$ \\
\hline & m-PDMCH & Zone 2 & 0.8 & 0.9 & $10 \%$ \\
\hline & m-PDMCH & Whole house & 2.0 & 1.8 & $8.8 \%$ \\
\hline \multirow{3}{*}{$\mathrm{IaP} 1$} & PDCB & Whole house & 3.0 & 3.4 & $12 \%$ \\
\hline & $\mathrm{PMCH}$ & Whole house & 2.3 & 2.6 & $13 \%$ \\
\hline & m-PDMCH & Whole house & 1.4 & 1.5 & $8.9 \%$ \\
\hline \multirow{5}{*}{$\mathrm{IaP} 2$} & PDCB & Zone 2 & 4.4 & 4.0 & $9.0 \%$ \\
\hline & $\mathrm{PMCH}$ & Zone 1 & 3.4 & 3.0 & $12 \%$ \\
\hline & m-PDMCH & Zone 1 & 0.9 & 0.84 & $11 \%$ \\
\hline & m-PDMCH & Zone 2 & 1.0 & 0.91 & $8.4 \%$ \\
\hline & m-PDMCH & Whole house & 1.9 & 1.7 & $9.8 \%$ \\
\hline
\end{tabular}

(a) The absolute percent difference is calculated as $|(A-B) /(A+B) \times 2| \times 100 \%$.

It should be noted that emission rates were consistent over time and similar rates were obtained when various methods were used to calculate the rates. The emission rates in the table above were calculated 
using only the mass difference and elapsed time between weighing events before and after each specific deployment. We also calculated an average emission rate for each emitter based on the total mass difference and time interval over the several months of the pilot field study sampling campaign, and by regressing all mass measurements with respect to the times when measurements occurred. Emission rates calculated using these various methods are presented for each emitter in Appendix B.

\subsubsection{Measured PFT Concentrations}

The PFT tracer concentrations were measured both actively and passively at each sampling location in the homes and the measured concentrations for each tracer gas are summarized in Table 5.4. These concentration values are used with the emission rates reported in Table 5.3 to calculate the observed fresh-air dilution rate in the defined zones (i.e., floors) and the whole house during each sampling event. 
Table 5.4. Valid PFT Concentrations $\left(\right.$ in $\mu \mathrm{g} \mathrm{m}^{-3}$ ) Determined in the Three Sampled Homes

\begin{tabular}{lcccccc}
\hline \multicolumn{1}{c}{ Sample Name } & Zone & Period & Active/Passive & PDCB & PMCH & mPDCH \\
\hline & & & & & & \\
C1-PRE-IN3-PFT & 1 & PRE & Active & 23.8 & 12.3 & 10.6 \\
1-PRE-IN5-PFT & 2 & PRE & Active & 24.4 & 28.2 & 12.3 \\
C1-PRE-IN6-PFT & 2 & PRE & Active & 19.7 & 21.1 & 11.7 \\
C1-POST1-IN3-PFT & 1 & POST & Active & 21.6 & 23.6 & 15.4 \\
C1-POST1-IN4-PFT & 1 & POST & Active & 32.0 & 21.3 & 17.4 \\
C1-POST1-IN5-PFT & 2 & POST & Active & 22.1 & 24.9 & 12.1 \\
C1-POST1-IN6-PFT & 2 & POST & Active & a) & 26.3 & 10.9 \\
C1-POST1-IN3P-PFT & 2 & POST & Passive & 24.6 & 27.9 & 12.4 \\
C1-POST1-IN4P-PFT & 2 & POST & Passive & 23.1 & 26.4 & 11.9 \\
C1-POST1-IN5P-PFT & 1 & POST & Passive & 42.8 & 18.9 & 14.0 \\
C1-POST1-IN6P-PFT & 1 & POST & Passive & 35.1 & 16.5 & 11.7 \\
C1-POST1-IN7P-PFT & 2 & POST & Passive & 20.8 & 25.9 & 11.24 \\
\hline & & & & & & \\
IAP1-PRE-IN3-PFT & 1 & PRE & Active & 18.4 & 20.4 & 22.2 \\
IAP1-PRE-IN5-PFT & 1 & PRE & Active & 30.0 & 22.7 & 13.6 \\
IAP1-POST1-IN3-PFT & 1 & POST & Active & 29.7 & 34.3 & 27.3 \\
IAP1-POST1-IN4-PFT & 1 & POST & Active & 30.2 & 25.7 & 15.6 \\
IAP1-POST1-IN5-PFT & 1 & POST & Active & 38.0 & 39.4 & 32.4 \\
IAP1-POST1-IN6-PFT & 1 & POST & Active & 22.0 & 19.4 & 11.4 \\
IAP1-POST1-IN3P-PFT & 1 & POST & Passive & 63.5 & 43.9 & 24.9 \\
IAP1-POST1-IN4P-PFT & 1 & POST & Passive & 56.0 & 38.2 & 22.1 \\
IAP1-POST1-IN5P-PFT & 1 & POST & Passive & 52.5 & 37.4 & 20.7 \\
IAP1-POST1-IN6P-PFT & 1 & POST & Passive & 59.0 & 43.7 & 23.5 \\
IAP1-POST1-IN7P-PFT & 1 & POST & Passive & 60.8 & 43.4 & 24.3 \\
IAP1-POST1-IN8P-PFT & 0 & POST & Passive & 52.7 & 38.4 & 21.0 \\
\hline & & & & & & \\
IAP2-PRE2-IN4-PFT & 2 & PRE & Active & 30.1 & 28.6 & 18.9 \\
IAP2-POST1-IN3-PFT & 2 & POST & Active & 23.5 & 21.2 & 10.7 \\
IAP2-POST1-IN4-PFT & 2 & POST & Active & 27.8 & 24.8 & 12.2 \\
IAP2-POST1-IN5-PFT & 1 & POST & Active & 38.5 & 38.6 & 26.3 \\
IAP2-POST1-IN6-PFT & 1 & POST & Active & 33.1 & 32.1 & 23.6 \\
\hline (a) Invalid quantitation. & & & & & & \\
IA & & & & & \\
\hline
\end{tabular}

\subsubsection{Calculated Outdoor Air Dilution Rates}

Dilution rates were calculated by zone using a mass balance approach, and this information was used to determine the dilution rate for the whole house $\left(\mathrm{m}^{3} \mathrm{~h}^{-1}\right)$ and the area-specific whole-house dilution rate $\left(\mathrm{m}^{3} \mathrm{~m}^{-2} / \mathrm{h}^{-1}\right)$. The information by zone is useful to indicate directional airflow, which can help interpret observed concentrations of IAQ contaminants in the different zones. However, only the whole-house dilution rates were used to calculate the space normalized pollutant emission rates. The dilution rates for each sampling event are reported in Table 5.5. The calculated dilution rates were consistent over all the sampling periods for the $\mathrm{C} 1$ (differing by less than $12 \%$ across all periods) and IaP2 (differing by less than $3 \%$ across all periods). In contrast, in IaP 1 , the dilution rate was fairly consistent between the preand post-occupancy active sampling periods, but dropped between the post-occupancy active sampling 
event and the post-occupancy passive sampling event. This drop in dilution rate indicates that the home was tighter during the natural period compared to the controlled period. This may be due to decreased infiltration via duct leakage, since the air handler was operated continuously during the active sampling period and auto (the homeowner's preferred setting) during the passive sampling period, to represent typical use. It is also worth noting that, due to the short time frame of active sampling ( 18-24 hours), both pre- and post-occupancy, it is likely that the PFTs had not reached equilibrium and, as such, the dilution rate for the first sampling period, or even the active period in general, may be slightly overestimated.

Table 5.5. Whole-House Dilution Rates (expressed in $\mathrm{m}^{3} \mathrm{~h}^{-1}$ )

\begin{tabular}{llcc}
\hline House & \multicolumn{1}{c}{ Condition } & $\begin{array}{c}\text { Whole-House } \\
\text { Dilution Rate } \\
\left(\mathbf{m}^{\mathbf{3}} \mathbf{h}^{\mathbf{- 1}}\right)\end{array}$ & $\begin{array}{c}\text { Area Normalized } \\
\text { Dilution Rate } \\
\left(\mathbf{m}^{\mathbf{3}} \mathbf{~ m}^{-\mathbf{2}} \mathbf{h}^{-\mathbf{1}}\right)\end{array}$ \\
\hline \multirow{2}{*}{$\mathrm{C} 1$} & Pre-occupancy & 162 & 0.406 \\
& Post (active sampling) & 144 & 0.360 \\
& Post (passive sampling) & 147 & 0.368 \\
\hline \multirow{2}{*}{ IaP1 } & Pre-occupancy & 107 & 0.638 \\
& Post (active sampling) & 99 & 0.590 \\
& Post (passive sampling) & 64 & 0.382 \\
\hline \multirow{2}{*}{ IaP2 } & Pre-occupancy & 121 & 0.377 \\
& Post (active sampling) & 118 & 0.368 \\
\hline
\end{tabular}

A change in dilution rate is expected to change the observed pollutant concentration in a home for a given emission rate. Since the goal of this project is to compare emission rates, the variation in dilution across homes and the change in dilution for different sampling events in IaP1 illustrates the importance of converting measured concentrations to normalized emission rates when comparing performance of materials across homes and across different periods in a given home.

\subsection{Pollutant Concentrations}

Active and passive samples of volatile carbonyls and VOCs were collected during the pre-occupancy and post-occupancy sampling periods in several locations indoors and one location outdoors in $\mathrm{C} 1$ and IaP1. In IaP2, only pre- and post-occupancy active samples were collected. The following sections present the quantified concentrations of volatile carbonyls and VOCs in each house, for each sampling period, and at each sampler location. These concentrations can then be normalized based on the dilution rate observed in each home to compare pollutant emission rates between homes and sampling periods.

\subsubsection{Concentrations of Volatile Carbonyls}

Volatile carbonyl concentrations were determined for active and passive samples. Active sample results for formaldehyde, acetaldehyde, and acetone by location (in/out), home, and for IaP1 by sampling time are provided in Figure 5.13 through Figure 5.15. Error bars show the standard deviation for columns representing three to four samples or range for columns representing two samples. No uncertainty bars are shown for single samples. Outdoor results in most cases reflect the average of outdoor samples collected at $4 \mathrm{AM}$ and $11 \mathrm{AM}$. In $\mathrm{C} 1$ and $\mathrm{IaP} 2$, indoor concentrations measured at $4 \mathrm{AM}$ were not 
substantially or consistently different from those measured at 11 AM. As such, in C1 and IaP2, measurements from the two sampling periods are combined. In IaP1 post-occupancy, there was a clear difference between concentrations measured at 4 AM and 11 AM. Samples from the 11 AM preoccupancy event in IaP1 were lost due to pump failure; so it is not known if this temporal trend applied during that sampling event or not. The data for this home are nevertheless presented by sampling time to provide a more transparent comparison between pre- and post-occupancy results. The field blank indicated a contamination issue with acetaldehyde in IaP2 post-occupancy indoor and outdoor samples; so those data are not shown.

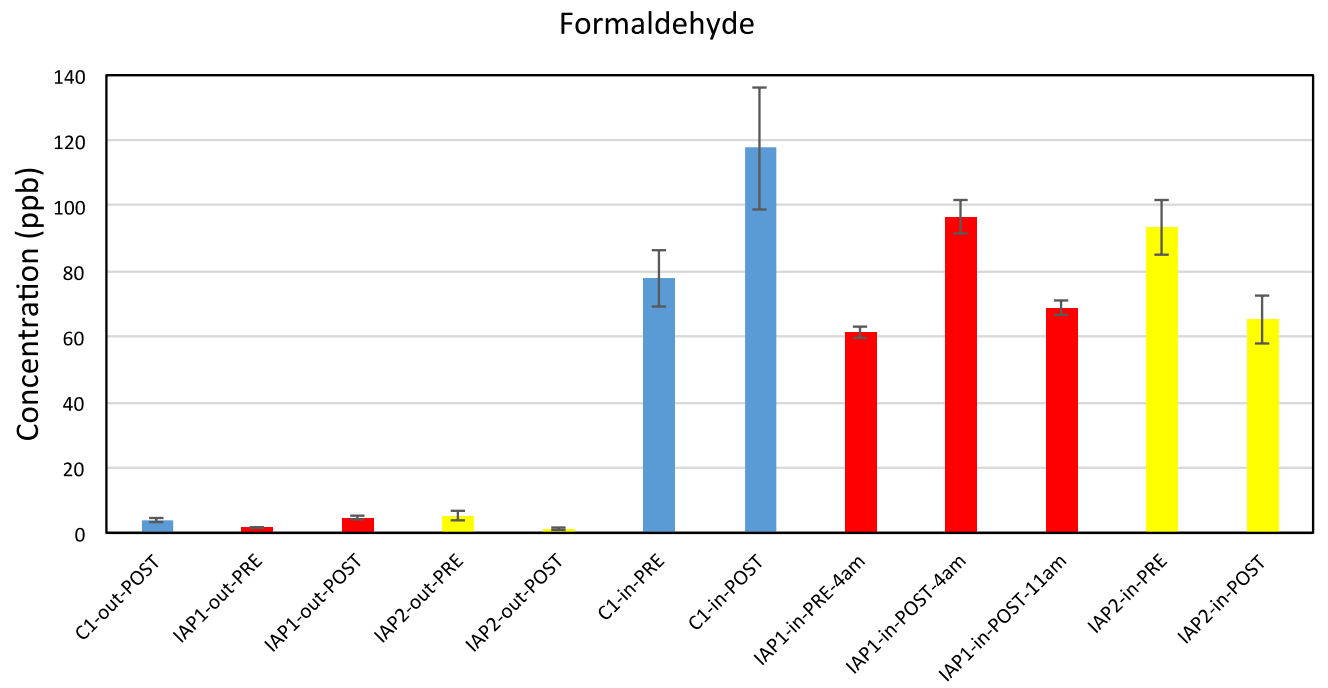

Figure 5.13. Formaldehyde Concentrations in the Three Study Homes, Determined with Active Sampling. Error bars represent range of $n=2$ or standard deviation of $n \geq 3$ samples.

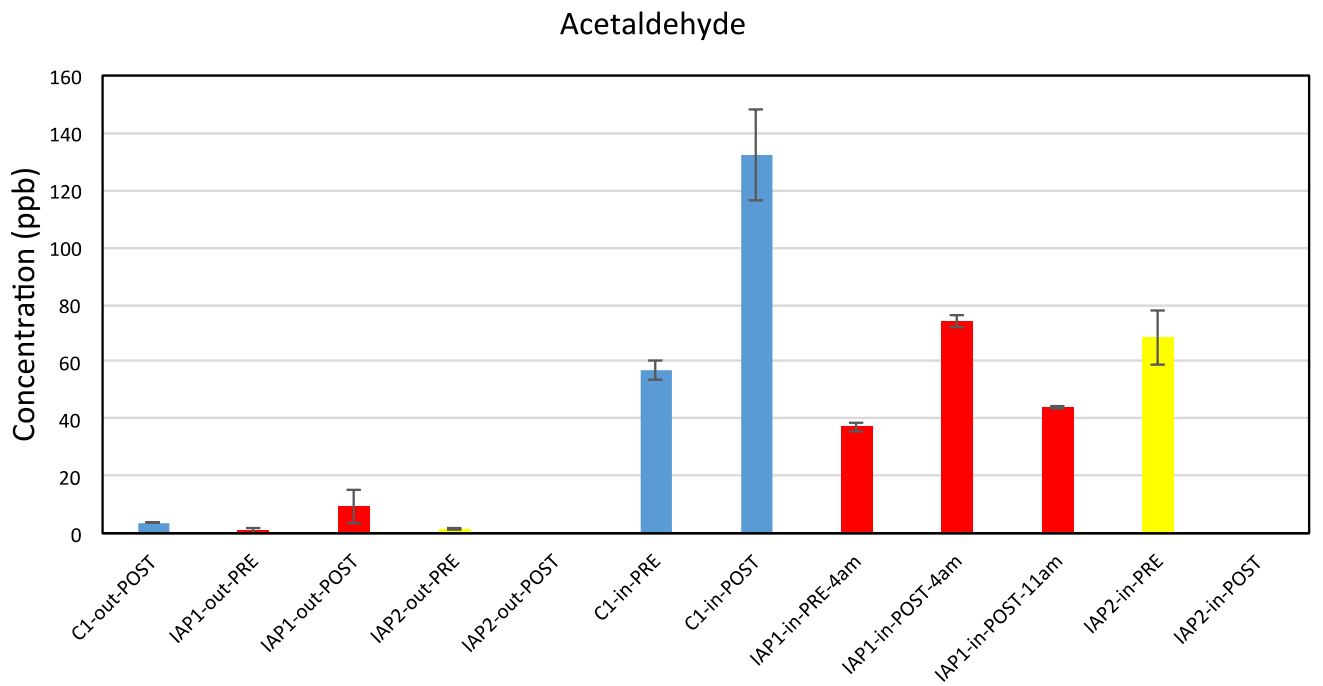

Figure 5.14. Acetaldehyde Concentrations in the Three Study Homes, Determined with Active Sampling. Error bars represent range of $n=2$ or standard deviation of $n \geq 3$ samples. 


\section{Acetone}

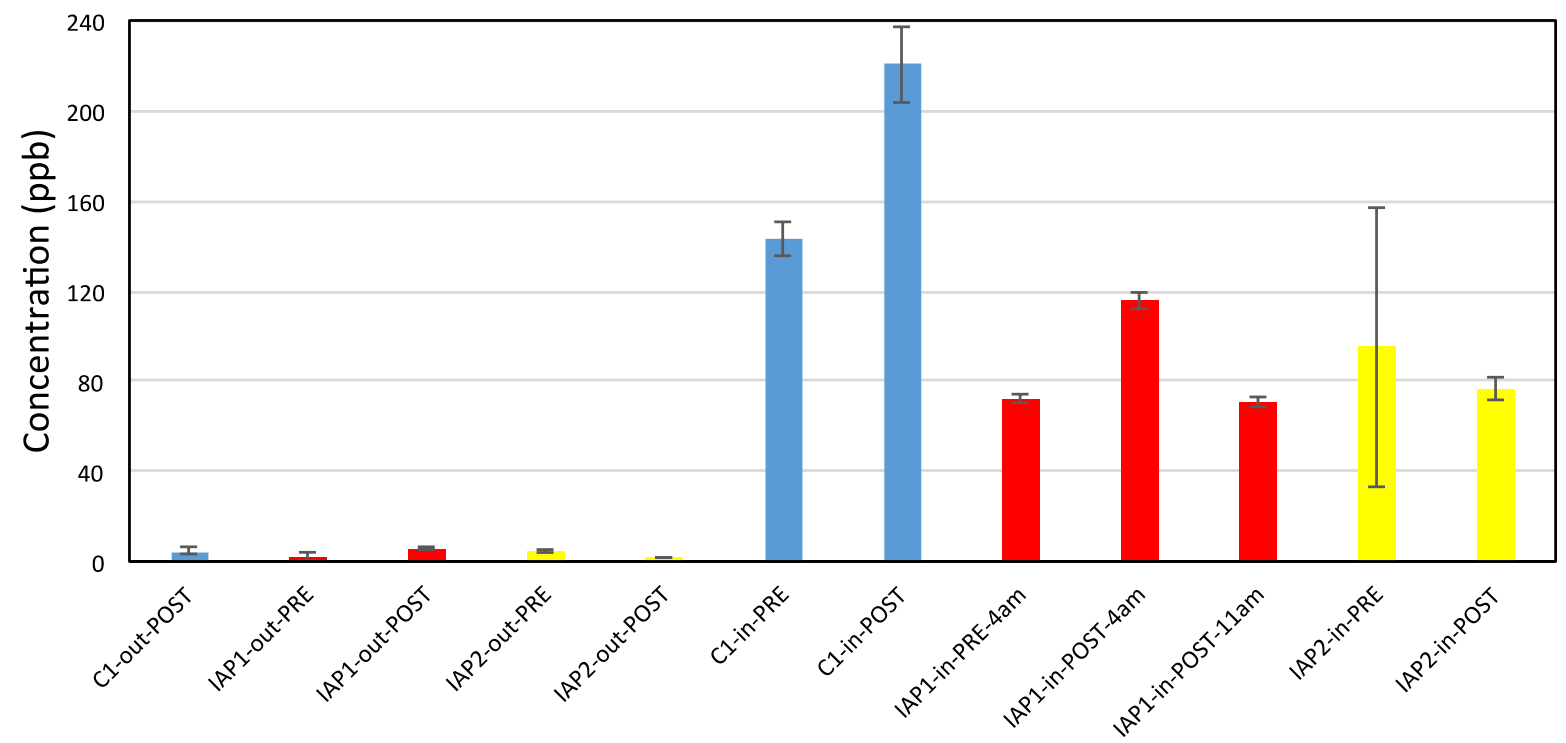

Figure 5.15. Acetone Concentrations in the Three Studied Homes, Determined with Active Sampling. Error bars represent range of $n=2$ or standard deviation of $n \geq 3$ samples.

Similar trends were observed for the three volatile carbonyls across the homes and sampling periods. For all three carbonyls at all three homes, the outdoor concentrations were more than an order of magnitude smaller than indoor levels, which indicates that the source of such emissions comes from indoors (e.g., building materials or other furnishings). In $\mathrm{C} 1$ and IaP1, concentrations increased from preto post-occupancy and increases were of similar magnitudes by compound: factors of 1.5-1.6 for formaldehyde and acetone, factors of 2.0-2.3 for acetaldehyde. This suggests an increase in pollutant sources in those homes, likely due to furnishings introduced by the homeowner and occupant-related activities. In IaP2, formaldehyde and acetone concentrations decreased from pre- to post-occupancy by $30 \%$ and $20 \%$, respectively. A similar directional trend - of pre- to post- increases in C1 and IaP1, and pre- to post- decrease in IaP2 - was observed for other VOCs as described later in this report. It is worth noting that the volatile carbonyl and VOC concentrations were significantly higher in IaP2 than in the other homes and, thus, any increase in emission sources with the introduction of additional furnishings or homeowner activities may have been overwhelmed by the decrease in emissions over time of some building- or construction-related source.

Carbonyl concentrations inside these homes were higher than those measured in a recent study of "new" homes in New Mexico that were built to LEED standards and feature low-emitting materials (Hult et al. 2014). But those homes had a median age of 0.8 months; the homes in this study were much newer. Similarly, formaldehyde and acetaldehyde levels were higher than the medians reported by Offermann (2009) for 2- to 5-year-old homes in California, of 29 and 16 ppb, respectively.

Formaldehyde and acetaldehyde concentrations were also calculated for the two houses in which passive samples were collected post-occupancy (C1 and IaP1). Results provided in Table 5.6 show generally similar concentrations during the controlled conditions in which the active sampling occurred and the typical household conditions in which passive samples were collected. These results, and the somewhat higher acetaldehyde concentrations during active sampling in $\mathrm{C} 1$, suggest that occupant 
activities did not dramatically impact the measured concentrations of these pollutants in these homes and the increase was probably due to increased long-term emission sources, such as furnishings.

Table 5.6. Comparison of Aldehyde Concentrations Determined with Active and Passive Sampling. Results presented as mean $+/$ - one standard deviation.

\begin{tabular}{cccc}
\hline Sample & Aldehyde & Active Sampling $(\mathbf{p p b})$ & Passive Sampling (ppb) \\
\hline C1-post-IN & formaldehyde & $117 \pm 19$ & $113 \pm 18(\mathrm{n}=5)$ \\
& acetaldehyde & $132 \pm 16$ & $98 \pm 26$ \\
IaP1-post-IN & formaldehyde & $83 \pm 17$ & $79 \pm 5$ \\
& acetaldehyde & $59 \pm 17$ & $63 \pm 34$ \\
\hline
\end{tabular}

\subsubsection{Concentrations of Other Volatile Organic Compounds}

Concentrations were determined for active and passive samplers ${ }^{1}$ in each home pre- and postoccupancy for over 40 specific VOCs based on calibrations developed from pure standards and GC/MS identification and quantitation (Figure 5.16). The concentrations of these individual compounds were summed to obtain a metric for VOC emissions and concentrations generally. Regarding the concentrations of VOCs generally, it was observed that both C1 and IAP2 had higher VOC concentrations pre-occupancy, but VOC levels increased in IAP1 after occupants moved in. This is mostly due to the fact that pre-occupancy levels in IAP1 were very low. The very high pre-occupancy levels recorded for IAP2 are discussed below. Variations in pre-occupancy VOCs may arise from variations in the time since finishing work was completed in the homes.

\section{Sum of VOC concentrations measured indoors}

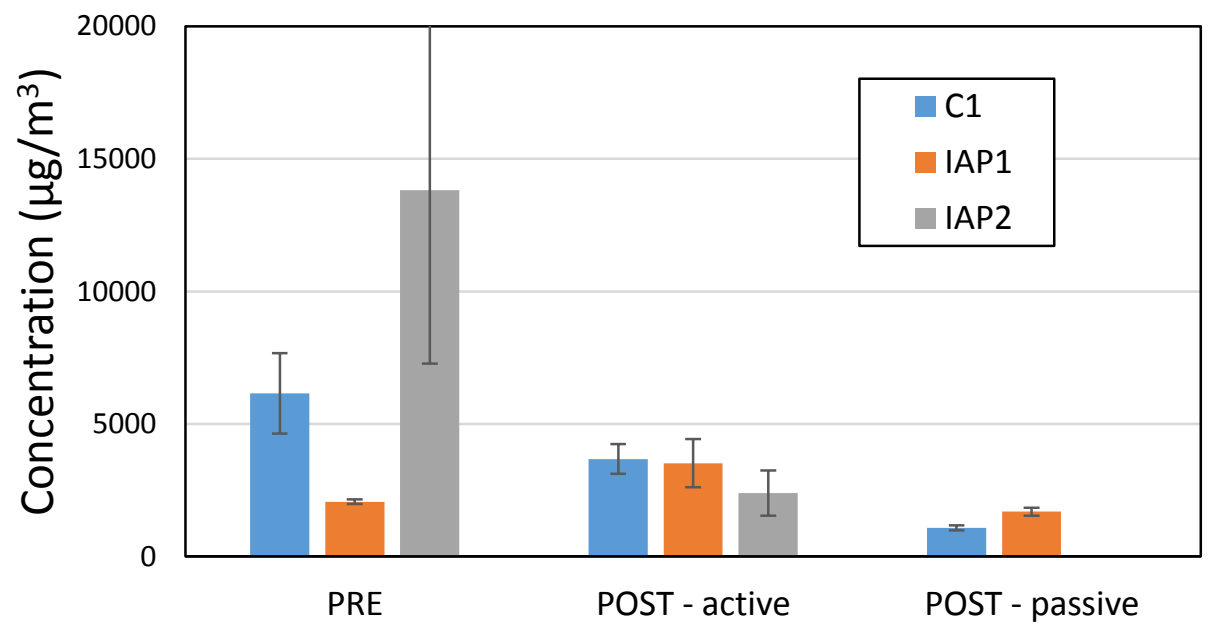

Figure 5.16. Sum of VOC Concentrations Measured Indoors on the Three Homes

\footnotetext{
${ }^{1}$ As mentioned previously, no passive samplers were collected in IaP2.
} 
The speciated VOCs determined from indoor active and passive samples in the three pilot homes are presented by sampling period in Table 5.7. Visual review of the chromatograms from several homes indicated that the compounds listed in Table 5.7 represent the vast majority of VOCs present in the homes and, as such, present a useful metric to quantify and compare general trends regarding building-related VOCs in homes.

Table 5.7. Speciated VOC Concentrations $\left(\mu \mathrm{g} \mathrm{m}^{-3}\right)$ Determined from Active and Passive Sampling

\begin{tabular}{|c|c|c|c|c|c|c|c|c|}
\hline \multirow[b]{3}{*}{ Pollutant } & \multicolumn{8}{|c|}{ Home } \\
\hline & \multicolumn{3}{|c|}{ C1 } & \multicolumn{3}{|c|}{ IaP1 } & \multicolumn{2}{|c|}{ IaP2 } \\
\hline & $\begin{array}{l}\text { PRE- } \\
\text { active } \\
(n=4)\end{array}$ & $\begin{array}{c}\text { POST - } \\
\text { active } \\
(n=4) \\
\end{array}$ & $\begin{array}{l}\text { POST - } \\
\text { passive } \\
(\mathrm{n}=2)\end{array}$ & $\begin{array}{l}\text { PRE- } \\
\text { active } \\
(n=2) \\
\end{array}$ & $\begin{array}{c}\text { POST - } \\
\text { active } \\
(n=4)\end{array}$ & $\begin{array}{l}\text { POST - } \\
\text { passive } \\
(n=6)\end{array}$ & $\begin{array}{l}\text { PRE- } \\
\text { active } \\
(n=2) \\
\end{array}$ & $\begin{array}{c}\text { POST - } \\
\text { active } \\
(\mathbf{n}=3)\end{array}$ \\
\hline Butanal & 50 & 30 & 10 & 12 & 27 & 14 & 69 & 10 \\
\hline Hexanal & 3348 & 2029 & 549 & 800 & 1776 & 829 & 6211 & 1093 \\
\hline Heptanal & 22 & 20 & 7.5 & 3.5 & 11 & 3.6 & 37 & 6.1 \\
\hline Benzaldehyde & 13 & 26 & 13 & 5.5 & 15 & 13 & 34 & 7.7 \\
\hline Octanal & 23 & 31 & 12 & 4 & 13 & 4 & 57 & 8.1 \\
\hline Nonanal & 59 & 55 & 26 & 12 & 26 & 7.7 & 62 & 18 \\
\hline Decanal & 2.2 & 3.5 & NA & 1.1 & 4.8 & NA & 8.1 & 2.9 \\
\hline Sum of Aldehydes & 3517 & 2195 & 618 & 838 & 1873 & 871 & 6478 & 1146 \\
\hline Hexane & 153 & 28 & 6.5 & 4.9 & 13 & 12 & 651 & 5.1 \\
\hline Heptane & 33 & 9.8 & 2 & 2.4 & 9.3 & 5.2 & 94 & 1.6 \\
\hline Octane & 43 & 16 & 2.7 & 4 & 7.6 & 3.5 & 111 & 2.9 \\
\hline Decane & 35 & 23 & 5.9 & 25 & 23 & 6.5 & 178 & 13 \\
\hline Undecane & 76 & 48 & 15 & 23 & 22 & 7 & 91 & 5.9 \\
\hline Dodecane & 53 & 42 & 15 & 13 & 15 & 4.8 & 37 & 3.9 \\
\hline Tetradecane & 11 & 33 & 11 & 4.9 & 7.7 & 2.1 & 21 & 4 \\
\hline Hexadecane & 2.5 & 6.1 & 2 & 0.6 & 3 & 1.1 & 6.7 & 2.1 \\
\hline Sum of Alkanes & 406 & 206 & 60 & 78 & 101 & 42 & 1190 & 39 \\
\hline Benzene & 32 & 5.4 & bd & 0.8 & 8.6 & 8.8 & 39 & bd \\
\hline Toluene & 452 & 131 & 16 & 39 & 128 & 44 & 597 & 57 \\
\hline Ethylbenzene & 229 & 52 & 8.3 & 33 & 22 & 11 & 573 & 23 \\
\hline $\mathrm{m} / \mathrm{p}$-Xylene & 705 & 204 & 25 & 176 & 76 & 30 & 1321 & 74 \\
\hline o-Xylene & 179 & 79 & 12 & 41 & 33 & 21 & 342 & 27 \\
\hline Styrene & 24 & 37 & NA & 10 & 19 & NA & 138 & 18 \\
\hline Benzene, 1,2,4-trimethyl- & 14 & 10 & 3.4 & 4.8 & 18 & 7.3 & 13 & 1.8 \\
\hline Benzene, 1,2,3-trimethyl- & 4.3 & 3.4 & 1.2 & 2.2 & 5.5 & 2 & 5.4 & 0.7 \\
\hline Benzene, butyl- & 1.1 & 1 & 0.3 & 0.9 & 2.4 & 0.8 & 2.1 & 0.3 \\
\hline Phenol & 3 & 4.7 & NA & 3.4 & 5.7 & NA & 30 & 7.1 \\
\hline Naphthalene & 1.8 & 1.3 & NA & 1.3 & 8.2 & NA & 20 & 4.3 \\
\hline
\end{tabular}


Table 5.7. (contd)

\begin{tabular}{|c|c|c|c|c|c|c|c|c|}
\hline \multirow[b]{3}{*}{ Pollutant } & \multicolumn{8}{|c|}{ Home } \\
\hline & \multicolumn{3}{|c|}{ C1 } & \multicolumn{3}{|c|}{ IaP1 } & \multicolumn{2}{|c|}{ IaP2 } \\
\hline & $\begin{array}{l}\text { PRE- } \\
\text { active } \\
(n=4)\end{array}$ & $\begin{array}{l}\text { POST - } \\
\text { active } \\
(n=4)\end{array}$ & $\begin{array}{l}\text { POST - } \\
\text { passive } \\
(\mathbf{n}=2)\end{array}$ & $\begin{array}{l}\text { PRE- } \\
\text { active } \\
(\mathrm{n}=2)\end{array}$ & $\begin{array}{c}\text { POST - } \\
\text { active } \\
(n=4)\end{array}$ & $\begin{array}{l}\text { POST - } \\
\text { passive } \\
(n=6)\end{array}$ & $\begin{array}{l}\text { PRE- } \\
\text { active } \\
(\mathrm{n}=2)\end{array}$ & $\begin{array}{l}\text { POST - } \\
\text { active } \\
(\mathbf{n}=3)\end{array}$ \\
\hline Sum of Aromatics & 1645 & 529 & 66 & 312 & 326 & 125 & 3081 & 213 \\
\hline 2-Butoxyethanol & 16 & 22 & 7.8 & 8.9 & 21.7 & 13 & 22 & 19 \\
\hline 1-Hexanol, 2-ethyl- & 8.7 & 13 & 6.9 & 1.6 & 20 & 3.7 & 23 & 3.7 \\
\hline TMPD-MIB & 43 & 20 & 7.3 & 407 & 354 & 157 & 1193 & 299 \\
\hline Dimethyl phthalate & 0.1 & 0.4 & 0.1 & bd & 0.1 & 0.1 & 0.4 & 0.1 \\
\hline TMPD-DIB & 5.1 & 8.6 & 1.3 & 90 & 119 & 26 & 170 & 29 \\
\hline Diethyl phthalate & $<0.1$ & 0.2 & 0.5 & $<0.1$ & 0.1 & 0.3 & 0.4 & $<0.1$ \\
\hline Dibutyl phthalate & $<0.1$ & 0.3 & $<0.1$ & $<0.1$ & $<0.1$ & $<0.1$ & 1.2 & 0.1 \\
\hline Sum of esters/ethers & 73 & 64 & 24 & 508 & 515 & 200 & 1410 & 351 \\
\hline Trichloromethane & 1 & 8.3 & NA & 0.2 & 1.2 & NA & 579 & 93 \\
\hline Tetrachloroethylene & 1.5 & 1.1 & 0.1 & 0.1 & 0.2 & bd & 0.8 & 0.4 \\
\hline Benzene, 1,4-dichloro & 0 & 0.2 & bd & 0 & 0.7 & bd & 1.3 & 0.1 \\
\hline Sum of halogenated & 2.5 & 9.6 & 0.1 & 0.3 & 2.1 & $\mathbf{0}$ & 581 & 94 \\
\hline D3 & 0.7 & 1.4 & NA & 3.7 & 13 & NA & 46 & 7.3 \\
\hline D4 & 5.2 & 33 & NA & 3.8 & 8 & NA & 90 & 70 \\
\hline D5 & 9.2 & 114 & NA & 1.8 & 91 & NA & 43 & 6.7 \\
\hline Sum of siloxanes & 15 & 148 & 0 & 9.3 & 112 & $\mathbf{0}$ & 179 & 84 \\
\hline a-Pinene & 368 & 353 & 261 & 251 & 402 & 396 & 571 & 400 \\
\hline 3-Carene & 47 & 53 & 16 & 25 & 70 & 22 & 97 & 20 \\
\hline D-Limonene & 73 & 115 & 34 & 40 & 109 & 31 & 210 & 36 \\
\hline g-Terpinene & 3.1 & 6.2 & 1.7 & 2.8 & 5.7 & 1.2 & 21 & 2.8 \\
\hline a-Terpineol & 3.3 & 2.9 & 0.9 & 1.6 & 4.7 & 1.2 & 14 & 3.7 \\
\hline Sum of terpenes & 494 & 530 & 313 & 320 & 591 & 451 & 913 & 463 \\
\hline Sum of VOCs & 6153 & 3679 & 1080 & 2068 & 3521 & 1691 & 13820 & 2387 \\
\hline
\end{tabular}

$\mathrm{NA}=$ passive measurements do not include this compound; bd = below detection limit.

Table 5.7 presents average concentrations of all target VOC compounds measured during each sampling event in each home, sorted by chemical classification. The higher molecular weight carbonyls are quantified with the VOCs and listed in the first set of target compounds. The dominant aldehyde in this set is consistently hexanal. Hexanal has a distinct odor and is used in flavors and perfumes; but in new homes its most important source is from oxidative breakdown of linoleic acid. Linoleic acid is a major constituent in several wood finish products (e.g., linseed oil, tung oil, walnut oil, hemp oil) and the three study homes had large areas with wood finishes. The concentration of hexanal typically dropped between pre- and post-occupancy sampling; this would be expected as time progressed from the initial source application assumed to occur pre-occupancy. The bump of hexanal in IaP1 between pre- and postoccupancy could be due to finishing activities that took place just prior to the post-occupancy deployment or the recent introduction of several large pieces of new wood furniture (a bed frame, dressers, and shelving). Butanal is also elevated somewhat in the pre-occupancy sampling events and drops over time 
indicating a building material source. Butanal is used in resins, rubbers, and plasticizers for higher molecular weight polymers typically used in new home construction.

The second class of VOCs presented in Table 5.7 is alkanes. Alkanes have a variety of sources including fuels, solvents, and finish coatings (paint and varnishes). Hexane and undecane are both elevated in $\mathrm{C} 1$ during the pre-occupancy test. It was noted that there was a fuel can in the garage of the home and outdoor cleaning activity (pressure washing of deck) that may have been a source of gasoline vapors in the home. The levels of hexane dropped significantly between the pre- and post-occupancy measurements. In IaP2 home we also noted large concentrations of hydrocarbon related alkanes, indicating gasoline sources nearby during the pre-occupancy sampling period. These values also dropped dramatically between the pre- and post-occupancy sampling. In this case, the source of such emissions can only be hypothesized. However, significant construction activity was occurring around the IaP2 house in the 24 hours prior to the pre-occupancy sampling, such as pouring concrete for the sidewalks. In all cases, these alkanes may be related to building product coatings and finishes, but the timing of the elevated alkanes and the field observations of activities associated with gasoline and combustion engines nearby make it likely that much of the alkane concentration is not related to the building materials or the building contents rather to intermittent activities associated with the combustion of gasoline.

Further supporting the result related to alkanes, several aromatic compounds also associated with gasoline motors and combustion were detected at high concentrations in $\mathrm{C} 1$ and IaP2 pre-occupancy. Specifically, the concentrations on toluene, ethyl benzene, and xylenes were elevated during the preoccupancy sampling events in $\mathrm{C} 1$ and IaP2, where we noted stored gasoline in the garage and construction activity using gasoline engines. The gasoline-related aromatic compounds dropped between the pre- and post-occupancy period, correlating with the alkanes and further indicating a fuel source and not necessarily a building-related source. The alkylated benzenes are, in addition to being related to fuel, markers of plasticizers used in some resilient vinyl flooring. The alkylated benzenes followed a pattern more typical of new construction although the contribution of fuel cannot be ignored. Naphthalene is a marker of vehicle exhaust (and smoking) but is also found in some products. The elevated level of naphthalene in IaP2 during the pre-occupancy period further indicates a vehicle exhaust source.

The next class of VOCs presented is esters and ethers. These chemicals are mostly related to plasticizers and coatings. TMPD-MIB (common name Texanol) is a common ingredient of latex paint and clearly a building-related source. The Texanol drops in all homes over time, which is consistent with an initial wet source or coating. Variation in concentrations of Texanol across homes during the preoccupancy measurements, where $\mathrm{C} 1$, IaP1, and IaP2 saw concentrations of 43, 407, and $1193 \mu \mathrm{g} \mathrm{m}^{-3}$, respectively, suggests different amounts of time since painting was completed. The builder conducted some painting "touch up" work in the days prior to IaP2 pre-occupancy sampling, which could explain the elevated Texanol concentration in IaP2. The compound TMPD-DIB (common name TXIB) is a softener used in resilient vinyl flooring and again would be expected to follow a decreasing trend with age of the vinyl flooring in the home. However, in both the $\mathrm{C} 1$ and IaP1, the concentration of TXIB increased after the home was occupied. This may be related to new sources or to the installation of vinyl in the homes after the pre-occupancy sample event (i.e., drawer and cabinet liners). The 2-butoxy ethanol is found in finishes and coatings but also in several personal care products and household cleaners; so the lack of a clear trend between pre- and post-occupancy for this compound is not surprising. The phthalates are typically related to building contents or the occupant's belongings, so an increase in these compounds between the two measurement events is consistent with expectations, although IaP2 seemed to have lower phthalates during the post-occupancy event. 
The halogenated compounds are typically found in dry-cleaning products (cloths) or sometimes emitted from water in some regions of the United States. Concentrations are expected to be very low indoors in modern homes. The very high level of trichloromethane in IaP2 pre-occupancy suggests recent use of a paint-stripping product. IaP2 had just undergone the "final cleaning" prior to the pre-occupancy sampling event and the cleaners report that Goof Off ${ }^{\circledR}$ is sometimes used to remove paint.

The siloxanes are almost exclusively related to personal care products, although some are used in the manufacture of silicone products that may be part of building construction. We would expect these compounds to increase primarily as part of the occupants' activities and their belongings, but be mostly related to the use of personal care products in the home. This is consistent with the observed trend in $\mathrm{C} 1$ and IaP1, where concentrations of siloxanes increased from pre-occupancy to post-occupancy. However, IaP2 saw a slight drop in siloxanes where the pre-occupancy samples had elevated levels that dropped some over time. This could be explained by a negligible change in the presence and use of personal care products by the occupant just before or during the post-occupancy event. It is not clear, however, why elevated levels of siloxanes were observed pre-occupancy in IaP2.

The last VOC class presented is terpenes. These are emitted by building products, building contents, and occupants so we would expect to see variable trends in concentration for these compounds between the pre- and post-occupancy and over time. On average, the sum of all terpenes increased with occupancy, which may be related to the use of fragrances and cleaning products in the home where the base concentrations are in part due to construction materials and wood products.

\subsection{Pollutant Emission Rates}

The carbonyl and VOC concentrations determined in Section 5.3 were used to calculate the emission rates in each home and condition. Emission rates were normalized by floor area to account for the different amount of sources present in each home, which are assumed to be proportional to the amount of occupied space. The normalized emission rate $E_{i}$ of each pollutant $i$ was calculated as follows:

$$
E_{i}=\frac{C_{i} \times D_{w h}}{A}
$$

where $C_{i}$ is the average concentration of the pollutant in the home (in $\mu \mathrm{g} \mathrm{\textrm {m } ^ { - 3 }}$ ), $D_{w h}$ is the dilution rate for the whole house determined as an average for the three tracers in all the zones (in $\mathrm{m}^{3} \mathrm{~h}^{-1}$ ), and $A$ is the floor plan area (in $\mathrm{m}^{2}$ ). The normalized emission rate is expressed in units of $\mu \mathrm{g} \mathrm{h}^{-1} \mathrm{~m}^{-2}$.

\subsubsection{Emission Rates of Very Volatile Carbonyls}

The results for formaldehyde, acetaldehyde and acetone are presented in Figure 5.17 through Figure 5.19. The error bars correspond to an average $30 \%$ uncertainty, arising from the estimated combined experimental error in determining pollutant concentrations and dilution rates. 


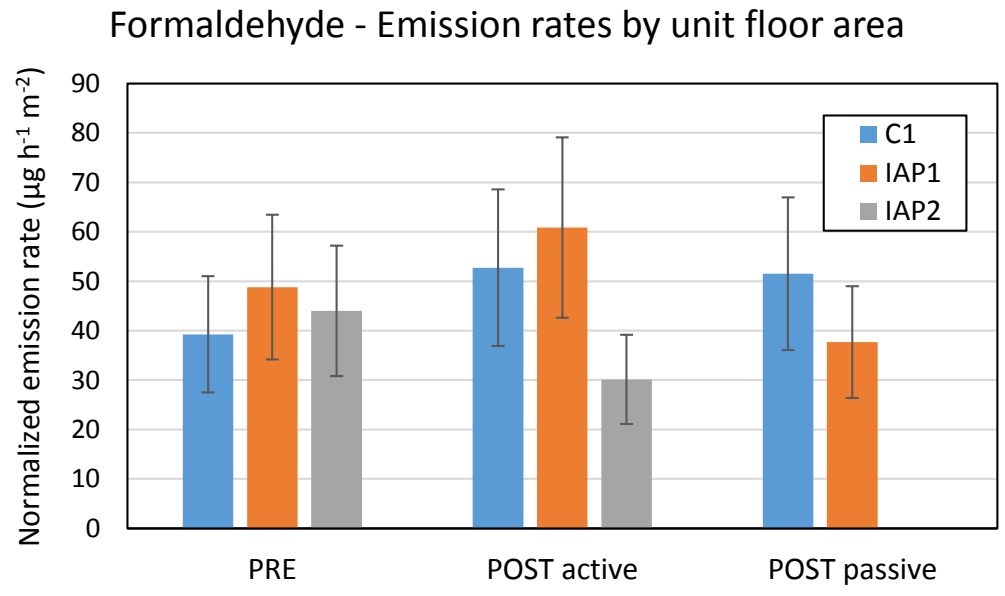

Figure 5.17. Normalized Emission Rates of Formaldehyde in the Three Study Homes

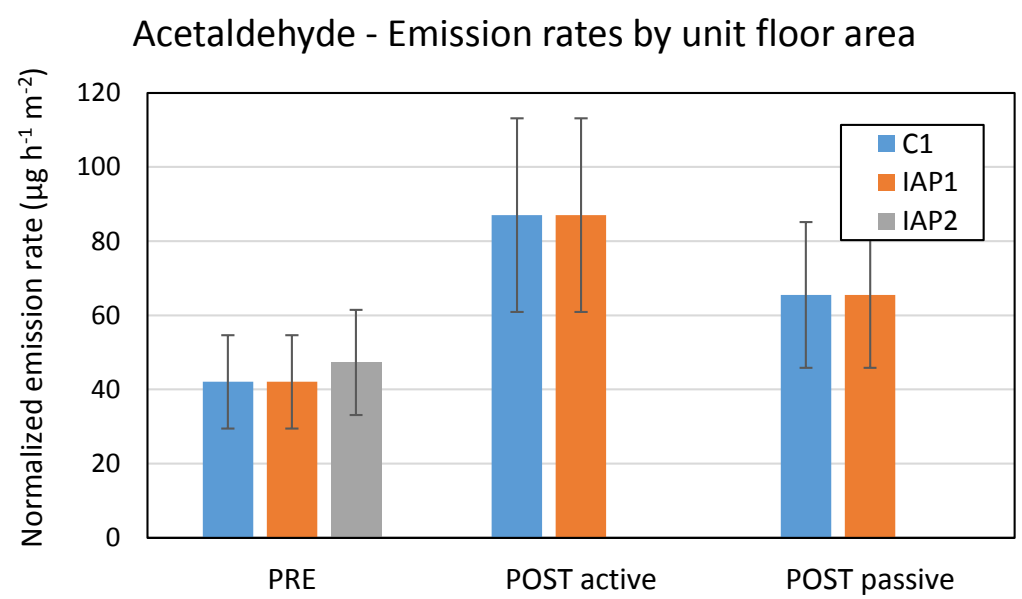

Figure 5.18. Normalized Emission Rates of Acetaldehyde in the Three Study Homes

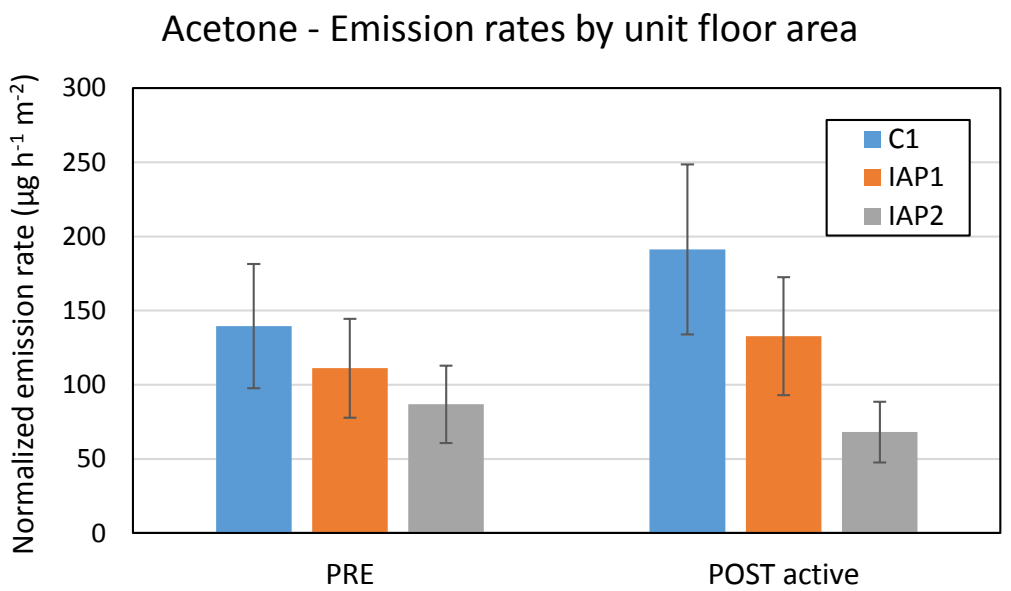

Figure 5.19. Normalized Emission Rates of Acetone in the Three Study Homes 
The pre-occupancy formaldehyde emission rates were very similar in all three homes, between 40 and $50 \mu \mathrm{g} \mathrm{h}^{-1} \mathrm{~m}^{-2}$. This result suggests that the emission rate from materials used in IaP1 and IaP2 may not have contributed significantly to reducing indoor levels for this important indoor pollutant, or may not be significantly different from the emission rates of materials used in $\mathrm{C} 1$. Although the builder of $\mathrm{C} 1$ did not intentionally select low-formaldehyde-emitting materials, after gathering more information from the component manufacturers of these materials, it was discovered that the materials used to construct $\mathrm{C} 1$ were in fact, for the most part, low-emitting as well. Sometimes, the material was not even advertised as being low-emitting, but the manufacturer confirmed that it met CARB or some other low-formaldehyde standard.

Similarly, concentrations of acetaldehyde and acetone in pre-occupancy samples were similar in all three homes. The samples collected post-occupancy suggest that levels of these compounds were slightly higher for $\mathrm{C} 1$ and IaP1, possibly due to new sources brought by occupants, activities and use of household products.

\subsubsection{Emission Rates of Other Volatile Organic Compounds}

A normalized emission rate analysis was carried out for other VOCs. Emission rates for the sum of all individual VOCs determined by this method are presented in Figure 5.20.

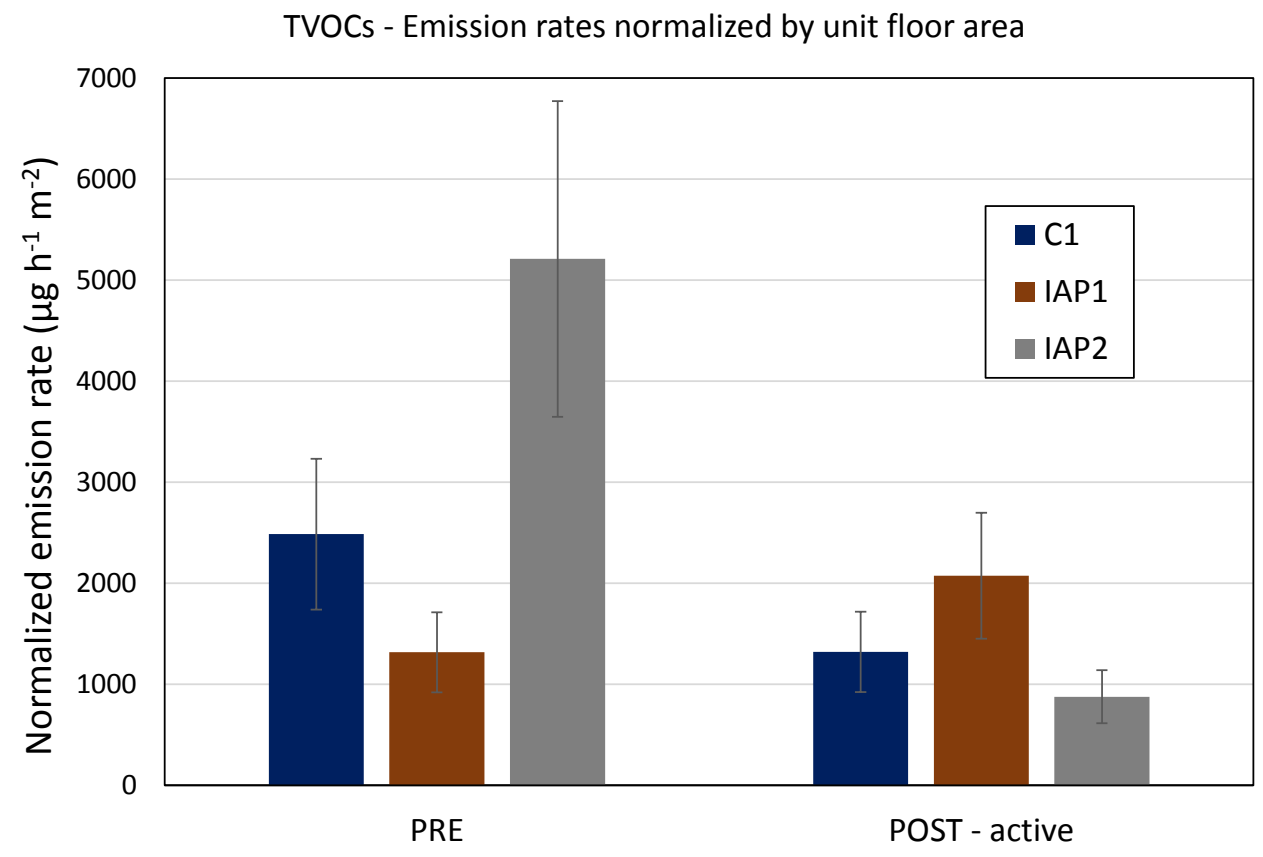

Figure 5.20. Normalized Emission Rates of the Sum of All Identified VOCs (TVOCs) in Each Home During Active Sampling Periods

The emission rates for $\mathrm{C} 1$ and IaP1 during both pre-occupancy and post-occupancy periods were in the range of $\sim 1-2.5 \mathrm{mg} \mathrm{h}^{-1} \mathrm{~m}^{-2}$. The emission rate post-occupancy in IaP2 was also observed to be in the same range, but the pre-occupancy measurement was much higher than that observed in other homes, which was likely impacted by a combination of very recent finishing work in the home and possibly an outdoor gasoline source related to ongoing construction activity. Emission rates in IaP1 were initially 
almost half of those in $\mathrm{C} 1$, but those emissions increased with occupancy, likely due to the presence of new materials and activities. Despite the large uncertainties in these determinations, the results illustrate these opposite trends in both homes and the difficulty and variability in making conclusions regarding IAQ with such a small sample of homes.

Figure 5.21 illustrates two of the individual VOCs evaluated in this analysis, illustrating two different trends. In the case of toluene (a common indoor pollutant emitted by multiple sources, both buildingrelated and occupant-related), emissions rates follow roughly the same tendencies described above for TVOCs; that is, concentrations decreased in $\mathrm{C} 1$ and IaP2 and increased in IaP1 from pre-occupancy to post-occupancy. However, emissions rates for the cyclic siloxane D5 were almost negligible preoccupancy and grew significantly when occupants were present. This compound is typically present in personal care and household products. 

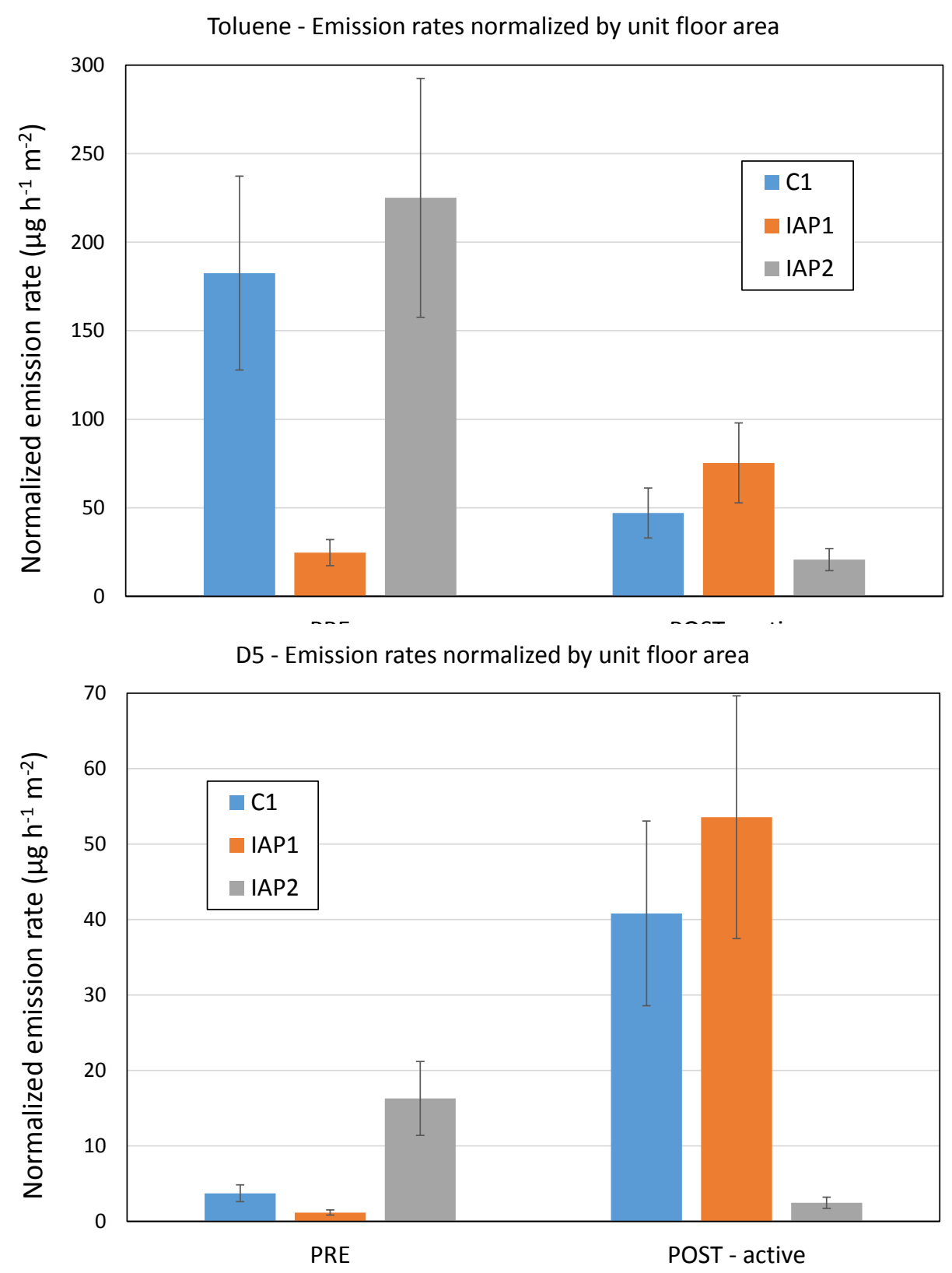

Figure 5.21. Normalized Emission Rates of Two Individual VOCs in Each Home During Active Sampling Periods 


\subsection{Conclusions}

We learned some valuable lessons related to homeowner recruitment and the design and implementation of the experimental plan relative to on-the-ground realities in the field, and we derived some key findings from the study.

\subsection{Lessons Learned on Recruitment and Experimental Plan}

One of the primary outcomes of the project is the detailed and thorough study design, presented as Appendix A, that can be used in the future to collect additional data related to quantifying and understanding the relationship between the use of low-emitting materials in home construction and resultant impacts on IAQ, including specifically addressing the contributions of building furnishings and occupant activities on measured concentrations. The pilot field study implemented in the summer of 2014 collected useful and interesting data on one conventional home and two IaP homes. However, several logistical challenges were encountered during the pilot field study that should be noted to potentially improve the implementation of future, similar research projects.

First, the research team encountered issues recruiting the expected number of homes meeting the selection criteria established in the experimental plan. Unfortunately, due to delays in construction at Badger Mountain South and the ambiguity of construction time frames for local builders, identifying candidate homes was more difficult that the research team had anticipated. Since the Badger Mountain South community was not moving forward as originally anticipated with a significant number of DOE Zero Energy Ready Homes constructed and occupied in the identified study time frame, researchers identified builders that build near-IaP homes that typically comply with HBATC BuiltGreen specifications. In addition, construction time frames are often flexible and change as materials and contracting crews are available, making them difficult to reliably predict and coordinate around. This caused several candidate homes to be removed from the sample due to changes in home completion timing.

Once candidate homes were identified and builders had expressed interest in participating, the homeowner needed to be contacted and recruited. Many builders worked through realtors and did not have direct relationships with the homeowners, which further complicated recruiting interested homeowners. Further, homeowners were often not aware of the closing date or when they would be moving into their home until a week or less prior to the move-in date. This often left little to no time to schedule pre-occupancy sampling. Also, some homeowners declined to participate due to the chaotic nature of the transition, including potentially selling a previous house. The research team also discovered that moving schedules can be somewhat fluid and extend over a longer period of time than anticipated in the experimental plan. For example, as noted previously, in IaP2, the home had not undergone the "final clean" and had a few remaining punch-list items prior to completion when the pre-occupancy sampling occurred, but it had already contained some of the new homeowners' personal belongings.

Once homeowners were engaged in the study, it was also difficult to ensure strict adherence to the controlled sampling criteria established in the experimental plan. For example, one home's HVAC system malfunctioned during the short-term, active sampling period. While the home was intended to be operated under controlled conditions during this 24-hour period, the homeowner was forced to open the windows to keep the home cool enough to sleep until the HVAC could be serviced the following 
morning. Despite significant efforts to work with homeowners to understand and cooperate with the agreed-upon sampling protocols, reacting to unanticipated events such as these is the nature of field work. While, these events clearly affect the results of the study, since they are well-documented the IAQ measurements and results can account for any discrepancies resulting from such peculiarities or deviations from the sampling protocol.

Another observation with implications for all residential field research projects is that it was more challenging than anticipated to find homeowners who were away from home (e.g., at work) routinely during the day. As work schedules and flextime/working from home becomes more prevalent, research protocols need to be adapted to these realities.

While many procedural improvements are possible, it may just be fundamentally extremely difficult to execute a standardized pre-occupancy sampling event without substantially controlling the highly variable course of events that occur around new home completion and occupancy. Since many homes are not fully completed until just before and sometimes after the initial occupancy, the impact of solvents, paints, floor finishes, cleaners, etc. on VOC concentrations pre-occupancy is extremely variable. If the study is ever continued with its current design, substantial effort should be budgeted to documenting the timing and details of builder activities prior to pre-occupancy.

If pursuing this research in the future is desired, we note two alternative approaches that should be considered.

- The first approach would be to conduct a highly controlled study in which collections of materials and finishes that would go into IaP and non-IaP homes are selected in consultation with builders and material suppliers, and these materials and finishes are combined in appropriate ratios into simulated new homes that are evaluated over time in laboratory chamber testing. Such a study could be conducted, overtime, in spec homes in close consultation with the builder. This would provide clear information about differences between the materials and finishes used in the homes, though the relative importance of occupant materials and activities would remain unknown.

- Another approach would be to measure VOCs in a large enough number of IaP and non-IaP homes roughly 6 months post-occupancy to assess whether there is any discernible difference in VOCs. The homes could be paired by season and location and conditions could be constrained if not tightly controlled. The sampling events would be much less costly than those of our proposed study design; so larger sample sizes would be achievable with similar budgets. The rationale for such an approach is that any important benefit of the source control provisions should be both durable and observable through the variations in VOCs that result from variable occupant possessions and activities.

\subsection{Key Findings}

One major finding resulting from the pilot study is the ubiquity of low-emitting materials. Although the research team recruited the conventional builder based on the fact that he reported not intentionally having used any low-emitting or certified products, after more thorough investigation it was found that $\mathrm{C} 1$ was constructed using a significant quantity of low-emitting materials. In some cases, such information was not known by the builder or the distributor, or advertised on the manufacturer's website. However, after calling the manufacturer of the product, it was determined that, commonly, a manufacturer would have fully transitioned the entire line or even its entire product offering to low-emitting materials 
meeting CARB or some other certification standard. This points to the success of IaP, CARB, and other programs that encourage or require the use of low-emitting materials at increasing the penetration of such materials in the market place.

Overall concentrations of VOCs measured during pre-occupancy varied widely across the three homes; the highest levels, measured in IaP2, were more than $2 \mathrm{x}$ and $6 \mathrm{x}$ as high as pre-occupancy VOCs in $\mathrm{C} 1$ and IaP1, respectively. There was a very steep drop in overall VOC levels between pre- and postoccupancy in IaP2 (from 13,800 to $2400 \mu \mathrm{g} \mathrm{m}^{-3}$ ) despite relatively similar outdoor air dilution rates during the two sampling events and only about a 3-week interval. The steepness of this decline suggests one or more emissions sources occurring just before or even during the pre-occupancy sampling event. The builder noted that some finish work and an extensive cleaning occurred in the days just before the measurements were made and several of the specific VOCs that were present at high concentrations are indicative of paint stripping, paint, and wood floor finishes. Potentially also significant, the research team also observed that significant construction activity was occurring around the home just prior to this sampling event. The VOC mixture observed during IaP2 pre-occupancy sampling contained very high concentrations of chemicals that are used as solvents but also present in gasoline. Gasoline-powered equipment could have been the source of many of the elevated VOCs observed during this sampling period.

Overall VOC levels decreased between pre- and post-occupancy in $\mathrm{C} 1$ but increased between preand post-occupancy in IaP1. The post-occupancy concentrations of the summed VOCs were more similar across homes, covering the range of $2,400 \mu \mathrm{g} \mathrm{m}^{-3}$ (IaP2) to $3,700 \mu \mathrm{g} \mathrm{m}^{-3}(\mathrm{C} 1)$. There were substantial increases $(>50 \%)$ in volatile carbonyl concentrations between pre- and post-occupancy in $\mathrm{C} 1$ and IaP1. IaP2 had the highest concentrations of formaldehyde and acetaldehyde pre-occupancy, but postoccupancy concentrations of these compounds were lower in IaP2 than in the other two homes. Floor area-normalized emission rates of formaldehyde and acetaldehyde - two air pollutants that most commonly exceed health-based standards in homes - were very similar across the three homes.

In two of the homes we see a drop in the sum of all target VOCs between the pre-occupancy and postoccupancy sampling event, indicating that many of the main VOCs in the homes are related to the building materials and are dropping in concentration with time as expected. However, IaP1 exhibit san increase in VOC concentration across all VOC classes between pre- and post-occupancy and very low initial VOC concentrations. This finding might be due in part to the decrease in fresh-air dilution between the sampling periods. The other significant finding was the larger than expected drop in VOCs between the sampling events for IaP2, which may indicate an additional non-building-related source during the pre-occupancy measurement event, possibly related to an evaporative source of gasoline and combustion products along with the high hexanal signal. Both findings reinforce the importance and significance of sampling timing, both with regard to the age of materials and related construction activities. 


\subsection{References}

\subsection{General References:}

Challenge Home

http://www1.eere.energy.gov/buildings/residential/ch_guidelines.html

http://www1.eere.energy.gov/buildings/residential/pdfs/doe_challenge_home_requirementsv3.pdf

Indoor airPLUS - Version 1 (Rev. 01): http://www.epa.gov/IaPlus01/construction_specifications.html http://www.epa.gov/IaPlus01/pdfs/construction_specifications.pdf

\section{Energy Star for Homes - version 3.0}

http://www.energystar.gov/index.cfm?c=bldrs lenders raters.nh v3 guidelines

http://www.energystar.gov/ia/partners/bldrs_lenders_raters/downloads/National_Program_Requirements. pdf?bd14-d3c0

Federal Standards on Formaldehyde:

http://www.epa.gov/opptintr/chemtest/formaldehyde/

The Formaldehyde Standards for Composite Wood Products Act of 2010 (Title VI of Toxic Substances Control Act) sets national emission standards that mirror standards previously established by the California Air Resources Board for composite wood products: hardwood plywood, medium-density fiberboard, and particleboard.

California Formaldehyde Standard:

http://www.arb.ca.gov/toxics/compwood/compwood.htm

\section{LBNL Report on Material Certification Programs}

Chemical Emissions of Residential Materials and Products: Review of Available Information by Willem et al.

http://eetd.lbl.gov/node/50579

\subsection{Cited Literature}

ASHRAE (Association of Heating, Refrigeration, and Air-Conditioning Engineers). 2014. Method of Test for Determining the Design and Seasonal Efficiencies of Residential Thermal Distribution Systems. ASHRAE Standard 152, Atlanta, Georgia.

ASHRAE (Association of Heating, Refrigeration, and Air-Conditioning Engineers). 2013. ASHRAE Standard 55 - Thermal Environmental Conditions for Human Occupancy. ASHRAE, Atlanta, Georgia.

ASHRAE (Association of Heating, Refrigeration, and Air-Conditioning Engineers). 2010. ASHRAE Standard 62.2 - Ventilation and Acceptable Indoor Air Quality in Low-Rise Residential Buildings. ASHRAE, Atlanta, Georgia.

Hult EL, Willem H, Price PN, Hothci T, Russell ML, Singer BC. 2014 (Accepted for Publication). Formaldehyde exposure mitigation in US residences: In-home measurements of ventilation control and source control. Indoor Air.. 
Maddalena R, A Parra, M Russell, W-Y Lee. 2013. Measurement of Passive Uptake Rates for Volatile Organic Compounds on Commercial Thermal Desorption Tubes and the Effect of Ozone on Sampling. LBNL-6257E, Lawrence Berkeley National Laboratory, Berkely, California..

Mullen NA, ML Russell, MM Lunden, and BC Singer. 2013. Investigation of formaldehyde and acetaldehyde sampling rate and ozone interference for passive deployment of Waters Sep-Pak XPoSure samplers. Atmospheric Environment 80:184-189.

Offermann FJ. 2009. Ventilation and Indoor Air Quality in New Homes. CEC-500-2009-085, Collaborative Report by the California Air Resources Board and California Energy Commissions, PIER Energy-Related Environmental Research Program.

Safebridge Consultants, Inc. 2013a. "Development of Acceptable Air Concentrations for Five Perfluorinated Tracers (PFTs) First Report." CONFIDENTIAL. Oak Ridge National Laboratory on behalf of the U.S. Department of Energy. Washington, D.C.

Safebridge Consultants, Inc. 2013b. "Development of Acceptable Air Concentrations for Five Perfluorinated Tracers (PFTs) Second Report." CONFIDENTIAL. Oak Ridge National Laboratory on behalf of the U.S. Department of Energy. Washington, D.C.

EPA (U.S. Environmental Protection Agency). 1999a. "Compendium Method TO-11A: Determination of Formaldehyde in Ambient Air Using Adsorbent Cartridge Followed by High-Performance Liquid Chromatography (HPLC) [Active Sampling Methodology]." Compendium of Methods for Determining Toxic Organic Compounds in Ambient Air, EPA/625/R-96/010b, U.S. Environmental Protection Agency, Cincinnati, Ohio.

EPA (U.S. Environmental Protection Agency). 1999b. "Compendium Method TO-17: Determination of Volatile Organic Compounds in Ambient Air Using Active Sampling Onto Sorbent Tubes." Compendium of Methods for Determining Toxic Organic Compounds in Ambient Air, EPA/625/R 96/010b, U.S. Environmental Protection Agency, Cincinnati, Ohio.

Willem H, EL Hult, T Hotchi, ML Russell, RL Maddalena, and BC Singer. 2013. Ventilation Control of Volatile Organic Compounds in New U.S. Homes: Results of a Controlled Field Study in Nine Residential Units. LBNL-6022E, Lawrence Berkeley National Laboratory, Berkeley, California. .

Willem H and BC Singer. 2010. Chemical Emissions of Residential Materials and Products: Review of Available Information. LBNL-3938E, Lawrence Berkeley National Laboratory, Berkeley, California. 



\section{Appendix A}

\section{Experimental Plan}



Appendix A

\section{Experimental Plan}




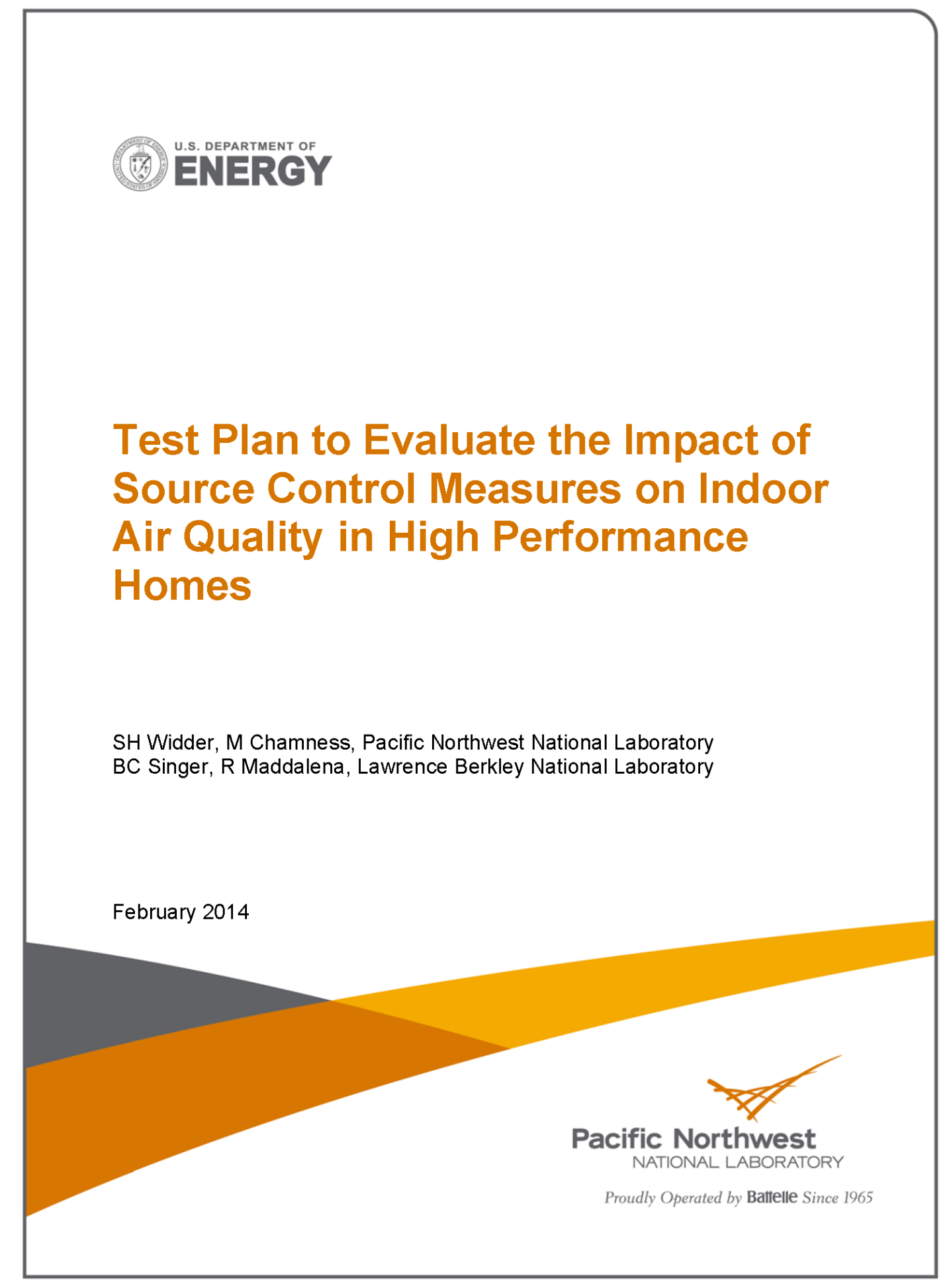




\section{DISCLAIMER}

This report was prepared as an account of work sponsored by an agency of the United States Government. Neither the United States Government nor any agency thereof, nor Battelle Memorial Institute, nor any of their employees, makes any warranty, express or implied, or assumes any legal liability or responsibility for the accuracy, completeness, or usefulness of any information, apparatus, product, or process disclosed, or represents that its use would not infringe privately owned rights. Reference herein to any specific commercial product, process, or service by trade name, trademark, manufacturer, or otherwise does not necessarily constitute or imply its endorsement, recommendation, or favoring by the United States Government or any agency thereof, or Battelle Memorial Institute. The views and opinions of authors expressed herein do not necessarily state or reflect those of the United States Government or any agency thereof.

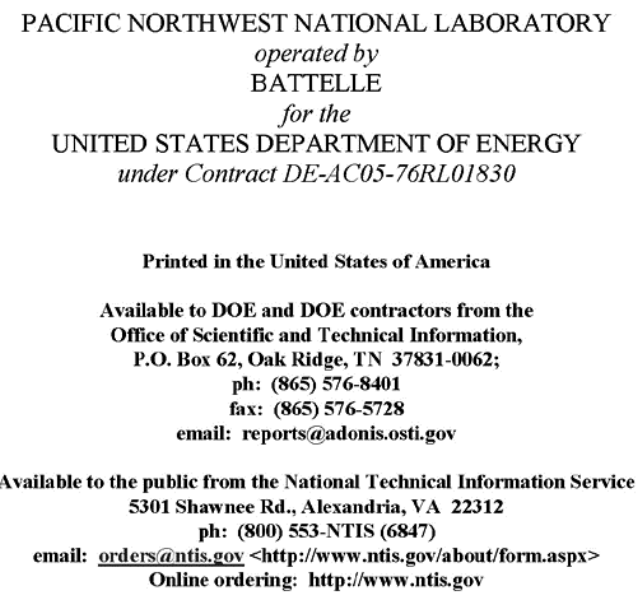

This document was printed on recycled paper.

(8/2010) 


\section{Test Plan to Evaluate the Impact of Source Control Measures on Indoor Air Quality in High Performance Homes}

SH Widder, M Chamness, Pacific Northwest National Laboratory BC Singer, R Maddalena, Lawrence Berkeley National Laboratory

February 2014

Prepared for

the U.S. Department of Energy

under Contract DE-AC05-76RL01830

Pacific Northwest National Laboratory

Richland, Washington 99352 
PNNL-Internal Planning Document 


\section{Acronyms and Abbreviations}

$\begin{array}{ll}\begin{array}{l}\text { AER } \\ \text { ffm }\end{array} & \begin{array}{l}\text { air exchange rate } \\ \text { cubic feet per minute } \\ \text { cfm } 25\end{array} \\ \text { cfm } 50 & \begin{array}{l}\text { cubic feet per minute at } 25 \text { pascals of depressurization with respect to the outside } \\ \text { carbon dioxide } \\ \mathrm{CO}_{2}\end{array} \\ \mathrm{CT} & \text { current transducer } \\ \text { DOE } & \text { U.S. Department of Energy } \\ \text { EPA } & \text { U.S. Environmental Protection Agency } \\ \text { HBATC } & \text { Home Builders Association of the Tri Cities } \\ \text { IAP } & \text { Indoor airPLUS } \\ \text { IAQ } & \text { Indoor Air Quality } \\ \text { LEED } & \text { Leadership in Energy and Environmental Design } \\ \text { OSB } & \text { Oriented Strand Board } \\ \text { PFT } & \text { perfluorocarbon tracer } \\ \text { RH } & \text { relative humidity } \\ \text { T } & \text { temperature } \\ \text { VOC } & \text { volatile organic compounds } \\ \text { Wh } & \text { watt-hour }\end{array}$




$$
\text { A. } 7
$$




\section{Figures}

Figure 2.1. Overall Schedule for Homeowner and Builder Engagement, Sampling Periods, Data

Analysis, and Reporting

Figure 3.1....... Schematic and photograph of an eGauge energy metering system, consisting of a 1) main power meter unit, 2) current transformers, 3) voltage taps connected to a dual-pole breaker, 4) HomePlug communication adapter, and 5) an internet router. Note that the HomePlug and Internet router are not shown in breaker panel photograph.

\section{Tables}

Table 2.1. Checklist of Experimental Activities for Each Home, Including Timing and Relevant

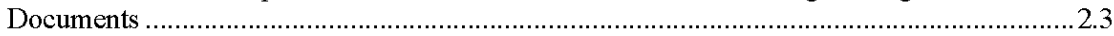

Table 2.2. Criteria to Determine Candidate Homes for Study Participation.....................................2.4

Table 2.3. Characteristics of Homeowners Used to Determine Inclusion or Exclusion ..................2.5

Table 2.4. Schedule of Homeowner Stipends and Amounts........................................................ 2.7

Table 2.5. Summary of Average High, Low, Record High, and Record Low Temperatures in F (with years, as applicable) and Average Precipitation in the Tri Cities, WA (actual data from Kenniwick, WA)

Table 2.6. Summary List of Compounds that are Typically Found Indoors along with Possible

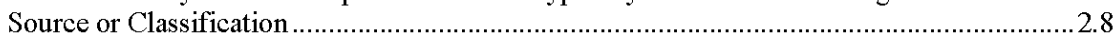

Table 3.1. Summary of Measurements Occurring During Each Sampling Period ........................... 3.1

Table 3.2. Measurement Parameters, Measurement Equipment, and Sampling Rates...................3.3

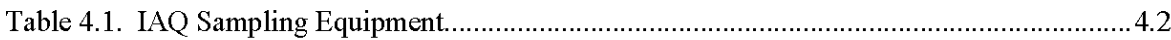

Table 4.2. Tracers available for gas air flow studies................................................................. 4.3

Table 4.3. Collection Matrix Illustrating the Number and Location of Samples for the PreOccupancy Sampling. ............................................................................................ 4.5

Table 4.4. Collection Matrix Illustrating the Number and Location of Samples for the PostOccupancy Period. 


$$
\text { A. } 9
$$




\subsection{Introduction}

\subsection{Background}

As tighter homes are constructed and an increasing number of synthetic compounds are introduced into the built environment there is potential to change the types and concentrations of chemicals to which occupants are exposed. Recent data indicate that new airtight homes commonly have levels of some volatile organic compounds (VOCs) that exceed health-based standards. Increased exposure could lead to decreased indoor air quality and health issues in especially tight high-performance homes.

VOCs can be mitigated by increasing ventilation or by controlling sources. Increased ventilation can lead to increased energy use and, thus, effective means of minimizing sources of indoor air contaminants could be an efficient and effective means of achieving acceptable or improved indoor air quality in new homes. A variety of standards and rating programs have been introduced to identify building materials that are designed to have lower emission rates of key contaminants of concern and a number of building materials are being introduced that are certified to these standards. For example, DOE Challenge Home requires the use EPA's Indoor airPLUS label, which requires the use of PS1 or PS2 certified plywood and OSB; low-formaldehyde emitting wood products; low- or no-VOC paints and coatings as certified by Green Seal Standard GS-11, GreenGuard, SCS Indoor Advantage Gold Standard, MPI Green Performance Standard, or another third party rating program; and Green Label-certified carpet and carpet cushions. However, given the variety of standards and ratings, it is not clear the effect of these requirements on achieving measureable reductions in indoor air concentrations of VOCs and aldehydes and related exposures.

While DOE Challenge Home and other voluntary programs encourage selection of low-emitting materials and finishes to improve indoor air quality via the Indoor airPLUS requirements, little is known regarding the efficacy of the Indoor airPLUS requirements. Without this data, it is not possible to determine how using low-emitting materials might affect the necessary ventilation rate for highperformance homes. If source emission rates are in fact decreased by use of Indoor airPLUS-certified materials and finishes, then it should be possible to reduce the necessary "building-related" ventilation rate in those homes, further reducing energy use and possibly reducing capital costs of providing mechanical ventilation.

\subsection{Standards Related to Low-emitting Materials}

Several major home labeling programs are currently available. The U.S. Environmental Protection Agency (EPA) launched the Indoor airPLUS home labeling program in 2009, a significant milestone in the effort to assist homebuyers in identifying residences with good indoor air quality. The program recognizes new homes equipped with a comprehensive set of Indoor Air Quality (IAQ) features, which includes use of low-emission materials and coatings. Other major programs include the Leadership in Energy and Environmental Design (LEED) rating for Homes from the U.S. Green Building Council and the National Green Building Standard (NGBS) from the National Association of Home Builders (NAHB). The Department of Energy Challenge Home program offers two paths to be home labeling both of which include addressing indoor air quality based on the Indoor airPLUS specifications including use of low VOC emitting building materials. 
This study will specifically address requirements associated with the EPA's Indoor airPLUS program. Indoor airPLUS (IAP) requires the use of low-emitting and formaldehyde-free paints, coatings, carpet, carpet pads, OSB, and other wood products. Specifically, IAP 6.1, 6.2, and 6.3 specify certain certifications materials must meet. In addition, IAP section 7.2 requires the home to be ventilated after material installation and prior to occupancy, to help minimize exposure to any remaining contaminants.

The Home Builders Association of the Tri Cities (HBATC) also offers a BuiltGreen program with many similar requirements for material selection and installation. If a sufficient sample of DOE Challenge Homes cannot be identified, builders of home meeting equivalent Built Green specifications may be considered. Detailed specifications from both IAP and Built Green programs are provided as Appendix A.

With regard to certification agencies and procedures, various organizations and testing laboratories certify low-emission materials. In California, testing methods and performance criteria are based on California Department of Public Health Standard Method (Section 01350), "Standard Method for the Testing and Evaluation of Volatile Organic Chemical Emissions from Indoor Sources Using Environmental Chambers." The standard is gaining nationwide acceptance as the benchmark. It was first established for commercial buildings such as offices and schools; a section for new single-family residences was added later. Scientific Certification Systems (SCS) and the GREENGUARD Environmental Institute (GEI) are two major certification organizations in the U.S. with substantial databases on low-emission materials and household products. Lists of certified low-emission materials or products are also compiled by other organizations. The information is generally available through their websites. These include the Low Emitting Materials Table from the Collaborative for High Performance School (CHPS) developed in partnership with the EPA (a report on emissions characteristics of new materials and their older counterparts using California Specification 01350 is available through the CHPS program), the LEED Green Building Rating Systems, and the Pharos Project materials rating system from the Healthy Building Network (HBN).

Although emissions characteristics of building materials have been extensively reported, health-based standards or guidelines to ensure good indoor air quality, and regulations to control the production of potentially hazardous materials are still lacking. Although current rating systems and low emitting material certifications are aimed at addressing issues of sustainability, energy efficiency and indoor air quality, there is a lack of field validation of the efficacy of such rating and certification systems on achieving measurable improvements in indoor air quality.

\subsection{Problem Statement}

The objective of this project is to verify and quantify the indoor air quality benefits of the Indoor airPLUS requirements for low-emitting materials and finishes for new home construction. DOE's Challenge Home and other voluntary programs currently include these requirements without in-use verification of effectiveness. This project will measure concentrations of volatile organic compound and aldehydes in same-age Challenge Homes and conventional reference homes built in the same geographic location. Sampling will occur in similar timeframes in both Challenge and conventional home cohorts prior to homeowners moving in (pre-occupancy), immediately following homeowners moving in (postoccupancy), and over periods of 3-12 months post-occupancy. 


\subsection{Experimental Approach}

In this task, PNNL will collaborate with LBNL and local builders and homeowners to collect data on indoor air quality impacts of Indoor airPLUS-approved low-emitting materials and finishes. This study will consist of evaluation of the difference between low-emitting and "conventional" materials in: (1) a longitudinal field evaluation to understand the impact of low-emitting materials as installed in homes as they age and (2) a highly controlled, short-term field evaluation specifically targeting the building related chemical emissions and building contents.

The field study will compare the measured speciated VOC and aldehyde concentrations normalized to measured air exchange rates (AER), temperature $(\mathrm{T})$, relative humidity $(\mathrm{RH})$, and carbon dioxide $\left(\mathrm{CO}_{2}\right)$ in 12 Indoor airPLUS (IAP) and 12 conventional homes of the same age. Homes will be selected in paired groups of IAP and conventional homes of similar age, location, and construction style, with up to 6 of each homes of each type included in the first sample period ( 12 homes total). The first 6 homes will be identified in the first year and measurements will be made prior to homeowners moving in (preoccupancy) and roughly 1,3 and 12 months post- occupancy. If continuation funding is received as expected, successive groups of 6 new homes will be brought into the study roughly every 6 months and sampled using the same measurement schedule of pre-occupancy and roughly 1,3 and 12 months postoccupancy.

Each sampling period will include two short-term active samples collected with the home operated under controlled and consistent conditions, one in the early morning and one in the afternoon. The first two post-occupancy sampling events ( 1 month and 3 months post-occupancy) will also include week-long passive measurements. Occupant behavior and weather conditions can confound field data making it difficult to differentiate building related emissions from building contents and emission related to occupants. The combination of detailed short-term measurements with the home under controlled/consistent conditions during pre- and post-occupancy, and the long-term field data provide the opportunity to begin to separate the different emission sources and help isolate and quantify variability in the monitored homes. The short-term samples collected pre-occupancy will provide home specific information about building related emissions while the short-term post-occupancy samples will provide information on the building contents. The long-term samples under natural conditions are expected to provide information about emissions related to occupant activities.

\subsection{Research Questions}

The primary research questions being addressed are:

- Are the concentrations and composition of VOCs and aldehydes measured in IAP homes significantly different than homes built with conventional materials?

- What is the relative contribution of building materials versus furniture and other occupantintroduced materials to measured concentrations of VOCs and aldehydes in IAP and conventional homes? 
- How do concentrations of VOCs and aldehydes change over time post-occupancy?

If timing and funding allow, the impact of the "first flush," required by IAP section 7.2, on measured concentrations of VOCs and aldehydes will also be evaluated.

\subsection{Schedule}

This research project will require phases of builder and homeowner engagement, data collection, analysis, and reporting. An overall proposed recruitment and sampling schedule in provided in Figure 2.1.

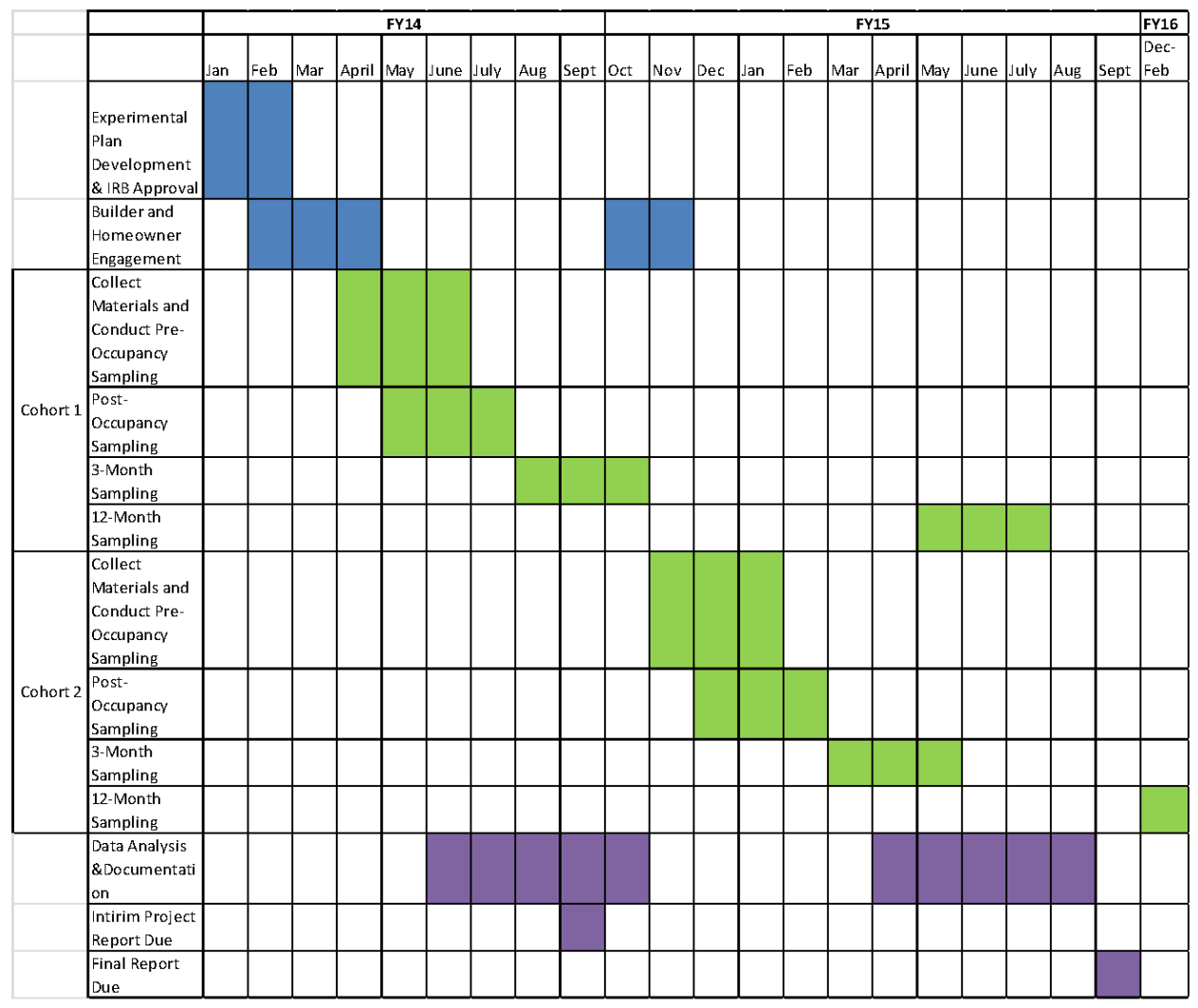

Figure 2.1. Overall Schedule for Homeowner and Builder Engagement, Sampling Periods, Data Analysis, and Reporting

A checklist for each home is included as Table 2.1. 
Table 2.1. Checklist of Experimental Activities for Each Home, Including Timing and Relevant Documents

\begin{tabular}{|l|l|l|}
\hline Activity & Timing & Relevant Documents \\
\hline Homeowner Agreement Signed? & $\begin{array}{l}\text { Homeowner Agreement \& Homeowner } \\
\text { Information Sheet }\end{array}$ \\
\hline $\begin{array}{l}\text { List of Materials Used in Construction } \\
\text { Obtained? }\end{array}$ & $\begin{array}{l}\text { At home } \\
\text { completion }\end{array}$ & $\begin{array}{l}\text { Materials Tracking Form and inspection } \\
\text { schedule }\end{array}$ \\
\hline $\begin{array}{l}\text { Home Construction Characteristics } \\
\text { Obtained (either via audit or from } \\
\text { builder/rater)? }\end{array}$ & $\begin{array}{l}\text { At home } \\
\text { completion }\end{array}$ & Building Audit Form or comparable \\
\hline Pre-Occupancy Sampling Conducted? & $\begin{array}{l}\text { Approximately 1 } \\
\text { week prior to } \\
\text { occupancy }\end{array}$ & IAQ Sampling Protocol \\
\hline Post-Occupancy Sampling Conducted? & $\begin{array}{l}\text { Within 4 weeks } \\
\text { post occupancy }\end{array}$ & $\begin{array}{l}\text { IAQ Sampling Protocol \& Homeowner } \\
\text { Questionnaire (full) }\end{array}$ \\
\hline 3-Month Sampling Conducted? & $\begin{array}{l}\text { 3 months post- } \\
\text { occupancy }\end{array}$ & $\begin{array}{l}\text { IAQ Sampling Protocol \& Homeowner } \\
\text { Questionnaire (IAQ only) }\end{array}$ \\
\hline 12-Month Sampling Conducted? & $\begin{array}{l}\text { 12months post- } \\
\text { occupancy }\end{array}$ & $\begin{array}{l}\text { IAQ Sampling Protocol \& Homeowner } \\
\text { Questionnaire (IAQ only) }\end{array}$ \\
\hline
\end{tabular}

Each IAQ sampling period will consist of short-term and long-term IAQ measurements. In general, the short-term, detailed measurements will occur two separate times in the early morning prior to the homeowners waking up and in the early afternoon prior to homeowners returning home from work $/$ school $^{1}$. The period of inactivity preceding the $30-60$ minute spot samples will help create conditions that characterize the "stead-state" emissions from building materials and furnishings, without the confounding influence of transient occupant behavior. The duplicate samples (morning and evening) are to capture any diurnal trends in the emission profile (e.g. greater emission rates in the afternoon due to increased solar heating). This controlled sample will occur during the 24-hours immediately prior to the 7 day long-term measurements. During the long-term passive sample, homeowners will not be asked to modify their behavior significantly. Thus, the long-term passive sample periods will capture the indoor air contaminant concentrations experienced during "typical" occupancy and evaluate the transient "people-related" emission sources, as compared to the constant "building-related" contaminant sources characterized during the controlled sample. This is representative of what the homeowners are exposed to. As homeowner activities and behavior can have a large impact on indoor contaminant generation and given the variability of activities homeowners may engage it, during passive events homeowners will be asked to $\log$ significant contaminant-generating activities to allow better understanding and analysis of the data. This logging will occur on a daily basis via an electronic tool. See Appendix F for more information.

${ }^{1}$ If the homeowners do not work will be asked to not be at home for a period of 4-6 hours on the controlled sample day. 
The timing and procedure for the short-term and long-term sampling events are described in more detail in section 4.0 .

\subsubsection{Builder Engagement}

Builders and homeowner engagement will be conducted by personal contact via phone and electronic means. An initial group of builders will be identified that are likely to be constructing homes during the timeframe of interest either fully complying with Indoor airPLUS low-emitting material requirements, IAP sections 6.1 through 6.3 and 7.2, or including no materials certified as low-emitting based on the standards listed in IAP section 6.1 through 6.3. This initial group of builders will be identified through coordination with the Home Builders Association of the Tri Cities (HBATC) and the developer of Badger Mountain South, a local development intending to build significant numbers of DOE Challenge Homes and/or homes built to the HBATC's BuiltGreen Program. Builders will be selected based on the timing of new home construction, whether the homes are intended to be "spec" homes or built to order, the materials used, and other construction specifications. The specific criteria used to select candidate homes are included as Table 2.2. A list of questions that will be asked of the builders during recruitment is included as Appendix B. Contingent on an executed homeowner agreement in one of their homes, builders will be provided a $\$ 500$ stipend to compensate them for their time and cooperation coordinating with PNNL researchers to collect materials samples, collect home construction characteristics, access homes prior to homeowner occupancy, and related activities.

Table 2.2. Criteria to Determine Candidate Homes for Study Participation

\begin{tabular}{|c|c|c|}
\hline Issue & Criteria & Notes \\
\hline Timing & $\begin{array}{l}\text { Constructing home that will be completed between } \\
\text { April } 15^{\text {th }} \text { and July } 30^{\text {th }} \text {, and occupied between } \\
\text { May } 1^{\text {st }} .2014 \text { and July } 15^{\text {th }} \text { for the summer cohort } \\
\text { of homes, } \\
\text { Constructing homes that will be occupied between } \\
\text { November } 1^{\text {st }}, 2014 \text { and January } 15^{\text {th }}, 2015 \text { for the } \\
\text { winter cohort of homes. }\end{array}$ & $\begin{array}{l}\text { Preference will be given to homes } \\
\text { completed by June } 30^{\text {th }} \text {. } \\
\text { Preference will be given to homes } \\
\text { completed by December } 15^{\text {th }}, 2014\end{array}$ \\
\hline $\begin{array}{l}\text { Construction } \\
\text { Materials }\end{array}$ & $\begin{array}{l}\text { Building homes that will completely comply with } \\
\text { IAP section } 6.1 \text { through } 6.3 \text { and } 7.2 \text { or constructing } \\
\text { homes with no materials certified as complying } \\
\text { with the standards referenced in IAP section } 6.1 \\
\text { and } 6.2 \text {. }\end{array}$ & $\begin{array}{l}\text { Preference will be given to home fully } \\
\text { complying with DOE Challenge Home } \\
\text { criteria }^{1} \text { for IAP homes and homes with no } \\
\text { low-emitting materials for conventional } \\
\text { homes. }\end{array}$ \\
\hline
\end{tabular}

\subsubsection{Homeowner Engagement}

Homeowners will be engaged based on their purchase of a house that is appropriate for inclusion in the study from one of the participating builders. Two recruitment mechanisms will be employed: (1) outreach through builders and (2) direct recruitment of homeowners having homes built in the Tri Cities. The primary recruitment mechanism will be outreach through builders. Once homes that meet the criteria

${ }^{1}$ U.S. Department of Energy. 2013. DOE Challenge Home National Program Requirements (Rev. 03). Available at: http:/www.energy.gov/sites/prod/files/2013/11/f5/doe challenge home requirementsv3.pdf 
listed in Table 2.2 are identified, the new homebuyers of that home will be contacted by PNNL researchers through the builder. The builder will be asked to share the information sheet (see Appendix C) with the new homebuyers, which will explain the background on the study, what participation entails, and provide contact information for the PNNL researchers conducting the study who the homeowner may contact for more information. The secondary recruitment mechanism will be outreach to individuals having homes built in the Tri Cities, whose homes meet the criteria established in Table 2.2. Recruitment directly to homeowners will occur first to PNNL employees using the PNNL Whiteboard discussion forum and $\mathrm{LabWeb}{ }^{1}$. Other Tri Cities residents may be informed and recruited via word of mouth. The content of PNNL Whiteboard and LabWeb communications is included as (Appendix D). The message provides a brief summary and explanation of the research, a description of the criteria for participating homes, and encourages interested new homebuyers to contact research personnel for more information.

If the homeowners are interested in finding out more, the homeowners will be asked to contact PNNL researchers and an in-person meeting will be scheduled to explain the study in more detail, answer any questions the homeowner may have, and if the homeowner chooses to participate, sign the homeowner agreement (Appendix E).

In general, participation in this study will be based on occupying a new home that meets the criteria listed in Table 2.2 and agreement to cooperate with researchers during the sampling events (demonstrated by signing the homeowner agreement). However, this study is designed to characterize the difference between VOCs (including aldehydes) in IAP versus conventional homes under typical occupancy scenarios. As such, occupants will be asked to provide information on several characteristics that may affect the quality or representative nature of the IAQ measurements and may be excluded on such a basis. Such information will be gathered based on an initial interview with homeowners. The requested information and the justification for exclusion are provided in Table 2.3.

Table 2.3. Characteristics of Homeowners Used to Determine Inclusion or Exclusion

\begin{tabular}{lll}
\hline Issue & Criteria & Notes \\
\hline Home & $\begin{array}{l}\text { Ownership of a home meeting the } \\
\text { criteria established in Table 2.2 }\end{array}$ & This is a primary criteria for inclusion \\
$\begin{array}{l}\text { Demonstration of willingness to } \\
\text { participate in the study through } \\
\text { signing of the Homeowner } \\
\text { Agreement (Appendix E) }\end{array}$ & This is a primary criteria for inclusion \\
Ventilation & $\begin{array}{l}\text { Operation of home ventilation } \\
\text { systems using typical schedules, } \\
\text { including window operation. }\end{array}$ & $\begin{array}{l}\text { Preference will be given to homeowners that do not } \\
\text { frequently open windows as it will be more likely } \\
\text { that they will comply with the request to keep } \\
\text { windows closed during the 24-hour controlled } \\
\text { sampling event. }\end{array}$ \\
& $\begin{array}{l}\text { Maintenance of home interior } \\
\text { temperature set points within } 4{ }^{\circ} \mathrm{F}\end{array}$ & $\begin{array}{l}\text { Interior temperature will affect the emission rate of } \\
\text { chemicals from various building materials and, thus, } \\
\text { will affect the concentrations of contaminants } \\
\text { measured in the homes. Especially warm or cold } \\
\text { homes could reduce or exaggerate emission rates }\end{array}$ \\
\hline
\end{tabular}

$\overline{{ }^{1} \text { See https://labweb.pnl.gov/whiteboard/Pages/Home.aspx and https://labweb.pnl.gov/Pages/Home.aspx. }}$ 


\begin{tabular}{lll}
\hline Occupancy & $\begin{array}{l}\text { No more than N+2 occupants } \\
\text { where N is the number of } \\
\text { bedrooms and no more than } 5 \\
\text { pets. }\end{array}$ & $\begin{array}{l}\text { and make comparison among homes difficult. } \\
\text { Extremely high occupancy or pet ownership could } \\
\text { result in excessive introduction of people-related } \\
\text { pollutants that will interfere with measurement of } \\
\text { building-related pollutants and may not be } \\
\text { representative of typical households. } \\
\text { Smoking, candle burning and use of incense are } \\
\text { known to generate significant amounts of } \\
\text { particulates, VOCs, and aldehydes that would likely } \\
\text { overwhelm other pollutant sources in the homes and } \\
\text { make it difficult to determine the impact of Indoor } \\
\text { airPLUS criteria. }\end{array}$ \\
$\begin{array}{lll}\text { Smoking } \\
\text { and other } \\
\text { particulate- } \\
\text { generating } \\
\text { activities }\end{array}$ & $\begin{array}{l}\text { No daily smoking, candle } \\
\text { burning, or use of incense in the } \\
\text { home. }\end{array}$ & $\begin{array}{l}\text { Homeowners that frequently engage in other } \\
\text { activities that would have a significant impact on } \\
\text { IAQ in the home or otherwise interfere with the } \\
\text { measurements or study results will be evaluated } \\
\text { individually. }\end{array}$ \\
$\begin{array}{l}\text { Other } \\
\text { activities }\end{array}$ & No specific criteria established &
\end{tabular}

Subsequent to entering the study, homeowners will be contacted via phone or email to schedule IAQ sampling visits. During this initial phone call, homeowners will be asked general questions regarding their anticipated activities for the upcoming sample week and these responses will be tracked. During IAQ sampling, homeowners will also be asked to log daily their activities using an online survey tool. Researchers will follow up with homeowners to verify responses and clarify any unusual responses when retrieving samplers or during a separate follow-up call. A copy of the general homeowner questionnaire and the daily logging questions are included as Appendix F.

Homeowners will be paid a stipend in compensation for any inconvenience and disruption caused by participation in the study according to the schedule in Table 2.4, with increasing amounts reflecting the increasing value of the data and encouraging homeowners to complete the full suite of IAQ sampling periods. However, it will be made clear that participation is purely voluntary and the homeowners may withdraw from the study at any time. The stipend amounts were selected to be large enough that they are significant, given the anticipated socioeconomic situation of the new homeowners likely to participate in the study (homebuyers in the Tri Cities), but low enough so as not to be unduly influencing of any decision to participate or not participate.

Depending on the success of recruitment, some homes may undergo an abbreviated sample schedule, consisting only of controlled pre-occupancy and 2-4 weeks post-occupancy measurements. The stipend amounts provided will reflect this (i.e. $\$ 50$ for the pre-occupancy sampling period and $\$ 100$ for the postoccupancy sampling period ${ }^{1}$ ). Homeowners will be made aware that all sample periods may not occur in all homes.

\footnotetext{
${ }^{1}$ Homeowners undergoing abbreviated sampling will still receive the $\$ 50$ available for logging, although they will not be required to complete a log since no long-term field sampling will occur. The $\$ 50$ will simply be to thank homeowners for their cooperation in the study
} 
Table 2.4. Schedule of Homeowner Stipends and Amounts

\begin{tabular}{lrr}
\hline IAQ Sam pling Period & $\begin{array}{r}\text { Sampling Stipend } \\
\text { Amount }\end{array}$ & $\begin{array}{r}\text { Maximum Available Logging } \\
\text { Stipend Amount* }\end{array}$ \\
\hline Pre-Occupancy & $\$ 50$ & $\$ 0$ \\
2-4 Weeks Post-Occupancy & $\$ 50$ & $\$ 50$ \\
6-13 Weeks Post-Occupancy & $\$ 100$ & $\$ 50$ \\
1 Year Post-Occupancy & $\$ 150$ & $\$ 50$ \\
Total & $\$ 350$ & $\$ 150$ \\
\hline * Logging to be completed daily, \$5/day + \$15 for completing the activity log all 7 days. \\
\hline
\end{tabular}

\subsection{Location}

Sampling will be performed in up to 24 new homes in the Tri Cities, WA. The homes will be selected based on the criteria presented in section 2.2.1 and will include two sampling cohorts (summer and winter) of up to 6 IAP homes and 6 conventional homes in each cohort. The IAP homes will generally be selected from homes in the Badger Mountain South development in Richland, WA, which has committed to encouraging builders and homeowners to consider DOE Challenge Home criteria and established the HBATC BuiltGreen criteria as a minimum standard for building in the community.

The conventional homes will be selected as homes of similar construction, constructed and occupied at a similar time also in the Tri Cities, WA. Note, the conventional homes will be built to the WA state code, which requires ventilation equipment and flow rates compliant with ASHRAE 62.2-2010. Thus, the primary difference affecting indoor air quality in the IAP homes is the use of low-emitting materials and conduction of a "first flush" prior to occupancy.

Sampling will occur at 1-3 locations indoors during the controlled sampling periods and 3-5 locations indoors during the long-term field measurements in each home, along with 1 location outdoors during each sampling period. Outdoor measurement will occur in an open area, away from large trees, 2 meters above the ground, and sheltered from the elements. Indoor measurements during the controlled period will be located near return air grilles while long-term passive samples will be distributed throughout the home in spaces including, for example, near the HVAC return grille, near the exhaust fan inlet, and/or a location farthest away from the return air grille. All indoor air quality measurements will, ideally, be taken in the breathing zone, which is described as between 2 feet and 5 feet from the floor and 3 feet from any wall.

Weather in the Tri Cities is generally very consistent throughout the summer and winter months, respectively, with short spring and fall periods in March/April and October/November, respectively. A summary of typical weather conditions in the Tri Cities, WA is provided in Table 2.5. 
Table 2.5. Summary of Average High, Low, Record High, and Record Low Temperatures in F (with years, as applicable) and Average Precipitation in the Tri Cities, WA (actual data from Kennewick, WA).

\begin{tabular}{|c|c|c|c|c|c|c|}
\hline Month & $\begin{array}{l}\text { Avg. } \\
\text { High }\end{array}$ & $\begin{array}{l}\text { Avg. } \\
\text { Low }\end{array}$ & Mean & $\begin{array}{c}\text { Avg. } \\
\text { Precip }\end{array}$ & $\begin{array}{c}\text { Record } \\
\text { High }\end{array}$ & $\begin{array}{c}\text { Record } \\
\text { Low }\end{array}$ \\
\hline$\underline{\mathrm{Jan}}$ & $42^{\circ} \mathrm{F}$ & $29^{\circ} \mathrm{F}$ & $36^{\circ} \mathrm{F}$ & $1.08 \mathrm{in.}$ & $69^{\circ} \mathrm{F}(2003)$ & $-19^{\circ} \mathrm{F}(1950)$ \\
\hline Feb & $48^{\circ} \mathrm{F}$ & $31^{\circ} \mathrm{F}$ & $40^{\circ} \mathrm{F}$ & $0.81 \mathrm{in.}$ & $74^{\circ} \mathrm{F}(1995)$ & $-23^{\circ} \mathrm{F}(1950)$ \\
\hline$\underline{\text { Mar }}$ & $58^{\circ} \mathrm{F}$ & $36^{\circ} \mathrm{F}$ & $47^{\circ} \mathrm{F}$ & 0.73 in. & $82^{\circ} \mathrm{F}(1960)$ & $10^{\circ} \mathrm{F}(1955)$ \\
\hline Apr & $66^{\circ} \mathrm{F}$ & $42^{\circ} \mathrm{F}$ & $54^{\circ} \mathrm{F}$ & 0.56 in. & $91^{\circ} \mathrm{F}(1987)$ & $22^{\circ} \mathrm{F}(1952)$ \\
\hline May & $75^{\circ} \mathrm{F}$ & $50^{\circ} \mathrm{F}$ & $63^{\circ} \mathrm{F}$ & $0.64 \mathrm{in.}$ & $104^{\circ} \mathrm{F}(1983)$ & $30^{\circ} \mathrm{F}(1986)$ \\
\hline$\underline{\text { Jun }}$ & $82^{\circ} \mathrm{F}$ & $56^{\circ} \mathrm{F}$ & $69^{\circ} \mathrm{F}$ & $0.51 \mathrm{in.}$ & $107^{\circ} \mathrm{F}(1992)$ & $38^{\circ} \mathrm{F}(1975)$ \\
\hline$\underline{\mathrm{Jul}}$ & $90^{\circ} \mathrm{F}$ & $62^{\circ} \mathrm{F}$ & $76^{\circ} \mathrm{F}$ & $0.22 \mathrm{in.}$ & $109^{\circ} \mathrm{F}(2006)$ & $42^{\circ} \mathrm{F}(1971)$ \\
\hline$\underline{\mathrm{Aug}}$ & $89^{\circ} \mathrm{F}$ & $61^{\circ} \mathrm{F}$ & $75^{\circ} \mathrm{F}$ & 0.18 in. & $110^{\circ} \mathrm{F}(1998)$ & $41^{\circ} \mathrm{F}(1965)$ \\
\hline$\underline{\text { Sep }}$ & $80^{\circ} \mathrm{F}$ & $52^{\circ} \mathrm{F}$ & $66^{\circ} \mathrm{F}$ & $0.30 \mathrm{in.}$ & $100^{\circ} \mathrm{F}(1987)$ & $30^{\circ} \mathrm{F}(1983)$ \\
\hline$\underline{\mathrm{Oct}}$ & $66^{\circ} \mathrm{F}$ & $42^{\circ} \mathrm{F}$ & $54^{\circ} \mathrm{F}$ & 0.60 in. & $89^{\circ} \mathrm{F}(1988)$ & $17^{\circ} \mathrm{F}(1971)$ \\
\hline$\underline{\text { Nov }}$ & $51^{\circ} \mathrm{F}$ & $36^{\circ} \mathrm{F}$ & $44^{\circ} \mathrm{F}$ & $1.00 \mathrm{in.}$ & $79^{\circ} \mathrm{F}(1999)$ & $-8^{\circ} \mathrm{F}(1985)$ \\
\hline$\underline{\underline{D e c}}$ & $40^{\circ} \mathrm{F}$ & $29^{\circ} \mathrm{F}$ & $35^{\circ} \mathrm{F}$ & $1.13 \mathrm{in.}$ & $69^{\circ} \mathrm{F}(2007)$ & $-7^{\circ} \mathrm{F}(1983)$ \\
\hline
\end{tabular}

Based on this information, sampling will ideally occur in the summer and winter time periods, to ensure samples with the paired homes and within the cohort are comparable, to the extent possible. Depending on the timing of occupancy, the 6-13 week sample and the 12 month sample may be adjusted to provide more consistent climactic behavior.

\subsection{Constituents of Concern}

There are hundreds of chemicals present in indoor air with some being related to the building materials; some related to the building contents (e.g. furniture, window coverings, toys, etc.); and some related to occupants and activities (e.g. cleaning products, personal care products, emission from cooking, candles, incenses, etc.). Table 2.6 provides a summary list of a subset of indoor chemicals along with a classification and/or source. A number of compounds can be found in a variety of products or materials making it difficult to characterize sources in fully furnished occupied homes. This study is designed to incrementally develop a target list of compounds for each home by starting with the unoccupied home to identify building related compounds, then sampling the occupied home in a highly controlled state to identify compounds related to the home contents and finally sampling in a naturally ventilated state with occupants carrying on their typical daily activities to identify compounds related to occupants.

Table 2.6. Summary List of Compounds that are Typically Found Indoors along with Possible Source or Classification

\begin{tabular}{|l|l|l|}
\hline Chemical & Classification or Source & Ref. \\
\hline Hexane & $\begin{array}{l}\text { Gasoline evaporative emissions; Cleaning agent in printing, textile, } \\
\text { automotive and furniture industries; Quick-drying glues for crafts } \\
\text { and in consumer products (shoes, leather) }\end{array}$ & 1 \\
\hline Methylene chloride & $\begin{array}{l}\text { Paint stripper; May be found in some aerosol and pesticide products; } \\
\text { Found in some holiday decorations }\end{array}$ & 1 \\
\hline Carbon tetrachloride & Dry cleaning solvent; Previously used as a refrigerant & 1 \\
\hline Chloroform & Water contaminant released during water use & 1 \\
\hline
\end{tabular}




\begin{tabular}{|c|c|c|}
\hline Benzene & Cigarette smoke ; Gasoline evaporative emissions & 1 \\
\hline Butanal & $\begin{array}{l}\text { Used in production of resins, rubber, solvents, plasticizers and high } \\
\text { molecular weight polymers; Naturally occurring in some foods and } \\
\text { plants }\end{array}$ & 2 \\
\hline $\begin{array}{l}\text { Heptane, Octane, } \\
\text { Butylbenzene }\end{array}$ & Gasoline evaporative emissions & 1,8 \\
\hline Toluene & $\begin{array}{l}\text { Consumer products including paint, paint thinners, lacquers, } \\
\text { adhesives and rubber; Cigarette smoke; Gasoline evaporative } \\
\text { emissions }\end{array}$ & 1 \\
\hline $\begin{array}{l}\text { Hexamethylcyclotrisiloxane, } \\
\text { Octamethylcyclotetrasiloxane, } \\
\text { Decamethylcyclopentasiloxane }\end{array}$ & $\begin{array}{l}\text { Manufacturer of silicones; Personal care products; Carriers, } \\
\text { lubricants and solvents in commercial applications }\end{array}$ & 3 \\
\hline Tetrachloroethylene & Dry cleaning solvent; Some consumer products & 1 \\
\hline $\begin{array}{l}\text { Hexanal, Heptanal, Octanal, } \\
\text { Nonanal, Decanal, } \\
\text { Benzaldehyde }\end{array}$ & $\begin{array}{l}\text { Flavors and perfumes; Product of secondary reactions between } \\
\text { ozone and unsaturated compounds }\end{array}$ & 1 \\
\hline Ethylbenzene & Inks and paints; Gasoline evaporative emissions & 1 \\
\hline $\mathrm{m} / \mathrm{p}$-Xylene, o-Xylene & $\begin{array}{l}\text { Consumer products including cleaning agents, paint thinners and } \\
\text { varnishes; Cigarette smoke; Gasoline evaporative emissions }\end{array}$ & 1 \\
\hline a-Pinene & $\begin{array}{l}\text { Fragrance in cleaning products, air fresheners, and personal care } \\
\text { products }\end{array}$ & 1 \\
\hline $\begin{array}{l}\text { Decane, Undecane, Dodecane, } \\
\text { Tetradecane, Hexadecane }\end{array}$ & $\begin{array}{l}\text { Kerosene, diesel and home heating oil evaporative emissions; } \\
\text { Solvent; Component of paints and varnishes; Used in the rubber } \\
\text { and paper industry }\end{array}$ & 4,5 \\
\hline 2-Butoxyethanol & $\begin{array}{l}\text { Paint thinners and strippers, varnish removers, and herbicide; Liquid } \\
\text { soaps, cosmetics, commercial and household cleaners, and dry } \\
\text { cleaning compounds; Some ink and spot removers }\end{array}$ & 1 \\
\hline 3-Carene, g-Terpinene & cologne, perfume, soap, shaving cream, deodorant, air freshener & 11 \\
\hline $\begin{array}{l}\text { 1,2,4-Trimethylbenzene, } \\
\text { 1,2,3-Trimethylbenzene }\end{array}$ & Fuel evaporative emissions; Paints; Cleaners & 6 \\
\hline d-Limonene & $\begin{array}{l}\text { Fragrance in air fresheners, insecticides, and personal care products } \\
\text { (hand sanitizers); Solvent for cleaning products }\end{array}$ & 1 \\
\hline 2-Ethyl-1-hexanol & $\begin{array}{l}\text { Cleaning products; Insecticides; Paint related products; Rugs and } \\
\text { bathmats; Sheet vinyl flooring }\end{array}$ & 9 \\
\hline a-Terpineol & Insecticides; Solvents; Plasticizers; Perfumes; Synthetic pine oil & 1 \\
\hline Texanol (mono-isomer) & Additive to latex paint & 10 \\
\hline $\begin{array}{l}\text { Dimethyl phthalate, Diethyl } \\
\text { phthalate, Dibutyl phthalate }\end{array}$ & Plasticizer in consumer products & $\begin{array}{l}1, \\
12 \\
\end{array}$ \\
\hline TXIB (di-isomer) & Plasticizer in resilient vinyl flooring & 1 \\
\hline \multicolumn{3}{|c|}{ 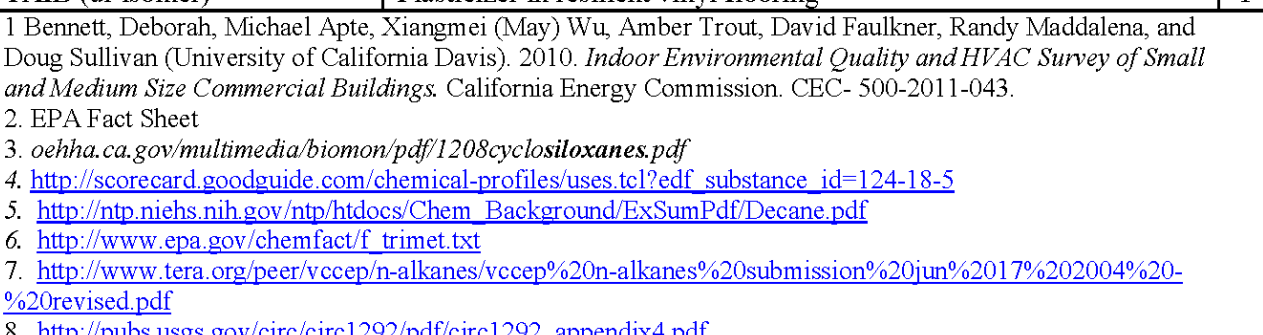 } \\
\hline
\end{tabular}


9. http://scorecard.goodguide.com/chemical-profiles/consumer-products.tcl?edf substance $\mathrm{id}=104 \% 2 \mathrm{~d} 76 \% 2 \mathrm{~d} 7$

10. Chemical also identified as Texanol -

http://www.tceq.state.tx.us/assets/public/implementation/tox/dsd/final/texanol_25265-77-4_final_4-15-08.pdf

11. http://www.herc.org/news/perfume/risks.htm

12. http://www.epa.gov/ttnatw01/hlthef/dimet-ph.html

\subsection{Technical Approach}

This project will measure IAQ constituents and other parameters, over time, in new homes constructed with materials compliant with Indoor airPLUS and similar homes constructed to the Washington state code with conventional materials. IAQ measurements will include speciated VOC and aldehyde concentrations, as well as concentrations of perfluorocarbon tracers (PFTs) and carbon dioxide to determine the fresh air ventilation or air exchange rate. These measurements and equipment are described in more detail in section 4.0. Other measured parameters include general home characteristics; characterization of large furnishings and associated materials; T and RH; energy use; operation of intermittent ventilation equipment; and occupancy characteristics. These additional measurements are described in section 3.0. Sampling will occur at least one time pre-occupancy and over a defined schedule post-occupancy indoors and outdoors. Post-occupancy samples will occur at 2-4 weeks postoccupancy, 6-13 weeks post-occupancy, and 12 months post-occupancy. Additional sampling periods pre-occupancy or after more than 12 months post-occupancy may be considered as timing and budget allow. Additional pre-occupancy sampling may include additional controlled sampling as different building materials are introduced, controlled sampling pre- and post-flush, and/or a long-term passive sample to serve as a baseline/comparison between subsequent controlled and natural samples. IAQ sampling may consist of a short-term, controlled active sample and subsequent, long-term passive sample, but both types of samples may not occur at all sample period. 


\subsection{Data Collection and Analysis}

The study will include sampling for low molecular weight aldehydes and VOCs and measuring air exchange rates over one-week periods during designated seasonal campaigns. Each house tested will include a minimum of two indoor sample locations during controlled sampling periods and up to five locations during long-term passive sampling periods. Each test homes will be associated with one outdoor location that is centrally located near the test home. ${ }^{1}$ A sampling event may include two consecutive sample collection periods:

(1) an initial 24-hour controlled sampling period during which time two short-term active samples will be collected and

(2) a longer-term, sampling period characterizing natural or typical operating conditions in the home. The samples collected during this period will be 7 day continuous passive measurements ${ }^{2}$.

However, both active and passive samples may not occur during all sample periods based on feasibility. In general, the experimental design will include short-term, active sampling pre-occupancy and both short-term and long-term sampling post-occupancy. Details regarding the IAQ measurements are provided in section 4.0 .

In addition to the IAQ monitoring described in section 4.0, field measurements will consist of information on general home characteristics; characterization of large furnishings and associated materials; $\mathrm{T}$ and $\mathrm{RH}$; energy use; operation of intermittent ventilation equipment; and occupancy characteristics. Some of these measurements will occur one time during an initial baseline audit, and some will occur at each sampling period in conjunction with IAQ sampling. Temperature is important to allow for adjustment of PFT emission rates used in determination of fresh air ventilation. Large swings in temperature and/or RH can also impact chemical emission rates from materials, although we do not expect to see large swings in conditions, particularly during the highly controlled sampling period. Nevertheless, it is important to log conditions during indoor air quality evaluations. The probable measurements for each sampling period are outlined in Table 3.1.

Table 3.1. Summary of Measurements Occurring During Each Sampling Period

\begin{tabular}{lcl}
\hline Sampling Period & Measurements \\
\hline Baseline Audit & - & Envelope air tightness. \\
& - & House-to-garage air leakage \\
& - & Duct tightness on supply and return sides. \\
& - & Airflows of all ventilation fans (as installed). \\
& - & Airflow of central air handler unit, if applicable. \\
Pre-Occupancy & - & VOCs and aldehydes (indoors + outdoors) using active samplers during \\
& & controlled sampling (2 locations)* \\
\hline
\end{tabular}

\footnotetext{
${ }^{1}$ To the extent that homes are located in a similar location and IAQ sampling occurs at the same time in these homes, several homes may share a single outdoor sample.

${ }^{2}$ Note, the timeframe of passive sampling may vary from the estimated 7-day period based on coordination of sampler deployment and retrieval and subject to homeowner convenience.
} 


\begin{tabular}{lll}
\hline & - & Air exchange rate using $\mathrm{CO}_{2}$ decay analysis and passive emitters* \\
& - & Door and window opening. \\
2-4 Weeks Post- & - & $\mathrm{T}, \mathrm{RH}$, and $\mathrm{CO}_{2}$ concentrations during sampling \\
Occupancy, & - & Characterization of types of materials and finishes \\
$6-13$ Weeks Post- & - & VOCs and aldehydes (indoors + outdoors) using active samplers (2 \\
Occupancy, and & locations) under controlled conditions* \\
12 Months Post- & VOCs and aldehydes (indoors + outdoors) using passive sampling \\
Occupancy & (multiple locations) under natural conditions* \\
& Air exchange rate using passive emitters and samplers during both \\
& controlled and natural (multiple PFT tracers)* \\
& CO $\mathrm{O}_{2}$ in at least 3 locations + outdoors: HV AC return, kitchen, master \\
& bedroom. \\
& T \& RH in same locations as $\mathrm{CO}_{2}+$ at least one other bedroom and each \\
& bathroom. \\
- & Bath fan operation \\
- & Kitchen fan operation \\
- & Operation of electric oven, toaster, toaster oven either via survey or \\
& energy measurement. \\
- & Operation of other exhaust systems within the pressure boundary, e.g. \\
& dryers, water heater either via survey or energy measurement. \\
- & Door and window opening \\
- & Characterization of types of major furnishings and wall/window coverings \\
- & Homeowner survey \\
\hline see section 4.0 for more information.
\end{tabular}

An inventory of materials used to construct each home and the building characteristics will be documented along with the documentation of major furnishings and wall/window coverings (see Appendix I for an example material tracking data form) to help understand differences in observed indoor contaminant concentrations. Measurements of envelope air tightness and air flows of all ventilation fans (as installed) may be taken after initial baseline to verify consistent operation, as necessary.

The methods for building envelope and ventilation system characterization consist of measuring air flow and pressure differentials in specific areas with respect to a reference. Building envelope leakage, air exchange rates, and ventilation system performance testing equipment was selected to represent measurement techniques most commonly used by home auditors in the field and is discussed in sections 3.1.1 and 3.1.2, below.

A precise field sampling protocol is included as Appendix $\mathrm{H}$.

\subsection{Sampling Equipment}

Table 3.2 lists the various measurement parameters, measurement equipment, and sampling rates for all but the IAQ measurements, which are discussed in section 4.0. 
Table 3.2. Measurement Parameters, Measurement Equipment, and Sampling Rates.

\begin{tabular}{|c|c|c|}
\hline Measurement & Equipment Needed & Sampling Interval \\
\hline Infiltration (cfm50) & Blower Door & Initial baseline $^{1}$ \\
\hline Duct Leakage (cfm25) & Duct Blaster & Initial baseline $^{1}$ \\
\hline Exhaust fan flow (cfm) & Powered flow hood & Initial baseline $^{1}$ \\
\hline Total Energy (Wh) & eGauge (CT) & $\min /$ hourly \\
\hline $\begin{array}{l}\text { Air Handler Energy (Wh) / Runtime } \\
\qquad(\mathrm{min} / \mathrm{hr})\end{array}$ & eGauge (CT) & $\min /$ hourly \\
\hline Condenser Energy (Wh) & eGauge (CT) & $\min /$ hourly \\
\hline Bath Fan Power (Wh) / Runtime (min/hr) & $\begin{array}{c}\text { eGauge (CT) or U-12 HOBO } \\
(\mathrm{CT})^{2}\end{array}$ & $\min /$ hourly \\
\hline $\begin{array}{l}\text { Kitchen Exhaust Fan Power (Wh) / } \\
\text { Runtime ( } \mathrm{min} / \mathrm{hr})\end{array}$ & $\begin{array}{c}\text { eGauge (CT) or U-12 HOBO } \\
(\mathrm{CT})^{2}\end{array}$ & $\min /$ hourly \\
\hline $\begin{array}{l}\text { Operation of kitchen, dryer, and other } \\
\text { exhausting appliances (Wh)/ Runtime } \\
(\mathrm{min} / \mathrm{hr})\end{array}$ & $\begin{array}{c}\text { eGauge (CT) or U-12 HOBO } \\
(\mathrm{CT})^{2}\end{array}$ & $\min /$ hourly \\
\hline Interior and Ambient $\mathrm{CO}_{2}(\mathrm{ppm})$ & $\begin{array}{l}\text { (1) Vaisala GMW } 115 \text { and (2) } \\
\mathrm{HOBO} \mathrm{CO}_{2} / \mathrm{T} / \mathrm{RH} \text { (U-09, U- } \\
10, \mathrm{U}-12 \text { or similar) }\end{array}$ & $15 \mathrm{~min}$ \\
\hline Space T \& RH (4 interior locations) & $\begin{array}{c}\mathrm{HOBO} \mathrm{CO} / \mathrm{T} / \mathrm{RH}(\mathrm{U}-09, \mathrm{U}- \\
10, \mathrm{U}-12 \text { or similar })\end{array}$ & $15 \mathrm{~min}$ \\
\hline Door and window openings & Contact closure sensors & Continuous, per event \\
\hline
\end{tabular}

Details on sample collection and analysis are discussed below.

\subsubsection{Building Envelope and Duct System Performance}

For building envelope sampling, test equipment will include a blower door fan, door frame and cloth, monometer, plastic tubing, and a computer with TechTite software installed for multipoint testing. All blower door equipment is manufacturer by Minneapolis Blower Door.

Building envelope leakage testing will be conducted in accordance with ASTM E779, Standard Test Method for Determining Air Leakage Rate by Fan Pressurization. This test determines building envelope leakage by testing using a blower door. The test will be performed with all doors and windows closed to determine only inadvertent leakage pathways. The blower door will pull a measured volume of air through the door way and the manometer will measure the pressure differential between the indoors and outdoors. The TechTite software will be used to determine the fan flow and relative pressure differential at multiple points. The multipoint test gives a more accurate measurement of required fan flow in cubic feet per minute to reach -50 Pascals with respect to the outside (referred to as $\mathrm{cfm} 50$ ).

Duct leakage testing will be conducted in accordance with ASHRAE 152, Method of Test for Determining the Design and Seasonal Efficiencies of Residential Thermal Distribution Systems (ASHRAE 2014). The duct system performance testing, test equipment will include a DuctBlaster $\mathbb{R}$ fan 
and associated accessories, DG-700 Digital Pressure Gauge, and plastic tubing, all produced by Minneapolis Blower Door. The test will determine total duct leakage and duct leakage to outside by measuring the quantity of air required to reach a depressurization of -25 Pascals with respect to outside (referred to as cfm25).

\subsubsection{Ventilation Fan Flow Rate}

For ventilation system performance testing, equipment will include a powered flow hood. A powered flow hood was chosen due to the increased accuracy of this system as compared to an exhaust fan flow box (Wray, et al 2002). Accuracy is especially important due to the small flows being measured in this study, typically around $30-50 \mathrm{cfm}$ for a conventional exhaust bath fan. The ventilation system performance testing equipment are a FlowBlaster $\AA$ Capture Hood, a DG-700 Digital Pressure Gauge, and DuctBlasterß fan, both produced by Minneapolis Blower Door. This will occur as a one-time measurement, that is correlated with the time the ventilation fan is on, as determined based on the energy use information.

\subsubsection{Energy Use}

Disaggregated energy use, including the whole house, air handler, condenser, bath fan, kitchen exhaust fan, and dryer, will be monitored using eGauge energy meter (eGauge Systems LLC, Boulder, Colorado) to determine operation frequency and duration of ventilation systems and appliances that significantly affect air exchange. The eGauge device must be connected to main voltage leads inside the breaker panel so installation will be performed by licensed electricians.

The eGauge metering system consists of a main power meter unit, current transformers (CTs), a HomePlug communication adapter and an Internet router, as shown schematically and photographically in

Figure 3.1. The main metering unit allows for three-phase voltage connections, but only two phases are necessary for residential applications. Up to $12 \mathrm{CT}$ s can be connected to the main power unit, allowing 12 separate $120 \mathrm{VAC}$ or $240 \mathrm{VAC}$ appliances to be monitored. However, care should be used when monitoring $240 \mathrm{VAC}$ appliances that contain substantial $120 \mathrm{VAC}$ loads and may not be phase balanced. The main unit communicates via Power Line Carrier technology to the HomePlug adapter, which is connected directly to an Internet router. The eGauge meter data then is accessible via the Internet, obviating the need for local downloading of data. 

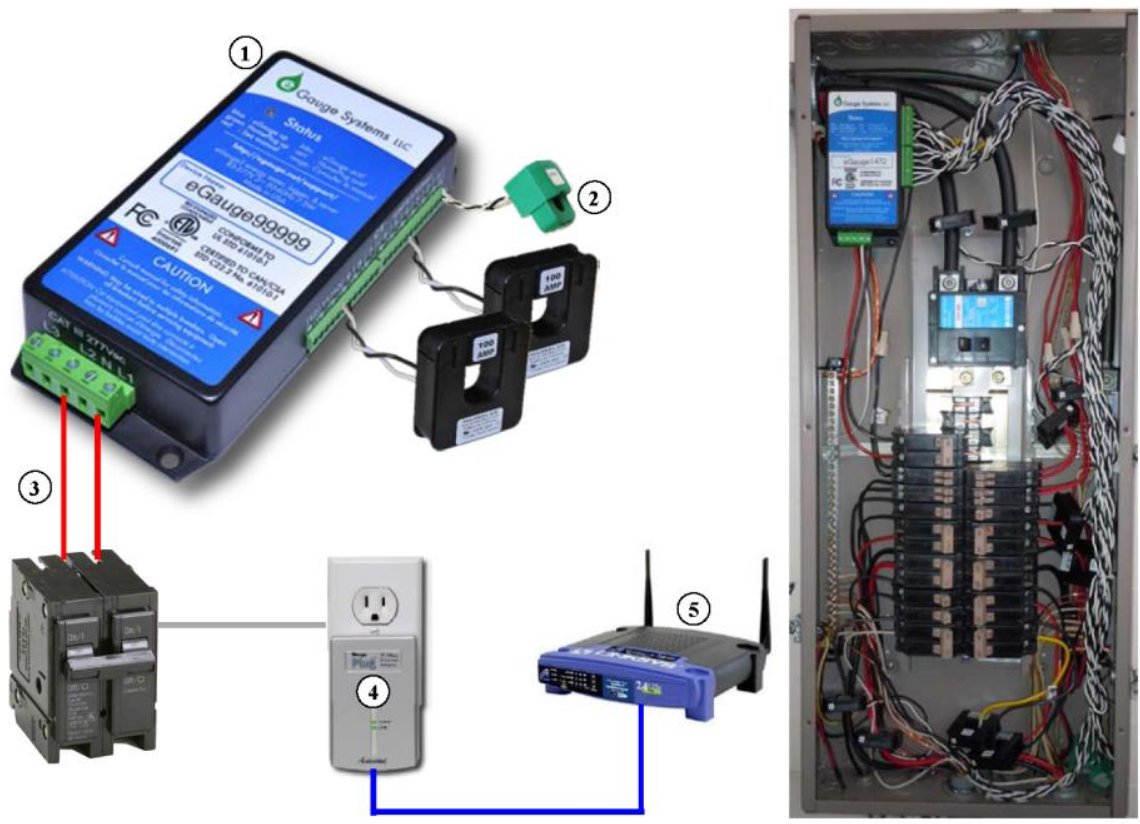

Figure 3.1. Schematic and photograph of an eGauge energy metering system, consisting of a 1) main power meter unit, 2) current transformers, 3) voltage taps connected to a dual-pole breaker, 4) HomePlug communication adapter, and 5) an internet router. Note that the HomePlug and Internet router are not shown in breaker panel photograph.

The HomePlug adapter should be placed as close to the eGauge main unit (i.e., the breaker panel) as possible to ensure consistent communication. In addition, the main unit should be powered via its own separate breaker, to provide for the potential need to re-boot the unit.

Data from the eGauge devices will be downloaded via the Internet at 1-minute and 1-hour intervals. The eGauge interface allows the researchers and user to select power or energy, interval and duration of data to save and creates a comma-separated value file. The Internet interface also provides a convenient dashboard for viewing energy use and other trended information

\subsection{1 $\mathrm{CO}_{2}$ Measurement}

The Vaisala GMW115 $\mathrm{CO}_{2}$ Monitors will be used to continuously record $\mathrm{CO}_{2}$ throughout the natural ventilation period. The $\mathrm{CO}_{2}$ sensor is a silicon-based non-dispersive infrared sensor with an accuracy of $\pm 2 \%$ of the range $+2 \%$ of the reading from 0 to $5,000 \mathrm{ppm}$, which is appropriate for the expected ambient concentrations of 380 to $800 \mathrm{ppm}$.

\subsubsection{Temperature and Relative Humidity}

To measure temperature and relative humidity, HOBO U12-011 loggers will be used, which records temperature and relative humidity in the ranges expected in homes; -4 to $158^{\circ} \mathrm{F}$ and 5 to $95 \%$ relative 
humidity, respectively. The accuracy of the HOBO U12-011 over the range of interest is $\pm 0.35^{\circ} \mathrm{F}$ and $0.3 \% \mathrm{RH}$, which is more than sufficient to resolve differences resulting from changes in ventilation rate. The meter will be set up to sample every 15 seconds and average over 5 minutes, or 20 measurements. It is believed that the 15 second sampling interval will be sufficient to capture any fluctuations from pollutant release events and 15 minute averaging will be a good representation of expose for that time period.

\subsection{Experimental Procedure}

The sampling procedure will consist of several phases, as presented in Table 3.1. During the initial baseline audit, data will be taken to characterize the home and system performance, characterize materials used in home construction, and document construction timeline. An example of the materials tracking inventory, used by builders and research personnel to record relevant information on building materials used in home construction is included as Appendix I.

During the post-occupancy sampling periods, controlled and natural IAQ measurements will occur and, in addition, data will be collected regarding any large furnishings or wall/window coverings that have been introduced into the home and home operation characteristics will be collected via the homeowner survey (Appendix F), which will be administered electronically.

\subsection{Additional Information}

In addition to collecting ambient air samples, weather data will be logged as obtained by observation and data from the National Oceanic and Atmospheric Administration (NOAA) ${ }^{1}$.

${ }^{1}$ http://www.noaa.gov/wx.html 


\subsection{Indoor Air Quality Measurements}

The plan is to collect VOC, PFT and aldehyde samples longitudinally beginning pre-occupancy and continuing as the home ages using methods that provide information about concentrations (1) during highly controlled or standard conditions with occupant activity minimized and (2) during natural conditions including normal occupant activities.

The highly controlled sampling conditions will include two short-term actively collected samples (one in the AM and one in the PM) with the home set to standard conditions for temperature and ventilation and after periods of low occupant activity. The highly controlled samples that are collected pre-occupancy in the finished home will provide baseline data on the chemicals emitted from the building materials in Challenge and conventional homes. The highly controlled samples that are collected post occupancy will provide data on the combined chemicals from both the building materials and the house contents with minimal contribution from occupant activity-based emissions. The highly controlled samples collected longitudinally at $1^{1}, 3^{2}$ and 12 months will provide data on the aging (decline) of building material emissions and building contents emissions. All of the highly controlled samples will be collected using programmable sampling units set to collect integrated (pumped) samples before occupants begin their daily activities (e.g., 03:30-04:30) and before occupants return home in the afternoon (e.g., $15: 30-16: 30$ ). For homeowners that are typically home all day, researchers will request that they schedule activities such that the home is unoccupied for a period of 4-6 hours prior to sampling on the active sampling day.

Occupants will be asked to slightly modify their behavior on these controlled sampling days for the 24 hour period beginning the evening before the controlled sample and extending until the homeowners return home after the second controlled sample collection. Specifically, homeowners will be asked to maintain their thermostat set point between $74-78^{\circ} \mathrm{F}$ in summer and $68-72{ }^{\circ} \mathrm{F}$ in winter with no setbacks, to operate the air handler fan continuously, to refrain from opening windows and exterior doors, and to refrain from activities that are known to emit large quantities of VOC into the home (e.g. cleaning, cooking without a range hood, etc.). Homeowners will be provided with a list and verbally reminded prior to each sampling event. A sample list is provided as Appendix G.

The long-term field monitoring will immediately follow each highly controlled sampling period (excluding the pre-occupancy period(s)) and continue for 7 days with the occupants conducting their normal daily activity and the home operated per occupant preference. No restrictions will be placed on occupants during this period, except that sampling should be scheduled for a week of "typical" activity (i.e. no large parties, oven cleaning, or vacations, etc.). Samples will be collected passively during this period providing an integrated sample that captures the time-integrated concentration over the full duration of sampling. The sample collected during natural conditions - in combination with the highly controlled samples - provides a measure of the contribution of occupants to indoor air quality (emission of personal care products, cleaning products, combustion, fragrances) and the effect that occupant's activities have on emissions from building materials and contents. All samples collected during the

${ }^{1} 2-4$ weeks

${ }^{2}$ 6-13 weeks 
natural conditions will be sampled passively (no pump) using calibrated commercially available sampling tubes and cartridges. IAQ sampling equipment is described in more detail in section 4.1.

Fresh air ventilation measurements will be made during the pre-occupancy sampling period(s) using both a $\mathrm{CO}_{2}$ decay method and perfluorocarbon tracer (PFT) gas mass balance approach and during the post-occupancy sampling periods using only the perfluorocarbon tracer gas mass balance method. Using the $\mathrm{CO} 2$ decay and PFT mass balance simultaneously during the pre-occupancy period will allow for the estimation of effective home volume. Fresh air ventilation is an important parameter for conversion of measured concentrations in the air to whole-house emission rates which can be compared across different homes. In addition, the ventilation rates are important for this study as a way to monitor the ventilation normalized aging for building (and contents) related emissions. The tracer gas measurements are described further in section 0 .

\subsection{Measurements and Equipment}

Samples will be collected at 2-4 indoor locations and one nearby outdoor location for each home. The equipment used to collect IAQ samples is listed in Table 4.1.

Table 4.1. IAQ Sampling Equipment

\begin{tabular}{|c|c|c|c|}
\hline Sampling Type & Measurement or Purpose & Equipment Needed & $\begin{array}{c}\text { Sampling } \\
\text { Interval }\end{array}$ \\
\hline \multirow{4}{*}{$\begin{array}{l}\text { Active, Controlled } \\
\text { Sample }\end{array}$} & $\begin{array}{l}\text { Air exchange Rate - Decay } \\
\text { Method and PFT mass balance } \\
\text { for pre-occupancy period and } \\
\text { PFT mass balance for post- } \\
\text { occupancy. }\end{array}$ & $\begin{array}{l}\text { PP Systems EGM-4 } \\
\text { for CO2 measurement; } \\
\text { PFT passive emitters } \\
\text { and TD tubes w/ } \\
\text { sorbent media for PFT } \\
\text { measurements }\end{array}$ & \multirow{4}{*}{$\begin{array}{l}0.5-1 \text { hour } \\
\text { twice in } 24 \text {-hour } \\
\text { period }\end{array}$} \\
\hline & $\begin{array}{l}\text { Volatile Organic Compounds } \\
\text { (ppb) }\end{array}$ & $\begin{array}{l}\text { TD tubes } \mathrm{w} / \text { sorbent } \\
\text { media }\end{array}$ & \\
\hline & Aldehydes ( $\mathrm{ppb}$ ) & $\begin{array}{l}\text { XPoSure Aldehyde } \\
\text { Sampler, Waters } \\
\text { Corporation }\end{array}$ & \\
\hline & Active Sampling Pump & $\begin{array}{l}\text { Master Flex R7553-80 or } \\
\text { similar }\end{array}$ & \\
\hline \multirow{3}{*}{$\begin{array}{l}\text { Natural } 7 \text { day }^{1} \\
\text { Field Sample }\end{array}$} & $\begin{array}{l}\text { Air Exchange Rate - PFT mass } \\
\text { balance }\end{array}$ & $\begin{array}{l}\text { PFT passive emitters } \\
\text { and TD tubes }\end{array}$ & \multirow{3}{*}{7 days } \\
\hline & $\begin{array}{l}\text { Volatile Organic Compounds } \\
\text { (ppb) }\end{array}$ & $\begin{array}{l}\text { TD tubes } \mathrm{w} / \text { sorbent } \\
\text { media }\end{array}$ & \\
\hline & Aldehydes (ppb) & $\begin{array}{l}\text { XPoSure Aldehyde } \\
\text { Sampler, Waters } \\
\text { Corporation }\end{array}$ & \\
\hline
\end{tabular}

\footnotetext{
${ }^{1}$ Note, the timeframe of passive sampling may vary from the estimated 7-day period based on coordination of
} sampler deployment and retrieval and subject to homeowner convenience. 


\subsubsection{Air Exchange Rate}

The air exchange rate will be determined to measure total air movement into or out of the house, including infiltration and mechanical ventilation. The air exchange rate will be determined based on two types of tracer gas measurements. The first is a tracer decay method where $\mathrm{CO}_{2}$ is released into the space and the decay in $\mathrm{CO}_{2}$ concentration is monitored and used to estimate the air exchange rate in the space. The second method uses PFTs emitted into the space at a known and constant rate with fresh air ventilation estimated using a mass balance. The emitters will be constructed and initially calibrated at LBNL. The emitters consist of a 2 dram (7.5 ml) glass vial filled with one of three different PFTs, placed approximately every 200 to $300 \mathrm{ft}^{2}$ throughout the home, with approximately one in each major room (approximately 10 emitters per home). The emitters are placed upside down to maintain emission rates through constant contact with the dram cap (a septum cap). The emission rate of the PFT emitters has been preliminary determined in the lab as approximately $0.1 \mathrm{mg} / \mathrm{hr}$ and will be confirmed in the field by weighing the emitters before and after each IAQ sampling event. PFTs that are available for use in ventilation applications are listed in Table 4.2 along with their chemical formula and chemical abstract number. Candidate PFTs for the current study include PMCH, $\mathrm{m}-\mathrm{PDMCH}$ and PDMEP with PDCB included as an optional additional PFT as needed for detailed spatial evaluations. Note, all of these PFTs have been reviewed by toxicologists at PNNL and SafeBridge, for DOE, and determined to be non-toxic in the concentration of $<1 \mathrm{ppm}$ (SafeBridge, 2013a,b). Perfluoro-1,2-dimethylcyclobutane (PDCB), perfluoromethylcyclohexane (PMCH), and perfluoro-1,3-dimethylcyclohexane (m-PDMCH or m-PDCH) were analyzed together as cohort of similar perfluorinated tracers based on their chemical structure (Safebridge 2013a). Perfluoro-2,4-dimethyl-3-ethylpentane (PDEMP) was analyzed with perfluoromethylethylpetane as a group of aliphatic perfluorinated tracers and was found to have similar toxicological effects and higher acceptable air concentration limit for 1-week exposures of $20 \mathrm{ppm}$ (Safebridge 2013b).

Table 4.2. Tracers available for gas air flow studies

\begin{tabular}{llll}
\hline Compound & Name & Formula & CAS \# \\
\hline Perfluoro-1,2-dimethylcyclobutane $^{1}$ & PDCB & C6F12 & $2994-71-0$ \\
Perfluoromethylcyclohexane $^{2}$ & PMCH & C7F14 & $355-02-2$ \\
Perfluoro-1,3-dimethylcyclohexane $^{3}$ & m-PDMCH & C8F16 & $335-27-3$ \\
Perfluoro-2,4-dimethyl-3-ethylpentane $^{4}$ & PDMEP & C9F20 & $50285-18-2$ \\
\hline
\end{tabular}

${ }^{1}$ MSDS available at: $h$ ttp://www.chemicalbook.com/ProductChemicalPropertiesCB8403290 EN.htm

${ }^{2}$ MSDS available at: http://www.chemicalbook.com/ProductChemicalPropertiesCB9301481 EN.htm

${ }^{3}$ MSDS available at: $\underline{\mathrm{http}} / / \mathrm{www}$.chemicalbook.com/ProductChemicalPropertiesCB0490412 EN.htm

${ }^{4}$ MSDS available at: http://www.chemicalbook.com/ProductChemicalPropertiesCB5919426 EN.htm

\subsubsection{Formaldehyde and Acetaldehyde}

The target compounds in the aldehyde analysis include formaldehyde and acetaldehyde. Higher molecular weight aldehydes are analyzed along with the VOCs. Aldehyde samples are collected on commercially available silica gel cartridges coated with 2,4-dinitrophenyl-hydrazine (XPoSure Aldehyde Sampler, Waters Corporation). Ozone scrubbers are used on sample cartridges during active sampling and diffusion caps are used during passive samples. 


\subsubsection{Speciated Volatile Organic Compounds (VOCs)}

Both passive (natural ventilation) and active (controlled conditions) sampling is conducted for VOCs with commercially available thermal desorption tubes. Thermal desorption (TD) tubes made from either glass or stainless steel $(0.6 \mathrm{~cm} \mathrm{OD} \times 17.5 \mathrm{~cm} \mathrm{~L})$ contain a sorbent bed consisting of 2 parts $(\mathrm{v} / \mathrm{v})$ CarboPack-B 60/80 mesh backed with 1 part CarboPack-X 60/80 (Supelco). Carbopack is a graphitized carbon material similar to small bits of charcoal that adsorb VOCs and PFTs from air at a known sampling rate.

\subsection{Sampling Procedure}

The active samples collected during the pre-occupancy period(s) and the 24-hour controlled postoccupancy periods will be collected using time-programmable pumps that are pre-calibrated and loaded with sample tubes/cartridges and deployed in the homes in at least two indoor locations (minimum of one location on each floor) that are expected to be reasonably well mixed (i.e., close to return air or exhaust duct) and one outdoor location. A technician will visit each home the day before the early morning sample collection to deploy PFT emitters (described previously), timer-controlled pumps loaded with samplers, and data loggers for $\mathrm{T} / \mathrm{RH} / \mathrm{CO}_{2}$. The time-controlled pumps will collect active samples (VOC/PFT/aldehyde) in the early morning and then again during the afternoon of the following day. The technician will return on the evening following the active sampling event to retrieve samples and pumps and to deploy passive samplers at the same locations used for active sampling with up to three additional passive sampling locations in the home. Additional locations may be sampled during both active and passive sampling periods to explore directional airflows and spatial variability in the homes. Duplicate samples and/or field blanks will be placed at a subset of locations for quality assurance.

During the highly controlled sampling period, participants will be expected to operate homes under controlled conditions starting the morning prior to the first early morning sampling period and continuing through the following afternoon when the controlled sampling period ends. Controlled conditions include the following:

- All windows and exterior doors closed;

- "Whole house" mechanical ventilation system operating;

- Temperature thermostatically controlled to remain between $74-78^{\circ} \mathrm{F}$ for summer and $68-72$ ${ }^{\circ} \mathrm{F}$ for winter sample periods;

- Minimize activities in the home that are known to result in high emissions of VOCs.

During the visit to set up sampling pumps and equipment, the technician will place small vials containing different PFTs (e.g., emitters) in different locations on each floor. The emitters will be constructed and initially calibrated by LBNL with subsequent weights determined by PNNL before and after each deployment. The change in mass of the emitters is used to determine the rate of emission of the PFTs during deployment. Emitters are similar to diffusive air fresheners that release compounds at a constant rate into the surround space but without the scent. An emitter will be placed in each major room excluding bathrooms, closets and small rooms with a minimum of one every $200-300 \mathrm{ft}^{2}$ of living area. The emitters will be placed within $2-5 \mathrm{ft}$ from the floor in areas that are not directly impacted by heating 
or cooling sources or exposed to direct sunlight. Homes with more than one floor will have a different PFT on each floor with a third PFT distributed throughout the home. This will allow us to understand the inter-floor mixing characteristics. We anticipate using between 10-20 emitters in each home, depending on home square footage. The target PFT concentration will be approximately $1-10 \mathrm{ppb}$. The fresh air ventilation rate is calculated from the measured PFTs concentrations and the known emission rate of the emitters. A summary of the sampling activity during a pre-occupancy monitoring event is given in Table 4.3 and for a post-occupancy monitoring event in Table 4.4. Locations are identified by number indoors with replicates indicated for each location along with field blanks. The design for the pre-occupancy monitoring event generates a minimum of 7 VOC samples, 7 PFT samples and 4 aldehyde (ALD) samples while the post-occupancy monitoring event generates 18 VOC samples, 14 PFT samples and 14 ALD samples.

Table 4.3. Collection Matrix Illustrating the Number and Location of Samples for the PreOccupancy Sampling.

\begin{tabular}{|c|c|c|c|c|c|c|c|c|c|}
\hline \multirow[b]{3}{*}{ Location } & \multicolumn{6}{|c|}{ Controlled sampling period } & \multirow{2}{*}{\multicolumn{3}{|c|}{$\begin{array}{c}\text { Natural sampling } \\
\text { period }\end{array}$}} \\
\hline & \multicolumn{3}{|c|}{ AM } & \multicolumn{3}{|c|}{ PM } & & & \\
\hline & VOC & PFT & ALD & VOC & PFT & ALD & VOC & PFT & $A L D$ \\
\hline 1 & & & & & & & & & \\
\hline 1_rep & & & & & & & & & \\
\hline 2 & & & & & & & & & \\
\hline 3 & & & & & & & & & \\
\hline 3_rep & & & & & & & & & \\
\hline Out & & & & & & & & & \\
\hline Out_rep & & & & & & & & & \\
\hline blank & & & & & & & & & \\
\hline
\end{tabular}


Table 4.4. Collection Matrix Illustrating the Number and Location of Samples for the PostOccupancy Period.

\begin{tabular}{|c|c|c|c|c|c|c|c|c|c|}
\hline \multirow[b]{3}{*}{ Location } & \multicolumn{6}{|c|}{ Controlled sampling period } & \multirow{2}{*}{\multicolumn{3}{|c|}{$\begin{array}{c}\text { Natural sampling } \\
\text { period }\end{array}$}} \\
\hline & \multicolumn{3}{|c|}{ AM } & \multicolumn{3}{|c|}{ PM } & & & \\
\hline & VOC & PFT & ALD & VOC & PFT & ALD & VOC & PFT & $A L D$ \\
\hline 1 & & & & & & & & & \\
\hline 1_rep & & & & & & & & & \\
\hline 2 & & & & & & & & & \\
\hline 3 & & & & & & & & & \\
\hline 3_rep & & & & & & & & & \\
\hline Out & & & & & & & & & \\
\hline Out_rep & & & & & & & & & \\
\hline blank & & & & & & & & & \\
\hline
\end{tabular}

\subsection{Analysis Approach}

The samples under controlled conditions have the benefit of providing information about the home VOC identities and concentrations resulting from material emissions under a set of standard conditions. Once the home is occupied, VOC emissions from building contents and product use or activities will contribute to the VOC profile and concentrations. The sampling design provides an opportunity to disaggregate those chemicals that are from only the building, chemicals that are from contents and chemicals that are from occupant activities. Given assumptions about typical emission decay rates over time, the data can provide a first estimate of the relative importance of each of the major indoor sources (building, contents and occupants).

The measurement of PFT concentrations and potentially also the monitoring of fan use over the longterm, natural sample periods following each 24-hour controlled sample period will provide an estimate of ventilation and air exchange rates during intervening periods. This will at least provide us with information about the overall removal rate of chemicals released by materials.

All samples collected at households are packaged and shipped to Lawrence Berkeley National Laboratory for analysis and quantification.

\subsubsection{Chemical Analysis of Volatile Organic Compounds}

The sample media will be glass or stainless steel TD tubes containing a sorbent bed consisting of 2 parts (v/v) CarboPack-B 60/80 mesh backed with 1 part CarboPack-X 60/80. The TD tubes are conditioned prior to each use by helium purge $(\sim 30 \mathrm{cc} / \mathrm{min})$ for one hour at $300^{\circ} \mathrm{C}$ in batches of 10 tubes. Conditioned tubes (analytical blanks) are routinely analyzed to confirm target VOCs are below method quantification limits.

VOCs are quantitatively analyzed by thermal-desorption gas chromatography/mass spectrometry (TD-GC/MS) generally following U.S. EPA Method TO-17, "Determination of Volatile Organic Compounds in Ambient Air Using Active Sampling onto Sorbent Tubes" (U.S. EPA 1999b). Prior to analysis, a gaseous internal standard (ISTD) is added to each sampler by syringe then an additional 
helium flow is passed through the tube for three minutes. The ISTD consists of 180 nanograms (ng) of 1bromo-4-fluorobenzene (BFB) prepared continuously in a diffusion oven. The ISTD is used to check on the operation of the system, to provide a retention-time marker, and to enable quantitative analysis. Tubes are thermally desorbed and focused using a thermodesorption auto-sampler (Model TDSA2; Gerstel), a thermodesorption oven (Model TDS3, Gerstel) and a cooled injection system (Model CIS4; Gerstel). The cooled injection system is fitted with a sorbent filled glass liner. Tubes are desorbed at a starting temperature of $25^{\circ} \mathrm{C}$ with a 1 minute delay followed by a $60^{\circ} \mathrm{C} / \mathrm{min}$ ramp to $285^{\circ} \mathrm{C}$ and a 10 minute hold time with the transfer line temperature at $275^{\circ} \mathrm{C}$. The cryogenic inlet cooled throughout desorption then heated within 0.5 minutes to $300^{\circ} \mathrm{C}$ at a rate of $12{ }^{\circ} \mathrm{C} / \mathrm{s}$ and held for 3 minutes. A split injection is used to improve peak shape in the analysis. Compounds are resolved by gas chromatography and detected/quantified using either electron impact MS (5973; Agilent Technologies) operated in scan mode with mass range from 30.0 to $450 \mathrm{amu}$ for VOCs or a micro electron capture detector for PFTs. Target compounds are quantified by multi-point calibrations prepared with pure standards using BFB as an internal standard for the MS or using a multi-point external standard for the PFTs.

\subsubsection{Chemical Analysis of Aldehydes}

The target compounds in the aldehyde analysis include formaldehyde, acetaldehyde, and acetone. Higher molecular weight carbonyls are analyzed using the VOC method described above. Aldehyde samples are collected and analyzed following U.S. EPA method TO11 - Method for the Determination of Formaldehyde in Ambient Air Using Adsorbent Cartridge Followed by High Performance Liquid Chromatography (U.S. EPA 1999a). Samples were collected on commercially available silica gel cartridges coated with 2,4-dinitrophenyl-hydrazine (XPoSure Aldehyde Sampler, Waters Corporation). Ozone scrubbers are used on all active (pumped) samples and diffusion caps are used on passive samples. Sample cartridges are capped and stored in the freezer until extraction. Prior to analysis, cartridges are eluted with high-purity acetonitrile and the eluent is brought to a final volume of $2 \mathrm{~mL}$ before analysis. Extracts are analyzed by high-performance liquid chromatography (HPLC) (1200 Series, Agilent Technologies) using a C18 reverse-phase column with $65: 35 \mathrm{H} 2 \mathrm{O}$ :acetonitrile mobile phase at 0.35 $\mathrm{mL} / \mathrm{min}$ and UV detection at 360 nanometers. Commercially available hydrazone derivatives of formaldehyde, acetaldehyde, and acetone are used to prepare multipoint calibrations for quantification of the target aldehydes. 


\subsection{Quality Assurance and Quality Control}

Following is a brief discussion regarding QA/QC procedures to be followed during each sampling event.

\subsubsection{Field Procedures}

Field QA/QC procedures will include the following:

- VOC, $\mathrm{HCOH}, \mathrm{PFT}$ and $\mathrm{CO}_{2}$ data will be taken indoors and outdoors to ensure environmental factors are not confounding results.

- A blank sample (remains capped) of each constituent will be collected at each site for comparison.

- At least one duplicate sample of each constituent will be collected for each IAQ sampling event.

- Analysis will also include a unique analysis blank each analysis period.

\subsubsection{Field Log Book}

Relevant field data will be recorded on a field metering data sheet (Attachment 2) for each sampling site (each home and outdoors). This data will include, at a minimum:

- Date of sample collection

- Location of sample collection

- Times and dates corresponding to the start of sampling and the end of sampling

- Weather conditions

- Any other relevant information

- House information (type, area, and age of finishing materials such as carpet, wooden floor, wall, paints, and appliances using gas)

\subsubsection{Sample Labeling}

All samples will be labeled with the following information:

- Sampling date

- Home Number

- Location (indoor, outdoor, specific location to be coded later)

- Analyte

- If it is a duplicate (D) or field blank (FB) 


\subsection{Reporting and Future Work}

Successful completion of this and future research could lead to improved indoor air quality in new homes and remodels, as more data is available regarding the exposure rates of occupants from different materials and finishes. Real data regarding exposure rates in new high-performance homes may contribute to more robust health protections and improved indoor air quality in new homes through incorporation into EPA's Indoor airPLUS and other voluntary programs. Through these programs, builders may be incentivized to provide healthy indoor air to their homeowners in the most energyefficient and effective manner, by minimizing or eliminating sources of indoor air contaminants.

This research may also contribute to the availability of robust and data-based recommendations regarding the types of finishes and materials that results in lower building-level emission rates. This data may also lead to the development of methods to account for reduced source emission levels in the ventilation standard without compromising indoor air quality and health, so that supplemental mechanical ventilation is only provided, at a minimized level, to mitigate against those remaining building-related pollutants that cannot be controlled via source control and people-related pollutants.

Research will be translated to market through existing channels created by Indoor airPLUS and DOE Challenge Home. If modifications to the Indoor airPLUS specification are necessary, the research team will work directly with Energy Star to achieve necessary changes. 


\subsection{References}

\subsection{General References:}

Challenge Home

http://www1.eere.energy.gov/buildings/residential/ch guidelines.html

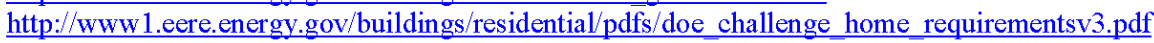

Indoor airPLUS - Version 1 (Rev. 01): http://www.epa.gov/iaplus01/construction specifications.htm1 http://www.epa.gov/iaplus01/pdfs/construction specifications.pdf

Energy Star for Homes - version 3.0

http://www.energystar.gov/index.cfm?c=bldrs lenders raters.nh v3 guidelines

http:/WwW.energystar.gov/ia/partners/bldrs lenders raters/downloads/National Program Requirements. pdf?bd14-d3c0

Federal Standards on Formaldehyde:

http://www.epa.gov/opptintr/chemtest/formaldehyde/

The Formaldehyde Standards for Composite Wood Products Act of 2010 (Title VI of Toxic Substances

Control Act) sets national emission standards that mirror standards previously established by the

California Air Resources Board for composite wood products: hardwood plywood, medium-density

fiberboard, and particleboard.

California Formaldehyde Standard:

http://www.arb.ca.gov/toxics/compwood/compwood.htm

LBNL Report on Material Certification Programs

Chemical Emissions of Residential Materials and Products: Review of Available

Information by Willem et al.

http://eetd.lbl.gov/node/50579

\subsection{Cited Literature}

Association of Heating, Refrigeration, and Air-Conditioning Engineers (ASHRAE). 2014. ASHRAE

Standard 152: Method of Test for Determining the Design and Seasonal Efficiencies of Residential

Thermal Distribution Systems." ASHRAE; Atlanta, GA.

Safebridge Consultants, Inc. 2013a. "Development of Acceptable Air Concentrations for Five Perfluorinated Tracers (PFTs) First Report." CONFIDENTIAL. Oak Ridge National Laboratory on behalf of the U.S. Department of Energy. Washington, D.C.

Safebridge Consultants, Inc. 2013b. "Development of Acceptable Air Concentrations for Five Perfluorinated Tracers (PFTs) Second Report." CONFIDENTIAL. Oak Ridge National Laboratory on behalf of the U.S. Department of Energy. Washington, D.C.

U.S. Environmental Protection Agency (EPA). 1999a. "Compendium Method TO-11A: Determination of Formaldehyde in Ambient Air Using Adsorbent Cartridge Followed by High-Performance Liquid 
Chromatography (HPLC) [Active Sampling Methodology]." Compendium of Methods for Determining Toxic Organic Compounds in Ambient Air, EPA/625/R-96/010b, U.S. Environmental Protection Agency, Cincinnati, Ohio.

U.S. Environmental Protection Agency (EPA). 1999b. "Compendium Method TO-17: Determination of Volatile Organic Compounds in Ambient Air Using Active Sampling Onto Sorbent Tubes."

Compendium of Methods for Determining Toxic Organic Compounds in Ambient Air, EPA/625/R

96/010b, U.S. Environmental Protection Agency, Cincinnati, Ohio.

Willem H. and B.C. Singer "Chemical Emissions of Residential Materials and Products: Review of Available Information" Lawrence Berkeley National Laboratory. LBNL-3938E. September 2010. 


\section{Appendix A \\ Indoor airPlus and HBATC BuiltGreen Specifications}

\begin{tabular}{|c|c|c|}
\hline $\begin{array}{l}\text { Indoor airPLUS } \\
\text { Section and } \\
\text { Specification } \\
\end{array}$ & Certification Details & $\begin{array}{l}\text { Tri Cities Home Builders Association } \\
\text { BuiltGreen Equivalent }\end{array}$ \\
\hline $\begin{array}{l}\text { Materials 6.1: } \\
\text { Certified low- } \\
\text { formaldehyde } \\
\text { composite wood } \\
\text { materials AND } \\
\text { structural plywood } \\
\text { AND OSB PS1 or } \\
\text { PS2 compliant. }\end{array}$ & $\begin{array}{l}\text { - } \text { Structural plywood and oriented strand board (OSB): } \\
\text { PS1 or PS2AND "Exposure 1" or "Exterior" on the American Plywood } \\
\text { Association (APA) trademark. } \\
\text { - Hardwood plywood products: } \\
\text { (1)ANSI/HPVA HP-1-2009 and U.S. HUD Title 24, Part 3280, OR } \\
\text { (2) certified compliant with CA Title } 17 . \\
\text {-Particleboard and MDF products: } \\
\text { (1) ANSI A208.1 and A208.2, respectively, and U.S. HUD Title 24, Part } \\
\text { 3280, OR (2) EPPS CPA 3-08 by the CPA Grademark certification } \\
\text { program, OR } \\
\text { (3) certified compliant with CA Title } 17 \text { (only option in CA). } \\
\text {-Cabinetry: } \\
\text { (1) component materials certified to appropriate standards above OR } \\
\text { (2) registered brands/products certified under KCMA's Environmental } \\
\text { Stewardship Certification Program (ESP 05-12). }\end{array}$ & $\begin{array}{l}\text { - Credit 4-27: Use plywood and } \\
\text { composites of exterior grade or urea- } \\
\text { formaldehyde-free (for interior use) } \\
\text { - Credit 4-28: Use cabinets and } \\
\text { countertops made without added urea- } \\
\text { formaldehyde board or exterior grade } \\
\text { plywood, and low- or non-toxic finish } \\
\text { - Credit 4-30: Use materials without } \\
\text { added urea-formaldehyde for finish } \\
\text { work, including shelving, window and } \\
\text { door trim, and base molding. }\end{array}$ \\
\hline $\begin{array}{l}\text { Materials } 6.2 \text { : } \\
\text { Certified low-VOC } \\
\text { or no-VOC interior } \\
\text { paints and finishes } \\
\text { used. }\end{array}$ & $\begin{array}{l}\text {-Interior paints and finished composing } \geq 90 \% \text { of interior covered surface } \\
\text { area: } \\
\left.\text { (1) Green Seal Standard GS-11 ( } 3^{\text {rd }} \mathrm{Ed} .2011\right) \text {, OR } \\
\text { (2) Greengaurd Certification Systems (CSC) Standard EC-10.2-2007, } \\
\text { Indoor Advantage Gold, OR } \\
\text { (3)Master Painters Institute (MPI) Green Performance Standards X- } \\
\text { Green, GPS-1 or GPS-2, OR } \\
\text { (4) A third-party low-emitting product list based on CA Section } 01350 \\
\text { (CDPH Standard Method V1.1-2010). }\end{array}$ & $\begin{array}{l}\text { - Credit 4-32: Use low- or non-VOC and } \\
\text { non-toxic interior paints and finishes on } \\
\text { all interior surfaces. }\end{array}$ \\
\hline Materials 6.3: & - Carpets and carpet adhesives: & Credit 4-13: If using carpet, specify low \\
\hline
\end{tabular}




\begin{tabular}{|c|c|c|}
\hline $\begin{array}{l}\text { Carpet, carpet } \\
\text { adhesives CRI Green } \\
\text { Label Plus AND } \\
\text { carpet cushion CRI } \\
\text { Green Label. }\end{array}$ & $\begin{array}{l}\text { At least } 90 \% \text { of the surface area covered by carpet and carpet adhesives } \\
\text { use labeled Carpet and Rug Institute (CRI) Green Label PLUS program } \\
A N D \text { carpet cushion certified to CRI Green Label program. }\end{array}$ & $\begin{array}{l}\text { VOC carpets with the CRI Indoor Air } \\
\text { Quality Program }\end{array}$ \\
\hline $\begin{array}{l}\text { Final 7.2: Home } \\
\text { ventilated before } \\
\text { occupancy. }\end{array}$ & $\begin{array}{l}\text { - Ventilate the home with outside air at the highest rate practical, meeting } \\
\text { ventilation requirements for outdoor air flow and humidity control: During } \\
\text { and shortly after installing products that are known sources of contaminants } \\
\text { (e.g., cabinets, carpet padding and painting), AND during the period } \\
\text { between finishing and occupancy. } \\
\text { - If whole house ventilation cannot be scheduled prior to occupancy, advise } \\
\text { the buyer to operate the ventilation system at the highest rate it can provide } \\
\text { during the first few months of occupancy, meeting the above requirements. }\end{array}$ & \\
\hline Complete & - Comply with all requirements of Indoor airPLUS & $\begin{array}{l}\text { Credit 4-2: Certify house under Energy } \\
\text { Star Indoor Air Package (or other } \\
\text { program as approved by the Director) }\end{array}$ \\
\hline
\end{tabular}

HBATC Built Green Program also addresses several materials not addressed by EPA's Indoor airPLUS program:

- Insulation

- Credit 4-24: use urea-formaldehyde-free insulation or Greengaurd certified product and

- Credit 4-25: do not use fiberglass insulation (excluding ductwork).

- Sealers, grouts, mortars, caulks, stains, pigments, additives, and adhesives

- Credit 4-26: use only non- or low-VOC/toxic, water-based, solvent-free sealers, grouts, mortars, caulks, stains, pigments, additives, and adhesives inside the house 


\section{Appendix B Builder Questionnaire}

Questions for Builders during recruitment period to allow us to determine who to recruit and what category of home they will build:

\section{Introduction}

- Provide builder with a brief description of the project, goals and who we are

- Ask if the builder might be interesting in participating

- If not, no reason to continue questions

- If so, say that you will be asking them a series of questions to determine if they qualify for participation and if so, what group they would be part of (Challenge or WA-Code)

\section{Questions for pre-recruitment}

- Do you anticipate completing a home in the next 12 months (i.e., completing home defined for our purposes as final inspection)?

- How many homes do you anticipate completing

- For each home that you plan to complete, what type of project is it?

- Pre-sale

- Spec-home

- Custom built home

For each home, are you plan to complete, will you use any of the following labeling schemes

- DOE Challenge home

- Indoor airPLUS

- NAHB BuiltGreen

- Energy Star V3

- WA Next Step Home

- For each home that you plan to complete that is not associated with a specific labeling scheme, i.e., WA-Code home, do you plan to include any special features

- Continuous ventilation bath fans

- Low- or No-VOC materials

- Special filtration in the HVAC including MERV rating, extra depth or particular brand

- (list other features related to labels)

- For each home, when do you anticipate completion? 
- In general, who procures materials for you?

- Do they buy them themselves or have an individual dedicated to this task?

- Do they have a list ("bill") of materials that they actually or typically use in each home?

- If so, could they share? If not, who could we talk to to help generate a list?

- When do you typically purchase materials for a given job?

- Do they try to do "just-in-time" purchasing or can materials sit around for a while?

- If the later, what materials and for how long before installation?

- What stages of the project do you typically subcontract?
- Utilities
- Concrete
- Framing
- Siding
- Roofing
- Plumbing
- Electrical
- HVAC
- Insulation
- Drywall
- Finish carpentry
- Painting
- Floor covering
- Landscaping

- What is your typical work week during construction?

- 5 days per week

- 6 days per week

- 7 days per week

- Would you be able to share specific details about scheduling?

- Inspection dates

- Major installation dates (see above list of construction stages) we are mostly interested in the activities after the rough in inspections

- Would you be willing to give access to the site during construction for measurements?

- explain that it would be conducted over a 48 hour period where setup takes place on a Friday evening and takedown on Sunday evening or early Monday moming 
Questions for Builders who have been recruited and categorized as Challenge or WA-Code

- What is the expected completion data of your home?

- Prior to July 15

- After July 15 but prior to January 15

- How soon after completion of the home do occupants move in? 


\section{Appendix C Homeowner Information Sheet}

\section{Evaluation of the Impact of Source Control Measures on Indoor Air Quality in High Performance Homes}

Pacific Northwest National Laboratory is conducting a study, in collaboration with local builders, to better understand the impact of EPA's Indoor airPLUS program on indoor air quality in new homes. This study is investigating the impact of using low-emitting or formaldehyde-free building materials and finishes (e.g. paints, carpets, finishes) in new homes and how this affects the interior levels of volatile organic compounds (VOCs) and formaldehyde. This sheet provides information on the study background, what participation entails, and who to contact for more information.

\section{Study Background}

Recent data indicate that new airtight homes commonly have levels of some (VOCs) that exceed health-based standards. Increases in levels of VOCs above these standards could lead to poor indoor air quality and to health or comfort issues for occupants of these homes. As tighter homes are constructed and an increasing number of synthetic compounds are introduced into buildings through carpeting, paint, cabinetry, and other building materials, there is potential to change the types and concentrations of chemicals to which homeowners are exposed through the choice of low-emitting materials.

The EPA's Indoor airPLUS label requires the use of certified low-emitting materials to improve indoor air quality and health, but the effect of these requirements on achieving measureable reductions in indoor air concentrations of VOCs and aldehydes and related exposures has not been documented in the field. The objective of this project is to verify and quantify the indoor air quality benefits of the Indoor airPLUS requirements for low-emitting materials and finishes for new home construction.

\section{Scope of the Project and What Participation Entails}

This project will measure concentrations of volatile organic compounds, aldehydes, temperature, relative humidity, and carbon dioxide; and will gather information on the operation of your home's ventilation systems, construction characteristics, and materials that may affect indoor air quality. Participation involves allowing PNNL researchers to take these measurements and gather this information. The researchers would only enter your home when you are present. Disruption to your lifestyle should be minimal. A small monetary stipend will be provided to compensate you for the inconvenience of participation. The sampling will occur four times over the 12 months after you occupy your house, on the following schedule, with the following stipends: 


\begin{tabular}{|l|l|l|}
\hline IAQ Sampling Period & $\begin{array}{l}\text { Sampling Stipend } \\
\text { Amount }\end{array}$ & $\begin{array}{l}\text { Maximum Available Logging Stipend } \\
\text { Amount* }\end{array}$ \\
\hline Pre-Occupancy & $\$ 50$ & $\$ 0$ \\
\hline $\begin{array}{l}\text { 2-4 Weeks Post- } \\
\text { Occupancy }\end{array}$ & $\$ 50$ & $\$ 50$ \\
\hline $\begin{array}{l}\text { 6-13 Weeks Post- } \\
\text { Occupancy }\end{array}$ & $\$ 100$ & $\$ 50$ \\
\hline $\begin{array}{l}12 \text { Months Post- } \\
\text { Occupancy }\end{array}$ & $\$ 150$ & $\$ 50$ \\
\hline Total & $\$ 400$ & $\$ 100$ \\
\hline * Logging to be completed daily, $\$ 5 /$ day $+\$ 15$ for completing the activity log all 7 days. \\
\hline
\end{tabular}

Generally, each sampling period will consist of a 24-hour, controlled sampling period followed by a 7-14 day field measurement under typical occupancy conditions.

During the 24-hr controlled sample, you will be asked to slightly modify your behavior beginning the evening before the controlled sample and extending until you return home the after the second controlled sample collection (24-hours later). Specifically, you will be asked to maintain your home in "controlled" conditions, which includes the following:

- maintain the thermostat set point between $74-78^{\circ} \mathrm{F}$ in summer and $68-72{ }^{\circ} \mathrm{F}$ in winter with no setbacks,

- operate the air handler fan continuously,

- refrain from opening windows and exterior doors more than necessary and keep interior doors open, and

- refrain from activities that are known to emit large quantities of VOC into the home (e.g. cleaning, cooking without a range hood, etc.).

The 7-10 day field sample is meant to represent periods of "typical occupancy," no special actions are necessary on your part, but it is important that you are home during that time (i.e. not on vacation) and there are no special activities that might affect the measurements (i.e. big parties, large cleaning events, etc). However, during the 7-10 day long-term sampling period, you will be asked to log basic information regarding use of exhaust fans, cooking, and other activities that affect indoor air quality.

Some homes may undergo an abbreviated sample schedule, consisting only of controlled preoccupancy and 2-4 weeks post-occupancy measurements. In that case, only stipend amounts for those periods (i.e. $\$ 50$ for the pre-occupancy sampling period and $\$ 100$ for the postoccupancy sampling period) will be provided. Participation in this research involves no more than minimal risk, primarily from minor inconvenience and loss of privacy from researchers entering your home and from the test equipment. We will try our best to minimize any 
inconvenience to you, and ask that you tell us if there are ways we can improve. There may be benefits to you, such as improved indoor air quality.

Part of the research involves accurately testing the ventilation rates in your home. This is done using a very small amount of an inert (i.e. non-reactive) chemical gas that has been used in ventilation rate testing in homes and commercial buildings for over 30 years. Because this chemical is non-reactive and non-naturally occurring, we can use it to determine how quickly the air in your home is replaced by outside air by measuring the concentration over time. Although there has not been extensive health testing done on these chemicals, toxicologists have studied these chemicals and concluded that these chemicals should be safe for the general public at the concentrations that will be used in our study. If you would like more information on this, please contact Sarah Widder at the phone number or email address listed below.

Your participation in this research is entirely voluntary and the terms of participation are described in the homeowner agreement. If you decide to participate, you may stop participating at any time without any penalty or loss of benefits to which you are entitled. If you decide you no longer want to participate, please notify any of the research team members listed below.

\section{Contact Information}

The primary researchers supporting this study from PNNL are Sarah Widder (sarah.widder@pnnl.gov or 509-372-6396) and Mickie Chamness (mickie.chamness@pnnl.gov or 509-371-7221). If you have questions or concerns at any time, please contact us. If you have questions about your rights as a research participant, please contact Kathy Ertell at the PNNL Institutional Review Board (IRB), 509-375-3610. The IRB is a committee that approves research with people to make sure their rights, health, and welfare are protected.

This study has been approved by the PNNL Institutional Review Board, IRB No. 2014-12 This document approved for use 3/31/2014 to 3/31/2015. 


\section{Appendix D}

\section{Homeowner Recruitment Messaging}

The following text will be shared in PNNL's LabWeb internal newsletter (https://abweb.pnl.gov/Pages/Home.aspx) and the Whiteboard Discussion forum (https://abweb.pnl.gov/whiteboard/Pages/Home.aspx).

\section{Seeking Participants for PNNL Study on Indoor Air Quality in New Homes.}

Researchers at PNNL are conducting a study, in collaboration with local builders, to better understand the impact of EPA's Indoor airPLUS program on indoor air quality in new homes. This study is investigating the impact of using low-emitting or formaldehyde-free building materials and finishes (e.g. paints, carpets) in new homes and how this affects the interior levels of volatile organic compounds (VOCs) and formaldehyde. Our study will test for these compounds, as well as for temperature, humidity and ventilation rates in new homes built with and without Indoor airPLUS-certified, low-emitting materials. We will also measure energy usage and ask homeowners about their energy use habits.

If you participate in the study, the researchers will do testing in your home before occupancy and then three more times over the 12 months after the house is occupied.

To conduct the study, we are seeking participants who are buying new homes or having homes built between April $15^{\text {th }} 2014$ and June $30^{\text {th }}, 2014$ or between November $1^{\text {st }}, 2014$ and January $15^{\text {th }}, 2015$. If you plan on moving into a new home in the time frames mentioned above and are interested in finding out more about the study and what participation entails, please contact mickie.chamness@pnnl.gov or sarah.widder@pnnl.gov. Thank you for your help understanding and developing the future of healthy, efficient housing! 


\title{
Appendix E
}

\section{Homeowner Agreement}

\author{
HOMEOWNER AGREEMENT \\ Battelle Memorial Institute, Pacific Northwest Division, \\ Operator of Pacific Northwest National Laboratory
}

Impact of Source Control Measures on Indoor Air Quality in High Performance Homes ID No.

\section{OVERVIEW}

This agreement is entered into this day of , 20 , between hereinafter referred to as the Homeowner, residing at , hereinafter referred to as the Residence, and the Research Organization: Battelle Memorial Institute, Pacific Northwest Division, a nonprofit corporation organized and existing under the laws of the State of Ohio, with principal offices in the City of Richland, Washington, in support of its contract with the U.S. Department of Energy (DOE) for the operation of Pacific Northwest National Laboratory (PNNL).

The Research Organization is conducting a research program in collaboration with local builders to better understand the impact of EPA's Indoor airPLUS program on indoor air quality (IAQ) in new homes. This study is investigating the impact of using low-emitting or formaldehyde-free building materials and finishes (e.g. paints, carpets, finishes) in new homes and how this affects the interior levels of volatile organic compounds (VOC's) and formaldehyde.

Accordingly, the Research Organization is seeking permission from occupants of homes that have been accepted into this research program to acquire data related to energy use, ventilation systems performance, and indoor air quality, including:

- monitored energy use,

- residence characteristics and materials,

- interior temperature and humidity levels,

- concentrations of indoor air quality indicators,

- ventilation and infiltration rates,

- type and age of large furnishings or wall/window coverings, and

- homeowner satisfaction and typical home operation schedules.

The main benefits of the study relate to better understanding of how building standards impact air quality in new homes. The only direct benefit to homeowners is learning more about the conditions in your home. This may help you learn how to use the features in your home or modify your lifestyle to maintain healthful indoor air.

If the Homeowner decides to participate and signs this agreement, the Homeowner agrees to voluntarily participate in the study, and to make its Residence available for use in the study as 
described in this agreement. Homeowner may withdraw from the study at any time without consequence. All visits to the Residence by the Research Organization or associated subcontractors will be scheduled in advance with the Homeowner. The period of performance for this agreement shall not exceed two years from the date the agreement is signed.

\section{SUMMARY OF STUDY DESIGN AND SCHEDULE}

A research team consisting of PNNL and Lawrence Berkeley National Laboratory (LBNL) is conducting a study in up to 24 new homes constructed in the Tri Cities, WA that focuses on the impact of the EPA's Indoor airPLUS low-emitting material and source control requirements on indoor air quality. Half of the participating homes will be built with low-emitting materials complying with EPA's Indoor airPLUS section 6 requirements and half of the homes will be constructed with conventional materials not selected for their emission characteristics. The study is roughly divided into initial baseline testing, four IAQ sampling periods, and continuous monitoring of energy use.

Prior to occupancy, a baseline air infiltration test and comprehensive building audit will be performed in each home. The baseline testing will determine building air leakage, duct leakage, indoor air quality, mechanical ventilation system operation, and other relevant building characteristics. The Research Organization will also catalogue all materials used in construction of the home and may take photographs of the unoccupied home.

Following the baseline test, equipment to measure energy consumption and exhaust fan runtime will be installed in the Residence.

In addition, the research team will measure concentrations of volatile organic compounds; aldehydes; temperature and relative humidity; carbon dioxide; and collect data on the operation of ventilation systems in the Residence. This will occur four times:

(1) Immediately prior to initial occupancy,

(2) Within 2-4 weeks post-occupancy,

(3) Approximately 6-13 months post-occupancy, and

(4) Approximately 12 months post-occupancy.

Indoor air quality assessments are expected to last approximately 8 days and will consist of a 24-hour controlled sampling period, followed by an approximately 7 day passive sampling period. The $24-\mathrm{hr}$ controlled sampling period is meant to provide a detailed characterization of emission rates of building materials. Controlled sampling will occur in 2 locations. The equipment will consist of an active sampling pump and small, metal sample tubes. Sampling should be relatively undisruptive, but to achieve good measurements the Homeowner will be requested to maintain their home in a controlled condition for the 24-hour period beginning the evening when the samplers are placed in the home, and ending the next evening. These are the "controlled" conditions that Homeowners will be asked to observe:

- maintain the thermostat set point between $74-78^{\circ} \mathrm{F}$ in summer and $68-72{ }^{\circ} \mathrm{F}$ in winter with no setbacks,

- operate the air handler fan continuously,

- refrain from opening windows and exterior doors more than necessary and keep 
interior doors open, and

- refrain from activities that are known to emit large quantities of VOC into the home (e.g. cleaning, cooking without a range hood, etc.).

- not open windows or doors for long periods of time and refrain from cleaning or other disruptive activities for 24 hours.

During the subsequent long-term ( $\sim 7$ day) sample period, passive, reasonably unobtrusive samplers will be placed throughout the Residence, in up to 5 locations, but primarily in a central living area and removed at the conclusion of the test period. During each sampling event, the Research Organization will visit the Residence 3 times:

(1) To deploy the controlled sampling test equipment,

(2) To retrieve controlled sampling test equipment and deploy passive samplers, and

(3) To retrieve the passive samplers.

Part of the research involves accurately testing the ventilation rates in your home. This is done using a very small amount $(\sim 1 \mathrm{ppb})$ of a type of chemical that has been used in ventilation rate testing in homes and commercial buildings for over 30 years (perfluorocarbon gases). Although there has not been extensive health testing done on these chemicals, toxicologists have studied these chemicals and concluded that these chemicals should be safe for the general public at the concentrations that will be used in the study. If you would like more information on this, please contact Sarah Widder at the 509-372-6396 or sarah.widder@pnnl.gov.

\section{i. Access to Residence}

Entry to the building will be required for the purpose of installing and removing monitoring equipment. Such entry shall be accomplished by prior arrangement with the Homeowner at least 24 hours in advance of entry. These activities will be conducted so as not to unduly interfere with the Homeowner's normal routine. The Homeowner shall designate a contact for coordinating project activities at the building. The Homeowner agrees to notify the Research Organization of any changes in maintenance practices, alterations to the building, or changes in occupancy during the term of this Homeowner Agreement. Homeowner agrees to allow the Research Organization reasonable access to areas of the Residence and associated property, but may verbally refuse the Research Organization to access any particular areas during visits.

\section{ii. Data Collection Equipment}

Project equipment installed by the Research Organization, including all sensors, air quality samplers, data collectors, and data storage devices, will be and remain the responsibility of the Research Organization, or their subcontractors. The Homeowner is not responsible for installed project equipment. The Homeowner shall not be charged for the purchase, use, installation or removal of the energy monitoring equipment, or any services provided by the Research Organization, or their subcontractors, as part of this project. Care will be taken to locate the equipment in discreet places to minimize aesthetic disturbances and out of the way locations to minimize disturbance from or risk to pets or small children. The Homeowner agrees not to disturb installed equipment in any way unless authorized by the Research Organization or 
as may become necessary for safety. The Homeowner agrees to inform the Research Organization of any inadvertent disturbances or displacement of the equipment, or any problems posed by the equipment.

\section{iii. Survey and Logging Information}

Prior to air quality sampling events, the Research Organization will administer a brief home operation questionnaire. Homeowners will also be interviewed regarding the operation of their homes' heating, cooling, and ventilation equipment and for perceptions of comfort and indoor quality. This will occur via phone call or in-person interview and use an online survey form. Homeowner agrees to participate in the interview but may choose not to answer any of the questions asked by the Research Organization that they do not wish to answer.

During the 7-10 day long-term sampling period, the Homeowner will be asked to log basic information regarding use of exhaust fans, cooking, and other activities that affect indoor air quality. This will be done via a web-based survey.

\section{iv. Data Storage, Reporting, and Privacy}

All data gathered becomes the property of the Research Organization. Upon request, the Homeowner will receive a copy of any report issued by the Research Organization in which the Residence was involved. The Research Organization agrees to keep the Homeowner's name, Residence address, and all data collected from Homeowner and Residence anonymous outside of the Research Organization study team. Homeowner gives permission to the Research Organization to publicly publish all data collected from Homeowner and Residence, including answers to individual interview questions, in an anonymous fashion by not linking the data to Homeowner or Residence. The Research Organization may request to keep the contact information of the Homeowner for use in subsequent studies; however, this will not be done without the consent of the Homeowner.

v. Compensation

Battelle agrees to compensate the Homeowner for participation in each IAQ sampling period and completion of related activities (i.e. logging), on an increasing scale based on the degree of inconvenience anticipated by the sampling procedure, for their cooperation in each IAQ sampling period. The stipend amounts are listed in the table below:

\begin{tabular}{lrr}
\hline IAQ Sampling Period & $\begin{array}{r}\text { Sampling Stipend } \\
\text { Amount }\end{array}$ & $\begin{array}{r}\text { Maximum Available } \\
\text { Logging Stipend Amount* }\end{array}$ \\
\hline Pre-Occupancy & $\$ 50$ & $\$ 0$ \\
$2-4$ Weeks Post-Occupancy & $\$ 50$ & $\$ 50$ \\
6-13 Weeks Post-Occupancy & $\$ 100$ & $\$ 50$ \\
1 Year Post-Occupancy & $\$ 150$ & $\$ 50$ \\
Total & $\mathbf{\$ 4 0 0}$ & $\mathbf{\$ 1 0 0}$ \\
\hline * Logging to be completed daily, \$5/day $+\$ 15$ for completing the activity log all 7 days.
\end{tabular}


Depending on the success of recruitment, some homes may undergo an abbreviated sample schedule, consisting only of controlled pre-occupancy and 2-4 weeks post-occupancy measurements. The stipend amounts provided will reflect this (i.e. $\$ 50$ for the pre-occupancy sampling period and $\$ 100$ for the post-occupancy sampling period).

$$
\text { v. Study Completion }
$$

Upon completion of the field study, all monitoring equipment will be removed and affected areas returned to "as-found" or better condition by the Research Organization.

\section{STATEMENT OF RISK AND LIABILITY}

Homeowner represents and warrants that Homeowner is at least 18 years of age, has the authority to enter into this agreement and that Homeowner is the rightful owner of the residence. The Research Organization acknowledge that it has relied upon the representations and warranties of the Homeowner set forth in this agreement, without independent investigation of said warranties or representations.

The Research Organization does not anticipate any physical risks or discomforts to its agents or to the Homeowner, Homeowner's family, or to the Residence. A small degree of inconvenience and risk will occur as a result of IAQ sampling and monitoring equipment installation. The Research Organization assumes any and all risks of personal injury and property damage attributable to the negligent acts or omissions of the Research Organization and its officers, employees, and servants thereof while acting within the scope of their employment by the Research Organization in connection with the research program described herein. There is a small risk that your private information could be inadvertently released. All personal information will be encrypted on secure servers, kept in locked file cabinets, and not shared outside the research team. Any published information will be kept anonymous.

\section{CONTRACT AGREEMENT}

This agreement embodies the entire agreement and understanding between the Homeowner and the Research Organization and supersedes all prior agreements and understandings relating to the subject matter hereof. Except as otherwise expressly provided for herein, this agreement may be changed, waived, discharged or terminated only by an instrument in writing, signed by the party against which enforcement of such change, waiver, discharge or termination is sought.

I have read the procedure described above. I confirm that I as the Homeowner and my home as the Residence meet the following minimum requirements for participation in this study:

$\square$ Homeowner is at least 18 years of age

No daily smoking, candle burning, or incense use occurs in the home

I voluntarily agree to participate in the Procedure and I have received a copy of this description. I consent to: 
$\square$ Permit the baseline testing

$\square$ Permit the installation and removal of energy, ventilation, and indoor air quality monitoring equipment

$\square$ Permit easonable access to the Residence to support data collection efforts

$\square$ Remain on the premises during all site visits by the Research Organization or their subcontractors

$\square$ Participat in the interviews and logging daily information during IAQ sampling periods

$\square$ Allow the Research Organization to use and publish all data anonymously

Homeowner executes this agreement, fully intending to be bound by the same.

Homeowner (PERMITOR):

Homeowner (PERMITOR):

Date

Date (if multiple)

\section{BATTELLE MEMORIAL INSTITUTE, PACIFIC NORTHWEST DIVISION}

By:

Date

Title

Contract Specialist

Witness 


\section{Appendix F}

\section{Homeowner Questionnaire}

\section{F.1 On-line Survey Instrument for PNNL/LBNL IAQ Study.}

A combination of in-person and on-line survey will be used to collect information from the head of household (or designated person within the household) immediately prior to start of a monitoring period and as a daily log during the monitoring period with clarification questions asked at the end of the monitoring period as needed. The information collected relates to occupancy, in-home activities, home operation and emissions sources that can impact the interpretation of IAQ monitoring results.

All questions on the pre-monitoring in-person survey and the on-line daily log version of the survey are included here.

The daily log version of the survey can be viewed at

insert-http-address

The head of household or designated individual will be given a unique code that will be used to access the on-line survey. The pre-monitoring survey will be completed in person or over the phone prior to start of the monitoring period. The purpose of the pre-monitoring questions is to collected information on the occupancy patterns in the home and possible changes to the home since move-in (or since the previous monitoring period was conducted).

The subject will be instructed during the pre-monitoring survey on how to complete the daily log during the monitoring period and the first pass through the daily log will be completed at that time.

The daily log version of the survey instrument can be completed either partially throughout the day or completely in one sitting at any time during each day. The log will be saved once per day. Log will be completed on-line using either the home-owners personal computer or a loaner notebook computer provided by LBNL.

The webmaster and the responsible individual supervising the study both receive automatic e-mail notification each time a subject completes a survey. The subject will receive an e-mail, phone call and/or text reminder (depending on stated preference) if a daily log has not been saved for the previous day.

Prior to the post-monitoring visit to the home, the responsible individual will review responses for the week's daily log and will ask clarification questions as needed when they visit the home to collect sampling equipment of by phone. 


\title{
Indoor Air Monitoring \\ Pre-Monitoring Survey Instrument
}

\begin{abstract}
To be completed in the presence of study technician or by phone interview prior to monitoring period.
\end{abstract}

Please answer the following questions: 
The following questions help us understand who lives in your home:

1. How many people live in the home?

$\begin{array}{cc}0 & 1 \\ 0 & 2 \\ 0 & 3 \\ 0 & 4 \\ 0 & 5 \\ 0 & 6 \text { or more }\end{array}$


2. For each person living in the home, starting with the youngest, please indicate the following

\begin{tabular}{l|c|c|c|c|c|c|c|}
\cline { 2 - 7 } & $\leq 2$ & $3-5$ & $6-12$ & $13-18$ & $19-60$ & $>60$ & $\begin{array}{c}\text { No } \\
\text { Answer }\end{array}$ \\
\hline Age at last birthday & 0 & 0 & 0 & 0 & 0 & 0 & 0 \\
\hline
\end{tabular}

\begin{tabular}{|c|c|c|c|}
\cline { 3 - 4 } 2.2 & Female & Male & $\begin{array}{c}\text { No } \\
\text { Answer }\end{array}$ \\
\hline \multicolumn{1}{l|}{ Gender } & 0 & $\bigcirc$ & 0
\end{tabular}

\begin{tabular}{l|c|c|c|c|c|c|c|c|}
\cline { 2 - 7 } $\begin{array}{l}\text { 2.3 Thinking of the } \\
\text { current calendar } \\
\text { day, when will } \\
\text { this individual be } \\
\text { indoors at home? }\end{array}$ & $\begin{array}{c}12 \mathrm{AM} \\
\text { (midnight) } \\
-6 \mathrm{AM}\end{array}$ & $\begin{array}{c}6 \mathrm{AM}- \\
8 \mathrm{AM}\end{array}$ & $\begin{array}{c}8 \mathrm{AM}- \\
12 \mathrm{PM} \\
\text { (noon) }\end{array}$ & $\begin{array}{c}12 \mathrm{PM} \\
\text { (noon) }- \\
4 \mathrm{PM}\end{array}$ & $\begin{array}{c}4 \mathrm{PM}- \\
6 \mathrm{PM}\end{array}$ & $\begin{array}{c}6 \mathrm{PM}- \\
8 \mathrm{PM}\end{array}$ & $\begin{array}{c}8 \mathrm{PM}- \\
12 \mathrm{AM} \\
\text { (midnight) }\end{array}$ & $\begin{array}{c}\text { Don't } \\
\text { Know }\end{array}$ \\
\hline \multicolumn{1}{c}{ weekday } & 0 & 0 & 0 & 0 & 0 & 0 & 0 & 0 \\
weekend & 0 & 0 & 0 & 0 & 0 & 0 & 0 & 0 \\
\hline
\end{tabular}

${ }^{*}$ Check all that apply

Please loop through question 2 until all occupants have been included. 
3. Please indicate the number of each type of indoor pet. If zero, leave blank.

\begin{tabular}{|c|c|c|c|c|c|}
\hline & 1 & 2 & 3 & 4 & $\geq 5$ \\
\hline Dog & O & 0 & 0 & 0 & 0 \\
\hline Cat & 0 & 0 & 0 & 0 & 0 \\
\hline Bird & 0 & 0 & 0 & 0 & 0 \\
\hline Reptile & 0 & 0 & 0 & 0 & 0 \\
\hline Other & O & 0 & O & 0 & $\mathrm{O}$ \\
\hline
\end{tabular}

4. Were any of the following NEW items installed during the last month?

\begin{tabular}{l|c}
\cline { 2 - 2 } \multicolumn{1}{c}{ Item } & $\begin{array}{c}\text { Installed } \\
\text { NEW }\end{array}$ \\
\hline Fabric covered furniture & $\bigcirc$ \\
Mattress & 0 \\
Hardwood furniture & $\bigcirc$ \\
Carpet or Rug (larger than five feet) & $\bigcirc$ \\
Cabinetry & $\bigcirc$ \\
Window covering/treatment & $\bigcirc$ \\
Office equipment or television & $\bigcirc$ \\
Interior wall finish like paint or wall paper & $\bigcirc$ \\
Bath/shower curtain & $\bigcirc$ \\
\hline
\end{tabular}

This is the end of the pre-monitoring survey.

The following daily log will help us understand how your home is operated during the time when we are collecting samples.

We will go through the daily log together the first time to make sure you understand the questions. 
You will be given a unique login ID to complete the survey. (Give subject the unique ID number)

Log in to the survey following the link (provided) using your unique home ID number (provided). 


\section{Please answer the following questions:}

1. Were any of the following used in your home today? (Please check a box for each row.)

\begin{tabular}{|c|c|c|c|c|}
\hline Item/Activity & Yes & No & $\begin{array}{l}\text { Don't } \\
\text { Know } \\
\end{array}$ & $\begin{array}{c}\text { Decline to } \\
\text { state }\end{array}$ \\
\hline Ceiling fan & 0 & $\mathrm{O}$ & $\mathrm{O}$ & 0 \\
\hline Oscillating or box type fan & $\mathrm{O}$ & $\mathrm{O}$ & $\mathrm{O}$ & $\mathrm{O}$ \\
\hline Range hood or other kitchen exhaust fan & 0 & $\mathrm{O}$ & 0 & O \\
\hline Bath fan & 0 & $\mathrm{O}$ & $\mathrm{O}$ & O \\
\hline Whole-house exhaust fan & 0 & $\mathrm{O}$ & $\mathrm{O}$ & O \\
\hline Open windows or doors for ventilation & $\mathrm{O}$ & $\mathrm{O}$ & $\mathrm{O}$ & O \\
\hline Portable cooling/heating & 0 & O & O & O \\
\hline Clothes dryer & $\mathrm{O}$ & $\mathrm{O}$ & $\mathrm{O}$ & O \\
\hline Change adjustments on thermostat & 0 & $O$ & $\mathrm{O}$ & O \\
\hline $\begin{array}{l}\text { Space heating stove or insert } \\
\text { (wood/gas/pellet) }\end{array}$ & $\mathrm{O}$ & $\mathrm{O}$ & $\mathrm{O}$ & 0 \\
\hline
\end{tabular}


1.1. Please provide details about the ventilation related activities in your home today.

(note: only those items selected yes in question 1 will come up)

\begin{tabular}{|c|c|}
\hline Ceiling fan & Number of hours operated $\square$ \\
\hline Oscillating or box type fan & Number of hours operated $\square$ \\
\hline Range hood exhaust fan & $\begin{array}{l}\text { During what time: Breakfast } O \text { Lunch } O \text { DInner } O \\
\text { Other } O \\
\text { Settings (select all that were used): high } O \text { med } O \\
\text { lowO }\end{array}$ \\
\hline Bath fan & Number of hours operated $\square$ \\
\hline Whole-house exhaust fan & Number of hours operated $\square$ \\
\hline Open windows or doors for ventilation & $\begin{array}{l}\text { Number of windows/doors open for ventilation } \square \\
\text { Number of hours open } \square \\
\text { Time of day windows open: morning } O \text {, afternoon } O \text {, } \\
\text { evening } O \text {, night } O \text {, }\end{array}$ \\
\hline Portable cooling/heating & $\begin{array}{l}\text { Number of units } \square \\
\text { Number of hours } \square \\
\text { Settings (select all that were used): highO medO } \\
\text { low } \mathrm{P}\end{array}$ \\
\hline Clothes dryer & $\begin{array}{l}\text { Number of loads } \square \\
\text { Number of hours operated } \square\end{array}$ \\
\hline $\begin{array}{l}\text { Change temperature setting on } \\
\text { thermostat }\end{array}$ & Settings (select all that apply): raised $\bigcirc$ lowered $\bigcirc$ \\
\hline $\begin{array}{l}\text { Space heating stove or insert } \\
\text { (wood/gas/pellet) }\end{array}$ & $\begin{array}{l}\text { Type and fuel determined during walkthrough } \\
\text { Number of hours } \square \\
\text { Setting: highO medO lowO }\end{array}$ \\
\hline $\begin{array}{l}\text { Indicates alphanumeric entry } \\
O \text { Indicates selection only }\end{array}$ & $\begin{array}{l}\text { 1hour } \\
4 \text { hours }\end{array} \quad \begin{array}{c}16 \text { hours or } \\
\text { more }\end{array}$ \\
\hline
\end{tabular}


2. Did any of the following activities occur in your home today? (Please check a box for each row)

\begin{tabular}{|c|c|c|c|c|}
\hline Activity & Yes & No & Don't know & $\begin{array}{c}\text { Decline to } \\
\text { state }\end{array}$ \\
\hline Cook using stove top or oven & 0 & $\mathrm{O}$ & 0 & 0 \\
\hline Cook using microwave & 0 & 0 & 0 & 0 \\
\hline Use of candles or incense & $\mathrm{O}$ & O & O & $\mathrm{O}$ \\
\hline Smoking & 0 & O & O & O \\
\hline Use of spray cleaning products & 0 & 0 & 0 & 0 \\
\hline Use of polishers & 0 & 0 & 0 & 0 \\
\hline Use spray air fresheners & 0 & O & $\mathrm{O}$ & $\mathrm{O}$ \\
\hline Use of plug-in type air fresheners & 0 & O & O & O \\
\hline $\begin{array}{l}\text { Hobbies that involve chemicals or } \\
\text { solvents }\end{array}$ & 0 & 0 & O & $\mathrm{O}$ \\
\hline Use of art supplies & 0 & 0 & 0 & 0 \\
\hline Use of pest control products & 0 & 0 & $\mathrm{O}$ & 0 \\
\hline Vacuum carpets & 0 & O & O & O \\
\hline Damp mop floors & 0 & O & 0 & 0 \\
\hline Use toaster or toaster oven & 0 & 0 & 0 & 0 \\
\hline Bring home dry cleaned clothing & 0 & 0 & $\mathrm{O}$ & $\mathrm{O}$ \\
\hline Stain remover (carpet or cloths) & 0 & 0 & 0 & 0 \\
\hline Professional house cleaning service & 0 & 0 & 0 & 0 \\
\hline
\end{tabular}


2.1. For each of the activities in your home today, please provide the following details

(note: only those items selected yes will come up)

\begin{tabular}{|c|c|c|c|}
\hline $\begin{array}{l}\text { Cook using stove top, microwave or } \\
\text { oven }\end{array}$ & $\begin{array}{l}\text { During what meals: Breakfast } O \\
\text { Other } O\end{array}$ & Lunch $\mathrm{O}$ & DInner O \\
\hline Cook using microwave & $\begin{array}{l}\text { During what meals: Breakfast } O \\
\text { Other } O\end{array}$ & Lunch $\bigcirc$ & DInner $O$ \\
\hline Toaster or toaster oven & $\begin{array}{l}\text { During what meals: Breakfast } O \\
\text { Other } O\end{array}$ & Lunch $\bigcirc$ & DInner $O$ \\
\hline Use of candles or incense & Number of hours operated $\square$ & & \\
\hline Use of spray cleaning products & How often do you use $\square$ & & \\
\hline Use of polishers & How often do you use $\square$ & & \\
\hline Use spray air fresheners & How often do you use $\square$ & & \\
\hline Use of plug-in type air fresheners & How many are in use $\square$ & & \\
\hline $\begin{array}{l}\text { Hobbies that involve chemicals or } \\
\text { solvents }\end{array}$ & How many hours $\square$ & & \\
\hline Use of art supplies & & Other & $\begin{array}{r}\text { Markers } \bigcirc \\
\text { Paints } \bigcirc \\
\text { Adhesives } O \\
\text { Sprays } \bigcirc \\
\text { wet supplies } O\end{array}$ \\
\hline Use of pest control products & & & $\begin{array}{r}\text { Spray } O \\
\text { Fumigant } O \\
\text { Wipe on } O \\
\text { Other } O\end{array}$ \\
\hline Laundry, i.e., washing cloths & How many loads were washed $\square$ & & \\
\hline Stain remover & How often used $\square$ & & \\
\hline
\end{tabular}

Thank you for completing this survey.

Submit Your Survey

F.10 
Exit Interview to be conducted at completion of monitoring period (in person or over phone)

\begin{tabular}{l|c|c|c|c|}
\cline { 2 - 5 } $\begin{array}{c}\text { Did any of the following activities occur } \\
\text { during the home the previous week? }\end{array}$ & Yes & No & Don't know & $\begin{array}{c}\text { Decline to } \\
\text { state }\end{array}$ \\
\hline Oven cleaning & 0 & $O$ & 0 & 0 \\
Professional home maintenance service & $O$ & 0 & 0 & 0 \\
\hline
\end{tabular}




\section{Appendix G List of Discouraged Activities during Active Sampling}

The following activities may affect indoor air quality measurements and are to be avoided, if at all possible, during active sampling events:

- operation of thermostat outside of the temperature range of $74-78{ }^{\circ} \mathrm{F}$ in summer and $68-72^{\circ} \mathrm{F}$ in winter with no setbacks;

- leaving windows and exterior doors open;

- extensive cooking at high temperature, especially frying or cooking in a skillet, such that residual odors will remain for a period of 6 hours or more;

- oven cleaning;

- major cleaning using cleaning products, such as Windex ${ }^{\circledR}, 409^{\circledR}, \mathrm{Clorox}^{\circledR}, \mathrm{Lysol}^{\circledR}$, or similar products (use on limited areas $\mathrm{OK}$, such as on a single counter or sink);

- use of candles and incense;

- use of air fresheners, including spray or plug-in products; and

- large use of solvents (e.g. gun cleaning, painting with oil paints, painting your nails, scale models, etc).

Engaging in these activities in your garage is $\mathrm{OK}$.

For the subsequent, 7-day passive sampling period, to significant change in activities is required. However, only activities that occur in a "typical" week should be performed. For example, if you typically clean your oven every week or every other week, it is $\mathrm{OK}$ to clean your oven during the passive sampling period. However, if you only clean your oven once a year, please do not clean your over during a passive sampling event. Similarly, if you regularly have large parties at your home, it is acceptable to have a large party during the passive sampling event. However, if you only have large parties a few times a year, please do not have large parties during the passive sampling event. 
Final Version

\section{Appendix $\mathrm{H}$ IAQ Sampling Protocol}

\section{Field Protocol for IAQ Monitoring}

Last edited 5/29/2014 by Sarah Widder

\section{Table of Contents}

Pre-Occupancy Site Visit H.1

Before Pre-Occupancy Site Visit Activities Checklist .................................................. H.2

Five days prior to the site visit complete the following: ................................................ H.2

Approximately three days prior to site visit complete the following: ....................................

At least one day prior to the site visit complete the following:..................................... H. 3

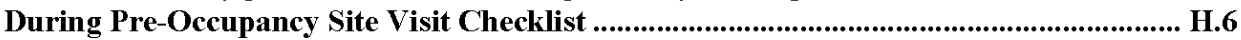

To be accomplished during Day 1 of pre-occupancy site visit ........................................ H.6

To be accomplished during PM of Day 2 of pre-occupancy site visit .............................. H.9

Immediately After Pre-Occupancy Site Visit Checklist..................................................... H.10

Soon After Pre-Occupancy Site Visit Checklist .......................................................... H.10

Initial Home Inspect Sample Site Monitoring Log ......................................................... H.11

\section{Introduction}

This protocol describes the operating procedures for active and passive sampling for the IAQ Source Control project in Richland, WA.

If any issues are encountered or questions arise when implementing this protocol, contact the following:

\begin{tabular}{l}
$\begin{array}{l}\text { Sarah Widder } \\
\text { sarah.widder@opnnl.gov }\end{array}$ \\
612-205-1606 \\
\hline
\end{tabular}

Randy Maddalena

rmaddalena@1bl.gov

209-770-3004 
Final Version

Pre-Occupancy Site Visits

\section{Before Pre-Occupancy Site Visit Activities Checklist}

Five days prior to the site visit complete the following:

Contact Homeowner or Contractor and confirm pre-occupancy site visit dates/times (three visits)

- Confirm there will be no activity in home during sampling period

- Gated community? If so, get access code or request pass.

- Building door key/code or plan to meet owner/contractor

- Alarm systems?

Get copy of operating instructions for HVAC system and thermostat, house plans, and rating information (if available)

- Rating information includes building air leakage as measured by a blower door, duct leakage, house insulation and construction specifications, etc (basically items listed on audit forms)

Approximately three days prior to site visit complete the following:

Compile/review home visit binder with appropriate forms

- Homeowner agreement

- If not already signed, include 2 full study consent forms

- Blank W-9

- Extra Homeowner Information Sheet

- Home inspection/audit form

- Material inventory and material loading form (if already complete, this would be a good time to check entries)

- main things to capture will be the general characteristics and extent of flooring types, walls (paints and finishes), cabinets (e.g. type/description of large surface area items and approximate sf)

- Hard copy of IAQ Field data sheet (in case computer doesn't work)

- Copy of initial questionnaire (although this won't be completed until post occupancy visit it might be good to look at)

- House plans (if available) 


\section{Final Version}

Confirm sufficient number of sampling tubes

- Conditioned, sealed and labeled VOC tubes - at least 7

- Conditioned, sealed and labeled PFT tubes - at least 7

- ALD cartridges in sealed foil bags - at least 7

- Ozone scrubber for each active ALD sample - at least 7

Blue ice in freezer -

- Blue ice

Charge sample pumps

\section{At least one day prior to the site visit complete the following:}

Visit home to:

- review floor plan (draw if not already provided)

- remove non-"house-related" sources of IAQ contaminants (e.g. air fresheners, cleaning products, gas cans, etc) from home and garage. OK to leave extra paint cans or other construction materials (i.e. stuff associated with the "house")

- perform initial ventilation "flush" by turning on whole house ventilation fan to maximum flow rate

Check that you have all equipment and supplies for home inspection (in blue Tupperware stored in Lab Home A closet)
- Flashlight
- Extra batteries
- Step ladder (make sure clean)
- Street map
- Extra waterproof pens
- Clipboard(s)
- Tape measure
- Booties
- Camera
- Blower door (if necessary)
- Duct blaster (if necessary)
- Exhaust fan flow box 
Final Version

- Manometer and extra tubing

- "Duct" tape, cardboard, extra tape

Ensure working order of all Air sampling pumps

- Bring SKC Universal Manual to field for trouble shooting

- Pump batteries fully charged

Check that you have all equipment and supplies for sample collection (in cardboard box in Lab Home A closet or sent by LBNL)

- Ziplock® Bags

- Latex and/or nitrile gloves

- Kimwipes® (large and small)

- Time piece

- Ice chest loaded with BlueIce (samplers should be stored in this)

- Extra batteries and plugs

- Zip-ties assorted sizes

- Residue free (FrotTape ${ }^{\circledR}$ or ScotchBlue ${ }^{\circledR}$ ) tape and cloth (Polyken Gaffers ${ }^{\circledR}$ ) tape

- AirCheck Samplers with fully charged batteries

- Extra tubing

- Master Charger

- Commercial packed Carbopack sorbent tubes $(\mathrm{n}=7)$

- Packed metal Carbopack sorbent tubes $(\mathrm{n}=7)$

- XPoSure Aldehyde sampler cartridges $(n=7)$

- Ozone scrubbers (1 for each aldehyde sampler)

- Sampler tripods ( 2 indoor and 1 outdoor)

- Emitter tripods (up to 6)

- Two EGM-4 $\mathrm{CO}_{2}$ analyzers or similar

- Source of $\mathrm{CO}_{2}$ (beverage cylinder) - located in LSL 1403

Computer to record data and check HOBOs (if necessary)

- Bring the software and shuttle cord (just in case)

- Bring computer charger (just in case)

- Have DataLog downloaded 


\section{Final Version}

To be completed as close as possible to pre-occupancy deployment (e.g. morning of deployment)

\section{Weigh PFT emitters}

- See protocol for weighing emitters

- Prepare 5-8 emitter sets per home with three different PFT emitters in each set (unless otherwise noted for zonal analysis) that need to be weighed before and after each deployment

- FIRST TIME ONLY: after getting pre-deployment weight, launch the HOBO that is attached to each emitter set 
Final Version

\section{During Pre-Occupancy Site Visit Checklist}

To be accomplished during Day 1 of pre-occupancy site visit

DO NOT STORE OR TRANSPORT EMITTERS WITH SAMPLERS (use separate vehicle or pelican case to transport emitters)

Enter home and check HVAC settings and make a note of any "first impressions" including odors

- Record HVAC settings on audit sheet.

- See "Initial Home Inspection Sample Site Monitoring Log" for odors of interst

Review full consent form with homeowner if not already done

- Have homeowner sign both copies

- Give one copy to homeowner and keep one copy for records

- What do we do if no homeowner? Do we have the builder sign the consent form?

- Confirm that there will be no activity in home during sampling period

Complete the home inspection form and review questionnaire with homeowner

- Talk about that this will happen, materials, furnishings, home cleaning practices.

Walk through home to identify locations for placing emitters, data loggers and air sampling stations

- Ask homeowner/contractor if any preferred location keeping in mind that we want to deploy the samplers and emitters in the same locations post occupancy to the extent possible

- Identify AHU return grill(s)

- Find outdoor location for sampling station

- Note all sample and emitter locations on house plans

Set HVAC conditions to target values and close all windows and exterior doors

- Ask homeowner preferred set point within control range of $68-72{ }^{\circ} \mathrm{F}$ and turn on air handler fan.

Deploy emitters

- Record details for location and start time on tracking sheet

- Distribute through house favoring near AHU return 
Final Version

- Keep away from the sample collection locations identified during walkthrough

- Place emitter cages on boxes, tripods, or other elevated location, secured with zip ties if necessary

- Should be out of direct sun

- Should be away from heat source (i.e., don't put near back of refrigerator)

- Use at least $0.002-0.003$ vials per square foot of living space (i.e., $5-8$ vials for a $2500 \mathrm{sq} \mathrm{ft} \mathrm{home)}$

- Take pictures of location of each emitter to confirm location

Setup active air sample stations

- Erect pump sample stands and secure pumps with black wedges (pump \# should correspond to \# on stand)

- Perform calibration check on each pump line using dummy tubes and Dry Cal and record flow rates on DataLog spreadsheet. See Appendix C for more detailed directions.

- $\mathrm{ALD} /$ Ozone (outside lines) $=500 \mathrm{cc} / \mathrm{min}$

- $\operatorname{VOC}($ middle line $)=100 \mathrm{cc} / \mathrm{min}$

- PFT (inside line) $=50 \mathrm{cc} / \mathrm{min}$

- Program delayed start of air sample stations (one pump at 4:00AM and one pump at 4:00PM for each sampling stand and record sample start and end time on DataLog spreadsheet

- Press mode to access delayed start menu and set number of minutes of delay from selected start time

- Press mode again twice and set pump time to 60 minutes, leave sample time blank (0 minutes)

- LEAVE pump until selected start time

- At selected start time, press Start.

- Wearing gloves, load sample tubes/cartridges for both AM and PM sampling and passive blank and CAREFULLY record sample serial numbers on DataLog according to the following table. See Appendix D for a picture of the sampling set up.

- Keep caps with sample bag (white caps/swagelock/etc) for use in pick up.

- Take pictures of each sampling stand to confirm proper configuration.

- Fill out chain of custody forms with sample ID and sign. 
Final Version

\begin{tabular}{|l|l|l|l|l|}
\hline $\begin{array}{l}\text { Sampler } \\
\text { Type }\end{array}$ & Description & Serial \# & To uncap & $\begin{array}{l}\text { Location (also see } \\
\text { Appendix D) }\end{array}$ \\
\hline ALD/Ozone & $\begin{array}{l}\text { White syringe } \\
\text { samplers in foil bags } \\
\text { (ALD and ozone } \\
\text { sampler connect } \\
\text { together) }\end{array}$ & N/A & $\begin{array}{l}\text { Remove white } \\
\text { plastic caps } \\
\text { on both ends } \\
\text { of each } \\
\text { sampler/ } \\
\text { scrubber }\end{array}$ & $\begin{array}{l}\text { Outside line of sample } \\
\text { pump, ALD should be } \\
\text { closer to pump than ozone } \\
\text { scrubber, oriented with the } \\
\text { wider inlet away from } \\
\text { sample stand }\end{array}$ \\
\hline VOC & $\begin{array}{l}\text { Clear glass tube with } \\
\text { white/black sorbet } \\
\text { material }\end{array}$ & $\begin{array}{l}\text { Red lettering } \\
\text { on side of tube } \\
\text { (typically } \\
\text { H\#\#\#\# or } \\
\text { G\#\#\#\#) }\end{array}$ & $\begin{array}{l}\text { Remove from } \\
\text { plastic } \\
\text { sampling } \\
\text { sleeve }\end{array}$ & $\begin{array}{l}\text { Middle line of pump, insert } \\
\text { tube in swage lock fitting } \\
\text { with sorbent away from } \\
\text { pump and tighten until snug } \\
\text { (be careful not to break the } \\
\text { tube!) }\end{array}$ \\
\hline VOC Blank & Same as VOC & Same as VOC & $\begin{array}{l}\text { Same as VOC } \\
\text { Above active sampling set } \\
\text { with passive diffuser (metal } \\
\text { cap with screen) - } \\
\text { RECORD TIME } \\
\text { UNCAPPED AS START } \\
\text { TIME }\end{array}$ \\
\hline PFT & $\begin{array}{l}\text { Metal thermal } \\
\text { sesorption tube with } \\
\text { swage lock fittings }\end{array}$ & $\begin{array}{l}\text { Etched number } \\
\text { typically \#.\# } \\
\text { or \#\#.\#) }\end{array}$ & $\begin{array}{l}\text { Undo swage } \\
\text { lock from } \\
\text { both ends of } \\
\text { tube }\end{array}$ & $\begin{array}{l}\text { Inner line of pump; insert } \\
\text { tube into swage lock fitting } \\
\text { with etching towards pump } \\
\text { and tighten until snug. }\end{array}$ \\
\hline PFT Blank & $\begin{array}{l}\text { Same as PFT } \\
\text { Same as PFT }\end{array}$ & $\begin{array}{l}\text { Above active sampling set } \\
\text { with passive diffuser (metal } \\
\text { cap with screen) - } \\
\text { RECORD TIME } \\
\text { UNCAPPED AS START } \\
\text { TIME }\end{array}$ \\
\hline
\end{tabular}

Setup and launch EGM-4 $\mathrm{CO}_{2}$ or similar analyzers at the location(s) selected for the indoor sample collection

- Note $\mathrm{CO}_{2}$ sampler type, serial number, and start time on DataLog

Setup and launch Q-Track $\mathrm{CO}_{2}$ analyzer at outdoor location

- If only one $\mathrm{CO}_{2}$ analyzer, set initial analyzer outside for as long as possible and record outdoor concentration prior to bringing indoors.

- Note $\mathrm{CO}_{2}$ sampler type, serial number, and start time on DataLog

\section{Audit home}

- Record, at a minimum, exhaust fan flow rates (bath vans, laundry room fans, kitchen range hoods, and dryer exhaust) and HVAC equipment specifics 
Final Version

- Take pictures of all nameplate values and each room

Complete material inventory and loading factor estimates (can do this on next morning also)

Start delayed timer on pumps to collect sample at 4:00 AM and 4:00 PM sampling periods at designated start time

Release $\mathrm{CO}_{2}$ in $\mathrm{AHU}$ return monitoring concentration on EGM-4 until concentration exceeds $2500 \mathrm{ppm}$

Exit, close and lock

Arrange with homeowner/builder for access during afternoon to retrieve all equipment

\section{To be accomplished during PM of Day 2 of pre-occupancy site visit}

Meet homeowner/builder and answer any questions as needed

Enter home and check HVAC settings and make a note of any "first impressions" including odors

- Reset HVAC settings to those found on Day 1.

Check each pump to insure sample runtime completed for AM \& PM period

- Should display 60.

- If pump displays other than 60 , record on DataLog.

Retrieve, cap, and label all indoor and outdoor sample tubes/cartridges and place in ice chest with blue ice

- When retrieving, double check sampler serial number and pump number. Note any inconsistencies on Data Log.

- No labels on tubes, record label on bag or sleeve. See Appendix B for an example of VOC sampler sleeve labeling

- Can pre-label bags and sleeves for convenience

Check and record pump flows using dummy tubes and Dry Cal using same procedure as in deployment

Breakdown indoor and outdoor sample station and cleanup area

Collect emitter cages (DO NOT STORE OR TRANSPORT EMITTERS WITH SAMPLERS) 
Final Version

- Transport in separate car or pelican case

Complete material inventory and loading factor estimates and audit (if not already done)

Cleanup, pack up and do final walkthrough

Close, lock and arrange with homeowner/builder to return key, as applicable

\section{$\underline{\text { Immediately After Pre-Occupancy Site Visit Checklist }}$}

Weigh emitters and record emitter weight on DataLog

- Store emitters in fume hood in LSL 1403

Send samplers to LBNL

- Pack all samplers in cooler in box with fresh blue ice

- Fill out shipping request form and bring to warehouse

- Send to: Marion Russell 70-222

Lawrence Berkeley National Lab Bldg 69

One Cyclotron Rd.

Berkeley, CA 94706

510-495-2915

- Notify Marion of tracking number

- If shipping is not immediately available, store samplers in refrigerator in Lab Home A

\section{Soon After Pre-Occupancy Site Visit Checklist}

Review all information to insure recorded correctly

If required, code answers that are not already coded in questionnaire and inspection forms

Download data from loggers

Restock supplies as needed

H.10 
Final Version

\section{Post-Occupancy Site Visits}

\section{Before Post-Occupancy Site Visit Activities Checklist}

Five days prior to the site visit complete the following:

Contact Homeowner and confirm pre-occupancy site visit dates/times (three visits)

- Confirm homeowners will be away during day of active sampling

Approximately three days prior to site visit complete the following:

Compile/review home visit binder with appropriate forms

- Material inventory and material loading form (if already complete, this would be a good time to check entries)

- main things to capture will be new furnishings, drapes, window coverings, art, wall hangings, etc

- Hard copy of IAQ Field data sheet (in case computer doesn't work)

- Copy of initial questionnaire (although this won't be completed until post occupancy visit it might be good to look at)

- House plans (if available)

Confirm sufficient number of sampling tubes

- Conditioned, sealed and labeled VOC tubes - at least 16

- Conditioned, sealed and labeled PFT tubes - at least 14

- ALD cartridges in sealed foil bags - at least 16

- Ozone scrubber for each active ALD sample - at least 7

Blue ice in freezer

Charge sample pumps

At least one day prior to the site visit complete the following:

Ensure working order of all Air sampling pumps

- Bring SKC Universal Manual to field for trouble shooting

- Pump batteries fully charged

H.11 
Check that you have all equipment and supplies for sample collection (in cardboard box or tupperware in Lab Home A closet or sent by LBNL)

- Step ladder (make sure clean)

- Extra waterproof pens

- Clipboard(s)

- Tape measure

Booties

- Camera

- Ziplock® Bags

- Latex and/or nitrile gloves

- Kimwipes® (large and small)

- Time piece

- Ice chest loaded with BlueIce (samplers should be stored in this)

- Extra batteries and plugs

- Zip-ties assorted sizes

- Residue free (FrotTape ${ }^{\circledR}$ or ScotchBlue ${ }^{\circledR}$ ) tape and cloth (Polyken Gaffers ${ }^{\circledR}$ ) tape

- AirCheck Samplers with fully charged batteries

- Extra tubing

- Master Charger

- Commercial packed Carbopack sorbent tubes $(\mathrm{n}=7)$

- Packed metal Carbopack sorbent tubes $(n=7)$

- XPoSure Aldehyde sampler cartridges $(n=7)$

- Ozone scrubbers (1 for each aldehyde sampler)

- Sampler tripods ( 2 indoor and 1 outdoor)

- Emitter tripods (up to 6)

- Two EGM-4 $\mathrm{CO}_{2}$ analyzers or similar

- Source of $\mathrm{CO}_{2}$ (beverage cylinder) - located in LSL 1403

Computer to record data and check HOBOs (if necessary)

- Bring the software and shuttle cord (just in case)

- Also bring power charger (just in case)

- Have DataLog downloaded 


\section{Final Version}

To be completed as close as possible to post-occupancy deployment (e.g. morning of deployment)

\section{Weigh PFT emitters}

- See protocol for weighing emitters

- Prepare 5-8 emitter sets per home with three different PFT emitters in each set (unless otherwise noted for zonal analysis) that need to be weighed before and after each deployment 
Final Version

\section{During Post-Occupancy Site Visit Checklist}

To be accomplished during Day 1 of post-occupancy site visit

DO NOT STORE OR TRANSPORT EMITTERS WITH SAMPLERS (use separate vehicle or pelican case to transport emitters)

Enter home and check HVAC settings and make a note of any "first impressions" including odors

- Record HVAC settings on audit sheet.

- See "Initial Home Inspection Sample Site Monitoring Log" for odors of interest

Discuss with homeowner anticipated sampling schedule and answer any questions

- Review homeowner logging questionnaire

- Confirm that there will be no activity in home during the day of active sampling period

- Review "activities to be avoided" during active sampling period

Set HVAC conditions to target values and close all windows and exterior doors

- Ask homeowner preferred set point within control range of $68-72^{\circ} \mathrm{F}$ and turn on air handler fan.

Deploy emitters

- Record details for location and start time on tracking sheet, attempting to be as similar as possible to pre-occupancy locations

- Distribute through house favoring near AHU return

- Keep away from the sample collection locations identified during walkthrough

- Place emitter cages on boxes, tripods, or other elevated location, secured with zip ties if necessary

- Should be out of direct sun

- Should be away from heat source (i.e., don't put near back of refrigerator)

- Use at least $0.002-0.003$ vials per square foot of living space (i.e., $5-8$ vials for a $2500 \mathrm{sq} \mathrm{ft} \mathrm{home)}$

- Take pictures of location of each emitter to confirm location

Setup active air sample stations

- Erect pump sample stands and secure pumps with black wedges (pump \# should correspond to \# on stand) 
Final Version

- Perform calibration check on each pump line using dummy tubes and Dry Cal and record flow rates on DataLog spreadsheet. See Appendix $\mathrm{C}$ for more detailed directions.

- $\mathrm{ALD} /$ Ozone (outside lines) $=500 \mathrm{cc} / \mathrm{min}$

- $\operatorname{VOC}($ middle line $)=100 \mathrm{cc} / \mathrm{min}$

- $P F T$ (inside line) $=50 \mathrm{cc} / \mathrm{min}$

- Program delayed start of air sample stations (one pump at 4:00AM and one pump at 4:00PM for each sampling stand and record sample start and end time on DataLog spreadsheet

- Press mode to access delayed start menu and set number of minutes of delay from selected start time

- Press mode again twice and set pump time to 60 minutes, leave sample time blank (0 minutes)

- LEAVE pump until selected start time

- At selected start time, press Start.

- Wearing gloves, load sample tubes/cartridges for both AM and PM sampling and passive blank and CAREFULLY record sample serial numbers on DataLog according to the following table. See Appendix D for a picture of the sampling set up.

- Keep caps with sample bag (white caps/swagelock/etc) for use in pick up.

- Take pictures of each sampling stand to confirm proper configuration.

- Fill out chain of custody forms with sample ID and sign.

\begin{tabular}{|l|l|l|l|l|}
\hline $\begin{array}{l}\text { Sampler } \\
\text { Type }\end{array}$ & Description & Serial \# & To uncap & $\begin{array}{l}\text { Location (also see } \\
\text { Appendix D) }\end{array}$ \\
\hline ALD/Ozone & $\begin{array}{l}\text { White syringe } \\
\text { samplers in foil bags } \\
\text { (ALD and ozone } \\
\text { sampler connect } \\
\text { together) }\end{array}$ & N/A & $\begin{array}{l}\text { Remove white } \\
\text { plastic caps } \\
\text { on both ends } \\
\text { of each } \\
\text { sampler/ } \\
\text { scrubber }\end{array}$ & $\begin{array}{l}\text { Outside line of sample } \\
\text { pump, ALD should be } \\
\text { closer to pump than ozone } \\
\text { scrubber, oriented with the } \\
\text { wider inlet away from } \\
\text { sample stand }\end{array}$ \\
\hline VOC & $\begin{array}{l}\text { Clear glass tube with } \\
\text { white/black sorbet } \\
\text { material }\end{array}$ & $\begin{array}{l}\text { Red lettering } \\
\text { on side of tube } \\
\text { (typically } \\
\text { H\#\#\#\#\# or } \\
\text { G\#\#\#\#) }\end{array}$ & $\begin{array}{l}\text { Remove from } \\
\text { plastic } \\
\text { sampling } \\
\text { sleeve }\end{array}$ & $\begin{array}{l}\text { Middle line of pump, insert } \\
\text { tube in swage lock fitting } \\
\text { with sorbent away from } \\
\text { pump and tighten until snug } \\
\text { (be careful not to break the } \\
\text { tube!) }\end{array}$ \\
\hline VOC Blank & Same as VOC & Same as VOC & Same as VOC & $\begin{array}{l}\text { Above active sampling set } \\
\text { with passive diffuser (metal } \\
\text { cap with screen) - } \\
\text { RECORD TIME } \\
\text { UNCAPPED AS START }\end{array}$ \\
\hline
\end{tabular}


Final Version

\begin{tabular}{|l|l|l|l|l|}
\hline & & & & TIME \\
\hline PFT & $\begin{array}{l}\text { Metal thermal } \\
\text { desorption tube with } \\
\text { Swage lock fittings } \\
\text { PFT Blank }\end{array}$ & $\begin{array}{l}\text { Etched number } \\
\text { (typically \#.\# } \\
\text { or \#\#.\#) }\end{array}$ & $\begin{array}{l}\text { Undo swage } \\
\text { lock from } \\
\text { both ends of } \\
\text { tube }\end{array}$ & $\begin{array}{l}\text { Inner line of pump; insert } \\
\text { tube into swage lock fitting } \\
\text { with etching towards pump } \\
\text { and tighten until snug. }\end{array}$ \\
\hline & Same as PFT & Same as PFT & $\begin{array}{l}\text { Above active sampling set } \\
\text { with passive diffuser (metal } \\
\text { cap with screen) - } \\
\text { RECORD TIME } \\
\text { UNCAPPED AS START } \\
\text { TIME }\end{array}$ \\
\hline
\end{tabular}

Complete material inventory for new furnishings and materials/cleaning products/air fresheners/etc

Start delayed timer on pumps to collect sample at 4:00 AM and 4:00 PM sampling periods at designated start time

Exit, close and lock

Arrange with homeowner for access during afternoon to retrieve active equipment and deploy passive samplers the following day

To be accomplished during PM of Day 2 of post-occupancy site visit

Meet homeowner and answer any questions as needed

Enter home and check HVAC settings and make a note of any "first impressions" including odors

- Reset HVAC settings to those found on Day 1.

Check each pump to insure sample runtime completed for AM \& PM period

- Should display 60.

- If pump displays other than 60 , record on DataLog.

Retrieve, cap, and label all indoor and outdoor sample tubes/cartridges and place in ice chest with blue ice

- When retrieving, double check sampler serial number and pump number. Note any inconsistencies on Data Log.

- No labels on tubes, record label on bag or sleeve. See Appendix B for an example of VOC sampler sleeve labeling 
Final Version

- Can pre-label bags and sleeves for convenience

Check and record pump flows using dummy tubes and Dry Cal using same procedure as in deployment

Breakdown indoor and outdoor sample station and cleanup area

Prepare and deploy 7 passive sampler stands (see picture in Appendix D). For each sample stand, prepare as follows:

- Uncap rear (skinny) end ONLY of ALD sampler and place on appropriate fitting No ozone scrubber is required. Record the sample ID on the DataLog. Store cap in bag with sampler ID noted on it.

- Uncap the etched end of the PFT sampler (metal tube) and remove the swage lock cap (keep screw fitting). Use screw fitting to secure PFT tube (etching side down) to sample stand. Store swage cap in bag labeled with sample ID. Record serial number on DataLog.

- Note time and record as start time for sample stand on DataLog.

- Remove VOC sampler from sleeve and place, sorbent side up, in sampler stand and secure with provided swage lock fitting. Note serial number on DataLog. Add diffuser cap to top of VOC sampler.

- Remove PFT swage lock cap from top of sampler and place in labeled bag with other sampler cap. Use screw fitting to secure a reducer to the top of the PFT sample tube.

- Remove ALD cap from top of sampler and place in appropriately labeled bag.

- Place passive sampler in appropriate location and note on DataLog and house plans (and take photo).

- One sampler outdoors, one in garage, others dispersed throughout the house in well-mixed, open areas, out of direct sunlight. Two samplers should be placed in a similar location to act as replicates.

- Repeat for each sample stand until all stands have been deployed.

Complete material inventory and loading factor estimates and audit (if not already done)

Cleanup, pack up and do final walkthrough

Close, lock and arrange with homeowner to return in one week to pick up passive samplers and emitters.

Store collected samplers in the refrigerator until passive samplers are collected. 
Final Version

To be accomplished during final post-occupancy site visit (after 7-day passive sample)

Meet with homeowner and discuss any "issues" encountered during the week.

- Go through logging information and resolve any questions.

Retrieve, cap, and label all indoor and outdoor sample tubes/cartridges and place in ice chest with blue ice

- When retrieving, double check sampler serial number and pump number. Note any inconsistencies on Data Log.

- No labels on tubes, record label on bag or sleeve. See Appendix B for an example of VOC sampler sleeve labeling

- Can pre-label bags and sleeves for convenience

Collect emitter cages (DO NOT STORE OR TRANSPORT EMITTERS WITH SAMPLERS)

- Transport in separate car or pelican case

Cleanup, pack up and do final walkthrough

Close, lock and arrange with homeowner to return key, as applicable

\section{$\underline{\text { Immediately After Post-Occupancy Site Visit Checklist }}$}

Weigh emitters and record emitter weight on DataLog

- Store emitters in fume hood in LSL 1403

Send all samplers to LBNL

- Pack all samplers in cooler in box with fresh blue ice

- Fill out shipping request form and bring to warehouse

- Send to: Marion Russell 70-222

Lawrence Berkeley National Lab Bldg 69

One Cyclotron Rd.

Berkeley, CA 94706

510-495-2915

- Notify Marion of tracking number

\section{Soon After Pre-Occupancy Site Visit Checklist}

Review all information to insure recorded correctly 


\section{Final Version}

If required, code answers that are not already coded in questionnaire and inspection forms

Download data from loggers

Restock supplies as needed 
Final Version

\section{Appendix A: Initial Home Inspect Sample Site Monitoring Log}

ECE ID\#

Date:

Technician

Any of the following pollutant sources observed in use during the sampling period?

\begin{tabular}{|l|l|l|l|l|}
\hline & Yes & No & Time(s) & Notes \\
\hline Tobacco Smoke? & & & & \\
\hline Cooking or Baking? & & & & \\
\hline $\begin{array}{l}\text { Adhesives, glues, } \\
\text { correction fluid, art } \\
\text { supplies, etc? }\end{array}$ & & & & \\
\hline Paints? & & & & \\
\hline Pesticides? & & & & \\
\hline Cleaners? & & & & \\
\hline Printer, photocopier, fax? & & & & \\
\hline
\end{tabular}

Any of the following odors observed in use during the sampling period?

\begin{tabular}{|l|l|l|l|l|}
\hline & Yes & No & Time(s) & Notes \\
\hline Tobacco Smoke? & & & & \\
\hline Cosmetics? & & & & \\
\hline Car or diesel exhaust? & & & & \\
\hline $\begin{array}{l}\text { Chemical odor from } \\
\text { cleaners, solvents, etc? }\end{array}$ & & & & \\
\hline Musty or mildew smell? & & & & \\
\hline
\end{tabular}

H.20 


\section{Final Version}

Any other unpleasant odor? 
Final Version

Appendix B: Sleeve Labeling Example

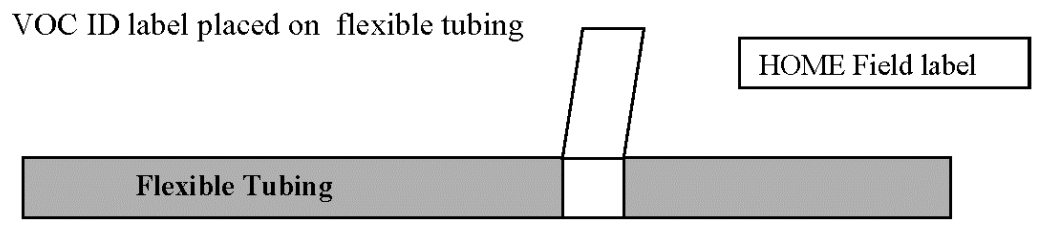

\section{Appendix C: Dry Cal Calibration Procedure}

- Assemble the calibration train using the dummy samplers and tygon tubbing tips to attach Dry Cal to the front of the sampling train (inlet of pump). Make sure all attachments and fittings are secure.

- Turn on the pump by putting the power switch on the face of the unit in the on position.

- Turn on the DryCal calibrator by pressing the "On" button. Auto off may shut the unit off after five minutes. If the DryCal cycles off, turn the DryCal on by pressing the "On" button. Depress the "Stop" button for a couple of seconds to clear the memory on the calibrator. After the calibrator has been cleared, turn on the air sampling pump so that it is running.

- Allow the pump flow to adjust for a minute then take your readings from the DryCal by depressing the "Read" button located on top of the unit. Repeat the read step two more times by pressing the "Read" button each time. Note the average flow rate indicated on the LCD of the DryCal directly under the flow reading. The average flow rate should bet that noted in the sampling procedure, above, for each sampler type. If the average flow reading is within range then $\log$ your results on the air sampling form. If the flow is outside of the optimal range, then adjustments are needed. Make the necessary flow adjustments on the air sample pump by turning the flow screw on the face of the unit with a small screw driver (set up only, do not adjust flows on calibration check during disassembly). Record calibration flow rate. 
Final Version

\section{Appendix D: Picture of Sampler Set Up for Sampling}

Active Sampling Stand

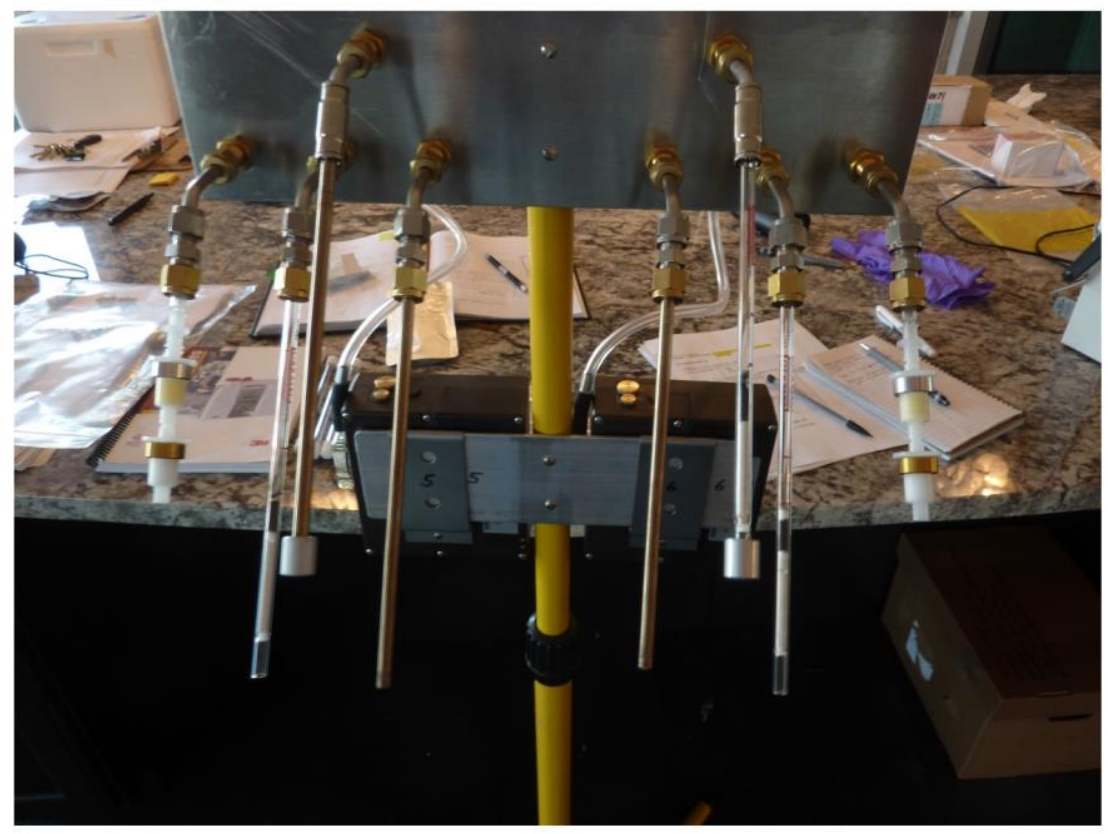

H.23 
Final Version

\section{Appendix I \\ Materials Inventory Tracking Form}

Table H.lprovide an abbreviated, clean example of the materials tracking form provided to builders and used by researchers to collect information on building materials with IaP low-emitting requirements. Additional information on each material, as well as information on other materials used in home construction can also be added and may prove useful in data analysis and interpretation.

Table H.1. Materials Tracking Inventory for IaP-relavent materials.

\begin{tabular}{|c|c|c|c|c|c|c|c|c|c|c|}
\hline Material Subtype & $\begin{array}{l}\text { Room } \\
1\end{array}$ & $\begin{array}{l}\text { Room } \\
2\end{array}$ & $\begin{array}{l}\text { Room } \\
3\end{array}$ & $\begin{array}{l}\text { Room } \\
4\end{array}$ & $\begin{array}{l}\text { Brand } \\
\text { Name }\end{array}$ & $\begin{array}{l}\text { Date } \\
\text { Manufactured }\end{array}$ & $\begin{array}{l}\text { Date } \\
\text { Purchased }\end{array}$ & Purchaser & $\begin{array}{l}\text { Date } \\
\text { Installed }\end{array}$ & $\begin{array}{l}\text { Does it meet } \\
\text { any air quality } \\
\text { standard? }\end{array}$ \\
\hline \multicolumn{11}{|l|}{ Composite Wood } \\
\hline \multicolumn{11}{|l|}{ Engineered hardwood flooring } \\
\hline \multicolumn{11}{|l|}{ Engineered hardwood - padding } \\
\hline \multicolumn{11}{|l|}{ Engineered hardwood - adhesive } \\
\hline \multicolumn{11}{|l|}{ Hardwood flooring } \\
\hline \multicolumn{11}{|l|}{ Hardwood underlayment } \\
\hline \multicolumn{11}{|l|}{ Wood floor sealer } \\
\hline \multicolumn{11}{|l|}{ Wood floor finish } \\
\hline \multicolumn{11}{|l|}{ Kitchen cabinets } \\
\hline \multicolumn{11}{|l|}{ Bathroom cabinets } \\
\hline \multicolumn{11}{|l|}{ Miscellaneous built-ins } \\
\hline \multicolumn{11}{|l|}{ Interior closet doors } \\
\hline \multicolumn{11}{|l|}{ Interior doors } \\
\hline \multicolumn{11}{|l|}{ Millwork } \\
\hline \multicolumn{11}{|l|}{ Wood stairs and railings } \\
\hline \multicolumn{11}{|l|}{ Wood mantels } \\
\hline Trim & & & & & & & & & & \\
\hline Interior window treatments & & & & & & & & & & \\
\hline
\end{tabular}


Final Version

\begin{tabular}{r}
\hline Interior Paints and Finishes \\
Wall paint (Eggshell/SG) \\
Ceiling paint (Flat) \\
Trim paint (High gloss) \\
Primer \\
Metal paint \\
Concrete paint \\
Interior stain and finish \\
Cabinet stain/finishes \\
Carpets and Carpet Adhesives \\
Carpet \\
Carpet - Padding \\
Carpet - Adhesive
\end{tabular} 


$$
\text { A.91 }
$$




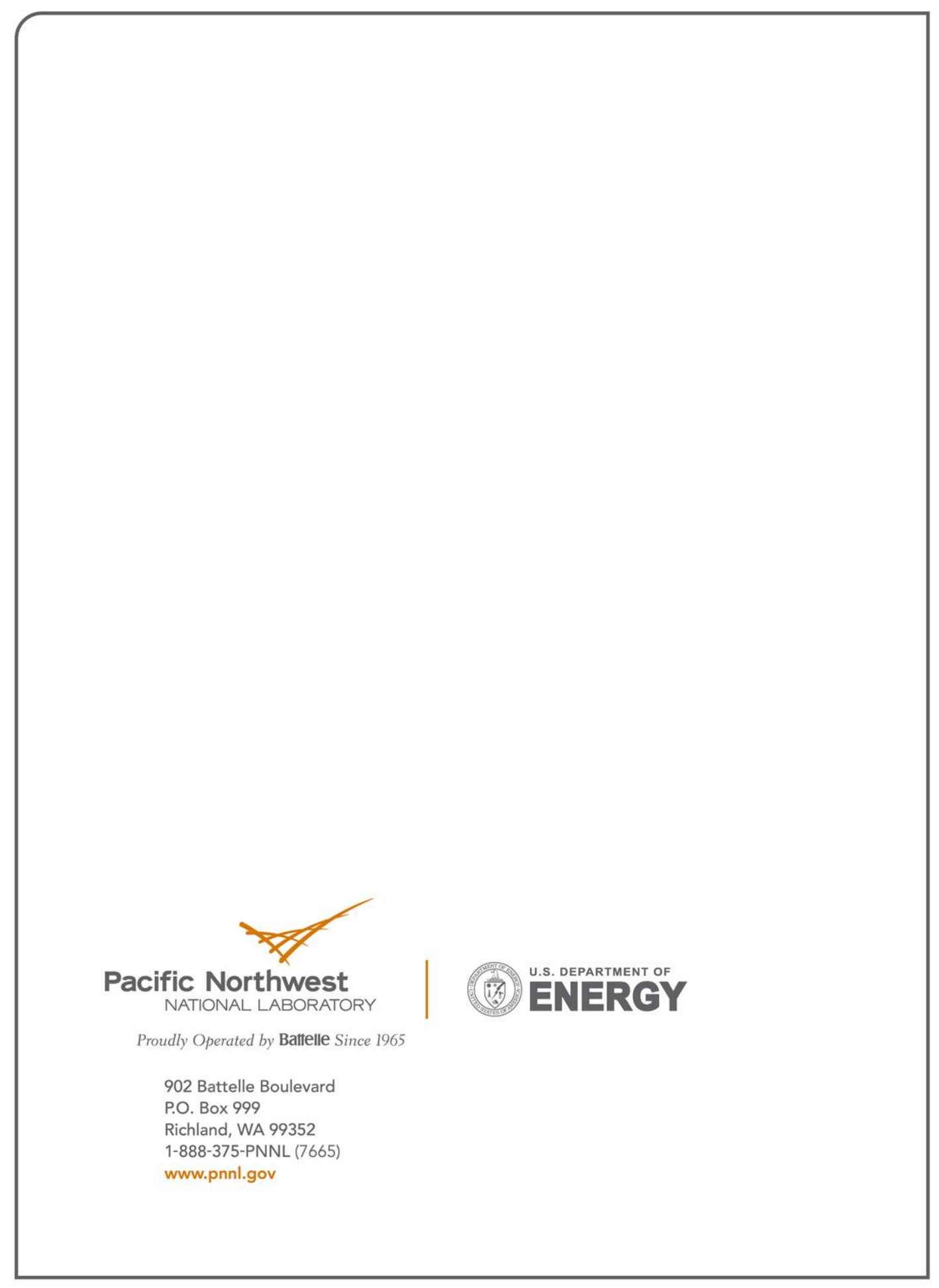




\section{Appendix B}

\section{Data}





\section{Appendix B}

\section{Data}

This appendix provides detailed perfluorocarbon tracer (PFT), volatile organic compounds (VOCs), and aldehyde data for each home and sampling period.

\section{B.1 PFT Emission Rates}

Emission rates for each PFT emitter were calculated four ways for each emitter, as described below:

1. The specific emission rate was calculated based on the mass measurements of the emitter taken immediately before and immediately after each deployment, divided by the time the sampler was deployed, for each sampling period. This is the emission rate that was used for calculating the dilution rate in the pilot study.

2. The total emission rate was calculated based on the total mass lost over the entire summer sampling campaign divided by the total time.

3. The regression emission rate was calculated by linearly regressing the change in mass of the emitter with time over the entire field campaign.

4. The average emission rate was calculated as an average of all individual determinations of emission rate using all emitter weights measured pre-deployment, post-deployment, and in between deployments to ensure a consistent emission rate was maintained.

Each of these emission rates for each of the sample periods in each of the homes is presented in Table B.1, Table B.2, and Table B.3 for C1, IaP1, and IaP2, respectively. 
Table B.1. Summary of Calculated Emission Rates for Each Emitter in C1

\begin{tabular}{|c|c|c|c|c|c|c|c|c|c|}
\hline Emitter & $\begin{array}{c}\text { Emitter } \\
\text { Cage }\end{array}$ & $\begin{array}{c}\text { PFT } \\
\text { Compound }\end{array}$ & Location & Zone & $\begin{array}{c}\text { Pre-Occ } \\
\text { Specific } \\
\text { Emission Rate } \\
{[\mathrm{mg} / \mathrm{hr}]} \\
\end{array}$ & $\begin{array}{c}\text { Post-Occ } \\
\text { Specific } \\
\text { Emission Rate } \\
\text { [mg/hr] } \\
\end{array}$ & $\begin{array}{c}\text { Total } \\
\text { Emission } \\
\text { Rate }[\mathrm{mg} / \mathrm{hr}]\end{array}$ & $\begin{array}{c}\text { Regression } \\
\text { Emission Rate } \\
{[\mathrm{mg} / \mathrm{hr}]}\end{array}$ & $\begin{array}{c}\text { Average } \\
\text { Emission Rate } \\
{[\mathrm{mg} / \mathrm{hr}]}\end{array}$ \\
\hline$\overline{\mathrm{A} 1}$ & 3 & PDCB & $\begin{array}{l}\text { on shelf in } \\
\text { theater }\end{array}$ & 1 & 0.4719 & 0.4951 & 0.5022 & 0.4560 & 0.4906 \\
\hline A10 & 4 & PDCB & $\begin{array}{l}\text { along wall } \\
\text { between } \\
\text { bedroom and } \\
\text { theater }\end{array}$ & 1 & 0.3927 & 0.4604 & 0.4509 & 0.4390 & 0.4352 \\
\hline $\mathrm{A} 2$ & 1 & PDCB & in blue room & 1 & 0.4134 & 0.4783 & 0.4618 & 0.4180 & 0.4505 \\
\hline A3 & 3 & PDCB & $\begin{array}{l}\text { on shelf in } \\
\text { theater }\end{array}$ & 1 & 0.4823 & 0.5227 & 0.5159 & 0.4670 & 0.5060 \\
\hline A4 & 2 & PDCB & in pink room & 1 & 0.4092 & 0.4865 & 0.4737 & 0.4290 & 0.4606 \\
\hline A6 & 2 & PDCB & in pink room & 1 & 0.4478 & 0.5038 & 0.4969 & 0.4480 & 0.4871 \\
\hline A8 & 4 & PDCB & $\begin{array}{l}\text { along wall } \\
\text { between } \\
\text { bedroom and } \\
\text { theater }\end{array}$ & 1 & 0.4788 & 0.5529 & 0.5364 & 0.5220 & 0.5191 \\
\hline A9 & 1 & PDCB & in blue room & 1 & 0.4340 & 0.5043 & 0.4876 & 0.4420 & 0.4761 \\
\hline B10 & 6 & $\mathrm{PMCH}$ & $\begin{array}{l}\text { on shelf in } \\
\text { mudroom }\end{array}$ & 2 & 0.2652 & 0.3889 & 0.3598 & 0.3260 & 0.3504 \\
\hline B3 & 7 & $\mathrm{PMCH}$ & $\begin{array}{l}\text { wall opposite } \\
\text { window in } \\
\text { office }\end{array}$ & 2 & 0.3583 & 0.4098 & 0.3858 & 0.3750 & 0.0000 \\
\hline B4 & 5 & $\mathrm{PMCH}$ & $\begin{array}{l}\text { master bedroom } \\
\text { next to } \mathrm{N} \text { wall }\end{array}$ & 2 & 0.3789 & 0.3970 & 0.3844 & 0.3450 & 0.3817 \\
\hline B5 & 6 & $\mathrm{PMCH}$ & $\begin{array}{l}\text { on shelf in } \\
\text { mudroom }\end{array}$ & 2 & 0.3548 & 0.4027 & 0.3787 & 0.4560 & 0.3695 \\
\hline B6 & 7 & $\mathrm{PMCH}$ & $\begin{array}{l}\text { wall opposite } \\
\text { window in } \\
\text { office }\end{array}$ & 2 & 0.3548 & 0.4016 & 0.3815 & 0.3710 & 0.3688 \\
\hline B7 & 8 & $\mathrm{PMCH}$ & $\begin{array}{l}2 \text { nd shelf on } \\
\text { bookshelf near } \\
\text { hall }\end{array}$ & 2 & 0.3927 & 0.4154 & 0.3850 & 0.3480 & 0.3782 \\
\hline
\end{tabular}


Table B.1. (contd)

\begin{tabular}{|c|c|c|c|c|c|c|c|c|c|}
\hline Emitter & $\begin{array}{c}\text { Emitter } \\
\text { Cage }\end{array}$ & $\begin{array}{c}\text { PFT } \\
\text { Compound }\end{array}$ & Location & Zone & $\begin{array}{c}\text { Pre-Occ } \\
\text { Specific } \\
\text { Emission Rate } \\
{[\mathrm{mg} / \mathrm{hr}]}\end{array}$ & $\begin{array}{c}\text { Post-Occ } \\
\text { Specific } \\
\text { Emission Rate } \\
{[\mathrm{mg} / \mathrm{hr}]}\end{array}$ & $\begin{array}{c}\text { Total } \\
\text { Emission } \\
\text { Rate }[\mathbf{m g} / \mathbf{h r}]\end{array}$ & $\begin{array}{c}\text { Regression } \\
\text { Emission Rate } \\
{[\mathbf{m g} / \mathbf{h r}]}\end{array}$ & $\begin{array}{c}\text { Average } \\
\text { Emission Rate } \\
{[\mathrm{mg} / \mathrm{hr}]}\end{array}$ \\
\hline $\bar{B} 8$ & 8 & $\mathrm{PMCH}$ & $\begin{array}{l}\text { 2nd shelf on } \\
\text { bookshelf near } \\
\text { hall }\end{array}$ & 2 & 0.3824 & 0.4098 & 0.3772 & 0.3410 & 0.3690 \\
\hline B9 & 5 & $\mathrm{PMCH}$ & $\begin{array}{l}\text { master bedroom } \\
\text { next to } \mathrm{N} \text { wall }\end{array}$ & 2 & 0.3617 & 0.3894 & 0.3835 & 0.3470 & 0.3728 \\
\hline $\mathrm{C} 1$ & 4 & m-PDMCH & $\begin{array}{l}\text { along wall } \\
\text { between } \\
\text { bedroom and } \\
\text { theater }\end{array}$ & 1 & 0.5236 & 0.1972 & 0.1951 & 0.1880 & 0.2121 \\
\hline $\mathrm{C} 2$ & 5 & m-PDMCH & $\begin{array}{l}\text { master bedroom } \\
\text { next to } \mathrm{N} \text { wall }\end{array}$ & 2 & 0.1722 & 0.1937 & 0.1916 & 0.1730 & 0.1988 \\
\hline $\mathrm{C} 3$ & 6 & m-PDMCH & $\begin{array}{l}\text { on shelf in } \\
\text { mudroom }\end{array}$ & 2 & 0.2515 & 0.2749 & 0.2521 & 0.2270 & 0.2466 \\
\hline $\mathrm{C} 4$ & 3 & m-PDMCH & $\begin{array}{l}\text { on shelf in } \\
\text { theater }\end{array}$ & 1 & 0.2342 & 0.2402 & 0.2348 & 0.2120 & 0.2207 \\
\hline $\mathrm{C} 5$ & 1 & m-PDMCH & in blue room & 1 & 0.2032 & 0.2320 & 0.2202 & 0.1990 & 0.2332 \\
\hline $\mathrm{C} 7$ & 8 & m-PDMCH & $\begin{array}{l}2 \text { nd shelf on } \\
\text { bookshelf near } \\
\text { hall }\end{array}$ & 2 & 0.2205 & 0.2402 & 0.2218 & 0.2000 & 0.2173 \\
\hline $\mathrm{C} 8$ & 7 & m-PDMCH & $\begin{array}{l}\text { wall opposite } \\
\text { window in office }\end{array}$ & 2 & 0.1963 & 0.2248 & 0.2110 & 0.2050 & 0.2043 \\
\hline C9 & 2 & m-PDMCH & in pink room & 1 & 0.2101 & 0.2325 & 0.2251 & 0.2040 & 0.2187 \\
\hline
\end{tabular}


Table B.2. Summary of Calculated Emission Rates for Each Emitter in IaP1

\begin{tabular}{|c|c|c|c|c|c|c|c|c|c|}
\hline Emitter & $\begin{array}{c}\text { Emitter } \\
\text { Cage }\end{array}$ & $\begin{array}{c}\text { PFT } \\
\text { Compound }\end{array}$ & Location & Zone & $\begin{array}{c}\text { Pre-Occ Specific } \\
\text { Emission Rate } \\
{[\mathrm{mg} / \mathrm{hr}]}\end{array}$ & $\begin{array}{c}\text { Post-Occ } \\
\text { Specific } \\
\text { Emission Rate } \\
{[\mathrm{mg} / \mathrm{hr}]}\end{array}$ & $\begin{array}{c}\text { Total } \\
\text { Emission } \\
\text { Rate }[\mathrm{mg} / \mathrm{hr}]\end{array}$ & $\begin{array}{c}\text { Regression } \\
\text { Emission Rate } \\
{[\mathrm{mg} / \mathrm{hr}]}\end{array}$ & $\begin{array}{c}\text { Average } \\
\text { Emission Rate } \\
{[\mathrm{mg} / \mathrm{hr}]}\end{array}$ \\
\hline $\mathrm{C} 3$ & 1 & m-PDMCH & laundry room & 1 & 0.2639 & 0.2775 & 0.2521 & 0.2270 & 0.2466 \\
\hline B10 & 1 & $\mathrm{PMCH}$ & laundry room & 1 & 0.3715 & 0.3977 & 0.3598 & 0.3260 & 0.3504 \\
\hline A3 & 1 & PDCB & laundry room & 1 & 0.5278 & 0.5769 & 0.5159 & 0.4670 & 0.5060 \\
\hline $\mathrm{C} 2$ & 2 & m-PDMCH & $\begin{array}{l}\text { living room } \\
\text { mantel }\end{array}$ & 1 & 0.1944 & 0.2200 & 0.1916 & 0.1730 & 0.1988 \\
\hline B9 & 2 & $\mathrm{PMCH}$ & $\begin{array}{l}\text { living room } \\
\text { mantel }\end{array}$ & 1 & 0.3750 & 0.4430 & 0.3835 & 0.3470 & 0.3728 \\
\hline A1 & 2 & PDCB & $\begin{array}{l}\text { living room } \\
\text { mantel }\end{array}$ & 1 & 0.4861 & 0.5886 & 0.5022 & 0.4560 & 0.4906 \\
\hline $\mathrm{C} 7$ & 3 & m-PDMCH & $\begin{array}{l}\text { SE corner of } \\
\text { SE bedroom }\end{array}$ & 1 & 0.2257 & 0.2520 & 0.2218 & 0.2000 & 0.2173 \\
\hline B8 & 3 & $\mathrm{PMCH}$ & $\begin{array}{l}\text { SE corner of } \\
\text { SE bedroom }\end{array}$ & 1 & 0.3715 & 0.4302 & 0.3772 & 0.3410 & 0.3690 \\
\hline A9 & 3 & PDCB & $\begin{array}{l}\text { SE corner of } \\
\text { SE bedroom }\end{array}$ & 1 & 0.5000 & 0.5591 & 0.4876 & 0.4420 & 0.4761 \\
\hline $\mathrm{C} 4$ & 4 & m-PDMCH & $\begin{array}{l}\text { SW corner of } \\
\text { SW bedroom }\end{array}$ & 1 & 0.2465 & 0.2678 & 0.2348 & 0.2120 & 0.2207 \\
\hline B7 & 4 & $\mathrm{PMCH}$ & $\begin{array}{l}\text { SW corner of } \\
\text { SW bedroom }\end{array}$ & 1 & 0.3889 & 0.4358 & 0.3850 & 0.3480 & 0.3782 \\
\hline A2 & 4 & PDCB & $\begin{array}{l}\text { SW corner of } \\
\text { SW bedroom }\end{array}$ & 1 & 0.4792 & 0.5311 & 0.4618 & 0.4180 & 0.4505 \\
\hline $\mathrm{C} 5$ & 5 & m-PDMCH & master bath & 1 & 0.2361 & 0.2556 & 0.2202 & 0.1990 & 0.2332 \\
\hline B4 & 5 & $\mathrm{PMCH}$ & master bath & 1 & 0.3993 & 0.4608 & 0.3844 & 0.3450 & 0.3817 \\
\hline A6 & 5 & PDCB & master bath & 1 & 0.5139 & 0.5896 & 0.4969 & 0.4480 & 0.4871 \\
\hline C9 & 6 & m-PDMCH & $\begin{array}{l}\text { SW corner } \\
\text { kitchen } \\
\text { counter }\end{array}$ & 1 & 0.2326 & 0.2597 & 0.2251 & 0.2040 & 0.2187 \\
\hline B5 & 6 & $\mathrm{PMCH}$ & $\begin{array}{l}\text { SW corner } \\
\text { kitchen } \\
\text { counter }\end{array}$ & 1 & 0.3889 & 0.4440 & 0.3787 & 0.4560 & 0.3695 \\
\hline A4 & 6 & PDCB & $\begin{array}{l}\text { SW corner } \\
\text { kitchen } \\
\text { counter }\end{array}$ & 1 & 0.4826 & 0.5519 & 0.4737 & 0.4290 & 0.4606 \\
\hline
\end{tabular}


Table B.2. (contd)

\begin{tabular}{|c|c|c|c|c|c|c|c|c|c|}
\hline Emitter & $\begin{array}{c}\text { Emitter } \\
\text { Cage }\end{array}$ & $\begin{array}{c}\text { PFT } \\
\text { Compound }\end{array}$ & Location & Zone & $\begin{array}{c}\text { Pre-Occ Specific } \\
\text { Emission Rate } \\
{[\mathrm{mg} / \mathrm{hr}]}\end{array}$ & $\begin{array}{c}\text { Post-Occ } \\
\text { Specific } \\
\text { Emission Rate } \\
{[\mathrm{mg} / \mathrm{hr}]}\end{array}$ & $\begin{array}{c}\text { Total } \\
\text { Emission } \\
\text { Rate }[\mathrm{mg} / \mathrm{hr}]\end{array}$ & $\begin{array}{c}\text { Regression } \\
\text { Emission Rate } \\
{[\mathrm{mg} / \mathrm{hr}]}\end{array}$ & $\begin{array}{c}\text { Average } \\
\text { Emission Rate } \\
{[\mathrm{mg} / \mathrm{hr}]}\end{array}$ \\
\hline $\mathrm{C} 8$ & & m-PDMCH & $\begin{array}{l}\text { Not used in } \\
\text { deployment }\end{array}$ & & 0.0000 & 0.2088 & 0.2110 & 0.2050 & 0.2043 \\
\hline $\mathrm{C} 1$ & & m-PDMCH & $\begin{array}{l}\text { Not used in } \\
\text { deployment }\end{array}$ & & 0.0000 & 0.1930 & 0.1951 & 0.1880 & 0.2121 \\
\hline B6 & & $\mathrm{PMCH}$ & $\begin{array}{l}\text { Not used in } \\
\text { deployment }\end{array}$ & & 0.0000 & 0.3758 & 0.3815 & 0.3710 & 0.3688 \\
\hline B3 & & $\mathrm{PMCH}$ & $\begin{array}{l}\text { Not used in } \\
\text { deployment }\end{array}$ & & 0.0000 & 0.3798 & 0.3858 & 0.3750 & 0.0000 \\
\hline A8 & & PDCB & $\begin{array}{l}\text { Not used in } \\
\text { deployment }\end{array}$ & & 0.0000 & 0.5290 & 0.5364 & 0.5220 & 0.5191 \\
\hline A10 & & PDCB & $\begin{array}{l}\text { Not used in } \\
\text { deployment }\end{array}$ & & 0.0000 & 0.4481 & 0.4509 & 0.4390 & 0.4352 \\
\hline
\end{tabular}

Table B.3. Summary of Calculated Emission Rates for Each Emitter in IaP2

\begin{tabular}{|c|c|c|c|c|c|c|c|c|c|}
\hline Emitter & $\begin{array}{c}\text { Emitter } \\
\text { Cage }\end{array}$ & $\begin{array}{c}\text { PFT } \\
\text { Compound }\end{array}$ & Location & Zone & $\begin{array}{c}\text { Pre-Occ } \\
\text { Specific } \\
\text { Emission Rate } \\
{[\mathrm{mg} / \mathrm{hr}]}\end{array}$ & $\begin{array}{c}\text { Post-Occ } \\
\text { Specific } \\
\text { Emission Rate } \\
{[\mathrm{mg} / \mathrm{hr}]}\end{array}$ & $\begin{array}{c}\text { Total } \\
\text { Emission } \\
\text { Rate }[\mathbf{m g} / \mathbf{h r}]\end{array}$ & $\begin{array}{c}\text { Regression } \\
\text { Emission Rate } \\
{[\mathrm{mg} / \mathrm{hr}]}\end{array}$ & $\begin{array}{c}\text { Average } \\
\text { Emission Rate } \\
{[\mathrm{mg} / \mathrm{hr}]}\end{array}$ \\
\hline A1 & 3 & PDCB & $\begin{array}{l}\text { on shelf in } \\
\text { theater }\end{array}$ & 1 & 0.5664 & 0.5210 & 0.5022 & 0.4560 & 0.4906 \\
\hline A10 & 4 & PDCB & $\begin{array}{l}\text { along wall } \\
\text { between } \\
\text { bedroom and } \\
\text { theater }\end{array}$ & 1 & 0.5040 & 0.4428 & 0.4509 & 0.4390 & 0.4352 \\
\hline $\mathrm{A} 2$ & 1 & PDCB & in blue room & 1 & 0.5083 & 0.4515 & 0.4618 & 0.4180 & 0.4505 \\
\hline A3 & 3 & PDCB & $\begin{array}{l}\text { on shelf in } \\
\text { theater }\end{array}$ & 1 & 0.5880 & 0.5384 & 0.5159 & 0.4670 & 0.5060 \\
\hline A4 & 2 & PDCB & in pink room & 1 & 0.5234 & 0.4819 & 0.4737 & 0.4290 & 0.4606 \\
\hline A6 & 2 & PDCB & in pink room & 1 & 0.5686 & 0.5253 & 0.4969 & 0.4480 & 0.4871 \\
\hline
\end{tabular}


Table B.3. (contd)

\begin{tabular}{|c|c|c|c|c|c|c|c|c|c|}
\hline Emitter & $\begin{array}{c}\text { Emitter } \\
\text { Cage }\end{array}$ & $\begin{array}{c}\text { PFT } \\
\text { Compound }\end{array}$ & Location & Zone & $\begin{array}{c}\text { Pre-Occ } \\
\text { Specific } \\
\text { Emission Rate } \\
{[\mathrm{mg} / \mathrm{hr}]}\end{array}$ & $\begin{array}{c}\text { Post-Occ } \\
\text { Specific } \\
\text { Emission Rate } \\
{[\mathrm{mg} / \mathrm{hr}]}\end{array}$ & $\begin{array}{c}\text { Total } \\
\text { Emission } \\
\text { Rate }[\mathrm{mg} / \mathrm{hr}]\end{array}$ & $\begin{array}{c}\text { Regression } \\
\text { Emission Rate } \\
{[\mathrm{mg} / \mathrm{hr}]}\end{array}$ & $\begin{array}{c}\text { Average } \\
\text { Emission Rate } \\
{[\mathrm{mg} / \mathrm{hr}]}\end{array}$ \\
\hline A8 & 4 & PDCB & $\begin{array}{l}\text { along wall } \\
\text { between } \\
\text { bedroom and } \\
\text { theater }\end{array}$ & 1 & 0.6009 & 0.5427 & 0.5364 & 0.5220 & 0.5191 \\
\hline A9 & 1 & PDCB & in blue room & 1 & 0.5363 & 0.5036 & 0.4876 & 0.4420 & 0.4761 \\
\hline B10 & 6 & $\mathrm{PMCH}$ & $\begin{array}{l}\text { on shelf in } \\
\text { mudroom }\end{array}$ & 2 & 0.4135 & 0.3560 & 0.3598 & 0.3260 & 0.3504 \\
\hline B3 & 7 & $\mathrm{PMCH}$ & $\begin{array}{l}\text { wall opposite } \\
\text { window in } \\
\text { office }\end{array}$ & 2 & 0.4243 & 0.3734 & 0.3858 & 0.3750 & 0.0000 \\
\hline B4 & 5 & $\mathrm{PMCH}$ & $\begin{array}{l}\text { master bedroom } \\
\text { next to } \mathrm{N} \text { wall }\end{array}$ & 2 & 0.4308 & 0.3951 & 0.3844 & 0.3450 & 0.3817 \\
\hline B5 & 6 & $\mathrm{PMCH}$ & $\begin{array}{l}\text { on shelf in } \\
\text { mudroom }\end{array}$ & 2 & 0.4092 & 0.3690 & 0.3787 & 0.4560 & 0.3695 \\
\hline B6 & 7 & $\mathrm{PMCH}$ & $\begin{array}{l}\text { wall opposite } \\
\text { window in } \\
\text { office }\end{array}$ & 2 & 0.4243 & 0.3690 & 0.3815 & 0.3710 & 0.3688 \\
\hline B7 & 8 & $\mathrm{PMCH}$ & $\begin{array}{l}\text { 2nd shelf on } \\
\text { bookshelf near } \\
\text { hall }\end{array}$ & 2 & 0.4200 & 0.3734 & 0.3850 & 0.3480 & 0.3782 \\
\hline B8 & 8 & $\mathrm{PMCH}$ & $\begin{array}{l}\text { 2nd shelf on } \\
\text { bookshelf near } \\
\text { hall }\end{array}$ & 2 & 0.4071 & 0.3690 & 0.3772 & 0.3410 & 0.3690 \\
\hline B9 & 5 & $\mathrm{PMCH}$ & $\begin{array}{l}\text { master bedroom } \\
\text { next to } \mathrm{N} \text { wall }\end{array}$ & 2 & 0.4178 & 0.3690 & 0.3835 & 0.3470 & 0.3728 \\
\hline $\mathrm{C} 1$ & 4 & m-PDMCH & $\begin{array}{l}\text { along wall } \\
\text { between } \\
\text { bedroom and } \\
\text { theater }\end{array}$ & 1 & 0.2154 & 0.1954 & 0.1951 & 0.1880 & 0.2121 \\
\hline $\mathrm{C} 2$ & 5 & m-PDMCH & $\begin{array}{l}\text { master bedroom } \\
\text { next to } \mathrm{N} \text { wall }\end{array}$ & 2 & 0.2111 & 0.1867 & 0.1916 & 0.1730 & 0.1988 \\
\hline $\mathrm{C} 3$ & 6 & m-PDMCH & $\begin{array}{l}\text { on shelf in } \\
\text { mudroom }\end{array}$ & 2 & 0.2843 & 0.2648 & 0.2521 & 0.2270 & 0.2466 \\
\hline
\end{tabular}


Table B.3. (contd)

\begin{tabular}{|c|c|c|c|c|c|c|c|c|c|}
\hline Emitter & $\begin{array}{c}\text { Emitter } \\
\text { Cage }\end{array}$ & $\begin{array}{c}\text { PFT } \\
\text { Compound }\end{array}$ & Location & Zone & $\begin{array}{c}\text { Pre-Occ } \\
\text { Specific } \\
\text { Emission Rate } \\
{[\mathrm{mg} / \mathrm{hr}]}\end{array}$ & $\begin{array}{c}\text { Post-Occ } \\
\text { Specific } \\
\text { Emission Rate } \\
{[\mathrm{mg} / \mathrm{hr}]}\end{array}$ & $\begin{array}{c}\text { Total } \\
\text { Emission } \\
\text { Rate }[\mathrm{mg} / \mathrm{hr}]\end{array}$ & $\begin{array}{c}\text { Regression } \\
\text { Emission Rate } \\
{[\mathrm{mg} / \mathrm{hr}]}\end{array}$ & $\begin{array}{c}\text { Average } \\
\text { Emission Rate } \\
{[\mathrm{mg} / \mathrm{hr}]}\end{array}$ \\
\hline$\overline{\mathrm{C} 4}$ & 3 & m-PDMCH & $\begin{array}{l}\text { on shelf in } \\
\text { theater }\end{array}$ & 1 & 0.2520 & 0.2301 & 0.2348 & 0.2120 & 0.2207 \\
\hline $\mathrm{C} 5$ & 1 & m-PDMCH & in blue room & 1 & 0.2412 & 0.2127 & 0.2202 & 0.1990 & 0.2332 \\
\hline $\mathrm{C} 7$ & 8 & m-PDMCH & $\begin{array}{l}2 \text { nd shelf on } \\
\text { bookshelf near } \\
\text { hall }\end{array}$ & 2 & 0.2391 & 0.2258 & 0.2218 & 0.2000 & 0.2173 \\
\hline $\mathrm{C} 8$ & 7 & m-PDMCH & $\begin{array}{l}\text { wall opposite } \\
\text { window in } \\
\text { office }\end{array}$ & 2 & 0.2348 & 0.2171 & 0.2110 & 0.2050 & 0.2043 \\
\hline C9 & 2 & m-PDMCH & in pink room & 1 & 0.2477 & 0.2171 & 0.2251 & 0.2040 & 0.2187 \\
\hline
\end{tabular}




\section{B.2 PFT Concentration Data}

PFT concentrations, in $\mu \mathrm{g} / \mathrm{m}^{3}$, for all valid samples are provided in Table B.4. Some invalid samples were experienced in the sampling campaign due to malfunction of the sampling pumps and deployment errors.

Table B.4. Summary of Calculated Emission Rates for Each Emitter

\begin{tabular}{|c|c|c|c|c|c|c|c|}
\hline Sample Name & Zone & $\begin{array}{l}\text { Sample } \\
\text { Period }\end{array}$ & $\begin{array}{l}\text { Active/ } \\
\text { Passive }\end{array}$ & $\begin{array}{c}\text { PDCB } \\
{\left[\mathbf{u g} / \mathbf{m}^{3}\right.} \\
]\end{array}$ & $\begin{array}{l}\text { PMCH } \\
{\left[\mathbf{u g} / \mathbf{m}^{3}\right]}\end{array}$ & $\begin{array}{c}\text { mPDCH } \\
{\left[\mathbf{u g} / \mathbf{m}^{3}\right]}\end{array}$ & Data Quality \\
\hline C1-PRE-N3-P & 1 & PRE & Active & 23.88 & 12.34 & 10.60 & \\
\hline C1-PRE-N5-P & 2 & PRE & Active & 24.48 & 28.23 & 12.32 & \\
\hline C1-PRE-N6-P & 2 & PRE & Active & 19.76 & 21.12 & 11.70 & \\
\hline C1-POST1-IN3-PFT & 1 & POST & Active & 21.66 & 23.65 & 15.49 & \\
\hline C1-POST1-IN4-PFT & 1 & POST & Active & 32.08 & 21.33 & 17.48 & \\
\hline C1-POST1-IN5-PFT & 2 & POST & Active & 22.13 & 24.93 & 12.17 & \\
\hline C1-POST1-IN6-PFT & 2 & POST & Active & 7.37 & 26.31 & 10.98 & $\begin{array}{r}\text { PDCB is low - } \\
\text { possible injection } \\
\text { failure - Invalid for } \\
\text { PDCB }\end{array}$ \\
\hline C1-POST1-IN3P-PFT & 2 & POST & Passive & 24.68 & 27.97 & 12.41 & \\
\hline C1-POST1-IN4P-PFT & 2 & POST & Passive & 23.19 & 26.40 & 11.97 & \\
\hline C1-POST1-IN5P-PFT & 1 & POST & Passive & 42.86 & 18.90 & 14.04 & \\
\hline C1-POST1-IN6P-PFT & 1 & POST & Passive & 35.10 & 16.59 & 11.79 & \\
\hline C1-POST1-IN7P-PFT & 2 & POST & Passive & 20.81 & 25.93 & 11.24 & \\
\hline IAP1-PRE-IN3-PFT & 1 & PRE & Active & 18.46 & 20.42 & 22.26 & \\
\hline IAP1-PRE-IN5-PFT & 1 & PRE & Active & 30.08 & 22.75 & 13.68 & \\
\hline IAP1-POST1-IN3-PFT & 1 & POST & Active & 29.76 & 34.36 & 27.37 & $\begin{array}{l}\text { Pump failure - } \\
\text { invalid }\end{array}$ \\
\hline IAP1-POST1-IN4-PFT & 1 & POST & Active & 30.25 & 25.78 & 15.68 & \\
\hline IAP1-POST1-IN5-PFT & 1 & POST & Active & 38.01 & 39.42 & 32.42 & \\
\hline IAP1-POST1-IN6-PFT & 1 & POST & Active & 22.08 & 19.49 & 11.44 & \\
\hline IAP1-POST1-IN3P-PFT & 1 & POST & Passive & 63.50 & 43.97 & 24.92 & \\
\hline
\end{tabular}





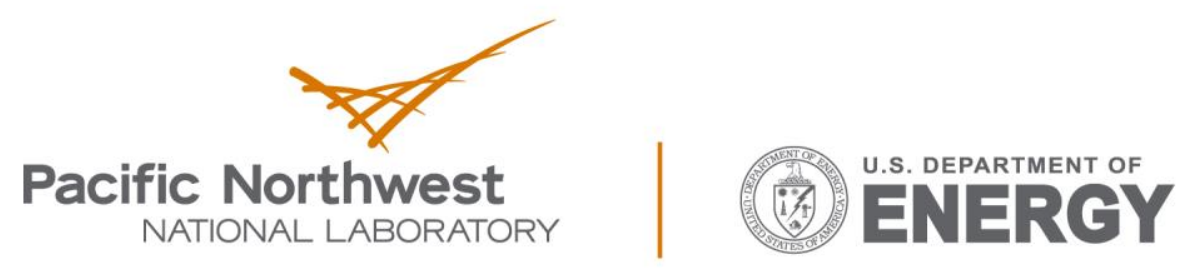

Proudly Operated by Battelle Since 1965

902 Battelle Boulevard

P.O. Box 999

Richland, WA 99352

1-888-375-PNNL (7665)

www.pnnl.gov 